ISSN: 1981-1896
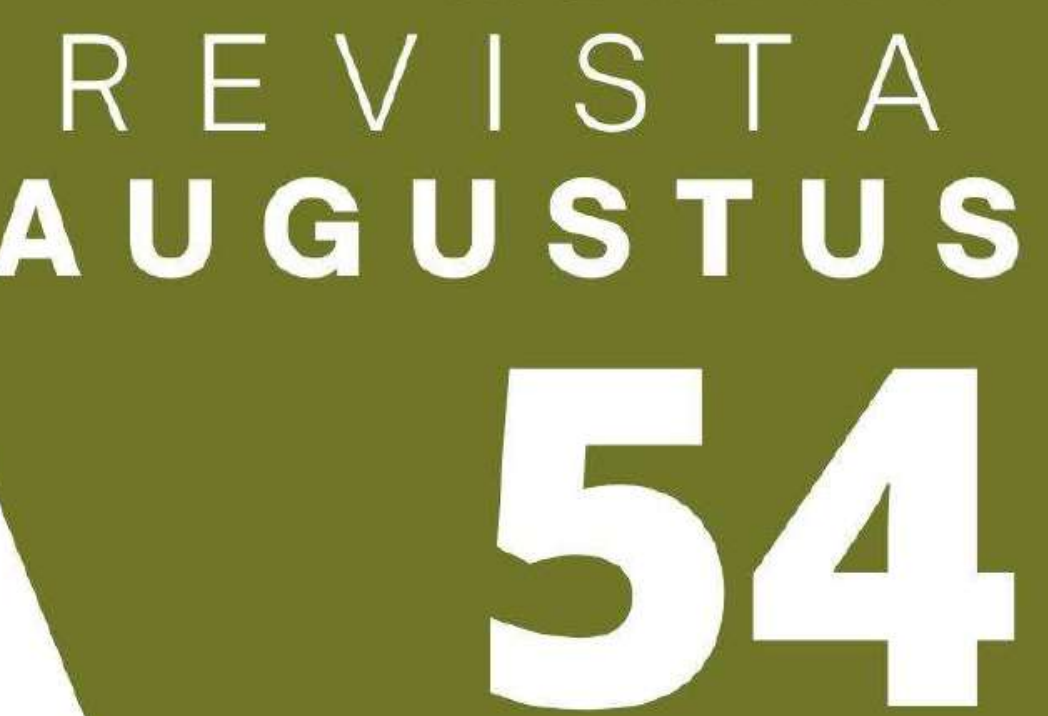

Rio de Janeiro | v.27 | n. 54 |ago/nov. 2021

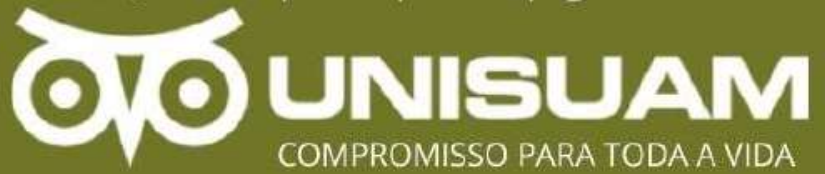


REVISTA AUGUSTUS

Rio de Janeiro: UNISUAM, 2020. Semestral.

DOI: 10.15202/1981-1896.v27n54 


\section{REVISTA AUGUSTUS}

ISSN: $1981-1896$

Rev. Augustus Rio de Janeiro $\quad$ v. 27 n. 54 p. 1-203 jul./out. 2021. 


\section{CONTATO}

Avenida Paris, 84 - Bonsucesso - Rio de Janeiro - RJ

CEP: 21041-020

\section{Contato Principal}

Prof. Dra. Maria Geralda de Miranda

Centro Universitário Augusto Motta - UNISUAM

Telefone (21) 3882-9797 Mestrado

revistaaugustus@unisuam.edu.br

Contato para Suporte Técnico

Prof. Bruno Matos de Farias

revistaaugustus@unisuam.edu.br

\section{DADOS PARA CATALOGAÇÃO}

Revista Augustus [recurso eletrônico] / Centro Universitário Augusto Motta - Vol. 16, n. 32 (jul. 2011).

Dados eletrônicos. - Rio de Janeiro: Centro Universitário Augusto Motta, 2011- v.; $30 \mathrm{~cm}$.

Semestral.

Modo de acesso: Internet:

$<$ http://revistas.unisuam.edu.br/index.php/revistaaugustu s> ISSN 1981-1896

Catalogação baseada no mais antigo número disponível na plataforma utilizada para produção da revista.

Início da publicação online no ano de 2001, de acordo com informações do site da revista.

1. Desenvolvimento científico. 2. Desenvolvimento tecnológico.

3. Desenvolvimento cultural. I. Centro Universitário Augusto Motta. 


\section{Revista Augustus \\ Periodicidade: quadrimestral \\ Tipo: temática}

\section{EQUIPE EDITORIAL}

\section{Editora-Chefe}

Maria Geralda de Miranda, Centro Universitário Augusto Motta (UNISUAM), Brasil

Editora-Seção Temática

Arlinda Cantero Dorsa, Universidade Católica Dom Bosco (UCDB), Brasil

\section{Editor-Gerente}

Bruno Matos de Farias, Centro Universitário Augusto Motta (UNISUAM), Brasil

Denise Moraes do Nascimento Vieira, Centro Universitário Augusto Motta (UNISUAM), Brasil

\section{Conselho Editorial}

- Adriana Martins Correia, Universidade Federal Fluminense (UFF), Brasil

- Agnaldo José Lopes, Centro Universitário Augusto Motta (UNISUAM), Brasil

- Alessandra Ésther de Mendonça, Universidade Federal Fluminense (UFF), Brasil

- Alexandre Palma, Universidade Federal do Rio de Janeiro (UFRJ), Brasil

- Ana Carolina Kalume Maranhão, Universidade Católica de Brasília (UCB), Brasil

- Andreia Regina Moura Mendes, Universidade Federal do Rio Grande do Norte (UFRN), Brasil

- Arlinda Cantero Dorsa, Universidade Católica Dom Bosco (UCDB), Brasil

- Arthur de Sá Ferreira, Centro Universitário Augusto Motta (UNISUAM), Brasil

- Clarissa Seixas Terenzi, Universidade Federal de Minas Gerais - Campus Macaé, Brasil

- Cláudia Costa, Centro Universitário Augusto Motta (UNISUAM), Brasil

- Cleyson de Moraes Mello, Universidade do estado do Rio de Janeiro (UERJ), Brasil

- Edilene Maria de Oliveira, Instituto Federal Matos Grosso do Sul (IFMS), Brasil

- Eduardo Barbuto Bicalho, Universidade Federal Fluminense, UFF, Brasil

- Eduardo Winter, Centro Universitário Augusto Motta (UNISUAM), Brasil

- Elaine Franco dos Santos Araujo, Universidade Federal do Rio de Janeiro (UFRJ)

- Elizabete Aparecida Sola, Universidade Federal do Paraná (UFPR), Brasil

- Everton Rangel Bispo, Centro Universitário Augusto Motta (UNISUAM), Brasil

- Fabiana Ferreira Koopmans, Centro Universitário Augusto Motta (UNISUAM), Brasil

- Felix Garcia Lopez Junior, Instituto de Pesquisa Econômica Aplicada (IPEA), Brasil

- Flavia Cristina Morone Pinto, Universidade Federal de Pernambuco (UFPE), Brasil

- Flavio Maldonado Bentes, Universidade Federal do Rio de Janeiro (UFRJ), Brasil

- Heitor Romero Marques Júnior, Universidade Católica Dom Bosco (UCDB), Brasil

- Helena Portes Sava de Farias, Centro Universitário Augusto Motta (UNISUAM), Brasil

- Jacqueline de Cassia Pinheiro Lima, Universidade Estadual do Norte Fluminense Darcy Ribeiro (UENF), Brasil

- Jesús Galindo Cáceres, Benemerita Universidad Autónoma de Puebla, Puebla- México, México

- José Luiz Fernandes, Centro Federal de Educação Tecnológica Celso Suckow da Fonseca (CEFET-RJ), Brasil

- Juliano de Carvalho Cury, Universidade Federal de São João Del-Rei (UFJS), Brasil

- Katia Cristina Montenegro Passos, Universidade Veiga de Almeida (UVA), Brasil

- Keyla Cristiane do Nascimento, Universidade Federal de Santa Catarina (UFSC), Brasil

- Leila Marques da Silva, Centro Federal de Educação Tecnológica Celso Suckow da Fonseca (CEFET-RJ), Brasil

- Ludmila Mourão, Universidade Federal de Juiz de Fora (UFJF), Brasil

- Luís C. Bittencourt, Universidade Veiga de Almeida (UVA), Brasil

- Luis Carlos Ferreira, Universidade Federal da Integração Lusíada Internacional da Lusofonia AfroBrasileira, Brasil

- Magda Guimarães de Araujo Faria, Universidade Federal do Rio de Janeiro (UFRJ), Brasil

- Márcia Teixeira Cavalcanti, Universidade Santa Úrsula (USU), Brasil; 
- Maria Augusta de Castilhos, Universidade Católica Dom Bosco (UCDB), Brasil

- Maria Geralda de Miranda, Centro Universitário Augusto Motta (UNISUAM), Brasil

- Miriam Maciel Nobrega, Centro Federal de Educação Tecnológica Celso Suckow da Fonseca (CEFET-RJ)

- Monique Ribeiro de Assis, Universidade do Estado do Rio de Janeiro (UERJ), Brasil

- Moraima Torres-Morillo, Universidad Pedagogica Experimental Libertador, Venezuela

- Patrícia dos Santos Vigário, Centro Universitário Augusto Motta (UNISUAM), Brasil

- Patrícia Maria Dusek, Centro Universitário Augusto Motta (UNISUAM), Brasil

- Raquel Villardi, Universidade do Estado do Rio de Janeiro (UERJ), Brasil

- Reis Friede, Centro Universitário Augusto Motta (UNISUAM), Brasil

- Sara Lucia Silveira de Menezes, Centro Universitário Augusto Motta (UNISUAM)/ Universidade Federal do Rio de Janeiro (UFRJ), Brasil

- Valeria Ferreira Romano, Universidade Federal do Rio de Janeiro (UFRJ), Brasil

- Yara Lacerda, Centro Universitário Celso Lisboa (UCL), Brasil

Pareceristas e Revisores Ad hoc

- Adriana Martins Correia, Universidade Federal Fluminense (UFF), Brasil

- Adriano Rosa da Silva, Universidade Santa Úrsula (USU), Brasil

- Agnaldo José Lopes, Centro Universitário Augusto Motta (UNISUAM), Brasil

- Alessandra Ésther de Mendonça, Universidade Federal Fluminense (UFF), Brasil

- Alexandre Palma, Universidade Federal do Rio de Janeiro (UFRJ), Brasil

- Alexandre Tourino Mendonça, Universidade Federal de Lavras (UFLA), Brasil

- Alisson Souza de Oliveira, Universidade Federal de Lavras (UFLA), Brasil

- Ana Carolina Kalume Maranhão, Universidade Católica de Brasília (UCB), Brasil

- André Luiz Carvalho Cardoso, Universidade Federal do Rio de Janeiro (UFRJ), Brasil

- Andréa Batista de Andrade Castelo Branco, Pontifícia Universidade Católica de Minas Gerais (PUCMinas), Brasil

- Andreia Regina Moura Mendes, Universidade Federal do Rio Grande do Norte (UFRN), Brasil

- Antonio José Caulliraux Pithon, Centro Federal de Educação Tecnológica Celso Suckow da Fonseca (CEFET-RJ), Brasil

- Arthur de Sá Ferreira, Centro Universitário Augusto Motta (UNISUAM), Brasil

- Aurivan Soares de Freitas, Universidade Federal de Lavras (UFLA), Brasil

- Carlos Alberto Figueiredo da Silva, Universidade Gama Filho (UGF), Brasil

- Carlos Alberto Mourão Júnior, Universidade Federal de São Paulo (UNIFESP), Brasil

- Christine de Sousa Veviani, Universidade Federal Fluminense (UFF), Brasil

- Clarissa Seixas Terenzi, Universidade Federal de Minas Gerais - Campus Macaé, Brasil

- Cláudia Costa, Centro Universitário Augusto Motta (UNISUAM), Brasil

- Claudia de Freitas Lopes Costa, Universidade do Estado do Rio de Janeiro (UERJ), Brasil

- Cleyson de Moraes Mello, Universidade do Estado do Rio de Janeiro (UERJ), Brasil

- Ediana Abreu Avelar, Universidade Católica de Petrópolis (UCP), Brasil

- Eduardo Barbuto Bicalho, Universidade Federal Fluminense (UFF), Brasil

- Eduardo Henrique Loreti, Universidade Federal do Espírito Santo (UFES), Brasil

- Eduardo Winter, Centro Universitário Augusto Motta (UNISUAM), Brasil

- Elaine Franco dos Santos Araujo, Universidade Federal do Rio de Janeiro (UFRJ)

- Eliana Alcantra, Universidade Federal de Lavras (UFLA), Brasil

- Elisa Dias de Melo, Universidade Federal de Viçosa (UFV), Brasil

- Elizabete Aparecida Sola, Universidade Federal do Paraná (UFPR), Brasil

- Emerson Ferreira da Rocha, Universidade do Estado do Rio de Janeiro (UERJ), Brasil

- Everton Rangel Bispo, Centro Universitário Augusto Motta (UNISUAM), Brasil

- Fabiana Ferreira Koopmans, Centro Universitário Augusto Motta (UNISUAM), Brasil

- Felipe Bernardes Silva, Universidade Federal de Viçosa (UFV), Brasil

- Felipe da Silva Triani, Universidade do Grande Rio (UNIGRANRIO), Brasil

- Felix Garcia Lopez Junior, Instituto de Pesquisa Econômica Aplicada (IPEA), Brasil

- Flavia Cristina Morone Pinto, Universidade Federal de Pernambuco (UFPE), Brasil

- Flavio Maldonado Bentes, Universidade Federal do Rio de Janeiro (UFRJ), Brasil

- Geraldo Motta Azevedo Júnior, Universidade Federal do Rio de Janeiro (UFRJ), Brasil

- Jacqueline de Cassia Pinheiro Lima, Universidade do Grande Rio (UNIGRANRIO), Brasil 
- Jesús Galindo Cáceres, Benemerita Universidad Autónoma de Puebla, Puebla- México, México

- João Olinto Trindade Junior, Universidade do Estado do Rio de Janeiro (UERJ), Brasil

- José Lúcio Nascimento Júnior, Universidade do Estado do Rio de Janeiro (UERJ), Brasil

- José Luiz Fernandes, Centro Federal de Educação Tecnológica Celso Suckow da Fonseca (CEFET-RJ), Brasil

- Josiel Gonçalves dos Santos, Centro Federal de Educação Tecnológica Celso Suckow da Fonseca (CEFET/RJ), Brasil

- Juliano de Carvalho Cury, Universidade Federal de São João Del-Rei (UFJS), Brasil

- Katia Cristina Montenegro Passos, Universidade Veiga de Almeida (UVA), Brasil

- Kátia Eliane Santos Avelar, Universidade Federal do Rio de Janeiro (UFRJ), Brasil

- Keyla Cristiane do Nascimento, Universidade Federal de Santa Catarina (UFSC), Brasil

- Klever Paulo Leal Filpo, Universidade Gama Filho (UGF), Brasil

- Letícia Rodrigues da Fonseca, Universidade Presbiteriana Mackenzie (MACKENZIE), Brasil

- Louise Calil Deterling, Instituto Biofísica Carlos Chagas Filho (IBCCF), Brasil

- Ludmila Mourão, Universidade Federal de Juiz de Fora (UFJF), Brasil

- Luís C. Bittencourt, Universidade Veiga de Almeida (UVA), Brasil

- Luis Carlos Ferreira, Universidade do Estado do Rio de Janeiro (UERJ), Brasil

- Luiz Carlos Ferreira, Universidade Federal de Minas Gerais (UFMG), Brasil

- Luiza Ferreira Rezende de Medeiros, Instituto Federal Goiano (IF Goiano) / Universidade Paulista (UNIP), Brasil

- Magda Guimarães de Araujo Faria, Universidade Federal do Rio de Janeiro (UFRJ), Brasil

- Marcia Teixeira Cavalcanti, Universidade Santa Úrsula (USU), Brasil

- Marcos dos Santos, Instituto Tecnológico da Aeronáutica (ITA), Brasil

- Marcus Alexandre de Padua Cavalcanti Bastos, Universidade do Grande Rio (UNIGRANRIO), Brasil

- Maria Alice Nunes Costa, Centro de Estudos Sociais da Universidade de Coimbra (CES/UC), Portugal

- Maria Geralda de Miranda, Centro Universitário Augusto Motta (UNISUAM), Brasil

- Miriam Maciel Nobrega, Centro Federal de Educação Tecnológica Celso Suckow da Fonseca (CEFET-RJ)

- Monique Ribeiro de Assis, Universidade do Estado do Rio de Janeiro (UERJ), Brasil

- Moraima Torres-Morillo, Universidad Pedagogica Experimental Libertador, Venezuela

- Newton José Ferro, , Universidade Federal Fluminense (UFF), Brasil

- Nilza Rogéria de Andrade Nunes, Universidade de Brasília (UnB), Brasil

- Patrícia dos Santos Vigário, Universidade Federal do Rio de Janeiro (UFRJ), Brasil

- Patrícia Maria Dusek, Centro Universitário Augusto Motta (UNISUAM), Brasil

- Paulo de Sá Filho, Instituto Federal Goiano (IF Goiano), Brasil

- Rafael Reis Pereira Bandeira de Mello, Universidade do Estado do Rio de Janeiro (UERJ), Brasil

- Ramiro Machado Rezende, Universidade Federal de Lavras (UFLA), Brasil

- Raquel Villardi, Universidade do Estado do Rio de Janeiro (UERJ), Brasil

- Reinaldo Viana Alvares, Universidade Federal do Estado do Rio de janeiro (UNIRIO), Brasil

- Renato Nunes Bittencourt, Universidade Federal do Rio de Janeiro (UFRJ), Brasil

- Rodrigo Grazinoli Garrido, Universidade Federal Rural do Rio de Janeiro (UFRRJ), Brasil

- Rosane Cristina de Oliveira, Universidade do Estado do Rio de Janeiro (UERJ), Brasil

- Rosângela Francisca de Paula Vitor Marques, Universidade Federal de Lavras (UFLA), Brasil

- Sandrelena da Silva Monteiro, Universidade Federal de Juiz de Fora (UFJF), Brasil

- Sara Lucia Silveira de Menezes, Centro Universitário Augusto Motta (UNISUAM)/ Universidade Federal do Rio de Janeiro (UFRJ), Brasil

- Susana Ortiz Costa, Universidade Federal do Rio de Janeiro (UFRJ), Brasil

- Tânia Horsth Noronha Jardim, Pontifícia Universidade Católica do Rio de Janeiro (PUC-Rio), Brasil

- Thiago Araújo, Universidade Santa Úrsula (USU), Brasil

- Tiago Miguel Patrício Ribeiro, Centro Universitário Augusto Motta (UNISUAM), Brasil

- Tiago Miguel Patrício Ribeiro, Centro Universitário Augusto Motta (UNISUAM), Brasil

- Valeria Ferreira Romano, Universidade Federal do Rio de Janeiro (UFRJ), Brasil

- Yara Lacerda, Centro Universitário Celso Lisboa, Brasil

- Yzel Rondon Súarez, Universidade Estadual Paulista Júlio de Mesquita Filho (UNESP), Brasil 


\section{SUMÁRIO}

\begin{tabular}{|c|c|}
\hline & $\begin{array}{l}\text { APRESENTAÇÃO } \\
\text { Os Editores }\end{array}$ \\
\hline & |ARTIGOS \\
\hline & $\begin{array}{l}\text { USO DE PLANTAS MEDICINAIS NAS CIDADES DE CRUZÍLIA, SÃO } \\
\text { GONÇALO DO SAPUCAÍ E VARGINHA MG } \\
\text { Aurivan Soares de Freitas, Andresa de Oliveira Brandão, Karina Luiza de Souza, Larissa } \\
\text { Aparecida Silva Saturnino }\end{array}$ \\
\hline & $\begin{array}{l}\text { DE NORTE A SUL: UMA ANÁLISE SOBRE AS CARACTERÍSTICAS } \\
\text { ECONÔMICAS E GASTRONÔMICAS DAS PRINCIPAIS FRUTAS } \\
\text { IDENTITÁRIAS NO BRASIL } \\
\text { Gabriela Ferreira Rodrigues, Aline Gomes Santana, Neide Kazue Sakugawa Shinohara }\end{array}$ \\
\hline & $\begin{array}{l}\text { APROVEITAMENTO DO SILÍCIO DERIVADO DA EXTRAÇÃO DO } \\
\text { QUARTZITO SÃO THOMÉ NA CULTURA DO PEPINO } \\
\text { Eliana Alcantra, Marco Antônio Sales Martins, Fredderico Avelar Viana Corrêa, } \\
\text { Rosângela Francisca de Paula Vitor Marques }\end{array}$ \\
\hline & $\begin{array}{l}\text { AVALIAÇÃO ANTIMICROBIANA DA EFICÁCIA DOS EXTRATOS } \\
\text { HIDROALCOÓLICOS DA PITANGUEIRA E DA GOIABEIRA, IN VITRO, } \\
\text { CONTRA STAPHYLOCOCCUS AUREUS ISOLADOS DE MASTITE BOVINA } \\
\text { Alexandre Tourino Mendonça, Glei dos Anjos de Carvalho Castro, Maria Clara } \\
\text { Pereira Inácio, Miriam de Andrade Pereira }\end{array}$ \\
\hline & $\begin{array}{l}\text { ANÁLISE TÉCNICA E ECONÔMICA PARA IMPLANTAÇÃO DE UM } \\
\text { CENTRO DE COLETA SELETIVA EM MONSENHOR PAULO - MG } \\
\text { Leonardo Martins da Silva Arantes, Thales Fernandes Leal, Rosângela Francisca de } \\
\text { Paula Vitor Marques, Alisson Souza de Oliveira }\end{array}$ \\
\hline & $\begin{array}{l}\text { POLÍTICA DE PROIBIÇÃO DA DIPIRONA: UMA REFLEXÃO } \\
\text { Flávia de Paula Gonçalves Guimarães, Ernane Cláudio Souza-Júnior, Carlos Alberto } \\
\text { Mourão Júnior, Jorge Willian Leandro Nascimento }\end{array}$ \\
\hline & $\begin{array}{l}\text { POSSÍVEIS EVIDÊNCIAS DA VITAMINA B12 NA DOR NEUROPÁTICA: } \\
\text { Seria um fator de proteção em Doenças Neurológicas? } \\
\text { Adalgiza Mafra Moreno, Marco Orsini, Jacqueline Stephanie Fernandes do } \\
\text { Nascimento, Nicolle dos Santos Moraes Nunes }\end{array}$ \\
\hline & $\begin{array}{l}\text { EDUCAÇÃO AMBIENTAL: DIAGNÓSTICO DOS PROJETOS } \\
\text { DESENVOLVIDOS NAS ESCOLAS MUNICIPAIS DE CURITIBA, PR } \\
\text { Tatiane Lima Ho, Daniela Biondi, Mayssa Mascarenhas Grise }\end{array}$ \\
\hline
\end{tabular}




\begin{tabular}{|l|l|l|}
\hline 137 & $\begin{array}{l}\text { NARRATIVAS DIGITAIS DE PROFESSORES: UMA REVISÃO SISTEMÁTICA } \\
\text { EM TESES E DISSERTAÇÕES BRASILEIRAS } \\
\text { Marcus Alexandre de Pádua Cavalcanti Bastos, Eliane Cristina Tenório Cavalcanti, } \\
\text { Marcelo de Jesus Pereira, Shirley Araújo Cabral, Nathan da Costa Cavalcanti Bastos }\end{array}$ \\
\hline 151 & $\begin{array}{l}\text { RELAÇÃO COVID-19 X EVASÃO NO ENSINO SUPERIOR LATO SENSU NA } \\
\text { MODALIDADE EAD } \\
\text { Dayane Priscila Bicalho de Souza }\end{array}$ \\
\hline 167 & $\begin{array}{l}\text { O ENSINO REMOTO EMERGENCIAL E AS LIÇÕES DO NOVO } \\
\text { CORONAVíRUS PARA A SEARA DA EDUCAÇÃO } \\
\text { Hildon Oliveira Santiago Carade }\end{array}$ \\
\hline 189 & $\begin{array}{l}\text { ESTUDO DE CASO À LUZ DA PSICOLOGIA SÓCIO-HISTÓRICA SOBRE O } \\
\text { FILME “EXTRAORDINÁRIO”: ANÁLISE DA AUTOESTIMA DO } \\
\text { PERSONAGEM AUGGIE PULLMAN } \\
\text { Gilson Gomes Coelho, Ana Luiza Machado Fulaneti, Maycon Douglas Silva Ribeiro }\end{array}$ \\
\hline
\end{tabular}




\section{APRESENTAÇÃO}

Os editores da Revista Augustus apresentam a Edição 54, que traz doze estudos de pesquisadores e professores de diversas instituições de ensino e pesquisa do Brasil. $\mathrm{O}$ artigo que abre este número, USO DE PLANTAS MEDICINAIS NAS CIDADES DE CRUZíLIA, SÃO GONÇALO DO SAPUCAÍ E VARGINHA MG, tem como objetivo avaliar o uso de plantas medicinais nos municípios de Cruzília, São Gonçalo do Sapucaí e Varginha MG.

O segundo artigo, DE NORTE A SUL: UMA ANÁLISE SOBRE AS CARACTERÍSTICAS ECONÔMICAS E GASTRONÔMICAS DAS PRINCIPAIS FRUTAS IDENTITÁRIAS NO BRASIL, analisa as características de algumas frutas no território brasileiro, sob a perspectiva do consumo, economia e versatilidade gastronômica. Foram selecionadas as frutas pequi, butiá, jabuticaba, caju e açaí, visto a representatividade de cada uma nas cinco regiões do Brasil.

Dando seguimento, o terceiro trabalho, APROVEITAMENTO DO SILícIO DERIVADO DA EXTRAÇÃO DO QUARTZITO SÃO THOMÉ NA CULTURA DO PEPINO, mostra que a absorção de silício melhora a eficiência fotossintética das plantas, e que é muito eficiente na proteção de estresses abióticos e bióticos de muitas culturas e pode conferir resistência ao ataque de insetos-praga e nematóides.

O quarto trabalho, AVALIAÇÃO ANTIMICROBIANA DA EFICÁCIA DOS EXTRATOS HIDROALCOÓlICOS DA PITANGUEIRA E DA GOIABEIRA, IN VITRO, CONTRA STAPHYLOCOCCUS AUREUS ISOLADOS DE MASTITE BOVINA, testou a atividade antimicrobiana in vitro por determinação da Concentração Inibitória Mínima (CMI) dos extratos hidroalcoólicos frente às cepas de S. aureus isolados do leite de mastite bovina, e comparar com os antibióticos de uso comum.

O estudo seguinte, ANÁLISE TÉCNICA E ECONÔMICA PARA IMPLANTAÇÃO DE UM CENTRO DE COLETA SELETIVA EM MONSENHOR PAULO - MG, analisou a viabilidade técnica e econômica de implantação de um centro de coleta seletiva no município de Monsenhor Paulo, Sul de Minas Gerais.

POLÍTICA DE PROIBIÇÃO DA DIPIRONA: UMA REFLEXÃO analisa as possíveis reações adversas e toxicidade associadas ao uso da dipirona, bem como a polêmica questão relacionada à sua proibição. 
O sétimo artigo, POSSÍVEIS EVIDÊNCIAS DA VITAMINA B12 NA DOR NEUROPÁTICA: Seria um fator de proteção em Doenças Neurológicas?, discute, por meio de revisão integrativa de literatura, o uso da vitamina B12 associadas às dores neuropáticas.

EDUCAÇÃO AMBIENTAL: DIAGNÓSTICO DOS PROJETOS DESENVOLVIDOS NAS ESCOLAS MUNICIPAIS DE CURITIBA, PR, avaliou os projetos de educação ambiental nas escolas municipais de Curitiba, PR. Foram entrevistadas 35 escolas, divididas em escolas municipais com educação integral, com as séries iniciais e finais.

NARRATIVAS DIGITAIS DE PROFESSORES: UMA REVISÃO SISTEMÁTICA EM TESES E DISSERTAÇÕES BRASILEIRAS realizou uma revisão sistemática de teses e dissertações que tratam de narrativas digitais de professores atuantes em escolas de Educação Básica e Educação Superior no país.

RELAÇÃO COVID-19 X EVASÃO NO ENSINO SUPERIOR LATO SENSU NA MODALIDADE EAD buscou identificar a relação entre casos confirmados de COVID-19 e evasão de alunos nas cidades e regiões brasileiras. A pesquisa trouxe dados sobre a relação COVID-19 x Evasão, relacionados aos números de desempregos no Brasil.

\section{O ENSINO REMOTO EMERGENCIAL E AS LIÇÕES DO NOVO CORONAVÍRUS PARA A SEARA} DA EDUCAÇÃO apresenta reflexões sobre a adoção do ensino remoto emergencial. As narrativas colhidas levaram a um debate pedagógico sobre o lugar da escola e dos estudantes no processo de ensino-aprendizagem.

Por fim, o ESTUDO DE CASO À LUZ DA PSICOLOGIA SÓCIOHISTÓRICA SOBRE O FILME “EXTRAORDINÁRIO": ANÁLISE DA AUTOESTIMA DO PERSONAGEM AUGGIE PULLMAN estudou O processo de construção da autoestima do protagonista Auggie Pullman do filme "O extraordinário", através de uma pesquisa qualitativa, do tipo estudo de caso e baseada na teoria da Psicologia Sócio-histórica.

Desejamos a todos uma boa leitura!

Os Editores. 


\title{
USO DE PLANTAS MEDICINAIS NAS CIDADES DE CRUZÍLIA, SÃO GONÇALO DO SAPUCAÍ E VARGINHA MG
}

\author{
Aurivan Soares de Freitas \\ Professor na Universidade Vale do Rio Verde (UninCor), \\ Três Corações, Minas Gerais, Brasil. \\ aurivan.soares@hotmail.com \\ Andresa de Oliveira Brandão \\ Graduada em Farmácia pela Universidade Vale do Rio Verde (UninCor), \\ Três Corações, Minas Gerais, Brasil. \\ dressabrand_brandao@live.com \\ Karina Luiza de Souza \\ Graduada em Farmácia pela Universidade Vale do Rio Verde (UninCor), \\ Três Corações, Minas Gerais, Brasil. \\ karinasouza00729@gmail.com \\ Larissa Aparecida Silva Saturnino \\ Graduanda em Farmácia pela Universidade Vale do Rio Verde (UninCor), \\ Três Corações, Minas Gerais, Brasil. \\ Larissa_outlook@outlook.com
}

\begin{abstract}
RESUMO
As plantas medicinais vêm sendo usadas como medicamento para a cura e o tratamento de doenças há muito tempo. Todavia, se essa prática não for realizada corretamente, poderá comprometer à saúde humana. Nesse sentido, foi objetivo do presente trabalho avaliar o uso de plantas medicinais nos municípios de Cruzília, São Gonçalo do Sapucaí e Varginha MG. A amostragem do tipo probabilístico foi realizada aplicando 20 questionários em cada município, totalizando 60 questionários. Constatou-se que a maioria das pessoas que usa plantas medicinais é do sexo feminino. Em Cruzília, São Gonçalo e Varginha 65, 95 e 25 \% dos participantes relataram fazer uso de plantas medicinais, respectivamente. A maioria dos participantes relataram conseguir plantas medicinais através de hortas caseiras e utiliza as plantas na forma de chá. Entre as plantas mais utilizadas nas três cidades estão hortelã, erva doce, boldo e erva cidreira. Em Cruzília e Varginha, 69 e 60\% dos participantes, respectivamente, sempre viram resultados no tratamento, enquanto em São Gonçalo do Sapucaí, apenas 37\%. Apesar desse resultado, em São Gonçalo do Sapucaí 89\% dos participantes responderam que já apresentaram alguma reação adversa devido ao uso de plantas medicinais. Diante deste contexto, destaca-se a importância das plantas medicinais como alternativa no tratamento de doenças, entretanto, alerta-se quanto aos riscos do uso indiscriminado de certas espécies.
\end{abstract}

Palavras-chave: Fitoterapia. Intoxicação. Enfermidades. Tratamento. 


\title{
USE OF MEDICINAL PLANTS IN THE CITIES OF CRUZÍLIA, SÃO GONÇALO DO SAPUCAÍ AND VARGINHA MG
}

\begin{abstract}
Medicinal plants have been used as a medicine for the cure and treatment of diseases for a long time. However, if this practice is not performed correctly, it may compromise human health. In this sense, the objective of the present study was to evaluate the use of medicinal plants in the cities of Cruzília, São Gonçalo do Sapucaí and Varginha MG. The probabilistic sampling was carried out by applying 20 questionnaires in each municipality, totaling 60 questionnaires. It was found that the majority of people who use medicinal plants are female. In Cruzília, São Gonçalo and Varginha 65, 95 and 25\% of the participants reported using medicinal plants, respectively. Most participants reported getting medicinal plants through home gardens and using the plants in the form of tea. Among the plants most used in the three cities are mint, fennel, bilberry and lemongrass. In Cruzília and Varginha, 69 and $60 \%$ of the participants, respectively, always saw results in the treatment, while in São Gonçalo do Sapucaí, only $37 \%$. Despite this result, in São Gonçalo do Sapucaí $89 \%$ of the participants replied that they already had an adverse reaction due to the use of medicinal plants. In this context, the importance of medicinal plants as an alternative in the treatment of diseases is highlighted, however, it is warned about the risks of indiscriminate use of certain species.
\end{abstract}

Keywords: Phytotherapy. Intoxication. Diseases. Treatment 
USO DE PLANTAS MEDICINAIS

NAS CIDADES DE CRUZÍLIA,

SÃO GONÇALO DO SAPUCAÍ

E VARGINHA MG
Aurivan Soares de Freitas Andresa de Oliveira Brandão Karina Luiza de Souza Larissa Aparecida Silva Saturnino

\section{INTRODUÇÃO}

O termo Fitoterapia refere-se ao uso de vegetais para o tratamento de doenças, que podem ser em forma de medicamentos ou o seu uso in natura. Sua origem vem de grego Phyton que significa vegetal e Therapia que significa tratamento (TEIXEIRA et al., 2012). De acordo com a Anvisa (BRASIL, 2010) as plantas que contenham substâncias, ou classes de substâncias, responsáveis pela ação terapêutica, após processos de coleta ou colheita, estabilização e secagem, íntegras, rasuradas, trituradas ou pulverizadas são consideradas plantas medicinais.

As plantas medicinais são utilizadas na maioria das vezes por adultos e idosos que buscam complementar o tratamento de uma doença crônica e acreditam que as plantas medicinais são uma boa alternativa, não tendo efeitos colaterais (CARNEIRO et al., 2014). O uso de remédios à base de ervas foi importante para tribos primitivas em que as mulheres se encarregavam de extrair das plantas os princípios ativos necessários na cura das doenças (PANIZZA, 2005). Tal prática persiste até o presente momento em todo o mundo.

Além do efeito benéfico para a saúde essa atividade permite ao ser humano interagir com o meio ambiente, ajudando o organismo a tratar enfermidades e fortalece o sistema imunológico e normalizando as funções fisiológicas, promovendo um melhor funcionamento do sistema imunológico, desintoxicação e rejuvenescimento. Nos países em desenvolvimento, os apelos da mídia para o consumo de produtos à base de fontes naturais têm aumentado a cada dia (VEIGA JUNIOR; PINTO; MACIEL, 2005).

Observa-se um crescimento na utilização de plantas medicinais pela população brasileira. Dois fatores explicam este aumento. O primeiro diz respeito aos avanços ocorridos na área científica, que permitiram o desenvolvimento de fitoterápicos reconhecidamente seguros e eficazes. O segundo é a tendência de busca, pela população, por terapias mais naturais e menos agressivas utilizando as plantas medicinais (ARAÚJO, 2002). Neste sentido, a orientação vinda de um profissional da área da saúde é fundamental para que o paciente possa ser alertado sobre os riscos, interações medicamentosas e melhores formas de utilização das terapias naturais (MOREIRA; NOVAES, 2011).

Se uma planta medicinal não for utilizada corretamente, poderá comprometer a saúde humana. Entre os problemas, destacam-se reações alérgicas e os efeitos tóxicos em vários órgãos humanos e até mesmo a morte. A crença popular de que as plantas, por serem 
USO DE PLANTAS MEDICINAIS

NAS CIDADES DE CRUZÍLIA,

SÃO GONÇALO DO SAPUCAÍ

E VARGINHA MG
Aurivan Soares de Freitas Andresa de Oliveira Brandão Karina Luiza de Souza Larissa Aparecida Silva Saturnino

naturais, não fazem mal está incorreta. Por isso, todos os medicamentos, inclusive, os "naturais" têm que ser usados com muita prudência, evitando que se coloque em risco a saúde do consumidor (MATTOS et al., 2015).

Dessa forma, torna-se necessário obter informações sobre uso de plantas medicinais. Sendo assim, objetivou-se com esse trabalho realizar um levantamento sobre o uso de plantas medicinais nos municípios de Cruzília, São Gonçalo do Sapucaí e Varginha - MG.

\section{MATERIAIS E MÉTODOS}

O trabalho foi desenvolvido nos municípios de Cruzília (latitude $21^{\circ} 50^{\prime} 19^{\prime \prime} \mathrm{S}$ e longitude $44^{\circ} 48^{\prime} 30^{\prime \prime}$ W, altitude 1010 m e área 524,9 Km²), São Gonçalo do Sapucaí (Latitude $21^{\circ} 53^{\prime} 32^{\prime \prime} \mathrm{S}$ e Longitude $45^{\circ} 35^{\prime} 43^{\prime \prime} \mathrm{W}$, altitude $868 \mathrm{~m}$ e área $519,3 \mathrm{Km}^{2}$ ) e Varginha (Latitude 21 $33^{\prime} 05^{\prime \prime} \mathrm{S}$ e Longitude $45^{\circ} 25^{\prime} 49^{\prime \prime} \mathrm{W}$, altitude $916 \mathrm{~m}$ e área $396,6 \mathrm{Km}^{2}$ ) localizados no Sul de Minas Gerais.

Anteriormente à realização da pesquisa foi elaborado um questionário (Apêndice A) contendo 22 questões referentes ao uso de plantas medicinais. Após parecer favorável do Comitê de Ética em Pesquisa - CEP da Universidade Vale do Rio Verde (UninCor), protocolo com o número do CAAE - 21285319.6.0000.5158, a pesquisa foi iniciada nos municípios citados acima.

Em cada município foram aplicados 20 questionários, totalizando 60 nos três municípios. Foram escolhidas pessoas de ambos os sexos com idade igual ou superior a 18 anos. A amostragem foi do tipo probabilístico, com as residências incluídas ao acaso.

Os dados obtidos foram avaliados a partir dos questionários aplicados. Os dados foram digitalizados no programa Microsoft Office 365 Excel para confecção de gráficos.

\section{RESULTADOS E DISCUSSÕES}

Em relação ao uso de plantas medicinais, constatou-se que a maioria das pessoas usa plantas medicinais independentemente do município estudado. A maior porcentagem de pessoas que usavam plantas medicinais foi encontrada em São Gonçalo do Sapucaí (95\%), seguida por Cruzília foram (65\%) e Varginha (25\%) (Gráfico 1). Zucchi et al. (2013) em estudo realizado em Ipameri (Goiás) constataram que 62,5\% das famílias usavam plantas medicinais, enquanto $37,5 \%$ afirmaram não fazer uso, valores próximos ao encontrado nesta pesquisa na 
USO DE PLANTAS MEDICINAIS

NAS CIDADES DE CRUZÍLIA,

SÃO GONÇALO DO SAPUCAÍ

E VARGINHA MG
Aurivan Soares de Freitas Andresa de Oliveira Brandão Karina Luiza de Souza Larissa Aparecida Silva Saturnino

cidade de Cruzília. O baixo número de pessoas que usa plantas medicinais em Varginha provavelmente se deve a idade dos participantes da pesquisa, já que $35 \%$ deles tinham entre 29 e 38 anos e nenhum deles tinha mais de 66 anos (Gráfico 2). Para alguns autores a faixa etária é um fator importante sobre os conhecimentos acumulados do uso medicinal das plantas, pois nesse contexto a idade avançada pode indicar experiência em relação aos benefícios dos remédios caseiros (VIU; VIU; CAMPOS, 2010; SANTOS et al., 2019).

Gráfico 1 - Uso de plantas medicinais por pessoas nos municípios de Cruzília, São Gonçalo do Sapucaí e Varginha MG

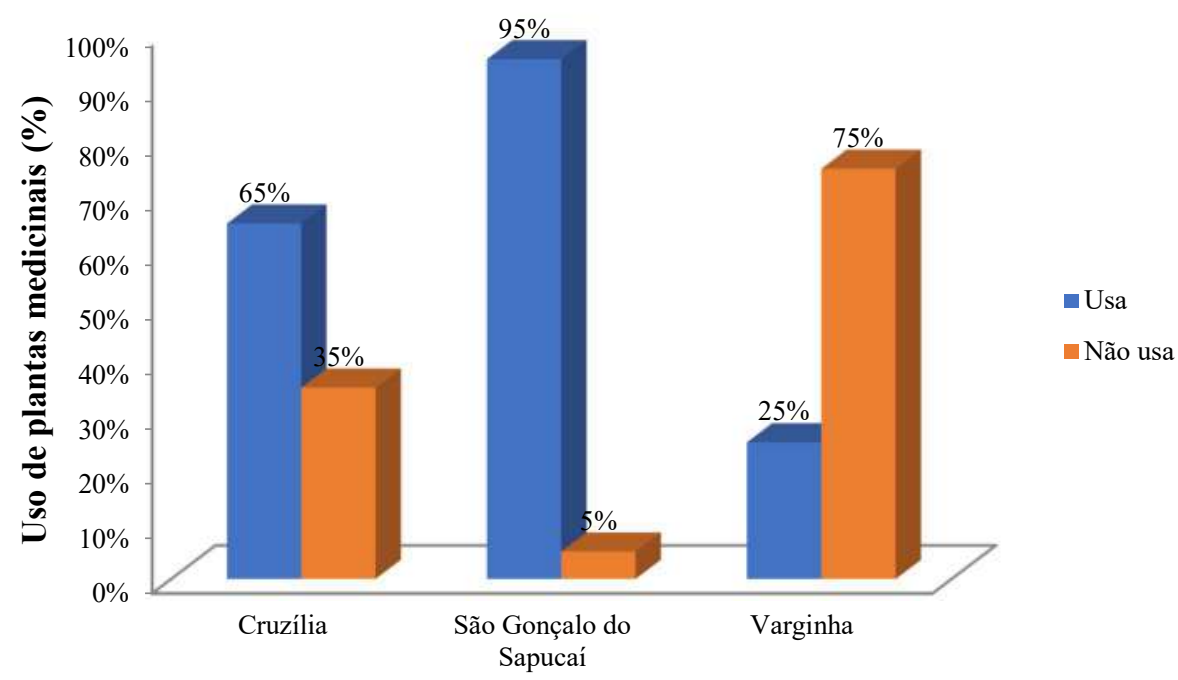

Fonte: Elaborado pelos autores, 2019.

Oliveira e Menini Neto (2012) em estudo realizado em Lima Duarte MG constaram que o maior número de informações e conhecimentos sobre as plantas medicinais concentrou-se na faixa etária de 51-60 anos. Esses resultados parecem ser semelhantes, independentemente da região. Em Quixadá $C E$, o maior número de informações e conhecimentos sobre as plantas medicinais concentrou-se na faixa etária de 51-60 anos $(24,71 \%)$, sendo que nas faixas anteriores houve um leve decréscimo (OLIVEIRA; LUCENA, 2015). 
USO DE PLANTAS MEDICINAIS NAS CIDADES DE CRUZÍLIA, SÃO GONÇALO DO SAPUCAÍ E VARGINHA MG
Aurivan Soares de Freitas Andresa de Oliveira Brandão Karina Luiza de Souza Larissa Aparecida Silva Saturnino

Gráfico 2 - Uso de plantas medicinais por idade nos municípios de Cruzília, São Gonçalo do Sapucaí e Varginha MG

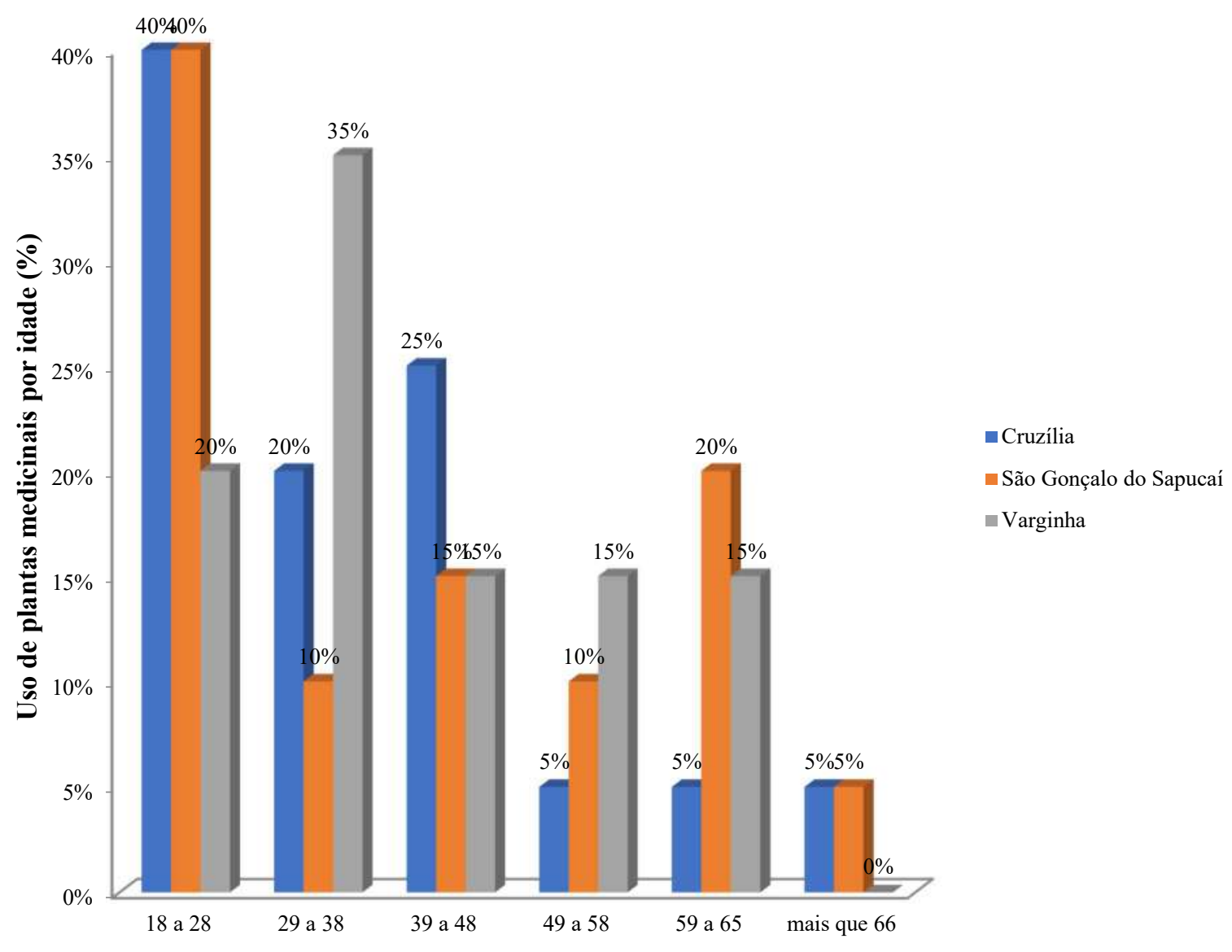

Fonte: Elaborado pelos autores, 2019.

Quanto ao gênero, constatou-se que a maioria das pessoas que fazem uso de plantas medicinais são do gênero feminino (Gráfico 3). Da mesma forma, em estudo realizado em Oliveira Fortes MG constatou-se que a maioria dos entrevistados foi do sexo feminino. Para os autores, o conhecimento a respeito das espécies vegetais é obtido principalmente das mães e avós e que sempre obtém o efeito desejado ao fazer uso das plantas medicinais (GABRIEL NETO; GOMES, 2018). Isso deve-se ao fato da maioria das mulheres de regiões interioranas permanecerem em casa cuidando dos afazeres domésticos, como evidenciado por Calábria et al. (2008) e Oliveira e Menini Neto (2012). 
USO DE PLANTAS MEDICINAIS

NAS CIDADES DE CRUZÍLIA,

SÃO GONÇALO DO SAPUCAÍ

E VARGINHA MG
Aurivan Soares de Freitas Andresa de Oliveira Brandão Karina Luiza de Souza Larissa Aparecida Silva Saturnino

Gráfico 3 - Uso de plantas medicinais por pessoas do sexo masculino e feminino nos municípios de Cruzília, São Gonçalo do Sapucaí e Varginha MG

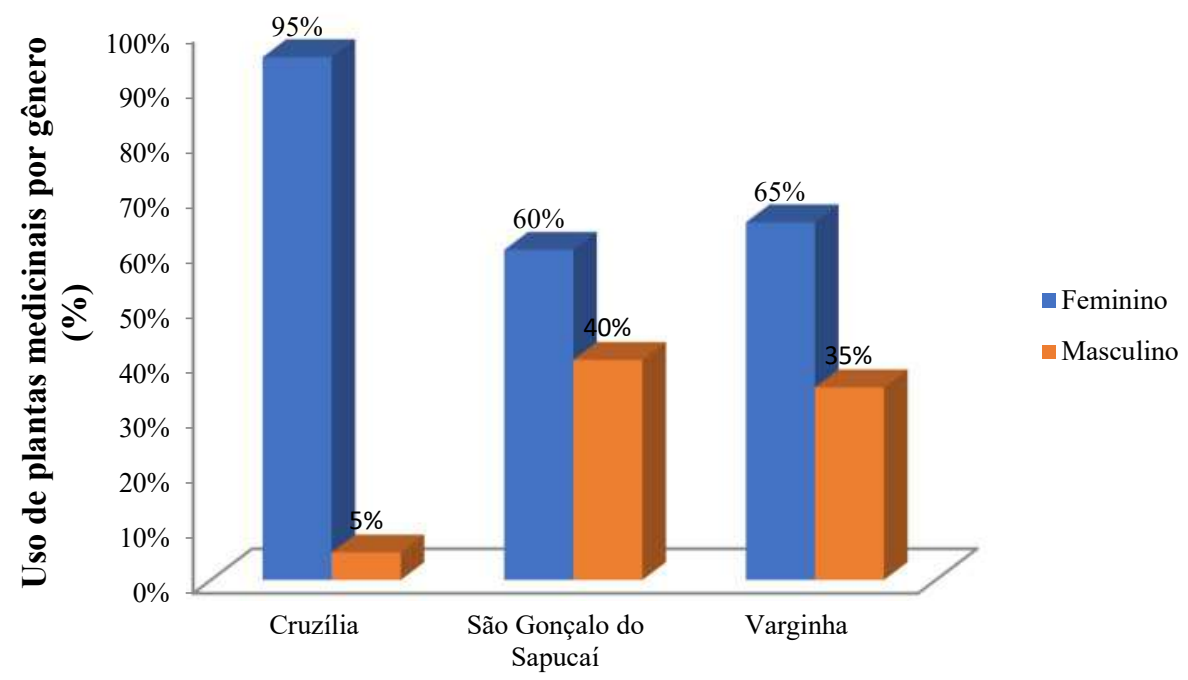

Fonte: Elaborado pelos autores, 2019.

Em todas as cidades, a maioria dos entrevistados consegue plantas medicinais através de hortas caseiras, como em São Gonçalo do Sapucaí, com 85\%, Cruzília, com 53\% e, Varginha, com 34\% (Gráfico 4). Esses resultados estão de acordo com diversos estudos nos quais se enfatiza a importância da produção de plantas medicinais nos quintais próximos às residências (ZUCCHI et al., 2013; SANTOS et al., 2019). Essa informação pode ser confirmada no estudo desenvolvido por Gabriel Neto e Gomes (2018) no qual observou-se que $76 \%$ dos entrevistados encontram plantas medicinais no quintal de casa, $22 \%$ obtêm as plantas do quintal de amigos ou vizinhos e apenas $2 \%$ realiza a compra no mercado. 
USO DE PLANTAS MEDICINAIS

NAS CIDADES DE CRUZÍLIA,

SÃO GONÇALO DO SAPUCAÍ

E VARGINHA MG
Aurivan Soares de Freitas Andresa de Oliveira Brandão Karina Luiza de Souza Larissa Aparecida Silva Saturnino

Gráfico 4-Como as plantas medicinais são adquiridas



Fonte: Elaborado pelos autores, 2019.

O chá foi a forma terapêutica mais consumida por todos os entrevistados, atingindo 100\% das respostas em São Gonçalo do Sapucaí e Varginha e 87\% em Cruzília (Gráfico 5). Em trabalho conduzido no Mercado Municipal Central de Montes Claros MG constatou-se que quanto ao modo de preparo das plantas medicinais, prevaleceu, também, a forma de chá através de infusão (46\%), seguido de decocção (40\%) e maceração (14\%), sendo que algumas plantas possuem mais de uma forma de preparo (MATTOS et al., 2015). Em Quixadá-CE evidenciou-se que $93,37 \%$ das pessoas utilizam plantas medicinais como medicamento na forma de chá e 6,63\% alegaram fazer a utilização do mesmo como alimento (OLIVEIRA; LUCENA, 2015). Esses resultados são semelhantes aos encontrados em outros estudos (CORRÊA JÚNIOR; MING; SCHEFFER, 1994; KFFURI, 2008; OLIVEIRA; MENINI NETO, 2012). 
USO DE PLANTAS MEDICINAIS

NAS CIDADES DE CRUZÍLIA,

SÃO GONÇALO DO SAPUCAÍ

E VARGINHA MG
Aurivan Soares de Freitas Andresa de Oliveira Brandão

Karina Luiza de Souza Larissa Aparecida Silva Saturnino

Gráfico 5 - Modo de uso das plantas medicinais



As plantas mais utilizadas nas três cidades foram hortelã (Mentha sp.), erva doce (Pimpinella anisum), boldo (Plectranthus barbatus) e erva cidreira (Melissa officinalis) com 26,47, 13,26, 10,29 e 10,29\%, respectivamente (Gráfico 6). Em estudo realizado em MaringáPR ficou evidenciado que as plantas medicinais mais citadas foram: hortelã, boldo, camomila (Matricaria recutita), guaco (Mikania glomerata) e erva cidreira (LOPES et al., 2015). No estudo de Oliveira \& Lucena (2015), em Quixadá CE, as plantas mais citadas pelos entrevistados foram erva-cidreira (Lippia alba (Mill) e hortelã. Em trabalho realizado no centro de educação infantil (CEI) de Goiânia GO verificou-se que erva cidreira (Melissa officinalis L) e hortelã corresponderam a 18 e $11 \%$ do uso, respectivamente (MOTTA; LIMA; VALE, 2016). Dessa forma, fica evidente que a espécie de planta medicinal usada pela população depende da região e da cultura das pessoas.

Entre aqueles que usam plantas medicinais, em São Gonçalo do Sapucaí 89\% já apresentaram alguma reação adversa devido ao uso de plantas, porém em Cruzília e Varginha não houve nenhum relato (Gráfico 7). Em Maringá PR, observou-se que entre as pessoas que usaram plantas medicinais $8,2 \%$ apresentaram alguma reação adversa (LOPES et al., 2015). É 
USO DE PLANTAS MEDICINAIS

NAS CIDADES DE CRUZÍLIA,

SÃO GONÇALO DO SAPUCAÍ

E VARGINHA MG
Aurivan Soares de Freitas Andresa de Oliveira Brandão Karina Luiza de Souza Larissa Aparecida Silva Saturnino

importante ressaltar que toda planta medicinal utilizada como medicamento é um xenobiótico, ou seja, um produto estranho ao organismo humano e que pode ser potencialmente tóxico quando mal usado (SILVEIRA; BANDEIRA; ARRAIS, 2008).

Gráfico 6 - Plantas medicinais mais utilizadas nos municípios de Cruzília, São Gonçalo do Sapucaí e Varginha MG



Fonte: Elaborado pelos autores, 2019. 
USO DE PLANTAS MEDICINAIS

NAS CIDADES DE CRUZÍLIA,

SÃO GONÇALO DO SAPUCAÍ

E VARGINHA MG
Aurivan Soares de Freitas Andresa de Oliveira Brandão

Karina Luiza de Souza Larissa Aparecida Silva Saturnino

Gráfico 7 - Reações adversas pelo uso de plantas medicinais nos municípios de Cruzília, São Gonçalo do Sapucaí e Varginha MG

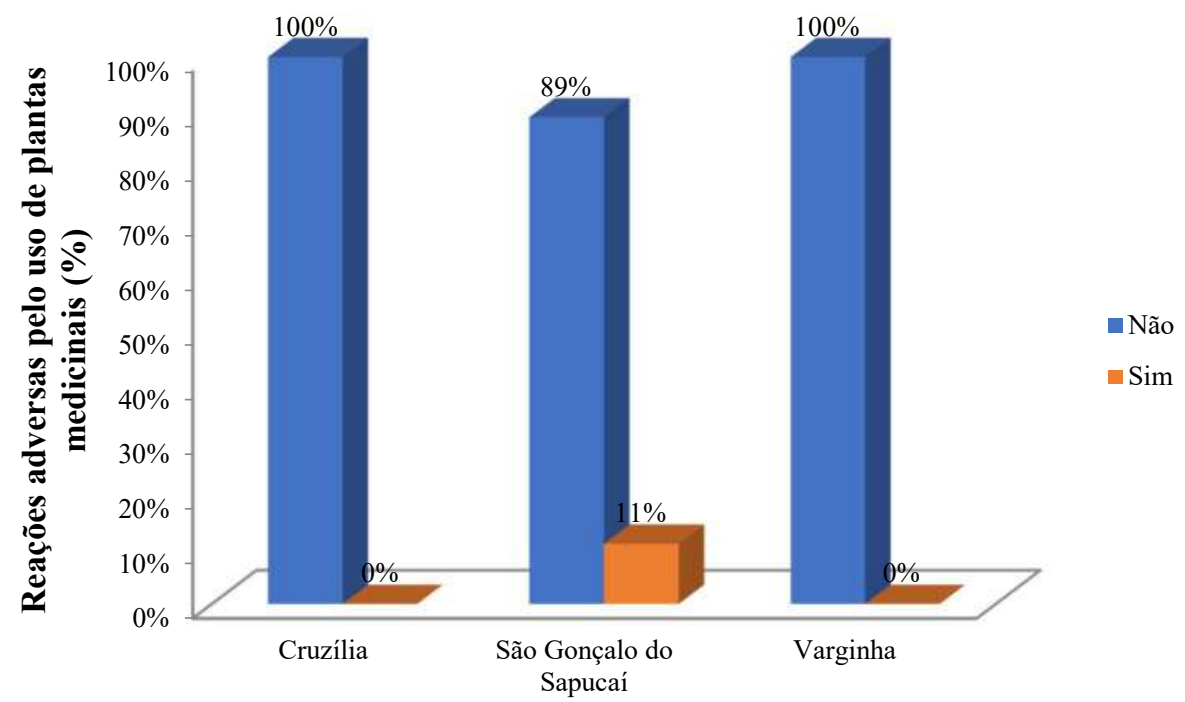

Fonte: Elaborado pelos autores, 2019.

O tratamento com plantas medicinais pode surtir o efeito esperado. Em Cruzília e Varginha, $69 \%$ e $60 \%$ dos entrevistados, respectivamente, sempre verificaram resultados no tratamento, enquanto em São Gonçalo do Sapucaí, apenas 37\% (gráfico 8) relataram obter resultados com o uso de plantas medicinais. Motta, Lima e Vale (2016) observaram que as mulheres, além de utilizarem com frequência as plantas medicinais em seus filhos, disseram que ao fazer uso das mesmas observaram o efeito desejado no tratamento de doenças.

Gráfico 8 - Resultados no tratamento com plantas medicinais por pessoas nos municípios de Cruzília, São Gonçalo do Sapucaí e Varginha MG.

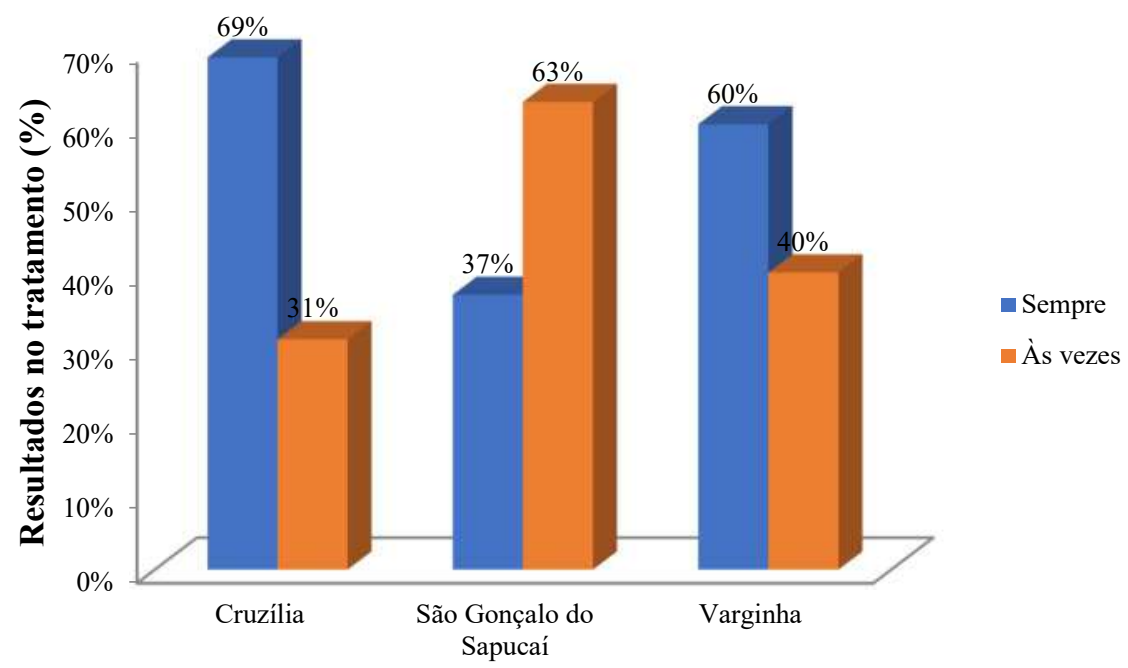

Fonte: Elaborado pelos autores, 2019. 
Apesar desses resultados é importante ressaltar que é importante conhecer as plantas medicinais e o seu uso deve ser feito com acompanhamento de um profissional habilitado, pois essa prática pode representar um perigo potencial para a população (ZENI et al., 2017).

\section{CONCLUSÕES}

As plantas medicinais mais utilizadas em São Gonçalo do Sapucaí, Cruzília e Varginha são Hortelã, Erva Doce, Boldo e Erva Cidreira. Apesar de todos os avanços tecnológicos na área da saúde, ainda há pessoas que optam por um meio mais natural para seu tratamento. Em Varginha, o uso de plantas medicinais é inferior aos encontrados nos municípios de São Gonçalo do Sapucaí e Cruzília. Apesar da maioria das pessoas de São Gonçalo do Sapucaí usar plantas medicinais, uma pequena minoria constatou resultados promissores no tratamento de doenças.

Em relação à segurança, quanto ao uso de plantas medicinais, ainda há pouco conhecimento das pessoas nos municípios de São Gonçalo do Sapucaí, Cruzília e Varginha. Também se observa que a maioria das pessoas não sabe os riscos do uso indiscriminado de certas substâncias e, esse comportamento pode causar complicações, como intoxicação.

\section{REFERÊNCIAS}

ARAÚJO, M. Das ervas medicinais à fitoterapia. São Paulo: Ateliê Editorial, 2002.

BRASIL. Resolução RDC $\mathbf{n}^{\circ} \mathbf{1 0}$, de 9 de março de 2010. Dispõe sobre a notificação de drogas vegetais junto à Agência Nacional de Vigilância Sanitária (ANVISA) e dá outras providências. Brasília, DF: Ministério da Saúde, 2010. Disponível em: http://bvsms.saude.gov.br/bvs/saudelegis/anvisa/2010/res0010_09_03_2010.html. Acesso em: 14 dez. 2020.

CALÁBRIA, L. et al. Levantamento etnobotânico e etnofarmacológico de plantas medicinais em Indianópolis, Minas Gerais, Brasil. Revista Brasileira de Plantas Medicinais, Botucatu, v. 10, n. $1, \quad$ p. 49-63, 2008.4 Disponível em: https://www1.ibb.unesp.br/Home/Departamentos/Botanica/RBPM-

RevistaBrasileiradePlantasMedicinais/artigo8.pdf. Acesso em: 14 dez. 2020.

CARNEIRO, F. M. et al. Tendências dos estudos com plantas medicinais no Brasil. Revista Sapiência: sociedade, saberes e práticas educacionais, Câmpus de Iporá, v.3, n. 2, p. 44-75, 
USO DE PLANTAS MEDICINAIS

NAS CIDADES DE CRUZÍLIA,

SÃO GONÇALO DO SAPUCAÍ

E VARGINHA MG
Aurivan Soares de Freitas Andresa de Oliveira Brandão Karina Luiza de Souza Larissa Aparecida Silva Saturnino

jul./dez.

2014.

Disponível

em:

https://crfmg.org.br/comunicacao/estudos_com_plantas_medicinais.pdf. Acesso em: 15 dez. 2020.

CORRÊA JÚNIOR, C.; MING, L.C.; SCHEFFER, M. C. Cultivo de plantas medicinais, aromáticas e condimentares. Jaboticabal: FUNEP, 1994. 162p.

GABRIEL NETO, L. A.; GOMES, F. T. Levantamento etnobotânico de plantas medicinais utilizadas pela população do município de Oliveira Fortes-MG. Perspectivas Online: Biológicas \& Saúde, [S.I.], v. 8, n. 27, 2018.

KFFURI, C.W. Etnobotânica de plantas medicinais no município de Senador Firmino, Minas Gerais. 2008. 88 f. Dissertação (Pós-Graduação em Fitotecnia) - Universidade Federal de Viçosa, Viçosa, 2008. Disponível em: https://www.locus.ufv.br/handle/123456789/4488. Acesso em: 15 dez. 2020.

LOPES, M. A. et al. Estudo das plantas medicinais, utilizadas pelos pacientes atendidos no programa "Estratégia saúde da família" em Maringá/PR/Brasil. Revista Brasileira de Plantas Medicinais, Campinas, v. 17, n. 4, p. 702-706, 2015. Disponível em: https://www.scielo.br/scielo.php?pid=S1516-

05722015000500702\&script=sci_abstract\&tIng=pt. Acesso em: 14 dez. 2020.

MATTOS, A. A. et al. Levantamento de plantas medicinais comercializadas por raizeiros do mercado municipal central de Montes Claros-MG. Revista Brasileira de Pesquisa em Ciências da Saúde, [S.I.], v. 2, n. 1, p. 11-17, 2015. Disponível em: http://revistas.icesp.br/index.php/RBPeCS/article/view/26. Acesso em: 17 dez. 2020.

MOREIRA, M. L.; NOVAES, H. M. D. Internações no sistema de serviços hospitalares, SUS e não SUS: Brasil, 2006. Revista Brasileira de Epidemiol, [São Paulo], v. 14, n. 3, p. 411-422, 2011. Disponível em: https://www.scielo.br/scielo.php?script=sci_arttext\&pid=S1415790X2011000300006. Acesso em: 15 dez. 2020.

MOTTA, A. O.; LIMA, D. C. S.; VALE, C. R. Levantamento do uso de Plantas Medicinais em um Centro de Educação Infantil em Goiânia-GO. Revista da Universidade Vale do Rio Verde, Três Corações, v. 14, n. 1, p. 629-646, jan./ jun. 2016. Disponível em: http://periodicos.unincor.br/index.php/revistaunincor/article/view/2613. Acesso em: 15 dez. 2020.

OLIVEIRA, D. M. S.; LUCENA, E. M. P. O uso de plantas medicinais por moradores de QuixadáCeará. Revista Brasileira de Plantas Medicinais, Campinas, v. 17, n. 3, p. 407-412, 2015. Disponível em: https://www.scielo.br/scielo.php?pid=S151605722015000300407\&script=sci_abstract\&tlng=pt. Acesso em: 16 dez. 2020.

OLIVEIRA, E. R.; MENINI NETO, L. Levantamento etnobotânico de plantas medicinais utilizadas pelos moradores do povoado de Manejo, Lima Duarte - MG. Revista Brasileira de Plantas Medicinais, Botucatu, v. 14, n. 2, p. 311-320, 2012 . Disponível em: 
https://www.scielo.br/scielo.php?pid=S1516-

05722012000200010\&script=sci_abstract\&tIng=pt. Acesso em: 14 dez. 2020.

PANIZZA, S. Ensinando a cuidar da saúde com as plantas medicinais: Guia prático de remédios simples da natureza. São Paulo, SP: Prestígio, 2005.

SANTOS, E. Q. et al. Etnobotânica da flora medicinal de quintais na comunidade Mamangal, Rio Meruú, Igarapé-Miri, Pará. Scientia Plena, [S.I.], v. 15, n. 5, 2019. Disponível em: https://www.scientiaplena.org.br/sp/article/view/4890. Acesso em: 16 dez. 2020.

SILVEIRA, P. F.; D. A.; BANDEIRA, M. A. M.; ARRAIS, P. S. D. Farmacovigilância e reações adversas às plantas medicinais e fitoterápicos: uma realidade. Rev. Bras. Farmacogn, [S.I.], v. 4, $\quad$ n. $18, \quad$ out./dez. 2008.2 Disponível em: https://www.scielo.br/pdf/rbfar/v18n4/v18n4a21.pdf. Acesso em: 17 dez. 2020.

TEIXEIRA, J. B. P. et al. A Fitoterapia no Brasil: da Medicina Popular à regulamentação pelo Ministério da Saúde. [2012?]. Disponível em: https://www.ufjf.br/proplamed/files/2012/04/A-Fitoterapia-no-Brasil-da-Medicina-Popular\%C3\%A0-regulamenta\%C3\%A7\%C3\%A3o-pelo-Minist\%C3\%A9rio-da-Sa\%C3\%BAde.pdf.

Acesso em: 17 dez. 2020.

VEIGA JUNIOR, V. F.; PINTO, A. C.; MACIEL, M. A. M. Plantas medicinais: cura segura. Química nova, [S.I.], v. 28, n. 3, p. 519-528, 2005. Disponível em: https://www.scielo.br/scielo.php?pid=S0100-

40422005000300026\&script=sci_abstract\&tlng=pt. Acesso em: 14 dez. 2020.

VIU, A. F. M.; VIU, M. A. O.; CAMPOS, L. Z. Etnobotânica: uma questão de gênero?. Revista Brasileira de Agroecologia, Porto Alegre, v. 5, n. 1, p. 138-147, 2010. Disponível em: https://orgprints.org/25047/1/Viu_Etnobot\%C3\%A2nica.pdf. Acesso em: 14 dez. 2020.

ZENI, A. L. B. et al. Utilização de plantas medicinais como remédio caseiro na Atenção Primária em Blumenau, Santa Catarina, Brasil. Ciência \& Saúde Coletiva, [S.I.], v. 22, p. 2703-2712, 2017. Disponível em: https://www.scielo.br/scielo.php?script=sci_abstract\&pid=S141381232017002802703\&lng=es\&nrm=iso\&tlng=pt. Acesso em: 15 dez. 2020.

ZUCCHI, M. R. et al. Levantamento etnobotânico de plantas medicinais na cidade de IpameriGO. Revista Brasileira de Plantas Medicinais, Campinas, v. 15, n. 2, p. 273-279, 2013. Disponível em: https://www.scielo.br/scielo.php?script=sci_arttext\&pid=S151605722013000200016. Acesso em: 14 dez. 2020. 


\section{APÊNDICE}

APÊNDICE A - Questionário utilizado no levantamento sobre o uso de plantas medicinais nas cidades de Cruzília, são Gonçalo do Sapucaí e VARGINHA MG

\section{Identificação \\ Nome:}

Endereço:

Telefone:

\section{Qual é a sua idade?}
( ) 18 a 28
( ) 29 a 38
( ) 39 a 48
( ) 49 a 58
( ) 59 a 65
( ) mais que 66

\section{Qual é o seu gênero?}

( ) masculino

( ) feminino

3. Qual é sua escolaridade?

( ) analfabeto

( ) sei ler e escrever (alfabetizado)

( ) ensino fundamental incompleto

( ) ensino fundamental completo

( ) ensino médio incompleto

( ) ensino médio completo

( ) ensino superior incompleto

( ) ensino superior completo

( ) outro:

4. Em qual cidade você reside?

( ) Cruzília - MG

( ) São Gonçalo do Sapucaí - MG

( ) Varginha-MG

\section{Faz o uso de Plantas Medicinais?}

( ) SIM

( ) NÃO

*Se sua resposta foi NÃO para o uso de plantas medicinais, encerra-se o questionário. 


\section{Onde adquire as plantas medicinais?}
( ) Feiras livres
( ) Lojas de produtos naturais
( ) Supermercados
( ) Farmácias
( ) Horta caseira
( ) Outros

7. Cultiva algum tipo de planta medicinal em casa?

( ) Sim

( ) Não

Qual/Quais:

\section{Há quanto tempo você usa plantas medicinais?}
( ) Sempre usei plantas medicinais
( ) Há mais de 1 ano
( ) Há mais de 5 anos
( ) Há mais de 10 anos

\section{Por que você usa plantas medicinais?}

( ) Porque acredito que as plantas medicinais podem me curar

( ) Para complementar o tratamento com outros medicamentos

( ) Para acalmar

( ) Por indicação de alguém

( ) Por ser mais barato

( ) Por causar menos efeitos colaterais

11. De que forma você utiliza as plantas medicinais?
( ) Chás
( ) Xaropes
( ) Tinturas
( ) Pomadas

12. Como você sabe se aquela planta que está usando é para determinado tipo de doença? 


\title{
13. Com que frequência você costuma fazer uso das plantas medicinais?
}

\author{
14. Você já viu resultados no tratamento com plantas? \\ ( ) Sempre \\ ( ) Nunca \\ ( ) Às vezes
}

15. Utiliza mais de uma planta por vez?

( ) $\operatorname{Sim}$

( ) Não

16. Através de quem (ou como) aprendeu a usar plantas medicinais?
( ) Pais
( ) Avós
( ) Vizinhos
( ) Televisão

17. Você sente mais confiança em medicamentos feitos à base de plantas medicinais ou alopáticos?

( ) Medicamentos à base de plantas medicinais

( ) Medicamentos Alopáticos

18. Já teve alguma reação adversa com o uso de plantas medicinais?

( ) Sim

( ) Não

Justifique

19. Você se informa sobre uma planta medicinal com um profissional de saúde antes de usá-la?

( ) Sim

( ) Não

20. Qual parte da planta você utiliza?

21. Qual tipo de uso?

( ) Interno (xaropes, chás)

( ) Externo (tintura, pomada) 
USO DE PLANTAS MEDICINAIS

NAS CIDADES DE CRUZÍLIA,

SÃO GONÇALO DO SAPUCAÍ

E VARGINHA MG
Aurivan Soares de Freitas Andresa de Oliveira Brandão

Karina Luiza de Souza Larissa Aparecida Silva Saturnino

22. Você conhece as propriedades das plantas que você utiliza?

Fonte: Elaborado pelos autores, 2019. 


\title{
DE NORTE A SUL: UMA ANÁLISE SOBRE AS CARACTERÍSTICAS ECONÔMICAS E GASTRONÔMICAS DAS PRINCIPAIS FRUTAS IDENTITÁRIAS NO BRASIL
}

\author{
Gabriela Ferreira Rodrigues \\ Universidade Federal Rural de Pernambuco, UFRPE, Brasil \\ gabriela.frodriguess@gmail.com \\ Aline Gomes Santana \\ Universidade Federal Rural de Pernambuco, UFRPE, Brasil \\ alinegsan157@gmail.com \\ Neide Kazue Sakugawa Shinohara \\ Universidade Federal Rural de Pernambuco, UFRPE, Brasil \\ neide.shinohara@ufrpe.br
}

\begin{abstract}
RESUMO
O presente estudo surge com o intuito de analisar as características de algumas frutas no território brasileiro sob a perspectiva do consumo, economia e versatilidade gastronômica. Foram selecionadas as frutas pequi, butiá, jabuticaba, caju e açaí, visto a representatividade de cada uma nas cinco regiões do Brasil. Além destas frutas também analisamos as características da banana, por estar presente no consumo frutífero de todas as regiões observadas. A partir de estudos bibliográficos, associados à coleta de dados no campo virtual através do método netnográfico, a pesquisa busca compreender e apresentar um pouco mais sobre cada uma das frutas ancorando-se em autores como Steele, Mourão e Fagundes além de dados de fontes como IBGE e Embrapa. Conforme as informações coletadas ao longo do estudo, consegue-se perceber a relevância destas frutas para o crescimento econômico da sua região de origem através de seu consumo que ocorre de diversas formas, sendo estimulado principalmente pela potencialidade e versatilidade gastronômica que estas oferecem. 0 estudo ainda traz uma breve observação da manifestação das frutas estudadas diante do cenário pandêmico em que o mundo se encontra, decorrente da propagação da Covid-19. Dessa forma, reforça a importância das frutas como elemento agregador e fortalecimento econômico para o mercado nacional.
\end{abstract}

Palavras-chave: Fruticultura. Consumo. Economia. Versatilidade. Pandemia. 


\title{
FROM NORTH TO SOUTH: AN ANALYSIS ON THE ECONOMIC AND GASTRONOMIC ASPECTS OF THE MOST CHARACTERISTIC FRUITS IN BRAZIL
}

\begin{abstract}
The present study aims to analyze the characteristics of some Brazilian fruits from the perspective of consumption, economy, and gastronomic versatility. Five specific fruits were selected, namely pequi, butiá, jabuticaba, caju, and açaí. These fruits were chosen considering the representativeness of each of these in the five Brazilian regions. In addition to these fruits, we also analyzed the characteristics of the banana, as it is present in the fruit consumption of all the observed regions. Based on bibliographic studies associated with data collection in the virtual field through the netnographic method, the research seeks to understand and shed some light on each of these fruits. Anchoring on authors such as Steele, Mourão and Fagundes besides data from sources such as IBGE and Embrapa. From the information collected throughout the study, we can claim the relevance of these fruits for the economic growth of their region of origin through their consumption that occurs in different ways, being stimulated mainly by the gastronomic versatility that they offer. The study also brings a brief observation on the manifestation of these fruits considering the pandemic which we are in due to the Covid-19 outbreak. Therefore, reinforcing the importance of fruits for the national fruit market.
\end{abstract}

Keywords: Fruit farming. Consumption. Economy. Versatility. Pandemic. 


\section{INTRODUÇÃO}

Falar de comes e bebes no território brasileiro engloba diversos segmentos, onde cada Estado da federação possui seus pratos tradicionais baseados em ingredientes típicos, sendo estes nativos e adotados, isso porque, o Brasil é um país continental que possui diversas culturas, sendo uma mistura entre tradições dos imigrantes, dos colonizadores, das pessoas escravizadas e dos povos indígenas. Com isso, cada região apresenta características únicas, pois, além da variedade de recursos naturais, a influência desses povos difere de acordo com o local. No entanto, como nação, há sim elementos que unem o país, como por exemplo as frutas, que tomam forma de bebidas e comidas (doce e salgado) estando presentes em todo território nacional.

A diversidade de florestas espalhadas pelos diferentes ecossistemas encontrados no Brasil, influencia diretamente no potencial frutífero do país. Segundo a Food and Agriculture Organization of the United Nations (FAO), conforme dados elaborados pelo Departamento de Economia da Secretaria de Agricultura e Abastecimento e o Departamento de Economia Rural do Paraná, o Brasil, em 2017, se encontrava como o terceiro maior produtor de frutas no mundo, sendo sua produção majoritariamente voltada para o comércio interno e com foco na Laranja, Banana e Abacaxi (ANDRADE, 2020). Além dessas frutas, há também no território brasileiro uma vasta quantidade de espécies pouco conhecidas e comercializadas, mas que compõem a alimentação diária das pessoas mais vulneráveis, minimizando a insegurança alimentar.

Inseridos no contexto da pandemia do novo coronavírus, desde 2020, os brasileiros vêm aumentando cada vez mais o consumo de frutas na sua dieta. De acordo com Steele et al. (2020), após uma pesquisa realizada com 10 mil pessoas de todas as regiões do país sobre os hábitos alimentares antes e durante a pandemia, observou-se um aumento na frequência de consumo de frutas, passando de $78,3 \%$ para $81,8 \%$.

Como existe uma grande disponibilidade de frutas no país, em espécies e quantidade, a exploração gastronômica deste grupo de alimento aumenta a cada ano. As frutas apresentam uma enorme versatilidade, sendo consumidas como bebida e/ou comida, 
passando por pratos salgados e doces, como acompanhante e até ingrediente principal, sendo aproveitada todas as partes comestíveis que a fruta oferece.

Neste contexto, o presente artigo traz uma discussão acerca de cinco frutas nativas do Brasil, açaí, caju, pequi, jabuticaba e butiá, e uma estrangeira, a banana. Tais frutas apresentam características comerciais e alimentícias diferentes, sendo cada uma delas representante de uma das 5 diferentes regiões do Brasil, norte, nordeste, centro-oeste, sudeste e sul, respectivamente. Já a banana se apresenta como a fruta mais consumida no país e vem como alimento que une os territórios de norte a sul. Desse modo, o objetivo do estudo foi analisar as seis frutas sob a perspectiva do consumo, em relação a sua importância na economia regional e nacional e sua versatilidade no uso gastronômico. Junto a isso, relacionamos tais aspectos culturais ao cenário atual de enfrentamento ao surto do covid-19 no Brasil.

Como método de estudo, diante da abrangência do tema, foi usada a netnografia e a pesquisa bibliográfica. Kozinets (2014, p. 62), define a netnografia como um meio que "usa comunicações mediadas por computador como fonte de dados para chegar à compreensão e à representação etnográfica de um fenômeno cultural ou comunal". Desse modo, foi possível, com base em textos escritos, imagens, fotos, áudios e vídeos, analisar com maior profundidade a forma de consumo das seis frutas nas regiões que são cultivadas. Ademais, a consulta em site e portais do governo dos Estados e das prefeituras foi de extremo valor, agregando dados e informações locais. Somada à netnografia, a pesquisa bibliográfica permitiu investigar o material já disponível acerca da temática, onde exploramos estudos científicos relacionados às frutas supracitadas.

\section{PROPRIEDADES E CARACTERÍSTICAS DAS FRUTAS}

Cada fruta citada neste artigo, possui propriedades e características únicas, tais como clima e solo em que são cultivadas, período de frutificação, tamanho e composição 
nutricional. Esses atributos interferem diretamente e indiretamente no consumo, na economia e no uso gastronômico.

Uma das frutas típicas do território brasileiro é o açaí, do tupi "yasa'i", oriundo da região norte $\mathrm{O}$ açaizeiro, nomeado cientificamente como Euterpe oleracea, é a árvore que dá origem ao açaí e que também fornece o palmito. Tal frutífera é predominante em solos de várzea baixa e locais que possuem clima quente e úmido, produzindo maior volume de açaí no segundo semestre do ano, apesar de frutificar durante o ano todo. Segundo Mourão (2010), a palmeira do açaí apresenta um estipe (caule) que atinge de 10 a 35 metros de altura. Além disso, o açaí possui alto valor calórico e se destaca pela riqueza de proteínas e, principalmente, lipídios.

O cajueiro (Anacardium occidentale) é uma planta cultivada em larga escala na região Nordeste do Brasil. Dessa árvore tem-se a castanha de caju, fruto (ovário desenvolvido) rico em proteínas e ácidos graxos poli-insaturados, e o caju, pseudofruto (tecido acessório que se desenvolve associado ao verdadeiro fruto) ou pedúnculo (haste ou tecido acessório que sustenta o fruto) abundante em açúcares, vitamina C e minerais (PAIVA et al., 2000). Segundo Crisóstomo et al. (2003), o cajueiro vem sendo dividido e estudado em dois grupos, o comum, é mais difundido e possui uma altura de 8 a 15 metros, e o anão, que atinge tamanhos inferiores a 4 metros. Para o cultivo, é recomendado uma área de clima tropical e com solo profundo, bem drenado e com boa reserva de nutrientes. Conforme Serrano e Pessoa (2016), a colheita de caju se dá no Estado do Ceará, principal produtor do Caju no país, entre outubro e novembro.

Nativo do cerrado, o pequi, segundo Soares (2018, p.9), tem seu valor nutricional "constituído por lipídios, proteínas, carboidratos, fibra alimentar, carotenóides e vitamina C". A fruta é proveniente do pequizeiro (Caryocar brasiliense Camb.), que necessita de um clima tropical ou subtropical para frutificar. Além disso, no estudo, de Santana e Naves (2007), realizado em vinte áreas do cerrado com predominância de pequizeiro, é relatada maior 
ocorrência da planta em regiões com solo de baixa fertilidade, destacando o cambissolo ${ }^{1}$ e o litossolo ${ }^{2}$. Com todas as condições de cultivo, ainda de acordo com Soares (2018), a árvore do pequi atinge até 10 metros de altura e a colheita dos frutos ocorre entre outubro e fevereiro na região do cerrado.

A jabuticaba, conhecida regionalmente como ouro negro, é um fruto globoso preto com polpa esbranquiçada. Conforme Lage et al. (2017), seu nome vem do tupi guarani "iapoti'ka", que significa "fruta botão", sua safra acontece nas estações da primavera e do verão e a jabuticabeira chega a atingir até 15 metros de altura. Para além disso, ela possui algumas variedades no Brasil, como a jabuticaba Sabará (Myrciaria jabuticaba) e a jabuticaba Paulista (Myrciaria cauliflora). Apesar de possuírem composições químicas diferentes, em geral a jabuticaba se apresenta "como fonte alternativa de minerais principalmente ferro, potássio, magnésio e manganês assim como de açúcares e ácidos orgânicos e vitamina C", de acordo com Lima (2009, p.97).

Nativa da região Sul do Brasil, do Paraguai e da Argentina, o butiazeiro é uma palmeira que dá frutos, de tons amarelos e polpas fibrosas, chamados de butiá. Segundo Patro (2014), o fruto é rico em betacaroteno, vitamina A e C. Se tratando do cultivo, o butiazeiro aprecia locais de clima subtropical e com solos drenados e ricos em matéria orgânica (PATRO, 2014). Desse modo, a partir das condições ideais, a árvore chega a produzir $20 \mathrm{~kg}$ de butiás por cachos, entre dezembro e fevereiro (EMBRAPA, 2019).

Vinda da Ásia, a banana (Musa spp.) foi trazida pelos colonizadores portugueses para o Brasil, e logo se adaptou aos diversos climas e solos do país (BARROS et al. 2016), sendo uma fruta bastante apreciada pelos brabarrosborgessileiros. Rico em carboidratos e potássio, este fruto possui uma extensa variedade de espécies como nanica, maçã, da terra, ouro e prata. É por essa diversidade que, segundo Barros et al. (2016), o tamanho da árvore pode variar de

\footnotetext{
${ }^{1}$ Tipo de solo constituído por material mineral e com o horizonte B ainda não transformado totalmente (SANTOS et al., 2018).

2 O litossolo é uma das subordens do Neossolo, caracterizado por ser um com pouca espessura de material orgânico ou muita matéria mineral e apresenta pouca ou nenhuma diferença em relação ao material originário (SANTOS et al., 2018).
} 
1,5 a 8 metros de altura. Assim como o comprimento, a época de colheita varia conforme a espécie e também de acordo com outros fatores como clima e período do plantio.

As frutas, cada uma com sua particularidade, se apresentam como uma ótima fonte de vitaminas, minerais, carboidratos, lipídios, proteínas e água. Desse modo, é recomendado, pelo guia alimentar para a população brasileira (BRASIL, 2014). O consumo diário desse alimento, que contribui para a prevenção de muitas doenças. Por essas e outras razões que as frutas estão sendo mais consumidas, no Brasil, durante a pandemia do covid-19 (STEELE et al., 2020).

\section{ECONOMIA REGIONAL E NACIONAL}

A fruticultura é um dos setores mais importantes na atualidade para a geração de receita, empregos, e principalmente, alimentos no Brasil. De acordo com dados divulgados em 2020 do Centro de Estudos Avançados em Economia Aplicada-CEPEA/USP em parceria com a Confederação da Agricultura e Pecuária do Brasil-CNA, o agronegócio, setor econômico que a fruticultura compõe, contribui em $21,4 \%$ no PIB brasileiro, gerando uma receita de $\mathrm{R} \$ 1,55$ trilhão em 2019 (CNA, 2020). Sendo que, 16\% da mão de obra do agronegócio é destinado à área frutícola, segundo a Associação Brasileira dos Produtores Exportadores de Frutas e Derivados- ABRAFRUTAS (2019).

Apesar de o Brasil ser o terceiro maior produtor de frutas no mundo, ele ainda destina a maior parte da produção para o mercado interno. No ano de 2019, o país ocupava a posição de 23 ㅇ lugar no ranking mundial, no quesito de exportação desses produtos, com cerca de 3\% da produção nacional destinada ao mercado externo (ABRAFRUTAS, 2019).

Dentro desse cenário, as frutas evidenciadas neste texto apresentam-se como figuras relevantes para a fruticultura por seus valores e protagonismo comercial em escala nacional e/ou local. Reforçando assim a ideia de Rufino (2008, p.5), ao pontuar que "a importância econômica das fruteiras para as diversas regiões do Brasil não pode ser mensurada apenas 
por dados estatísticos [visto que], essa atividade é uma das principais geradoras de renda, de empregos e desenvolvimento regional".

O açaí tem sua produção centralizada na região norte do Brasil. O maior produtor de do fruto no mundo é o Estado do Pará, seguido pelo Amazonas e pelo Maranhão (SERRA; SANTOS, 2021). Da região norte, o açaí é distribuído ao longo do Brasil. Ainda segundo os mesmos autores, de acordo com os dados entregues ao G1, em 2019, pelo Sindicato das Indústrias de Frutas e Derivados, o açaí do Pará movimenta em torno de 1,5 bilhão de dólares na economia estadual e, saindo do território paraense, a fruta se destina principalmente a São Paulo, Rio de Janeiro e Minas Gerais. Apesar de possuir grande repercussão em território brasileiro, o açaí vem conquistando cada vez mais o mercado externo. Atualmente, os Estados Unidos da América é o principal país importador da fruta, correspondendo a $66 \%$ do total exportado pelo Brasil, segundo Serra e Santos (2021).

Com 62,9\% da produção nacional em 2019, o Ceará é o principal estado produtor de castanha de caju no Brasil, seguido pelo Piauí e pelo Rio Grande do Norte (FAGUNDES, 2020). Apesar da expressiva quantidade produzida pelo Brasil, de acordo com a FAO (2020), o país que se destacou na produção mundial de castanha de caju com casca, em 2019, foi a Costa do Marfim. Ainda segundo Fagundes (2020), o Brasil exportou, entre janeiro e novembro de 2020, 14,6 mil toneladas de castanha de caju sem casca com destino, principalmente, aos Estados Unidos, Alemanha e Holanda.

O pequi, por sua vez, possui sua produção centralizada em Minas Gerais, com cerca de 18 mil toneladas do fruto em 2019, seguido pelo Tocantins e Goiás, segundo o Instituto Brasileiro de Geografia e Estatística-IBGE, (2020). Apesar disso, é notável a relevância do pequi para a região centro-oeste, principalmente no Estado de Goiás, pela presença na culinária local. O pequi se mostra extremamente importante na economia local, é o que afirma Ribeiro $(2013, s / p)$ :

[...]o fruto símbolo do cerrado era a garantia de alimentação durante o período da safra. Agora, o dinheiro que resulta das vendas do pequi também proporciona a 
compra de roupas, eletrodomésticos e outros bens de consumo, ajudando centenas de pessoas a amenizar o castigo da seca.

Em 2017, o maior produtor de Jabuticaba no país era o Estado de Goiás, com cerca de 1,7 mil toneladas, acompanhado por São Paulo e Minas Gerais, de acordo com o IBGE (2017). No cenário geral do Brasil, foi colhido, em 2017, aproximadamente de 3,7 mil toneladas de jabuticaba, gerando um valor de 10,5 milhões de reais (IBGE, 2017). Além disso, a fruta tem grande influência na economia local de algumas cidades. No município de Sabará, em Minas Gerais, gera-se uma circulação de renda de cerca de $\mathrm{R} \$ 5$ milhões durante os quatros dias do Festival de Jabuticaba da cidade (PATRÍCIO, 2020).

Fruto típico do Rio Grande do Sul, o Butiá é bastante comum na região sul do Brasil. Por ser um fruto ainda pouco comercial nacionalmente, os moradores de Santa Vitória do Palmar usam das folhas e frutos do butiazeiro para produzir receitas e artesanato, comercializando-os no mercado local e gerando uma renda extra para a família (TRZECIAK, 2012). Além disso, há 13 edições ocorre a Feira do Butiá na cidade de Giruá-RS, que movimenta a economia local trazendo produtos artesanais feitos com o butiá (GIRUÁ, 2019)

Além das frutas de cada região, tem-se a banana que se apresenta como um destaque na produção, tanto em escala nacional quanto mundial. Segundo o IBGE (2021), em 2020, o Brasil produziu cerca de 6,7 milhões de toneladas de banana, onde São Paulo foi o Estado que mais se destacou, seguido pela Bahia e por Minas Gerais. Ainda em 2020, o Brasil enviou para o mercado exterior, cerca de 84 mil toneladas de banana, de acordo com a ABRAFRUTAS (2021). Comparando os dados acima, é possível afirmar que a maior parte do que é produzido de banana no país é mantido no mercado interno. Mundialmente, a Índia se destaca na produção da fruta com 30 milhões de toneladas no ano de 2019 e ocupando segundo e terceiro lugar no ranking tem-se China e Brasil, respectivamente (FAO, 2020).

Com a pandemia do covid-19, muitos setores econômicos foram atingidos, sendo a fruticultura um deles. As frutas citadas no artigo foram impactadas de diferentes formas durante esse período. O açaí, segundo Serra e Santos (2021), teve queda nas exportações e o preço pago ao produtor foi menor no primeiro semestre de 2020 em relação ao mesmo período no ano anterior. Com o caju foi um pouco diferente, até novembro de 2020, o Brasil 
apresentou uma redução de $4 \%$ na quantidade exportada da fruta, mas o preço médio recebido pelo produtor aumentou em 32\% no décimo primeiro mês daquele ano, comparado ao ano de 2019 (FAGUNDES, 2020).

Mesmo com os preços mais baixos em 2020, a procura de pequi na região do Cariri, onde é muito consumido, diminuiu bastante segundo Rodrigues (2021), por conta da pandemia. Já com o butiá, o prejuízo se refletiu na feira da fruta, que teve que ser suspensa (GIRUÁ, 2020). Outro evento que foi impactado foi o Festival de Jabuticaba de Sabará que, apesar de ter acontecido remotamente, não teve o mesmo faturamento do ano de 2019 (PATRÍCIO, 2020). Em oposição aos casos citados, tem-se a banana que enviou para o mercado externo $5 \%$ a mais em quantidade e, somado a isso, o cenário nacional produziu mais de um milhão de toneladas de frutas, representando um crescimento de $6 \%$ no setor da exportação, em 2020 em comparação ao ano anterior (ABRAFRUTAS, 2021).

\section{CONSUMO E VERSATILIDADE GASTRONÔMICA}

O Brasil é um país com extensão continental, trazendo consigo alta diversidade de climas e solos. Desse modo, ao longo do seu território são produzidos e consumidos diferentes tipos de frutas. A gastronomia inclui saberes e fazeres na perspectiva de conservação, transformação e proteção de recursos alimentares locais à disposição das comunidades, que com o emprego de técnicas culinárias adequadas podem prolongar a oferta de frutas em preparações doces, salgadas, assim como sucos e bebidas.

Originalmente, o açaí é consumido pelas comunidades ribeirinhas do estuário amazônico. Porém, conforme Rossini (2019), o açaí só começou a se popularizar em outras regiões do Brasil, que não somente na região Norte, a partir da virada do milênio. Ao sair da sua região de origem, o fruto teve que sofrer adaptações para conseguir chegar sem oferecer um risco à saúde do consumidor, sendo feita a industrialização e congelamento da polpa (ROSSINI, 2019). Com isso, o açaí é consumido de diferentes formas ao longo do país, como diz Mourão (2010, p.84):

O açaí com farinha de mandioca acompanhado de uma proteína animal (carne, peixe e camarão fritos ou moqueados) constitui-se ainda na principal refeição das populações mais pobres do mundo urbano e rural na Amazônia. Com açúcar ou adoçante é um delicioso suco, ingerido como sobremesa ou lanche. Cozido com 
arroz, tapioca ou pasta de farinha puba é um nutritivo componente do café da manhã. Acrescente a estas modalidades de consumo os sorvetes, os cremes, mousses, pudins licores e bebidas alcoólicas como a cachaça e o vinho fermentado a semelhança da uva.

Muito comum na culinária nordestina, o caju oferece infinitas possibilidades de pratos doces e salgados tanto para o fruto quanto para o pedúnculo. Como bebida, o pseudofruto se apresenta combinado a destilados para drinks, como polpa para sucos e vinhos, e da sua castanha podemos fazer leites e queijos. Além disso, como patrimônio tombado pela Unesco juntamente ao IPHAN temos a Cajuína, bebida não alcoólica tradicional piauiense (SOUZA, 2018). Integrando pratos e refeições, o caju explora os limites da criatividade do cozinheiro. Com a castanha pode-se fazer farofas, bolos e pastas. Já com o pedúnculo, é possível elaborar geleias, compotas, mariolas (doce feito com banana, caju ou goiaba) rapaduras e doces em calda. Além disso, a carne de caju é uma ótima opção para substituir a proteína animal. Assim explica o chef Claudemir Barros na matéria de Souza (2018, s/p):

Mas ele [o caju] vai além. Se você olhar para a história, verá que, por décadas, serviu como proteína principal. A minha mãe fazia bife de caju sem a gente saber o que era. Ela aprendeu isso com minha avó e assim sucessivamente. Então, quantas receitas não existem à base da 'fruta brasileira'?

Nativo do cerrado brasileiro e fruta típica do Centro-Oeste, o pequi possui um sabor único e se constitui como base alimentar da população desse bioma. Diversos pratos regionais e tradicionais exaltam essa fruta, como por exemplo o Lagarto com Pequi, Arroz com Pequi, Frango com Pequi e até sendo o ingrediente principal como a Pequizada. Na forma de bebida, o pequi dá um excelente coquetel, se associado ao mel e à cachaça, e serve também um belo licor. Para além da alimentação, de acordo com Soares (2018), o pequi tem uso cosmético e medicinal, com propriedades antioxidantes e anti-inflamatória.

A jabuticaba é originária da Mata Atlântica, porém tem sua produção acentuada na região Sudeste e Centro-Oeste do país. Como a fruta é perecível e a árvore floresce poucas vezes ao ano, as populações locais exploram as infinitas possibilidades de elaborar os derivados da jabuticaba. Tamanha é a importância dessa fruta que em 2020 o Festival da Jabuticaba de Sabará completou 34 edições (VELOSO, 2020). Molhos, sorvetes, licores, 
jabuticabada, geleias, farinhas, cervejas, conhaque, pães e até mortadela da fruta são alguns exemplos da versatilidade que jabuticaba possui, até o momento.

Comumente encontrada no Estado do Rio Grande do Sul, o butiá atrai não somente os olhares humanos, mas também a fauna silvestre local, garantindo uma ótima fonte de energia para esses animais (PATRO, 2014). Na alimentação, o butiá ganha formas de recheio, sucos, rapadura, geleias, licores, bolos, sorvetes e mousses. Segundo Büttow et al. (2009), além do consumo in natura, a fruta também integra pratos como "Arroz com butiá" e possui uma amêndoa que é uma semente comestível.

A banana, musa do Brasil, é a fruta mais consumida no país (BORGES et al., 2015). Tal alimento apresenta praticidades particulares, como por exemplo a casca que é uma embalagem perfeita. Para além do consumo in natura no dia a dia, a banana é ingerida em pratos salgados na forma de nhoque, chips, farofa e em tortas. Já em pratos doces, a fruta possui grande abrangência, integrando bolos, tortas e sorvetes, além da própria bananada, da mariola e nego bom. Tradicional da cozinha brasileira, a cartola é uma sobremesa típica do Nordeste que leva banana, queijo, açúcar e canela. A fruta, também é uma ótima opção vegana, possibilitando o consumo da carne de casca de banana.

Considerando-se o contexto de pandemia da covid-19 enfrentado atualmente no Brasil, é de extrema importância destacar a necessidade do consumo de frutas, pelas propriedades nutricionais fornecidas. Em entrevista para Malavé (2020), Wanessa Marinho, coordenadora do Núcleo de Alimentação, Saúde e Ambiente (Nasa) da Fiocruz, e Débora Oliveira, nutricionista do Nasa, esclarecem que "até o momento, não há nenhum medicamento, substância, vitamina, alimento específico ou vacina que possa prevenir e/ou curar a infecção pelo novo coronavírus.". Apesar disso, fortalecer o sistema imunológico e manter uma alimentação saudável se torna um fator útil na hora do combate ao vírus (MALAVÉ, 2020).

Para o bom funcionamento do sistema imune é preciso ter uma dieta equilibrada entre macro e micronutriente. A partir do que foi relatado nos parágrafos anteriores, é possível afirmar que as frutas citadas possuem, cada uma com sua singularidade, os nutrientes para, 
junto a outros alimentos, garantir um bom funcionamento do organismo e do nosso sistema de defesa.

\section{CONCLUSÃO}

A partir das informações coletadas, é possível perceber que as frutas citadas no artigo apresentam características diferentes, entre elas, no setor econômico, na área do consumo e em suas propriedades nutricionais. Apesar disso, todas têm sua importância dietética, econômica e gastronômica, seja em escala regional, nacional e até mundial.

O açaí e o caju mostraram como as frutas nacionais conseguiram conquistar o paladar estrangeiro. Esse primeiro teve que sofrer adaptações para o comércio fora da região produtora, com o processo de congelamento da polpa e adição de conservantes e adoçantes, onde cada país tem sua prioridade quanto à proporção destes componentes. Já o caju expandiu de maneira a ser até produzido em outras regiões do planeta, superando os números do Brasil nesse setor.

No que se refere à banana o processo foi inverso, essa fruta estrangeira é a mais apreciada pelo brasileiro compondo receitas tradicionais do país, além de possuir protagonismo no Brasil como importante produto de exportação mundial.

Quanto a jabuticaba e o pequi, observou-se uma certa ambiguidade, em razão de que ambos apontam uma produtividade em uma região diferente daquela onde são mais consumidas, tendo grande importância cultural e gastronômica por onde transitam. Desse modo, fica explícito como ao longo dos anos a fruticultura brasileira expandiu para além das fronteiras regionais.

Ao longo da pesquisa, foi perceptível que o butiá ainda possui poucas informações disponíveis, podendo ser um reflexo do baixo protagonismo nacional. Entretanto, a fruta apresenta grande relevância na região sul do país, compondo até ditos populares como "cair os butiás do bolso".

É possível analisar também, a importância de festivais gastronômicos nas regiões produtoras dessas frutas. A jabuticaba e o butiá são um exemplo claro de como tais eventos 
podem movimentar a economia local, além de exaltar o potencial da fruta e estimular a criatividade dos comerciantes na produção de derivados.

Entretanto, com a pandemia do novo coronavírus, a comercialização e o consumo dessas frutas foram diretamente afetados. No que se refere ao consumo, ainda que a exportação, no setor frutífero, no Brasil tenha aumentado significativamente no ano de 2020, cada fruta se comportou de um jeito diante desse cenário. Enquanto a banana aumentou expressivamente na exportação, o açaí teve uma redução de $4 \%$. Já para as frutas pouco comerciais (pequi, jabuticaba e butiá) foi relatada uma queda na procura e na comercialização, que pode ter sido influenciada pelo fechamento dos comércios, pelo cancelamento ou adaptações dos festivais e pelas medidas de isolamento social. Quanto ao consumo, vemos a importância da ingestão desses alimentos, ainda mais num contexto de crise sanitária. Sendo assim, é de extrema relevância que a população continue aumentando o uso das frutas na alimentação diária conforme sugere Steele et al. (2020).

A diversidade brasileira enriquece nossa cultura e tradições. Cada região do país possui suas particularidades e dentro do potencial frutífero do Brasil, ainda há muito a ser explorado e descoberto.Além disso, muitas dessas frutas são extremamente relevantes como fonte de alimento e bebida para populações locais e de baixa renda.

Deste modo, a partir do estudo das frutas apresentadas no texto, podemos perceber como a fruticultura é relevante para economia nacional, e como o consumo das frutas nas mais diferentes formas contribui para o enriquecimento do campo gastronômico, por sua versatilidade, e para o desenvolvimento das diferentes regiões do Brasil.

\section{REFERÊNCIAS}

ANDRADE, P. F. S. Fruticultura. Governo do Estado do Paraná, Secretaria da Agricultura e do Abastecimento, 2020. Disponível em: <http://www.agricultura.pr.gov.br/sites/default/arquivos_restritos/files/documento/202001/fruticultura_2020.pdf>. Acesso em: 13 de fev. de 2021.

Associação Brasileira dos Produtores Exportadores de Frutas e Derivados. Brasil é o terceiro maior produtor de frutas do mundo, diz Abrafrutas. Brasília, 7 mar. 2019. Disponível em: 
<https://abrafrutas.org/2019/03/brasil-e-o-terceiro-maior-produtor-de-frutas-do-mundodiz-abrafrutas/> . Acesso em 15 de mar. de 2021.

Associação Brasileira dos Produtores Exportadores de Frutas e Derivados. Dados de Exportação 2020. Brasília, 2021. Disponível em:<https://abrafrutas.org/2021/02/dados-deexportacao-2020/>. Acesso em 15 de mar. de 2021.

BARROS, E. C. da D.; INÁCIO, R. A.; PINTO, F. O.; QUINTAS, E. da S.; RODRIGUES, M. D. A utilização da banana como fonte de renda para pequenos produtores. Revista Científica Interdisciplinar, $\quad$ v. $3, \quad$ n. $\quad 2, \quad$ p.22-37, $2016 . \quad$ Disponível em:<http://revista.srvroot.com/linkscienceplace/index.php/linkscienceplace/article/view/23 8>. Acesso em 09 de mar. de 2021.

BORGES, A. L.; MATOS, A. P. de; RITZINGER, C. H. S. P.; SOUZA, L. da S.; LIMA, M. B.; FANCELLI, M. Boas práticas agrícolas de campo no cultivo da bananeira.Cruz das Almas, BA: Embrapa Mandioca e Fruticultura, 52p., $2015 . \quad$ Disponível em : <https://www.infoteca.cnptia.embrapa.br/infoteca/handle/doc/1015213>. Acesso em : 17 de mar. de 2021.

BRASIL. Ministério da Saúde . Guia alimentar para a população brasileira: promovendo a alimentação saudável. 2o ed. Brasília, Ministério da Saúde, 2014. Disponível em: $<$ https://bvsms.saude.gov.br/bvs/publicacoes/guia_alimentar_populacao_brasileira_2ed.pd >. Acesso em 09 de mar. de 2021.

BÜTTOW, M. V.; BARBIERI, R. L.; NEITZKE, R. S.; HEIDEN, G. Conhecimento tradicional associado ao uso de Butiás (Butiá spp., Arecaceae) no sul do Brasil. Rev. Bras. Frutic., Jaboticabal, v. 31, n. 4, p. 1069-1075, dez. 2009. Disponível em:<https://www.scielo.br/pdf/rbf/v31n4/v31n4a21.pdf>. Acesso em: 11 de fev. de 2021 Confederação da Agricultura e Pecuária do Brasil-CNA. Panorama Agro. Brasília, jun. 2020. Disponível em: <https://www.cnabrasil.org.br/cna/panorama-do-agro\#_ftn1>. Acesso em: 27 de fev. de 2021.

CRISÓSTOMO, L. A.; SANTOS, F. J. de S.; OLIVEIRA, V. H. de; RAIJ, B. van; BERNARDI, A. C. de C.; SILVA, C. A.; SOARES, I. Cultivo do cajueiro anão precoce: aspectos fitotécnicos com ênfase na adubação e na irrigação.Fortaleza: Embrapa Agroindústria Tropical, out. 2003. Disponível em: <https://www.embrapa.br/busca-de-publicacoes/-/publicacao/424408/cultivo-docajueiro-anao-precoce-aspectos-fitotecnicos-com-enfase-na-adubacao-e-na-irrigacao $>$.

Acesso em: 08 de mar. de 2021.

EMBRAPA. Cuidados na colheita contribuem para longevidade do butiá. Brasília-DF: Embrapa Clima Temperado, 4 abr. 2019. Disponível em: <https://www.embrapa.br/busca-de-noticias//noticia/42442421/cuidados-na-colheita-contribuem-para-longevidade-do-butia>. Acesso em 09 de mar. de 2021.

FAGUNDES, M. H. Castanha de Caju - Análise Mensal - Novembro 2020.Brasília: Companhia Nacional de Abastecimento (CONAB), 14 dez. 2020. Disponível em: $<$ https://www.conab.gov.br/info-agro/analises-do-mercado-agropecuario-e- 
extrativista/analises-do-mercado/historico-mensal-de-castanha-de-caju>. Acesso em 15 de mar. de 2021.

FOOD AND AGRICULTURE ORGANIZATION OF THE UNITED NATIONS-FAO. FAOSTAT. Roma: FAO, 2020. Disponível em: <http://www.fao.org/faostat/en/\#data/QC> . Acesso em 15 de mar. de 2021.

GIRUÁ. Prefeitura Municipal de Giruá. Atrações artísticas da Expogiruá marcam a história do município. Giruá, $2019 . \quad$ Disponível em: <https://www.girua.rs.gov.br/site/noticias/expogirua/38442-atracoes-artisticas-daexpogirua-marcam-a-historia-do-municipio>. Acesso em 15 de mar. de 2021.

GIRUÁ. Prefeitura Municipal de Giruá. Município de Giruá suspende aulas até dia $\mathbf{2}$ de abril e transfere a 14a Feira do Butiá. Giruá, 2020. Disponível em: <https://www.girua.rs.gov.br/site/noticias/noticia/48327-municipio-de-girua-suspendeaulas-ate-dia-2-de-abril-e-transfere-a-14-feira-do-butia>. Acesso em 15 de abr. de 2021.

Instituto Brasileiro de Geografia e Estatística-IBGE. Censo agro 2017. Rio de Janeiro: IBGE, 2017.Disponível

em: <https://censos.ibge.gov.br/agro/2017/templates/censo_agro/resultadosagro/agricultura.ht ml ?localidade=0\&tema=76309> . Acesso em 15 de mar. de 2021.

Instituto Brasileiro de Geografia e Estatística-IBGE. Levantamento Sistemático da Produção Agrícola: Estatística da Produção Agrícola janeiro 2021. Rio de Janeiro: IBGE, 2021. Disponível em: $<$ https://biblioteca.ibge.gov.br/index.php/bibliotecacatalogo?id=72415\&view=detalhes $>$. Acesso em 15 de mar. de 2021

Instituto Brasileiro de Geografia e Estatística-IBGE. Produção da Extração Vegetal e Silvicultura 2019. Rio de Janeiro: IBGE, 2020. Disponível em: <https://cidades.ibge.gov.br/brasil/go/pesquisa/16/12705?localidade1\%3D31\%26localidade 2\%3D23\%26indicador\%3D12722=\&sa=D\&source=editors\&ust $=1615764789696000 \& u s g=A O$ vVaw0Qg6sWu0vO4ySr_ItlkJuG\&localidade1=31\&localidade2=17>. Acesso em 15 de mar. de 2021

KOZINETS, R. V. Netnografia: realizando pesquisa etnográfica online. Porto Alegre: Penso, 2014.

LAGE, C. A.; CARDOSO, N.; CARMO, L. A. M.; ELIAS, M. A. A versatilidade do consumo da jabuticaba: descobrindo possibilidades de aproveitamento dessa fruta no dia a dia. CES REVISTA, Juiz de Fora, v. 1, n. p.116-132, 2017. Disponível em : $<$ https://docplayer.com.br/50941663-A-versatilidade-do-consumo-da-jabuticabadescobrindo.html >. Acesso em: 12 de fev. de 2021 (Mart.) O. Berg]. 2009. Tese (Doutorado em Agroquímica)-Universidade Federal de Lavras, 
Lavras,

MG.

Disponível

em:<http://repositorio.ufla.br/jspui/bitstream/1/2586/1/TESE_Caracteriza\%C3\%A7\%C3\%A3 o\%20e\%20atividade\%20antioxidante\%20da\%20jabuticaba\%20\%5BMyrciaria\%20cauliflora\% 20\%28Mart.\%29\%200.\%20Berg\%5D.pdf>. Acesso em 08 de mar. de 2021.

MALAVÉ, M. M. Especialistas tiram dúvidas sobre alimentação e coronavírus. Rio de Janeiro: Fiocruz, 15 maio 2020. Disponível em: <https://portal.fiocruz.br/noticia/especialistas-tiramduvidas-sobre-alimentacao-e-coronavirus >. Acesso em 09 de mar. de 2021.

MOURÃO, L. História e natureza: açaí ao palmito. Revista Territórios e Fronteiras, v.3 n.2, p.74-96, 2010.2 Disponível em: <http://www.ppghis.com/territorios\&fronteiras/index.php/v03n02/article/view/69/68>. Acesso em: 13 de fev. de 2021.

PAIVA, F. F. de A.; GARRUTI, D. dos S.; SILVA NETO, R. M. da. Aproveitamento Industrial do caju. Fortaleza: Embrapa-CNPAT/SEBRAE/CE, 88p., 2000. Disponível em:<https://www.embrapa.br/busca-de-publicacoes/-

/publicacao/0422033/aproveitamento-industrial-do-caju>. Acesso em 08 de mar. de 2021.

PATRÍCIO, E. Pandemia derruba festivais gastronômicos e economia de Sabará. Estado de Minas, 10 ago. 2020.2 Disponível em: <https://www.em.com.br/app/noticia/economia/2020/08/10/internas_economia,1174609/ pandemia-derruba-festivais-gastronomicos-e-economia-de-sabara.shtml $>$. Acesso em 15 de mar. de 2021.

PATRO, R. Butiá - Butia capitata. Jardineiro.net, 27 fev. 2014 . Disponível em:<https://www.jardineiro.net/plantas/butia-butia-capitata.html>.Acesso em: 11 de fev. de 2021.

RIBEIRO, L. Pequi vira ouro do cerrado. Estado de Minas, 15 jul. 2013 Disponível em: <https://www.em.com.br/app/noticia/economia/2013/07/15/internas_economia,422647/p equi-vira-ouro-do-cerrado.shtml >. Acesso em 15 de mar. de 2021.

RODRIGUES, A. Em plena safra, vendas de pequi caem no Cariri devido à pandemia. Diário do Nordeste, 262021.2 jan. 20 em: $<$ https://diariodonordeste.verdesmares.com.br/regiao/em-plena-safra-vendas-de-pequicaem-no-cariri-devido-a-pandemia-1.3038249> . Acesso em 15 de mar. de 2021.

ROSSINI, M. C. Como o açaí conquistou o mundo. Super Interessante, 2019. Disponível em: <https://super.abril.com.br/especiais/as-raizes-do-acai/ >. Acesso em 16 de mar. de 2021.

RUFINO, M. S. M. Prioridades funcionais de frutas tropicais brasileiras não tradicionais. 2008. Tese (Doutorado em Agronomia). Universidade Federal Rural do Semi Árido, Mossoró-RN. 
Disponível em: <https://ppgfito.ufersa.edu.br/wp-content/uploads/sites/45/2021/01/Tesede-Maria-do-S

ocorro-Rufino.pdf> .Acesso em: 11 de fev. de 2021.

SANTANA, J. DAS G.; NAVES, R. V. Caracterização de ambientes de cerrado com alta densidade de pequizeiros (Caryocar brasiliense Camb.) na região Sudeste do Estado de Goiás. Pesquisa Agropecuária Tropical, v. 33, n. 1, p. 1-10, 15 nov. 2007. Disponível em:<https://www.revistas.ufg.br/pat/article/view/2380>. Acesso em 08 de mar. de 2021.

SANTOS, H. G. dos; JACOMINE, P. K. T; ANJOS, L. H. C. dos; OLIVEIRA, V. A. de; LUMBRERAS, J. F.; COELHO, M. R.; ALMEIDA, J. A. de; ARAUJO FILHO, J. C. de; OLIVEIRA, J. B. de; CUNHA, T. J. F.. Sistema Brasileiro de Classificação de Solos. 5o. ed. Brasília, DF: Embrapa, 2018. 356 p. Disponível em :<https://www.embrapa.br/solos/sibcs >. Acesso em 09 de mar. de 2021.

SERRA, F. R.; SANTOS, D. Açaí - Análise Mensal - Dezembro 2020. Brasília: Companhia Nacional de Abastecimento (CONAB), 08 jan. 2021. Disponível em: $<$ https://www.conab.gov.br/info-agro/analises-do-mercado-agropecuario-eextrativista/analises-do-mercado/historico-mensal-de-acai > . Acesso em 15 de mar. de 2021.

SERRANO, L. A. L.; PESSOA, P. F. A. P. Aspectos econômicos da cultura do cajueiro. $2^{a}$ ed. Rio de Janeiro: Embrapa Agroindústria Tropical, Sistema de Produção, jul. 2016. Disponível em: $<$ https://www.spo.cnptia.embrapa.br/conteudo?p_p_lifecycle=0\&p_p_id=conteudoportlet_ WAR_sistemasdeproducaolf6_1ga1ceportlet\&p_p_col_count $=1 \& p \_p \_c o l i d=c o l u m n-$ 2\&p_p_state $=$ normal\&p_r_p_-76293187_sistemaProducaold $=7705 \& p \_r \_p \_-$ 996514994_topicold=10308\&p_p_mode=view>. Acesso em 11 de mar. de 2021.

SOARES, C. T. Secagem da polpa de pequi por liofilização. 2018. Dissertação (mestrado) Universidade Estadual de Campinas, Faculdade de Engenharia Agrícola, Campinas-SP. Disponível em:<http://repositorio.unicamp.br/jspui/handle/REPOSIP/332599>. Acesso em 11 de mar. de 2021.

SOUZA, E. É tempo de caju na feira e no prato. Folha PE, 28 jul. 2018. Disponível em : $<$ https://www.folhape.com.br/sabores/e-tempo-de-caju-na-feira-e-no-prato/76213/>. Acesso em: 13 de fev. de 2021.

STEELE, E. M.; RAUBER, F.; COSTA, C. dos S.; LEITE, M. A.; GABE, K. T.; LOUZADA, M. L. da C.; LEVY, R. B.; MONTEIRO, C. A. Mudanças alimentares na coorte NutriNet Brasil durante a pandemia de covid-19. Revista de Saúde Pública, v. 54, p. 91, 2020. Disponível em: <https://www.revistas.usp.br/rsp/article/view/174857>. Acesso em: 3 mar. 2021.

TRZECIAK, D. Artesanato e receitas de butiá são fontes de renda no interior do RS. G1, 12 dez. 2012. Disponível em: <http://g1.globo.com/rs/rio-grande-do-sul/nossa- 
DE NORTE A SUL: UMA ANÁLISE SOBRE AS

CARACTERÍSTICAS ECONÔMICAS E GASTRONÔMICAS DAS PRINCIPAIS FRUTAS IDENTITÁRIAS NO BRASIL
Gabriela Ferreira Rodrigues Aline Gomes Santana Neide Kazue Sakugawa Shinohara

terra/2012/noticia/2012/12/artesanato-e-receitas-de-butia-sao-fontes-de-renda-nointerior-do-rs.html>. Acesso em 15 de mar. de 2021.

VELOSO, V. Na 34a edição, Festival da Jabuticaba de Sabará se reinventa. G1, 21 nov. 2020. Disponível em: <https:/g1.globo.com/mg/minas-gerais/noticia/2020/11/21/na-34a-edicaofestival-da-jabuticaba-de-sabara-se-reinventa.ghtml>. Acesso em 16 de mar. de 2021. 


\title{
APROVEITAMENTO DO SILÍCIO DERIVADO DA EXTRAÇÃO DO QUARTZITO SÃO THOMÉ NA CULTURA DO PEPINO
}

\author{
Eliana Alcantra \\ Doutora em Entomologia. Docente no Mestrado Sustentabilidade em Recursos Hídricos e no \\ curso de Agronomia na Universidade Vale do Rio Verde, Três Corações - MG \\ lialcantra@yahoo.com.br
}

Marco Antônio Sales Martins Bacharel em Agronomia Graduando do curso de Agronomia da Universidade Vale do Rio Verde-Unincor, Três Corações - MG. marcomartinspedras@hotmail.com

Fredderico Avelar Viana Corrêa Bacharel em Agronomia da Universidade Vale do Rio Verde-Unincor, Três Corações - MG. favc92@gmail.com

\section{Rosângela Francisca de Paula Vitor Marques}

Doutora em Recursos Hídricos. Docente da Universidade Vale do Rio Verde nos cursos de Mestrado em Sustentabilidade em Recursos Hídricos, Engenharia Ambiental e Sanitária e

Agronomia, Três Corações, MG. rosangela.marques@unincor.edu.br

\section{RESUMO}

O silício absorvido pelas plantas melhora a sua morfologia e fisiologia, com redução na taxa de transpiração e confere eficiência fotossintética às plantas, é muito eficiente na proteção de estresses abióticos e bióticos de muitas culturas e pode conferir resistência ao ataque de insetos-praga e nematóides. O silício derivado da extração e produção mineral de quartzito em São Thomé das Letras, MG tem se tornado um rejeito gerador de problema ambiental e o seu aproveitamento na agricultura pode ser uma forma de uso sustentável. Assim, objetivouse com este trabalho avaliar o uso do silício, derivado da extração e produção mineral de quartzito São Thomé, na cultura do pepino. O experimento foi implantado na Fazenda São Francisco de Assis, em Três Corações - MG. O delineamento foi em blocos casualizados com dois tratamentos e 10 repetições. Os tratamentos utilizados foram: T1: 3 ton.ha ${ }^{-1}$ de sílica pura ( $95 \%$ de $\mathrm{SiO}_{2}$ proveniente do processamento de britagem do rejeito de Quartzito), e T2: sem silício. As variáveis analisadas foram: altura de planta, diâmetro de haste, comprimento de raiz, comprimento e largura de folha, diâmetro vertical e horizontal de fruto, peso e número de frutos. Os dados foram analisados pelo teste de $\mathrm{F}$ com $5 \%$ de significância. Observou-se diferença significativa para altura de planta, peso de fruto e diâmetro vertical de fruto com os maiores valores médios obtidos nas plantas que receberam aplicação de silício. Conclui-se que o silício é promissor para o desenvolvimento e crescimento do pepineiro, podendo ser uma alternativa viável e sustentável para a produção de pepino e para o ambiente.

Palavras-chave: Cucumis sativus L.. Nutrição. Sustentabilidade. 


\title{
THE USE OF SILICON DERIVED FROM THE EXTRACTION OF QUARTZITE SÃO THOMÉ IN THE CUCUMBER CULTURE
}

\begin{abstract}
The silicon absorbed by plants improves their morphology and physiology, with a reduction in the rate of transpiration and gives photosynthetic efficiency to plants, is very efficient in protecting against abiotic and biotic stresses of many cultures and can confer resistance to attack by pest insects and nematodes. The silicon derived from the extraction and mineral production of quartzite in São Thomé das Letras, MG has become a waste that generates an environmental problem and its use in agriculture can be a form of sustainable. Thus, the objective of this work was to evaluate the use of silicon, derived from the extraction and mineral production of quartzite São Thomé, in the culture of cucumber. The experiment was implemented at Fazenda São Francisco de Assis, in Três Corações - MG. The design was in randomized blocks with two treatments and 10 repetitions. The treatments used were: T1: 3 ton.ha-1 of pure silica (95\% SiO2 from the crushing of Quartzite tailings), and T2: without silicon. The variables analyzed were: plant height, stem diameter, root length, leaf length and width, vertical and horizontal fruit diameter, weight and number of fruits. The data were analyzed by the $\mathrm{F}$ test with $5 \%$ significance. A significant difference was observed for plant height, fruit weight and vertical fruit diameter with the highest average values obtained in plants that received silicon application. It is concluded that silicon is promising for the development and growth of cucumber and can be a viable and sustainable alternative for cucumber production and for the environment.
\end{abstract}

Keywords: Cucumis sativus L.. Nutrition. Sustainability.

Recebido em: 21/10/2020. Aceito em: 14/01/2021. 


\section{INTRODUÇÃO}

Apesar do silício (Si) não se enquadrar nos critérios de essencialidade, é um elemento que pode ser considerado importante para o desenvolvimento de muitas culturas agrícolas (EPSTEIN; BLONN, 2005; GONZÁLEZ; CEBALLOS; BENAVIDES, 2015), pois proporciona grandes benefícios às plantas, tais como: diminuição do acamamento, estímulo ao crescimento, à produção e à proteção das plantas (PRADO, 2000).

Esses benefícios são mais evidentes e potencializados em plantas consideradas acumuladoras de $\mathrm{Si}$, aquelas que possuem teor foliar acima de $1 \%$. As plantas não acumuladoras possuem teor de silício menor que 0,5\%. A cucurbitácea, Cucumis sativus L, é considerada uma cultura intermediária quanto ao acúmulo de Si, com teor de sílica de 0,5 a 1 g.kg-1 (MA; MIYAKE; TAKAHASHI, 2001). Em geral as monocotiledôneas acumulam mais Si do que as dicotiledôneas, diferença que se deve mais a fatores filogenéticos que às condições ambientais (GONZÁLEZ; CEBALLOS; BENAVIDES, 2015; ZARGAR et al., 2019).

Estudos demonstram o envolvimento do silício em vários aspectos morfológicos, fisiológicos e bioquímicos da vida das plantas, com papéis diversos (LIMA et al., 2010; TUNES et al., 2014). O silício pode, por exemplo, provocar a ativação do mecanismo natural de defesa das plantas, como os compostos fenólicos como a quitina, peroxidases e acúmulo de lignina na parede celular proporcionando um papel importante nas relações planta-ambiente, pois pode dar à cultura melhores condições para suportar adversidades climáticas, edáficas e biológicas, tendo como resultado final um aumento na produção das plantas e produtos de maior qualidade (REIS et al., 2007). O Si é capaz de aumentar a resistência natural das plantas possibilitando uma agricultura mais sustentável (CAMARGO; KORNDÖRFER; PEREIRA, 2007; ZARGAR et al., 2019).

Assim a adubação com silício proporciona aumento no crescimento e na produção de muitas culturas (ALBUQUERQUE; SANTOS; FARIAS, 2014), como o pepineiro, considerada cultura intermediária em relação ao acúmulo de Si.

O pepineiro pertence à família Cucurbitaceae e está adaptado a regiões de clima tropical e com temperaturas elevadas até $30^{\circ} \mathrm{C}$ (GOTO, 2003; MARTINS et al., 2018). É uma cultura que necessita de condições de alta luminosidade ou fotoperíodo longo e solos férteis 
e bem drenados com pH em torno de 5,5 a 6,8; deve ser irrigado com frequência para que as plantas não sofram estresse hídrico.

O presente estudo representa uma alternativa ao problema de não haver área suficiente para expandir os depósitos de resíduos proveniente da extração de quartzito, e o seu aproveitamento na agricultura pode contribuir de forma significativa para a solução de questões ambientais, devido à reutilização deste mineral para nutrição de plantas e controle de pragas.

Em razão de muitas dúvidas que o agricultor possui em relação ao Si na agricultura e na produção de pepineiro, objetivou-se com o presente estudo avaliar o uso desse mineral no desenvolvimento e crescimento desta cultura, e principalmente encontrar soluções sustentáveis de aproveitamento de rejeito originário da extração e comercialização de quartzito São Thomé composto por 95\% de Si.

\section{MATERIAL E MÉTODOS}

O experimento foi instalado na Fazenda São Francisco de Assis no município de Três Corações/MG - Brasil. A região possui clima tropical de altitude predominante nos planaltos e serras do sudeste brasileiro, com altitude aproximada de 800 a 900 m, com precipitação e temperatura média anual de $1401 \mathrm{~mm}$ e 20,2ㅇ C respectivamente (IBGE, 2014).

Anteriormente à instalação do experimento foi realizada análise de solo (Tabela 1).

Tabela 1 - Análise de solo da Fazenda São Francisco De Assis - Três Corações - MG - (Labominas - Laboratório Agronômico)

\begin{tabular}{cccc}
\hline Elementos & Resultado & Interpretação & Val. Referência \\
\hline $\mathrm{pH}$ & 5,4 & Médio & Ideal $(5,5$ a 6,6$)$ \\
\hline $\mathrm{V} \%$ & $39 \%$ & Baixo & Ideal $(70-80 \%)$ \\
\hline $\mathrm{Ca}$ & $31 \%$ & Baixo & Ideal (60 a $70 \%)$ \\
\hline $\mathrm{Mg}$ & $7 \%$ & Baixo & Ideal $(10$ a $20 \%)$ \\
\hline P- disponível & $2,2 \mathrm{mg} / \mathrm{L}$ & Muito Baixo & Ideal $\left(>9 \mathrm{mg} / \mathrm{dm}^{3}\right)$ \\
\hline
\end{tabular}

Fonte: os autores.

O plantio do pepino foi realizado manualmente e em sulcos, na direção leste - oeste, pois o pepino necessita de condições de alta luminosidade ou com luz solar direta por algumas 
horas por dia. O espaçamento utilizado foi de 0,45 m entre plantas e 0,60 m entre linhas, compreendendo área total de $151,2 \mathrm{~m}^{2}$, e cada parcela com dimensão de $3,15 \mathrm{~m}$ de comprimento e 2,4 m de largura, totalizando 7,56 $\mathrm{m}^{2} /$ parcela.

Para o preparo do solo primeiramente foi incorporada a adubação orgânica com 10,58 ton.ha-1 ${ }^{-1}$ de esterco bovino curtido, o que correspondeu a $8 \mathrm{~kg} /$ parcela, incorporados manualmente a $10 \mathrm{~cm}$ de profundidade 30 dias antes do plantio em todas as parcelas.

Para a incorporação do silício ao solo foi realizada sua distribuição aos 14 dias antes do plantio. A sílica utilizada no experimento foi Sílica pura $\mathrm{SiO}_{2}$ com $95 \%$ de pureza com granulometria ou malha de 400 mm, adquiridas da Empresa de Extração de Pedras São Thomé Ltda, que para esta empresa e demais empresas mineradoras é um problema ambiental.

As sementes de pepino, cv. Caipira, obtidas no comércio local, foram semeadas em tubetes com substrato comercial. Foram três sementes por tubete e após emergência foi realizado o desbaste deixando-se a muda mais vigorosa.

O plantio e os tratos culturais foram realizados seguindo as recomendações para a cultura obtidas em Sediyama et al. (2012), como: desbaste, tutoramento, controle de plantas espontâneas com capina manual e irrigação por aspersão todos os dias no final da tarde até o final do ciclo da cultura.

O delineamento experimental foi realizado em blocos casualizados (DBC), com 10 blocos e 2 parcelas por/bloco.

Foram avaliados dois tratamentos sendo: T1: Sílica pura $\left(95 \% \mathrm{SiO}_{2}\right)$ incorporada na dosagem referente a 3 ton.ha-1 ou 2,26 kg por parcela e T2: sem aplicação de sílica.

No final do experimento, aos 90 dias do plantio, em três plantas por parcela, escolhidas ao acaso, foram avaliadas as variáveis altura de planta $(\mathrm{m})$, diâmetro de haste $(\mathrm{mm})$, comprimento de raiz de planta $(\mathrm{cm})$, largura e comprimento de folhas $(\mathrm{cm})$, diâmetro horizontal e vertical de frutos $(\mathrm{cm})$, número e peso $(\mathrm{Kg})$ de frutos. Para a medição do diâmetro foi utilizado paquímetro, e fita métrica para medir a altura de planta e comprimento de raiz. Para o peso de frutos foi utilizada balança manual digital.

Foi realizada a análise de dados pelo teste de $\mathrm{F}$ a $5 \%$ de significância com auxílio do sistema computacional SISVAR versão 5.2 (FERREIRA, 2011). 


\section{RESULTADOS E DISCUSSÃO}

A partir dos resultados obtidos observou-se resposta positiva à adubação com silício, obtendo-se maiores valores para altura de planta, diâmetro vertical de fruto e peso médio de frutos de pepineiro em comparação às plantas que não receberam adubação com silício (TABELA 2 e 3).

Tabela 2 - Altura de planta, diâmetro de haste, comprimento de raiz, comprimento e largura de folha de pepineiro com e sem silício. Fazenda São Francisco De Assis - Três Corações, MG

\begin{tabular}{cccccc}
\hline Tratamento & $\begin{array}{c}\text { Altura de } \\
\text { planta } \\
(\mathrm{m})^{*}\end{array}$ & $\begin{array}{c}\text { Diâmetro } \\
\text { de haste } \\
(\mathrm{mm})^{\mathrm{ns}}\end{array}$ & $\begin{array}{c}\text { Comprimento de } \\
\text { raiz }(\mathrm{cm})^{\mathrm{ns}}\end{array}$ & $\begin{array}{c}\text { Comprimento de } \\
\text { folha }(\mathrm{cm})^{\mathrm{ns}}\end{array}$ & $\begin{array}{c}\text { Largura de } \\
\text { folha }(\mathrm{cm})^{\mathrm{ns}}\end{array}$ \\
\hline Com Si & 1,31 & 3,4 & 20,44 & 11,17 & 4,32 \\
Sem Si & 0,96 & 2,8 & 9,04 & 4,76 & 0,34370 \\
\hline$P$ & 0,00129 & 0,277723 & 0,088285 & 0,31702 & 0,34 \\
\hline
\end{tabular}

*Médias significativas pelo teste de $\mathrm{F}(p \leq 0,05)$. ${ }^{\text {ns }}$ Médias não significativas pelo teste de $\mathrm{F}(p>0,05)$. Fonte: os autores.

Tabela 3 - Diâmetro vertical e horizontal de fruto, e número médio e peso médio de fruto de pepineiro com e sem silício. Fazenda São Francisco De Assis - Três Corações, MG

\begin{tabular}{ccccc}
\hline Tratamento & $\begin{array}{c}\text { Diâmetro horizontal de } \\
\text { fruto }(\mathrm{cm})^{\mathrm{ns}}\end{array}$ & $\begin{array}{c}\text { Diâmetro vertical } \\
\text { de fruto }(\mathrm{cm})^{*}\end{array}$ & $\begin{array}{c}\text { Número médio de } \\
\text { frutos }^{\mathrm{ns}}\end{array}$ & $\begin{array}{c}\text { Peso médio } \\
\text { de frutos } \\
(\mathrm{kg})^{*}\end{array}$ \\
\hline Com Si & 20,94 & 7,94 & 39,1 & 17,8 \\
Sem Si & 11,72 & 4,85 & 22,6 & 4,26 \\
\hline$P$ & 0,109837 & 0,02044 & 0,17757 & 0,023675
\end{tabular}

*Médias significativas pelo teste de $\mathrm{F}(p \leq 0,05)$. ${ }^{\text {ns }}$ Médias não significativas pelo teste de $\mathrm{F}(p>0,05)$. Fonte: os autores.

No entanto, as variáveis diâmetro de haste, comprimento de raiz e de folha, largura de folha, diâmetro horizontal e número médio de frutos, de plantas de pepino que receberam silício não apresentaram diferença significativa em comparação às plantas sem silício.

Silva (2016) ao realizar fertilização foliar com silicato de potássio também verificou incremento na altura das plantas de pepino como no presente trabalho. No entanto, não 
detectou diferença significativa para peso de fruto, diâmetro horizontal e vertical, provavelmente por utilizar silício foliar e não via solo, pois as plantas possuem metabolismo diferente para absorção de nutrientes.

Miyake e Takahashi (1982) também reportaram que a aplicação de silício provocou aumento significativo na altura de planta e no peso de frutos de pepinos. Contudo Santos et al. (2018) verificaram que plantas de pepineiro tiveram o desenvolvimento afetado por diferentes doses de silicato de cálcio e magnésio.

Em trigo, a adubação silicatada via solo também foi responsável pelo aumento no número de sementes, peso e no rendimento de sementes, além de manter a qualidade fisiológica das sementes produzidas (TAVARES et al., 2014). No entanto, para a cultura do milho a adubação silicatada via foliar não afetou significativamente a altura de plantas e o diâmetro do colmo (TEODORO et al., 2014).

A diferença na altura de planta e diâmetro vertical de fruto pode também ser explicada pelo acúmulo de silício nas células da epiderme, provocando à ativação da lignina, melhorando a rigidez das folhas, a absorção dos fotossintetizados e a translocação destes nutrientes para a parte aérea das plantas e também nos frutos, tornando - os mais suculentos e com maior desenvolvimento (ETESAMI; JEONG, 2018).

O comprimento total e número total de folhas, como também a matéria seca da parte aérea e matéria seca total de plantas de pepineiro apresentaram aumento significativo quando receberam tratamento com silício em comparação com outros produtos (BELAN et al., 2013).

Folhas de alface foram beneficiadas com a aplicação de silício, que proporcionou firmeza e turgidez aumentando a vida útil em 16 dias (GALATI et al., 2015).

Segundo os estudos de Lima Filho, Lima e Tsai (1999) as folhas de pepineiros com teor alto de Si apresentam um aumento significativo na atividade de RuBP-carboxilase melhorando a reação de conversão de dióxido de carbono em proteína solúvel, melhorando a parte morfológica das plantas de pepineiro explicando o aumento nas diferenças encontradas neste experimento.

As plantas de pepino do presente estudo não apresentaram dano significativo decorrente do ataque de insetos-praga e doenças, mas o efeito do silício no aumento da resistência de plantas a insetos e patógenos também pode ser observado em algumas plantas, 
como verificado nos trabalhos de Lima et al. (2010); Santos et al. (2010); Belan et al. (2013) e Santos et al. (2018). Por exemplo, pepineiros infectados com Sphaerotheca fuliginea, transferidos para um meio contendo Si, apresentaram uma rápida silicificação do tecido foliar, principalmente nas bases dos tricomas, e ao redor dos pontos de infecção, aumentando a resistência ao patógeno (SAMUELS et al., 1991; LIMA FILHO; LIMA; TSAI, 1999).

Em pepineiro Correa et al. (2005) verificaram efeitos negativos com a aplicação de Si no desenvolvimento e na população de mosca-branca, sendo apresentado como um produto alternativo a ser utilizado no manejo integrado de insetos-pragas de muitas outras culturas (PINTO et al., 2012; AMADO; RIZENTAL, 2015; MONTES; MONTES; RAGA, 2015; CAMARGO; 2016).

Os fertilizantes silicatados, do ponto de vista econômico, assumem 10 a $20 \%$ do custo de outros fertilizantes sendo relativamente acessível (FENG, 2000). Etesami e Jeong (2018) consideraram vital utilizar fertilizantes de Si na adubação de plantas.

O Si usado na adubação de plantas pode ser de fontes orgânicas como biocarvão, cinzas de cascas de arroz e compostos de esterco de gado e inorgânicos como a volastonite, sílica gel, escória rica em si, ácido silícico, silicato de sódio, silicato de potássio, silicato de cálcio, silicato de cálcio escória, sílica amorfa, etc. em áreas com falta de silício para que experimentar seus lucros econômicos e ecológicos. A aplicação de Si pode ser uma das vias disponíveis para melhorar o crescimento e produção de culturas (MEENA et al., 2014). O Si dessa forma pode ser considerado um fertilizante de alta qualidade, podendo ser usado numa agronomia economicamente correta (ZHU; GONG, 2014; ETESAMI; JEONG, 2018).

O silício proveniente das pedras de quartizito proporcionou um incremento em aspectos morfológicos de frutos de pepino (altura de planta, diâmetro vertical dos frutos e peso médio de fruto), sinalizando que o uso como adicional na nutrição de plantas poderá ser realizado como alternativa no incremento na produção de plantas, e em especial aquelas acumuladoras de silício a as intermediárias como o pepineiro.

\section{CONCLUSÃO}

O silício influenciou a altura, o diâmetro vertical e peso de frutos de pepineiro, sendo considerado promissor para o desenvolvimento e crescimento desta e de outras culturas, contribuindo também para uma agricultura mais sustentável, através da reutilização de 
resíduos do beneficiamento de minerais prejudiciais ao meio ambiente com teores de silício bastante elevado, chegando a $95 \%$ de pureza, além de proporcionar um custo benefício a mais para os produtores e mineradores de quartzito São Thomé.

\section{REFERÊNCIAS}

ALBUQUERQUE, ABEL W. de; SANTOS, J. M. dos; FARIAS, A. P. de. Produtividade e qualidade pós-colheita de Helicônia Golden Torch submetida a fontes e doses de silício. Revista Brasileira Engenharia Agrícola e Ambiental, v. 18, n. 2, p. 173-179, 2014.

AMADO, D.; RIZENTAL, M. Silício como indutor de resistência a Aphis gossypii (Hemiptera: Aphididae) e Bemisia tabaci (Hemiptera: Aleyrodidae) em algodoeiro. Conection Line, n. 12, 2015.

BELAN, L. et al. Manejo alternativo do oídio na cultura do pepino em ambiente protegido. Revista Acadêmica, Curitiba, v. 11, Supl. 2, p. S03-S112, 2013.

CAMARGO, M. S. de. Efeito do silício na tolerância das plantas aos estresses bióticos e abióticos. Informações agronômicas, n. 155, p. 1-8, 2016.

CAMARGO, M. S.; KORNDÖRfER, G. H.; PEREIRA, H. S. Solubilidade do silício em solos: Influência do calcário e ácido silícico aplicado. Bragantia, Campinas, v. 66, p. 637-647, 2007.

EPSTEIN, E.; BLOOM, A. J. Mineral nutrition of plants: principles and perspectives. Sunderland: Sinauer Associates, 2005.

ETESAMI, H., JEONG, B. R. Silicon (Si): Review and future prospects on the action mechanisms in alleviating biotic and abiotic stresses in plants. Ecotoxicology and Environmental Safety, v. 147, p. 881-896, 2018.

FERREIRA, D. F. Sisvar: a computer statistical analysis system. Ciência e Agrotecnologia (UFLA), Lavras, v. 35, n. 6, p. 1039-1042, 2011.

GALATI, V. C. et al. Aplicação de silício, em hidroponia, na conservação pós-colheita de alface americana 'Lucy Brown' minimamente processada. Ciência Rural, Santa Maria, v. 45, n. 11, p. 1932-1938, nov./2015.

GONZÁLEZ E. M.; CEBALLOS, J. M.; BENAVIDES, O. B. Producción de forraje verde hidropónico de maiz Zea mays. L. en invernadero con diferentes niveles de silício. Revista de ciências agrícolas, v. 32, n. 1 p. $75-83,2015$.

GOTO, R. Pepino: Cucumis sativus L.: Programa brasileiro para a modernização da horticultura. São Paulo: CQH/CEAGESP, 2003. Normas de classificação do pepino. Disponível em: http://www.ceagesp.gov.br/wp-content/uploads/2015/07/pepino.pdf. Acesso em: 16 jan. 2018. 
LIMA FILHO, O. F. de; LIMA, M. T. G. de; TSAI, S. M. O silício na agricultura. Informações Agronômicas, Piracicaba, n. 87, p. 1-7, 1999. (Encarte técnico, 132).

LIMA, et al. Quantificação da ferrugem asiática e aspectos nutricionais de soja suprida com silício em solução nutritiva. Summa Phytopathologica, v. 36, n. 1, p. 51-56, 2010.

MA, J. F.; MIYAKE, Y., TAKAHASHI, E. Silicon as a beneficial element for crop plant. In: DATNOFF, L.E.; SNYDER, G.H., KORNDÖRFER, G.H. (ed.). Silicon in agriculture. Amsterdam: Elsevier Science, 2001. p. 17-39.

MARTINS, J. K. D. et al. Avaliação da produtividade do pepino conduzido em sistemas de tutoramento horizontal e vertical com e sem consórcio com amendoim em Rondônia. Enciclopédia Biosfera, Goiânia, v. 15 n. 27, p. 151, 2018.

MEENA, V. et al. A case for silicon fertilization to improve crop yields in tropical soils. Proceedings of the National Academy of Sciences, India: Section B: Biological Sciences, v. 84, n. 3, p.505-518, 2014.

MIYAKE, Y.; TAKAHASHI, E. Effect of silicon on the growth of cucumber plants in a solution culture. Journal Soil Science Plant Nutrition, v.53, p. 15-22, 1982.

MONTES R. M., MONTES, S. M. N. M.; RAGA, A. O uso do silício no manejo de pragas. São Paulo: Instituto Biológico-APTA, 2015. Documento Técnico, n. 17, p. 1-13.

PINTO, D. G. et al. Alterações fisiológicas após aplicação de silício em cacau e sua influência na preferência por pulgões. Revista Ceres, Viçosa, MG, v. 59, n. 3, p. 360-367, 2012.

PRADO, R. M. Resposta da cana-de-açúcar à aplicação de escória silicatada como corretivo de acidez do solo. 2000. Dissertação (Mestrado em Agronomia) - Faculdade de Engenharia da Universidade Estadual Paulista, Ilha Solteira, 2000.

REIS, T. H. P. et al. O silício na nutrição e defesa de plantas. Boletim Técnico, v. 82, Belo Horizonte, 2007.

CORREA, R. S. B. et al. Silicon and acibenzolar-s-methyl as resistance iducers in cucumber, against the whitefly Bemisia tabaci (Gennadius) (Hemiptera: Aleyrodidae) biotype B. Neotropical Entomology, v. 34, n. 3, p.v429-433, 2005.

SAMUELS, G. J. et al. A synopsis of Nectria subg Dialonectria. Mycological Papers, v. 164, p. 147, 1991.

SANTOS, B. H. C. dos et al. Silicato de cálcio e magnésio no controle de Meloidogyne javanica em pepineiro em diferentes texturas de solo. Revista Brasileira de Agropecuária Sustentável, v.8, n. 1, p. 104-109, mar. 2018. 
SEDIYAMA, M. A. N. et al. Manejo da poda em plantas de pepino tipos Aodai, Japonês e Caipira. Horticultura brasileira, v. 30, n. 2, jul. 2012.

SILVA, A. M. Q. Respuesta a las aplicaciones de silicio en el cultivo de pepino (Cucumis sativus L) variedad modan, en condiciones de estrés hídrico bajo cubierta en culiacán, sinaloa. 2016. Tesis (Engenharia Agrônoma) - Universidad de Ciencias Aplicadas y Ambientales U.D.C.A, Facultad de Ingenierías, Bogotá, 2016.

TAVARES, L. C. et al. Adubação silicatada em trigo: qualidade e rendimento de sementes. Revista Faculdade Agronomica, v. 113, n. 1, p. 94-99, 2014.

TEODORO, P. E. et al. Desempenho de híbridos de milho sob aplicação foliar de Silício no cerrado sul-mato-grossense. Bioscince journal, Uberlandia, v. 30, supplement 1, p. 224-231, 2014.

TUNES, L. V. M. de et al. Qualidade fisiológica, sanitária e enzimática de sementes de arroz irrigado recobertas com silício. Revista Ceres, Viçosa, MG, v. 61, n.5, p. 675-685, set/out, 2014.

ZARGAR, S. M. et al. Role of silicon in plant stress tolerance: opportunities to achieve a sustainable cropping system. Biotech, v. 9, n. 73, 2019.

ZHU, Y., GONG, H. Beneficial effects of silicon on salt and drought tolerance in plants. Agronomy for Sustainable Development, v. 34, p. 455-472, 2014. 


\title{
AVALIAÇÃO ANTIMICROBIANA DA EFICÁCIA DOS EXTRATOS HIDROALCOÓLICOS DA PITANGUEIRA E DA GOIABEIRA, IN VITRO, CONTRA STAPHYLOCOCCUS AUREUS ISOLADOS DE MASTITE BOVINA
}

\author{
Alexandre Tourino Mendonça \\ Doutor em Ciências dos Alimentos pela Universidade Federal de Lavras (UFLA), \\ Lavras, MG, Brasil \\ alexandretourino@gmail.com \\ Glei dos Anjos de Carvalho Castro \\ Doutora em Ciências Veterinárias pela Universidade Federal de Lavras (UFLA), \\ Lavras, MG, Brasil \\ glei.castro@unincor.edu.br \\ Maria Clara Pereira Inácio \\ Graduando em Medicina Veterinária pela Universidade Vale do Rio Verde de Três Corações \\ (UNINCOR), Três Corações, MG, Brasil \\ mariaclarapereira325@gmail.com \\ Miriam de Andrade Pereira \\ Mestrado em Ciências Veterinárias pela Universidade Federal de Lavras (UFLA), \\ Lavras, MG, Brasil \\ miriam.pereira@unincor.edu.br
}

\begin{abstract}
RESUMO
A resistência bacteriana é motivo de preocupação para a medicina humana e veterinária, uma vez que se questiona a eficácia dos antibióticos disponíveis. Com isso pesquisa-se constantemente plantas com novos princípios ativos que combatam patógenos cada vez mais resistentes, como o Staphylococcus aureus. Nesse contexto, as árvores da família Myrtaceae, têm demonstrado potencial antimicrobiano, dentre elas a pitangueira (Eugenia uniflora L.) e a goiabeira (Psidium guajava L.) que foram objetos deste estudo realizado na UninCor de Três Corações, MG. Portanto, Objetivou-se testar a atividade antimicrobiana in vitro por determinação da Concentração Inibitória Mínima (CMI) dos extratos hidroalcoólicos frente às cepas de $S$. aureus isolados do leite de mastite bovina, e comparar com os antibióticos de uso comum. Os testes foram realizados em triplicata, com os extratos em concentrações de $100 \%$, $50 \%, 25 \%$ e 12,5\%, e comparados em dois períodos de preparação, 8 dias e com 3 meses. Baseado na estatística descritiva, o extrato hidroalcoolico da pitangueira na concentração de $100 \%$ nos dois tempos mostrou se mais eficiente, apresentado sensibilidade de $15,7 \%$ e $17,65 \%$, respectivamente frente a 9,8\% e 5,9\% da goiabeira na mesma concentração. Já ao se considerar os antibióticos Gentamicina, Norfloxacina, Amoxilina e Vancomicina, as sensibilidades foram de $100 \%, 100 \%, 88,2 \%$ e $29,4 \%$, ou seja, ação superior à da pitangueira e da goiabeira, sendo que a Norfloxacina e gentamicina mostraram maior eficiência em todas as cepas testadas. Portanto este estudo preliminar mostrou que os extratos hidroalcoólicos
\end{abstract}


AVALIAÇÃO ANTIMICROBIANA DA EFICÁCIA

DOS EXTRATOS HIDROALCÓLICOS DA PITANGUEIRA

E DA GOIABEIRA, IN VITRO, CONTRA

STAPHYLOCOCCUS AUREUS ISOLADOS DE MASTITE BOVINA
Alexandre Tourino Mendonça Glei dos Anjos de Carvalho Castro

Maria Clara Pereira Inácio Miriam de Andrade Pereira

aqui usados não foram eficientes contra $S$. aureus isolados de mastite bovina, entretanto futuros estudos abordando diferentes ensaios são necessários.

Palavras-Chave: Myrtaceae. Antimicrobiano. Norfloxacina.

\title{
EVALUATION OF ANTIMICROBIAL EFFICIENCY OF HYDROALCOHOLIC FROM EXTRACTS OF PITANGUEIRA AND GUAVA TREE, IN VITRO, AGAINST STAPHYLOCOCCUS AUREUS ISOLATED FROM BOVINE MASTITIS
}

\begin{abstract}
Bacterial resistance is a concern for human and veterinary medicine, since the effectiveness of the available antibiotics is being questioned. In this view, plants with new active ingredients that combat increasingly resistant pathogens, such as Staphylococcus aureus, are constantly being researched. In this context, the trees of the Myrtaceae family have shown antimicrobial potential, among them the pitangueira (Eugenia uniflora L.) and guava tree (Psidium guajava L.), which were the subjects of this study carried out at UninCor in Três Corações, MG. Therefore, the aim was to test the in vitro antimicrobial activity by determining the Minimum Inhibitory Concentration (MIC) of hydroalcoholic extracts against $S$. aureus strains isolated from bovine mastitis milk, and to compare them with commonly used antibiotics. The tests were performed in triplicate, with the extracts at concentrations of $100 \%, 50 \%, 25 \%$, and $12.5 \%$, and compared in two preparation periods, with 8 days and with 3 months. Based on descriptive statistics, the hydroalcoholic extract of pitangueira at $100 \%$ concentration in both times was more efficient, presenting sensibility of $15.7 \%$ and $17.65 \%$, respectively, against $9.8 \%$ and $5.9 \%$ of guava tree at the same concentration. When considering the antibiotics Gentamicin, Norfloxacin, Amoxillin and Vancomycin, the sensitivities were 100\%, 100\%, 88.2\% and $29.4 \%$, i.e., a higher action than in pitangueira and guava tree, with Norfloxacin and Gentamicin showing greater efficiency in all strains tested. Therefore, this preliminary study showed that the hydroalcoholic extracts used were not efficient against $S$. aureus isolated from bovine mastitis.
\end{abstract}

Keywords: Myrtaceae. Antimicrobial. Norfloxacin.

Recebido: $27 / 07 / 2020$. Aceito: 22/12/2020. 
AVALIAÇÃO ANTIMICROBIANA DA EFICÁCIA

DOS EXTRATOS HIDROALCÓLICOS DA PITANGUEIRA

E DA GOIABEIRA, IN VITRO, CONTRA

STAPHYLOCOCCUS AUREUS ISOLADOS DE MASTITE BOVINA
Alexandre Tourino Mendonça Glei dos Anjos de Carvalho Castro

Maria Clara Pereira Inácio Miriam de Andrade Pereira

\section{INTRODUÇÃO}

A resistência bacteriana é motivo de preocupação para a medicina humana e veterinária, uma vez que os antibióticos disponíveis já não são eficazes. Com isso pesquisa- se constantemente plantas com princípios ativos que combatam patógenos cada vez mais resistentes. De acordo com Freitas et al. (2013), o uso indiscriminado de antibióticos betalactâmicos sem realização de um antibiograma antes de iniciar a terapêutica está diretamente relacionado à presença de cepas de Staphylococcus aureus resistentes em animais domésticos e no homem. Diante deste problema a utilização de fitoterapia mostra uma potencial solução para o problema.

Dentre as famílias botânicas utilizadas como fitoterápicos, a Myrtaceae apresenta maior quantidade de elementos voláteis, com cerca de 3.500 espécies distribuídas mundialmente, tendo prevalência nas zonas tropicais e subtropicais da Austrália e América (STIEVEN; MOREIRA; SILVA, 2009).

Presentes na biodiversidade brasileira, as árvores conhecidas popularmente pela produção dos frutos e têm demonstrado potencial antimicrobiano, sendo objeto deste estudo a pitangueira (Eugenia unifloraL.) e a goiabeira (Psidium guajava L.).

A Eugenia unifloraL. apresenta-se como um arbusto ou árvore semidecídua, de 4 a $10 \mathrm{~m}$ de altura, copa estreita de tronco liso de cor pardo clara. As folhas são simples, cartáceas, de 3 a $7 \mathrm{~cm}$ de comprimento, com aroma característico. As flores são de cor branca, solitárias ou em grupos de 2-3 nas axilas nas extremidades dos ramos. Os frutos são do tipo drupa. Globosos e sulcados, brilhantes e de cor vermelha, amarela ou preta, com polpa carnosa e agridoce, contendo 1 a 2 sementes. Sua distribuição ocorre em todo o território brasileiro, podendo ser encontrada em abundância nos estados de Goiás, Bahia, Mato Grosso do Sul, Mato Grosso, Rio de Janeiro, São Paulo, Santa Catarina e Rio Grande do Sul (PRESTES, 2011; LORENZI; MATOS, 2008; LORENZONI et al., 2011).

De acordo com Mendonça (2016), os extratos de Eugenia uniflora L. são capazes de produzir substâncias com potencial antibiótico, utilizadas como mecanismo de defesa contra predação por microrganismos, insetos e herbívoros, devido a sua capacidade de produzir metabólitos secundários. Os metabólitos secundários sofrem influência e são afetados pelo meio externo e interno do vegetal como, por exemplo, espécie, variedade, estresse ambiental 
AVALIAÇÃO ANTIMICROBIANA DA EFICÁCIA

DOS EXTRATOS HIDROALCÓLICOS DA PITANGUEIRA

E DA GOIABEIRA, IN VITRO, CONTRA

STAPHYLOCOCCUS AUREUS ISOLADOS DE MASTITE BOVINA
Alexandre Tourino Mendonça Glei dos Anjos de Carvalho Castro

Maria Clara Pereira Inácio Miriam de Andrade Pereira

a que foi submetida à planta, estágios de crescimento e maturação, além da metodologia analítica empregada na determinação dos mesmos. (LORENZONI et al., 2013).

De acordo com Auricchio e Bacchi (2003), o óleo essencial da pitangueira tem efeito antimicrobiano frente a distintos microrganismos como Proteus vulgaris, Pseudomonas aeruginosa, Candida albicans e Trichophyton mentagrophytes. E esse potencial também está presente nos extratos das folhas que apresentam uma forte atividade antimicrobiana, sendo relatada atuando frente a bactérias Gram positivas, Gram negativas e fungos (HOLETZ et al. 2002).

Segundo Mendonça (2016), através da avaliação da concentração mínima inibitória (CMI), o extrato hidroalcoólico se destacou pela inibição do crescimento do Staphylococcus aureus. Já o extrato bruto apresentou a mesma concentração inibitória mínima para as cepas de Pseudomonas sp., Staphylococcus aureus e Escherichia coli.

A Psidium guajava L. é uma planta amplamente distribuída no território nacional e bem adaptada, popularmente chamada de goiabeira, é uma árvore frutífera de copa aberta, de até $7 \mathrm{~m}$ de altura, nativa da América do Sul, presente desde a Venezuela até o Rio de Janeiro e cultivada em todo o país. É utilizada de forma caseira no tratamento de diarreia na infância, devido a ação da quercetina, principal flavanóide constituinte da folha de goiabeira, que tem um efeito antipropulsor do trânsito intestinal e reduz a permeabilidade dos capilares abdominais (ZHANG et al., 2003). Há também relatos do uso do chá em bochechos e gargarejos nos casos de estomatites e faringites (LORENZI; MATOS, 2008).

Alguns estudos comprovaram o efeito antimicrobiano e antidiarreico de plantas da família Myrtaceae, Chah et al. (2006) relataram efeito antibacteriano de extratos metanólicos da goiabeira frente a diversas espécies bacterianas, entre elas a Escherichia coli, principal bactéria causadora de diarreia em recém-nascidos. (PRESTES, 2011).

O Staphylococcus aureus subsp. aureus (S. aureus) pertence ao gênero Staphylococcus e a família Staphylococcaceae. O S. aureus foi primeiramente descrito por Sir Alexander Ogston em 1882 e dois anos mais tarde, Rosenbach isolou em uma cultura pura e introduziu o nome S. aureus. O nome do organismo é derivado de palavras gregas staphyle (um cacho de uvas) e cocos (grãos ou baga). Este microrganismo é uma bactéria gram-positiva, anaeróbia facultativa, catalase-positiva, oxidase-negativa, DNase positiva, sem motilidade e não formadora de esporos. (SANTANA, 2015). 
AVALIAÇÃO ANTIMICROBIANA DA EFICÁCIA

DOS EXTRATOS HIDROALCÓLICOS DA PITANGUEIRA

E DA GOIABEIRA, IN VITRO, CONTRA

STAPHYLOCOCCUS AUREUS ISOLADOS DE MASTITE BOVINA
Alexandre Tourino Mendonça Glei dos Anjos de Carvalho Castro

Maria Clara Pereira Inácio Miriam de Andrade Pereira

De acordo com List of prokaryotic names há 69 espécies e 30 subespécies de Staphylococcus divididas em duas categorias: coagulase positivas e coagulase negativas (PARTE et al., 2020). Essa divisão é baseada na capacidade de coagulação do plasma, que é uma propriedade considerada importante como marcador de patogenicidade dos estafilococos (BEHME et al., 1996).

Os principais substratos utilizados por este organismo são os açúcares (glucose, frutose, galactose, manose, ribose, maltose, sacarose, trealose), álcoois (manitol), ácidos orgânicos (acetato), e em algumas condições aminoácidos (glutamina, arginina). Uma característica que distingue o S. aureus de outras bactérias patogênicas é a sua elevada tolerância a baixos valores de atividade de água e concentrações de $\mathrm{NaCl}$ até $20 \%$ (halotolerantes) (SANTANA, 2015).

Os S. aureus são mesófilos com temperatura ótima de crescimento entre $37^{\circ} \mathrm{C}$ a $40^{\circ} \mathrm{C}$, e temperatura mínima para o crescimento de cerca de $7,0^{\circ} \mathrm{C}$. São capazes de crescer numa faixa de $\mathrm{pH} 4,0-9,8$, com um pH ótimo entre 6-7. Esta bactéria sobrevive ao congelamento em carnes a $-18^{\circ} \mathrm{C}$ por aproximadamente seis meses, sem qualquer alteração nas contagens de UFC. Enquanto em temperaturas superiores a $46^{\circ} \mathrm{C}$ a maioria é inativada, com algumas exceções que crescem até $50^{\circ} \mathrm{C}$. Porém, as enterotoxinas podem resistir tanto ao processo de pasteurização quanto ao de esterilização de leite e de alimentos enlatados, e não são afetados mesmo que por uma dose de esterilização de radiação (MEDVEĎOVÁ; VALÍK, 2012).

Também é encontrado em úberes de fêmeas bovinas lactantes e canais dos tetos, constituindo-se em um dos principais agentes etiológicos da mastite contagiosa. E existindo a possibilidade do contato direto entre animais positivos e seres humanos imunossuprimidos, esses podem desenvolver infecções de difícil tratamento. (ASSUNÇÃO, 2001; MENDONÇA, 2004; FREITAS et al., 2013).

Assim como afirma Santos et al. (2007), o mecanismo de invasão do S. aureus ocorre a partir da aderência à pele ou mucosa, prosseguindo-se do rompimento do epitélio parasitado e de ligações intercelulares. Logo após, o microrganismo adota estratégias de evasão a opsonização pelo complemento, e a fagocitose e reduzindo a resposta imunológica pelo organismo do hospedeiro.

Assim, procurou-se por Determinação da Concentração Inibitória Mínima (CIM) avaliar a atividade antimicrobiana dos extratos hidroalcoólicos dos caules e folhas secas de 
AVALIAÇÃO ANTIMICROBIANA DA EFICÁCIA

DOS EXTRATOS HIDROALCÓLICOS DA PITANGUEIRA

E DA GOIABEIRA, IN VITRO, CONTRA

STAPHYLOCOCCUS AUREUS ISOLADOS DE MASTITE BOVINA
Alexandre Tourino Mendonça Glei dos Anjos de Carvalho Castro

Maria Clara Pereira Inácio Miriam de Andrade Pereira

goiabeira e pitangueira, contra S. aureus, isolados de mastite bovina assim como comparar a eficiência encontrada a antibióticos utilizados na bovinocultura leiteira.

\section{MATERIAL E MÉTODOS}

\subsection{Local de realização dos testes}

A pesquisa foi desenvolvida no Laboratório de Pesquisa I e no Laboratório de Microbiologia da Universidade Vale do Rio Verde - UninCor de Três Corações, Minas Gerais.

\subsection{Coleta de folhas e caules de Myrtaceae}

A colheita das folhas foi realizada segundo Prestes (2011), de árvores previamente identificadas com os nomes científicos e populares das plantas, na Fazenda Experimental da UninCor, localizada no bairro Cinturão Verde em Três Corações - MG no período de junho/2017. Posteriormente, folhas e caules foram lavadas e higienizadas com hipoclorito de sódio e acondicionadas em sacos de papel por três dias a temperatura de 30 ํ em estufa com aeração (MENDONÇA, 2016).

\subsection{Microrganismo testado}

As bactérias testadas foram foram isoladas de amostras de leite coletadas de animais diagnosticados com mastite a partir de triagem preventiva específica para detectar $S$. aureus em fazendas da região de Três Corações e em Carmo de Minas - MG. O controle positivo utilizado foi e a cepa controle ATCC 29213.

\subsubsection{Coleta e processamento do material}

Foram coletadas e analisadas 70 amostras de leite proveniente de fêmeas bovinas da raça Holandesa e seus cruzamentos, diagnosticadas com mastite a partir do controle da qualidade de leite realizado em propriedades localizadas no município de Três Corações, durante o período entre junho e setembro de 2017. 
AVALIAÇÃO ANTIMICROBIANA DA EFICÁCIA

DOS EXTRATOS HIDROALCÓLICOS DA PITANGUEIRA

E DA GOIABEIRA, IN VITRO, CONTRA

STAPHYLOCOCCUS AUREUS ISOLADOS DE MASTITE BOVINA
Alexandre Tourino Mendonça Glei dos Anjos de Carvalho Castro

Maria Clara Pereira Inácio

Miriam de Andrade Pereira

O processo de coleta iniciou-se com a devida antissepsia das mãos do ordenhador com água e sabão, que a seguir realizou o teste da caneca telada, pós pré-dipping e secagem com papel toalha. Aplicou-se álcool 70\% no esfíncter do teto, descartando-se os três primeiros jatos de leite e coletando-se cerca de $10 \mathrm{ml}$ de leite em tubo estéril. As amostras com identificação do animal foram acondicionadas em caixa isotérmica, transportada sob refrigeração de 4으 C, e no Laboratório de Microbiologia da Universidade Vale do Rio Verde Unincor, foram congeladas em uma temperatura média de -60 C visando conservar as amostras e, posteriormente realizou o descongelamento à temperatura ambiente para o cultivo microbiológico e análises bioquímicas.

\subsection{Isolamento do Staphylococcus aureus}

As amostras foram inoculadas em Ágar Baird Parker, enriquecido com gema de ovo com telurito de potássio, e incubadas a $37^{\circ} \mathrm{C}$ por 48 horas. As colônias caracterizadas como Staphylococcus spp. (colônias de cor negra, brilhantes, com zona de precipitação circundada por halo claro) foram submetidas à coloração de Gram e testes para a identificação da espécie S. aureus (prova da catalase, prova da coagulase e fermentação do manitol) (SAEKI, 2011).

\subsubsection{Preparação dos extratos hidroalcoólicos (EHA)}

Os EHA foram preparados da seguinte maneira: 50 gramas das folhas previamente secas e trituradas, foram homgenizadas a álcool 70\%, para início do processo da maceração. O extrato foi acondicionado em recipiente estéril de vidro âmbar, durante oito dias, em temperatura ambiente, ao abrigo de luz e umidade, com agitações periódicas. Logo após, iniciou-se o processo de filtração e acondicionamento em vidro âmbar, sob o abrigo de luz e umidade, em temperatura ambiente (NASCIMENTO, 2013).

Os testes antimicrobianos foram realizados em dois períodos, o primeiro após 8 dias de produção do extrato e o segundo após 3 meses. Além disso, foram realizados antibiogramas com 4 drogas convencionais frente às 17 cepas isoladas e a cepa controle. Os antibióticos avaliados pelo teste de difusão em disco foram Norfloxacina, Gentamicina, Amoxilina e Vancomicina. 
AVALIAÇÃO ANTIMICROBIANA DA EFICÁCIA

DOS EXTRATOS HIDROALCÓLICOS DA PITANGUEIRA

E DA GOIABEIRA, IN VITRO, CONTRA

STAPHYLOCOCCUS AUREUS ISOLADOS DE MASTITE BOVINA
Alexandre Tourino Mendonça Glei dos Anjos de Carvalho Castro

Maria Clara Pereira Inácio Miriam de Andrade Pereira

\subsection{Diluição dos extratos}

A diluição foi preparada em quatro tubos de ensaio estéreis $(10 \mathrm{~mL})$, identificados com suas respectivas concentrações. No primeiro tubo (vazio e estéril) adicionou-se $2 \mathrm{ml}$ do extrato puro (100\%) com auxílio de pipetas e ponteiras estéreis, em seguida retirou-se $1 \mathrm{ml}$ do primeiro tubo que foi adicionada ao segundo tubo contendo $1 \mathrm{ml}$ de solução salina $0,9 \%$ (concentração $50 \%$ de extrato), assim seguiu-se a diluição até o tubo quatro com concentração de 12,5\% (MENDONÇA, 2016). Esse processo foi realizado e testado frente ao S. aureus em dois tempos, o primeiro com 8 dias e o segundo, após 3 meses do extrato preparado e mantido sob abrigo de luz, buscando-se avaliar possível mudança da eficácia dos extratos.

\subsection{Preparação dos inóculos}

Os inóculos foram preparados e padronizados em solução fisiológica esterilizada, comparando-se a turbidez com o tubo no 0,5 da escala MC Farland a fim de se obter cerca de 106 UFC/ml (MENDONÇA, 2016).

\subsection{Difusão em disco e teste antimicrobiano dos extratos}

Na placa de Petri contendo Ágar Mueller Hinton como meio de cultura, espalhou-se, com o auxílio de "swabs" estéreis o inóculo bacteriano preparado com a solução salina estéril (com turvação 0,5 da escala de Mac Farland) e distribui-se uniformemente sobre a superfície do Ágar (SILVEIRA, 2009).

Na placa de Petri identificaram-se os locais onde foram alocados os discos de papel filtro estéreis impregnados (mergulhando os discos no extrato por 30 segundos) com o extrato em diferentes concentrações (STIEVEN; MOREIRA; SILVA, 2009), com espaço de 20mm entre os discos EHA e dos antibióticos Norfloxacina, Gentamicina, Amoxilina e Vancomicina e 15mm da borda externa da placa, realizou-se a distribuição dos discos com ajuda de uma pinça estéril. Em seguida, com as placas já estriadas e com os discos, as placas invertidas foram incubadas a $37^{\circ} \mathrm{C}$, por 24 horas, e após este período medidas as zonas de inibição, em milímetro. Todos os isolados, assim como a cepa controle foram testadas em triplicata. 
AVALIAÇÃO ANTIMICROBIANA DA EFICÁCIA

DOS EXTRATOS HIDROALCÓLICOS DA PITANGUEIRA

E DA GOIABEIRA, IN VITRO, CONTRA

STAPHYLOCOCCUS AUREUS ISOLADOS DE MASTITE BOVINA
Alexandre Tourino Mendonça Glei dos Anjos de Carvalho Castro

Maria Clara Pereira Inácio Miriam de Andrade Pereira

O resultado final foi determinado por estatística descritiva comparativa a partir dos halos de inibição do crescimento $(\mathrm{mm})$ encontrados, utilizando paquímetro universal para medir os halos formados (MENDONÇA, 2016).

\section{RESULTADOS E DISCUSSÃO}

Das 70 amostras provenientes de leite bovino de duas propriedades, conseguiu-se ao final de todos os testes bioquímicos e microbiológicos o isolamento de 17 cepas de S.aureus coagulase positiva. Sendo essas utilizadas em triplicata nos testes antimicrobianos, e tendo como cepa controle a S. aureus ATCC 29213 para controlar a precisão da reprodutibilidade e dos testes de disco-difusão.

A partir do controle realizado com a solução salina estéril e álcool 70\%, foi possível afirmar que estes não interferiram na ação dos extratos de pitangueira e goiabeira. Além disso, foram realizadas placas controles apenas com o meio ágar Mueller Hinton e também com cepas, certificando-se que as amostras controles foram efetivas na verificação de contaminação cruzada, não havendo crescimento de outras colônias bacterianas.

Os resultados obtidos nos ensaios de difusão em discos realizados com os extratos de pitangueira e goiabeira foram positivos (Figuras 1 e 2 ) houve atividade antimicrobiana frente Staphylococcus aureus, visto que após leitura da placa foi possível observar halos com diversos diâmetros, inclusive superiores a $8 \mathrm{~mm}$, como o preconizado por Mendonça (2016).

Figura 1 - (A) Cepa de mastite bovina, halos de inibição da Norfloxacina, Gentamicina e Amoxilina, sem inibição da Vancomicina; (B) Cepa controle ATCC 29213, halos de inibição frente aos mesmos antibióticos.

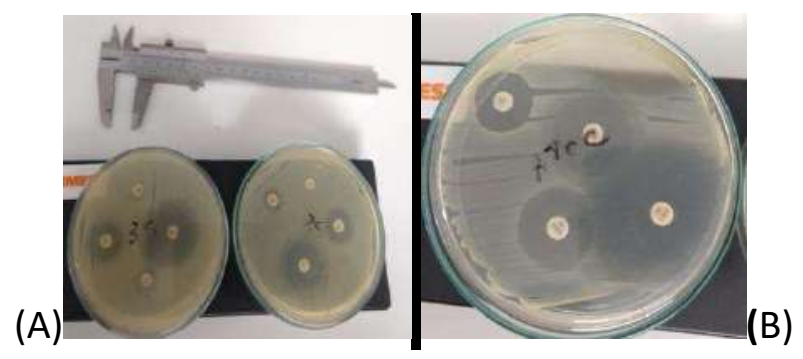

Fonte: Autores (2021).

Figura 2 - (A)(B) Cepas de mastite bovina, halos de inibição do extrato da pitangueira; (C) Cepas de mastite bovina, ausência de halos de inibição do extrato da goiabeira; (D) Cepa controle ATCC 29213, halos de inibição frente ao extrato da pitangueira. 
AVALIAÇÃO ANTIMICROBIANA DA EFICÁCIA DOS EXTRATOS HIDROALCÓLICOS DA PITANGUEIRA

E DA GOIABEIRA, IN VITRO, CONTRA

STAPHYLOCOCCUS AUREUS ISOLADOS DE MASTITE BOVINA
Alexandre Tourino Mendonça Glei dos Anjos de Carvalho Castro

Maria Clara Pereira Inácio Miriam de Andrade Pereira



Fonte: Autores (2021).

Nos gráficos (1, 2, 3 e 4) são apresentados os resultados obtidos nos testes antimicrobianos dos extratos hidroalcoólicos da pitangueira e da goiabeira frente às cepas de S. aureus isoladas de mastite e a cepa controle ATCC.

Gráfico 1 - Porcentagem de cepas com halos superiores a 8 mm de diâmetro, considerando 51 placas.

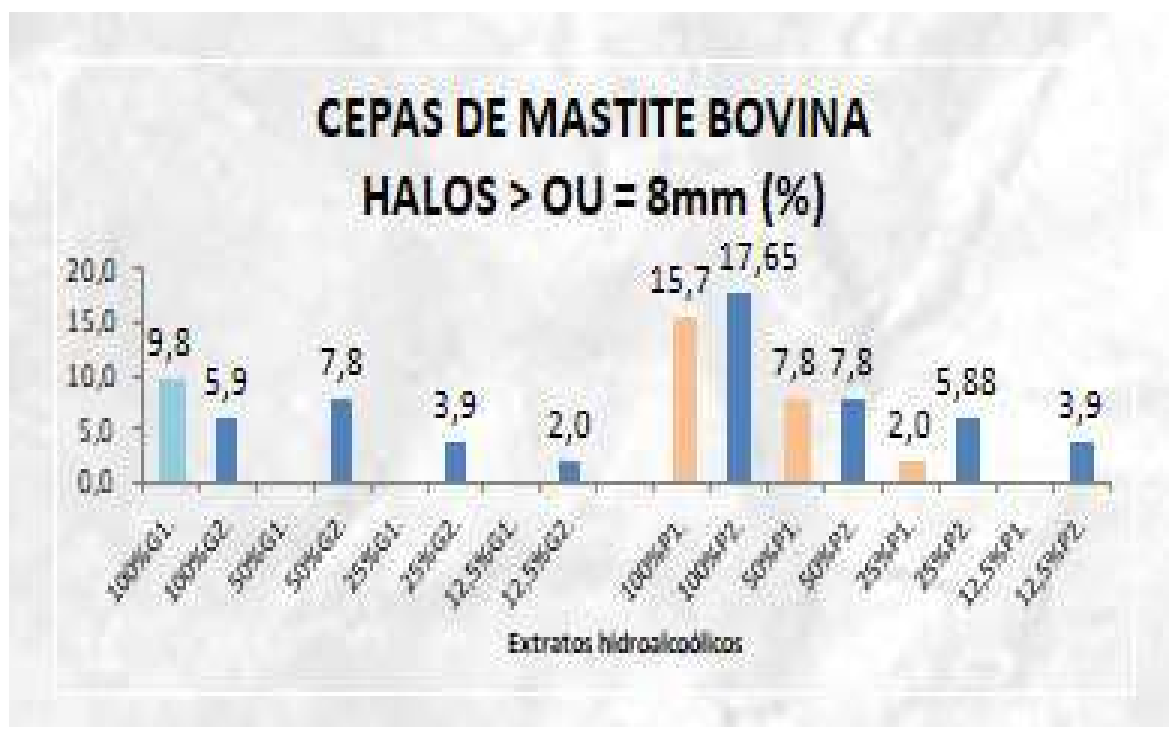

Fonte: Autores (2021)

Gráfico 2 - Porcentagem de cepas com halos superiores a $8 \mathrm{~mm}$ de diâmetro, considerando a cepa controle em triplicata. 
AVALIAÇÃO ANTIMICROBIANA DA EFICÁCIA

DOS EXTRATOS HIDROALCÓLICOS DA PITANGUEIRA

E DA GOIABEIRA, IN VITRO, CONTRA

STAPHYLOCOCCUS AUREUS ISOLADOS DE MASTITE BOVINA
Alexandre Tourino Mendonça Glei dos Anjos de Carvalho Castro

Maria Clara Pereira Inácio Miriam de Andrade Pereira



Fonte: Autores (2021).

A seguir tem-se a média de diâmetro dos halos que foram superiores a $8 \mathrm{~mm}$.

Gráfico 3 - Ação dos extratos hidroalcoólicos frente às 17 cepas isoladas de S. aureus, considerando a média dos halos superiores a $8 \mathrm{~mm}$.

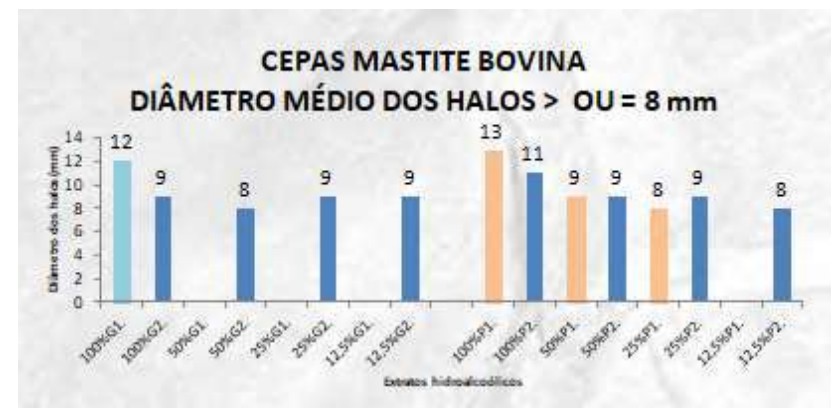

Fonte: Autores (2021).

Gráfico 4 - Ação dos extratos hidroalcoólicos frente à cepa controle.



Fonte: Autores (2021).

Ao se considerar a média de todos os diâmetros formados com os extratos hidroalcoólicos, os valores apresentam grande redução, tanto na cepa controle como nas isoladas de mastite, isso se explica pela dispersão de valores encontrados nas 51 placas analisadas, o que resulta um acentuado desvio padrão, como observado a seguir (gráficos 5, 6 e 7). 
AVALIAÇÃO ANTIMICROBIANA DA EFICÁCIA

DOS EXTRATOS HIDROALCÓLICOS DA PITANGUEIRA

E DA GOIABEIRA, IN VITRO, CONTRA

STAPHYLOCOCCUS AUREUS ISOLADOS DE MASTITE BOVINA
Alexandre Tourino Mendonça Glei dos Anjos de Carvalho Castro

Maria Clara Pereira Inácio

Miriam de Andrade Pereira

Gráfico 5 - Considerando os 51 valores encontrados desde 0 até os superiores a $8 \mathrm{~mm}$, o que acaba reduzindo muito a média geral.

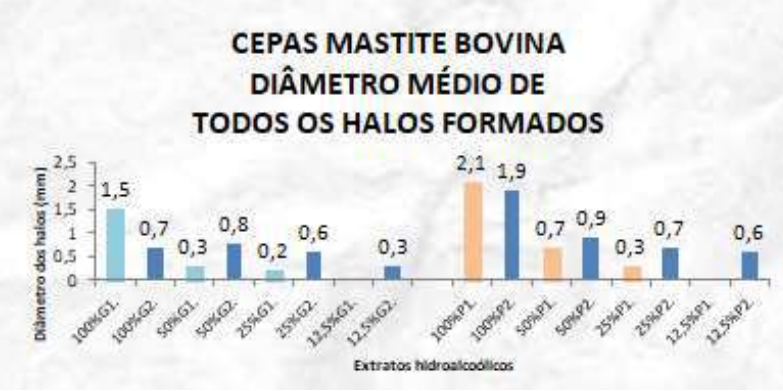

Fonte: Autores (2021).

Gráfico 6 - Demonstrando as médias e os desvios encontrados nos testes com extratos hidroalcoólicos.

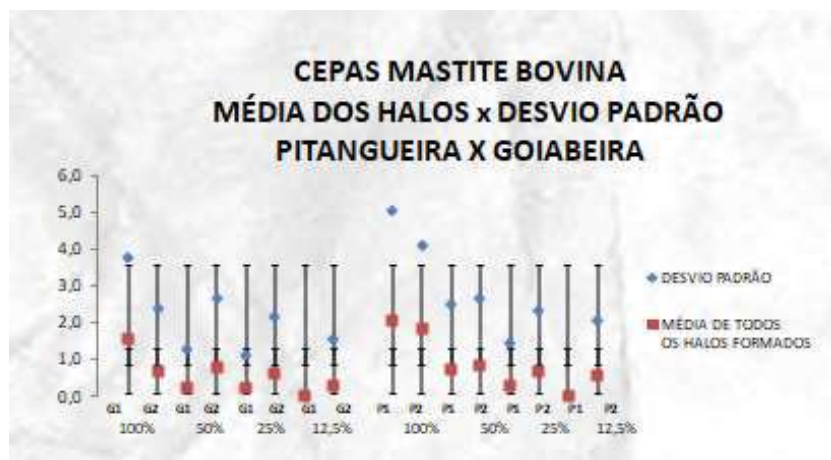

Fonte: Autores (2021).

Gráfico 7 - Cepa controle com diâmetro dos halos reduzidos quando considerados todos os valores.

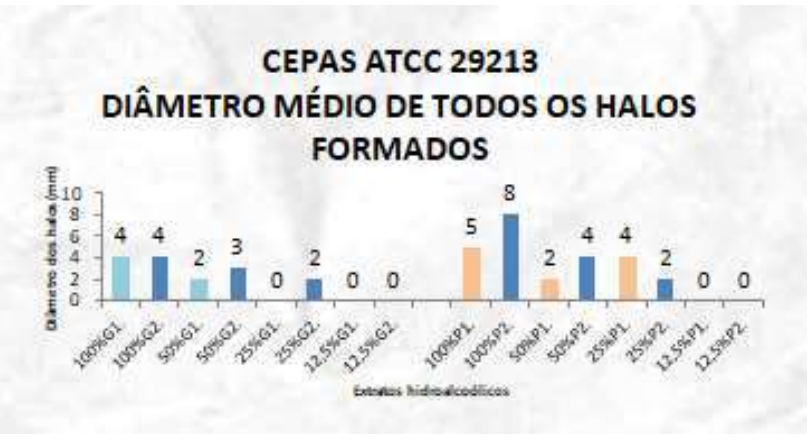

Fonte: Autores (2021).

A partir desses dados apresentados pode se observar que a pitangueira na concentração de $100 \%$ apresentou ação superior a goiabeira em qualquer concentração, 
AVALIAÇÃO ANTIMICROBIANA DA EFICÁCIA

DOS EXTRATOS HIDROALCÓLICOS DA PITANGUEIRA

E DA GOIABEIRA, IN VITRO, CONTRA

STAPHYLOCOCCUS AUREUS ISOLADOS DE MASTITE BOVINA
Alexandre Tourino Mendonça Glei dos Anjos de Carvalho Castro

Maria Clara Pereira Inácio Miriam de Andrade Pereira

sendo as cepas de mastite mais sensíveis à pitangueira com 8 dias de extrato e as cepas controles mais sensíveis ao extrato com 3 meses. Porém, ao analisar a abrangência de cepas sensíveis (\% de cepas com halos > ou = a $8 \mathrm{~mm}$ ), a pitangueira com 3 meses é mais eficaz, atingindo mais cepas de mastite bovina e também a controle. Essa eficácia da Eugenia uniflora também foi relatada por Duarte (2006) que testou substâncias reconhecidas cientificamente como 1,8-cineol, limoneno e linalol, geranial, germacreno-D e mentol que são produtos do metabolismo secundário da planta. Supõe-se que a ação antimicrobiana é mais eficaz no extrato com 3 meses devido uma maior concentração desses metabólitos, portanto novos estudos avaliando as substâncias presentes e o tempo para concentração são necessários .

Apesar de a cepa controle ter mostrado uma CIM de 25\% dos extratos da pitangueira e da goiabeira, os halos formados na presença do EHA apresentam média superior aos presentes nas 17 cepas de S. aureus (CIM de 12,5\%), e todos os antibióticos formaram halo de inibição na cepa controle ATCC 29213, o que sugere os isolados deste estudo são mais resistentes que a amostra ATCC utilizada como controle positivo.

Prestes (2011), ao testar os EHA obtidos de folhas secas durante o período de repouso como o realizado nesta pesquisa, encontrou CIM de $12,5 \%$ da pitangueira e $6,25 \%$ da goiabeira frente ao S. aureus ATCC 12600, o que revela uma sensibilidade ainda maior que a cepa ATCC 29213 utilizada nesse trabalho. E este autor ainda afirma que se tem CIM ainda mais reduzida quando realizados testes na época de floração com folhas secas da pitangueira (CMI 6,25\%) e frescas da goiabeira (CMI 3,125\%).

Apesar de mostrar a capacidade de inibição, os EHA aqui testados inibiram isolados neste trabalho, e os valores apresentados nos halos de inibição do teste de difusão em disco foram muito inferiores aos encontrados perante Norfloxacina, Gentamicina, Amoxilina e Vancomicina.

Ao analisar a eficácia dos antibióticos convencionais, a Norfloxacina e a Gentamicina obtiveram $100 \%$ de sensibilidade frente às 17 cepas de mastite bovinas e a cepa controle. Já a Amoxilina e a Vancomicina agiram com sensibilidade de $100 \%$ na cepa controle, mas com 79,4 e $29,4 \%$ nos isolados de mastite bovina, indicando-se resistência, como se pode observar a seguir (Gráfico 8).

Gráfico 8 - Cepas de mastite bovina e a cepa controle demonstraram sensibilidade aos antibióticos convencionais. 
AVALIAÇÃO ANTIMICROBIANA DA EFICÁCIA

DOS EXTRATOS HIDROALCÓLICOS DA PITANGUEIRA

E DA GOIABEIRA, IN VITRO, CONTRA

STAPHYLOCOCCUS AUREUS ISOLADOS DE MASTITE BOVINA
Alexandre Tourino Mendonça Glei dos Anjos de Carvalho Castro

Maria Clara Pereira Inácio Miriam de Andrade Pereira

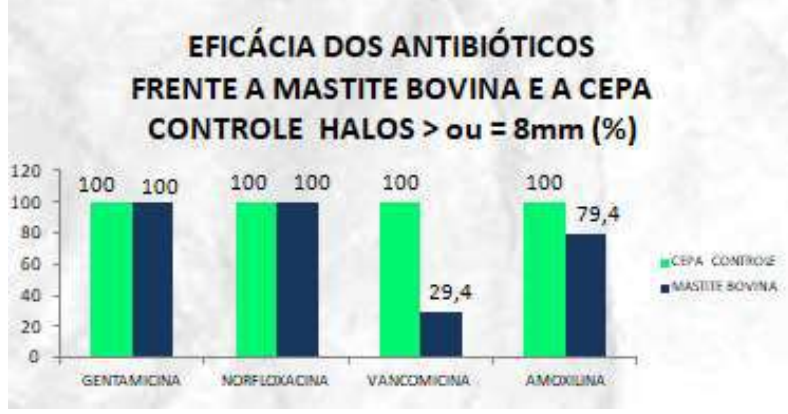

Fonte: Autores (2021).

Ao analisar o diâmetro médio de todos os halos formados frente aos 4 antibióticos, a cepa controle ATCC 29213 foi a mais sensível frente a todos, exceto a Norflaxacina, no qual se observou diferença de $2,5 \mathrm{~mm}$ em relação às médias dos halos formados nas cepas de $S$. aureus isoladas de mastite bovina (gráfico 9).

Gráfico 9 - Diâmetro médio de todos os halos formados nas cepas de mastite bovina e a cepa controle.

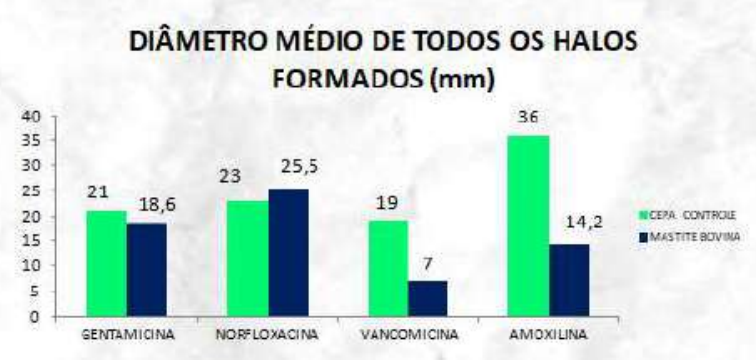

Fonte: Autores (2021).

E ao observar a ação dos antibióticos frente as 51 placas de $S$. aureus, obteve-se média alta e valor reduzido de desvio padrão nos resultados de sensibilidade obtidos frente à Gentamicina e à Norfloxacina. Entretanto, na Amoxicilina o desvio padrão aumenta e se aproxima da média por já ter um nível de resistência (20,6\%). E nos dados observados na Vancomicina a situação se inverte, a média apresentada é menor que o desvio (Gráfico 10), o que se justifica por alta resistência $(70,6 \%)$ e por halos que variam de 0 a $27 \mathrm{~mm}$.

Gráfico 10 - Demonstra o desvio padrão e a média de todos os halos formados pelos 4 antibióticos frente as 17 cepas de $S$. aureus isolados de mastite bovina. 
AVALIAÇÃO ANTIMICROBIANA DA EFICÁCIA

DOS EXTRATOS HIDROALCÓLICOS DA PITANGUEIRA

E DA GOIABEIRA, IN VITRO, CONTRA

STAPHYLOCOCCUS AUREUS ISOLADOS DE MASTITE BOVINA
Alexandre Tourino Mendonça Glei dos Anjos de Carvalho Castro

Maria Clara Pereira Inácio Miriam de Andrade Pereira



Fonte: Autores (2021).

Dentre as classes dos antibióticos testados nesse trabalho, foi observado a eficiência de Quinolona (Norfloxacina na concentração de $10 \mu \mathrm{g}$ ), no Aminoglicosídeo (Gentamicina 10 $\mu \mathrm{g}$ ), e logo após no $\beta$ - Lactâmico (Amoxicilina $30 \mu \mathrm{g}$ ) e com resultados mínimos no Glicopeptídeo (Vancomicina $30 \mu \mathrm{g}$ ), respectivamente. Sendo a sensibilidade baixa das cepas de $S$. aureus isoladas de mastite bovina provavelmente pelo fato dos dois últimos antibióticos citados terem mecanismo de ação na parede celular do agente, alterando apenas o sítio onde ocorre a inibição da síntese. Já a Norfloxacina age inibindo a síntese da Dna- girase das bactérias e a Gentamicina impede a síntese proteica bacteriana no ribossomo, mecanismos esses que demonstraram maior eficácia na ação antimicrobiana ao $S$. aureus isolado de mastite bovina (NCCLS, 2003).

De acordo com NCCLS (2003) a Vancomicina seria indicada a cepas gram-positivas resistentes aos $\beta$ - lactâmicos como os $S$. aureus resistentes à Meticilina (MRSA). Porém, frente às cepas testadas e a cepa controle ATCC 29213, os halos de inibição formados pela Amoxicilina são quase o dobro dos encontrados na Vancomicina. Porém isto não tem inferência científica já que o padrão de susceptibilidade destes antimicrobianos podem ser distintos.

Durante a pesquisa, constatou-se 4 cepas resistentes à Vancomicina, e sensíveis à pitangueira, e 3 dessas também a goiabeira. Um dado importante que demonstra uma alternativa futura de estudo, como se pode observar a seguir (gráfico 11).

Gráfico 11 - Cepas resistentes à Vancomicina, mas com sensibilidade à pitangueira e à goiabeira. 
AVALIAÇÃO ANTIMICROBIANA DA EFICÁCIA

DOS EXTRATOS HIDROALCÓLICOS DA PITANGUEIRA

E DA GOIABEIRA, IN VITRO, CONTRA

STAPHYLOCOCCUS AUREUS ISOLADOS DE MASTITE BOVINA
Alexandre Tourino Mendonça Glei dos Anjos de Carvalho Castro Maria Clara Pereira Inácio Miriam de Andrade Pereira

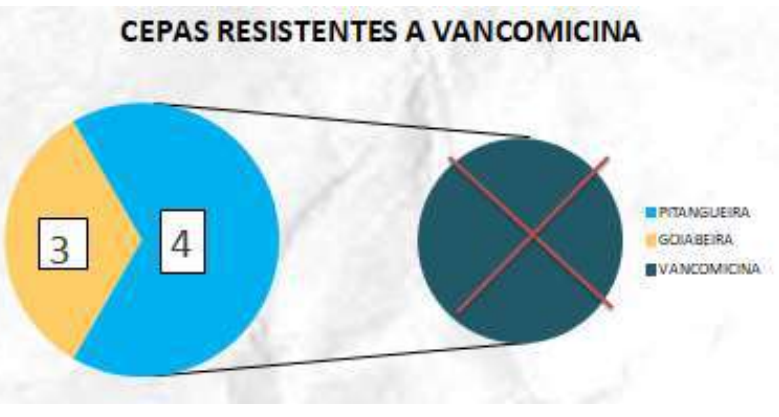

Fonte: Autores (2021).

Perante a resistência demonstrada à Vancomicina, uma alternativa seria como o realizado por Maia et al. (2009), que associou as folhas da goiabeira com a Norfloxacina em amostras de $S$. aureus isolados de bovinos, onde das 10 amostras utilizadas a CMI do antibiótico isolado foi de 1:2 e quando associado à Psidium guajava observou-se ação microbiana em diluições de 1:16 à 1:64. Já Coutinho et al. (2011) testou o efeito de Gentamicina associado ao extrato de Eugenia unifloraconseguindo diminuir a CMI de 8 para 4 $\mu \mathrm{g} / \mathrm{ml}$ na inibição de S.aureus SA358 resistentes a aminoglicosídeos. Diante dessas pesquisas é possível afirmar que existe efeito sinérgico. Assim, a associação das plantas da família Myrtaceae com antibióticos podem ser uma opção terapêutica para tratar infecções causadas por S.aureus.

\section{CONCLUSÕES}

Os extratos hidroalcoólicos da pitangueira (Eugenia unifloraL.) e da goiabeira (Psidium guajava L.) mostraram ação antimicrobiana nos isolados de S. aureus testados, sendo a pitangueira mais eficaz porém menos eficientes que os antibióticos tradicionais. Ao se abordar a concentração mínima inibitória para Staphylococcus aureus isolados de mastite bovina, tanto a goiabeira como a pitangueira apresentaram $\mathrm{CMI} 12,5 \%$, e frente à cepa controle elas apresentaram CIM de 25\%. Destacando-se assim, que existe potencial antimicrobiano, mas limitado principalmente ao se pensar no uso no campo veterinário.

\section{AGRADECIMENTOS}


AVALIAÇÃO ANTIMICROBIANA DA EFICÁCIA

DOS EXTRATOS HIDROALCÓLICOS DA PITANGUEIRA

E DA GOIABEIRA, IN VITRO, CONTRA

STAPHYLOCOCCUS AUREUS ISOLADOS DE MASTITE BOVINA
Alexandre Tourino Mendonça Glei dos Anjos de Carvalho Castro

Maria Clara Pereira Inácio

Miriam de Andrade Pereira

Agradecemos a FAPEMIG pela bolsa de pesquisa concedida, a UninCor pelos laboratórios e materiais disponibilizados e ao professor Geraldo Márcio da Costa (UFLA) por nos ter cedido a cepa controle.

\section{REFERÊNCIAS}

ASSUNÇÃO, E. G. Identificação dos pontos de contaminação microbiana ao logo do processamento de queijo prato: estudo de caso. 2001. Dissertação (Mestrado em Microbiologia de Alimentos) - Universidade Federal de Lavras, Lavras, 2001.

AURICCHIO, Mariangela T.; BACCHI, Elfried M. Fo-lhas de eugenia uniflora L. (pitanga: propriedades farmacobotânicas, químicas e farmacológicas. Rev. Inst. Adolfo Lutz, [S. I.], p. 55-61, 2003.

BEHME, Ronald J. et al. Identification of staphylococci with a self-educating system using fatty acid analysis and biochemical tests. Journal of clinical microbiology, [S. I.], v. 34, n. 12, p. 30753084, 1996.

$\mathrm{CHAH}, \mathrm{K}$. F. et al. Antibacterial and wound healing properties of methanolic extracts of some Nigerian medicinal plants. Journal of Ethnopharmacology, [S. I.], v. 104, n. 1-2, p. 164-167, 2006.

COUTINHO, $\mathrm{H}$. et al. Fruits to potentiate the antibiotic activity: the effect of Eugenia unifloraand Eugenia jam-bolanum L. against MRSA. Acta alimentaria, [S. I.], v. 41, n. 1, p. 6772, 2011.

DUARTE, Marta Cristina Teixeira. Atividade antimicrobiana de plantas medicinais e aromáticas utilizadas no Brasil. Revista MultiCiência, [S. I.], v. 7, n. 1, p. 1-16, 2006.

FREITAS, A. B. et al. Staphylococcus aureus resistentes em animais de companhia. Revista Eletrônica Novo Enfoque, [S. I.], v. 16, n. 16, p. 95-101, 2013.

HOLETZ, Fabíola Barbiéri et al. Screening of some plants used in the Brazilian folk medicine for the treatment of infectious diseases. Memórias do Instituto Oswaldo Cruz, [S. I.], v. 97, n. 7, p. 1027-1031, 2002.

PARTE, A. C.; SARDÀ CARBASSE, J.; MEIER-KOLTHOFF, J. P.; REIMER, L. C.; GÖKER, M. List of prokaryotic names with standing in nomenclature (LPSN) moves to the DSMZ. International Journal of Systematic and Evolutionary Microbiology, [S. I.], v. 70, p. 5607-5612, 2020.

LORENZI, H.; MATOS, F. J. A. Plantas medicinais no Brasil: nativas e exóticas. 2. ed. Nova Odessa: Instituto Plantarum, 2008.

LORENZONI, Luciana de Souza; BERNARDO, Flávia P. A.; MOULIN, Tatiane; GANDINI, Simony M. S. Utilização do extrato bruto de eugenia uniflora L. (pitanga) em teste antibacteriano in 
AVALIAÇÃO ANTIMICROBIANA DA EFICÁCIA

DOS EXTRATOS HIDROALCÓLICOS DA PITANGUEIRA

E DA GOIABEIRA, IN VITRO, CONTRA

STAPHYLOCOCCUS AUREUS ISOLADOS DE MASTITE BOVINA
Alexandre Tourino Mendonça Glei dos Anjos de Carvalho Castro

Maria Clara Pereira Inácio

Miriam de Andrade Pereira

vitro. ENCONTRO LATINO AMERICANO DE INICIAÇÃO CIENTÍFICA, 15.; ENCONTRO LATINO AMERICANO DE PÓS-GRADUAÇÃO, 11., 2011, Espírito Santo. Anais [...]. Espírito Santo: Instituto Federal de Educação Ciência e Tecnologia do Espírito Santo, 2011. p. 1-5.

LORENZONI, Luciana de Souza; GANDINI, Simony M. S.; SOUZA, Tércio da Silva; SANTOS JUNIOR, Alexandre Cristiano; ULISSES, Alessandra de Fátima. Estudo fitoquímico e antibacteriano do extrato etanólico de eugenia uniflora L. (myrtaceae). Enciclopédia Biosfera, Centro Científico Conhecer, Goiânia, v. 9, n. 17, p. 2796-2810, 2013.

MAIA, Rodrigo Rafael et al. Estudos do efeito antimicrobiano do extrato da goiabeira (Psidium guajava LINN) sobre Staphylococcus aureus multirre-sistente. Rev. ACSA, [S. I.], v. 5, n. 1, p. 36-40, 2009.

MEDVEĎOVÁ, Alžbeta; VALÍk, Ĺubomír. Staphylococcus aureus: characterisation and quantitative growth description in milk and artisanal raw milk cheese production. In: EISSA, Ayman Amer. Structure and function of food engineering. [S. I.]: InTech, 2012. p. 71-102.

MENDONÇA, A. T. Efeito dos óleos essenciais de condimentos sobre o crescimento de staphylococcus aureus em ricota cremosa. 2004. Tese (Doutorado em Ciência dos Alimentos) - Universidade Federal de Lavras, Lavras, 2004.

MENDONÇA, Alexandre Tourino et al. A utilização dos extratos hidroalcoólico e alcoólico de eugenia uniflora L. como agente antibacteriano. Revista da Universidade Vale do Rio Verde, Três Corações, v. 14, n. 1, p. 826-833, 2016.

NASCIMENTO, André Luiz Dias Ribeiro. Ação antimicrobiana do extrato de eugenia uniflora L. (pitanga) sobre Staphylococcus aureus, Pseudomonas aeruginosa e Escherichia coli. 2013. Trabalho de Conclusão de Curso (bacharelado em Farmácia) - Universidade Estadual da Paraíba, Campina Grande, 2013.

NCCLS. Performance standards for antimicrobial disk susceptibility tests; approved standard - eighth edition: NCCLS document M2-A8. Pennsylvania: NCCLS, 2003.

PRESTES, Luciana de Souza. Atividade antimicrobiana in vitro e antidiarréica em modelo experimental de extratos de folhas de plantas da família Myrtacea. 2011. Tese (Doutorado em Veterinária) - Universidade Federal de Pelotas, Pelotas, 2011.

SAEKI, Erika Kushikawa et al. Mastite bovina por Staphylococcus aureus: sensibilidade às drogas antimicrobianas e ao extrato alcoólico de própolis. Acta Veterinaria Brasilica, [S. I.], v. 5, n. 3, p. 284-290, 2011.

SANTANA, Thiago Coelho de. Uso do extrato de folhas do Jatobá (Hymenaea martiana Hayne) na redução das contagens de Salmonella spp., Escherichia coli e Staphylococcus aureus em leite cru. 2015. Dissertação (Mestrado em em Agricultura e Biodiversidade) Universidade Federal de Sergipe, Sergipe, 2015. 
AVALIAÇÃO ANTIMICROBIANA DA EFICÁCIA

DOS EXTRATOS HIDROALCÓLICOS DA PITANGUEIRA

E DA GOIABEIRA, IN VITRO, CONTRA

STAPHYLOCOCCUS AUREUS ISOLADOS DE MASTITE BOVINA
Alexandre Tourino Mendonça Glei dos Anjos de Carvalho Castro

Maria Clara Pereira Inácio

Miriam de Andrade Pereira

SANTOS, André Luis et al. Staphylococcus aureus: visitando uma cepa de importância hospitalar. Jornal Brasileiro de Patologia e Medicina Laboratorial, [S. I.], v. 43, n. 6, p. 413423, 2007.

SILVEIRA, Luiz Mário da Silva et al. Metodologias de atividade antimicrobiana aplicadas a extratos de plantas: comparação entre duas técnicas de ágar difusão. Rev. Bras. Farm, [S. I.], v. 90, n. 2, p. 124-128, 2009.

STIEVEN, A. C.; MOREIRA, J. J. S.; SILVA, C. F. Óleos essenciais de uvaia (Eugenia pyriformis Cam-bess): avaliação das atividades microbiana e antioxidan-te. Eclética Química, [S. I.], v. 34, n. 3, p. 7-13, 2009.

ZHANG, W. J. et al. Mechanism of quercetin as an antidiarrheal agent. Academic journal of the first medical college of PLA, [S. I.], v. 23, n. 10, p. 1029-1031, 2003. 


\title{
ANÁLISE TÉCNICA E ECONÔMICA PARA IMPLANTAÇÃO DE UM CENTRO DE COLETA SELETIVA EM MONSENHOR PAULO - MG
}

\author{
Leonardo Martins da Silva Arantes \\ Engenheiro Ambiental e Sanitarista pela Universidade Vale do Rio Verde (UNINCOR), Três Corações, \\ MG, Brasil \\ leoarantes_18@hotmail.com \\ Thales Fernandes Leal \\ Engenheiro Ambiental e Sanitarista pela Universidade Vale do Rio Verde (UNINCOR), Três Corações, \\ MG, Brasil \\ thalesfleal@hotmail.com \\ Rosângela Francisca de Paula Vitor Marques \\ Doutora em Recursos Hídricos, professora da Universidade Vale do Rio Verde (UNINCOR), Três \\ Corações, MG, Brasil \\ roeflorestal@hotmail.com \\ Alisson Souza de Oliveira \\ Doutor em Recursos Hídricos, professor da Universidade Vale do Rio Verde (UNINCOR), Três \\ Corações, MG, Brasil \\ alissonso@hotmail.com
}

\begin{abstract}
RESUMO
Um dos grandes problemas na atualidade está ligado aos resíduos sólidos urbanos, gerados diariamente em quantidades e variedades, causando diversos danos ao meio ambiente. Uma maneira de mitigar esse problema é através do gerenciamento dos resíduos, uma ferramenta muito importante nesse contexto é a coleta seletiva. Nesse contexto, objetivou-se analisar a viabilidade técnica e econômica de implantação de um centro de coleta seletiva no município de Monsenhor Paulo, Sul de Minas Gerais. Foram realizados levantamentos, como a quantificação da geração de resíduos sólidos, análise de custos, estruturas necessárias, ponto de instalação e modo de funcionamento, além de visitas técnicas visando avaliar a coleta seletiva em duas cidades com modelos diferentes, e posteriormente definir uma metodologia de trabalho que melhor se enquadrasse com a realidade local do município. Na estimativa do fluxo de caixa, o custo operacional encontrava-se abaixo do lucro, ou seja, teoricamente o projeto se manteve, porém foi projetado um valor em cima de $100 \%$ da coleta de materiais recicláveis dentro do município, o que seria algo muito distante de acontecer, levando em consideração a cultura tanto local como do País, ou seja, o brasileiro de modo geral não tem o hábito de separar o seu resíduo domiciliar, sendo necessárias ações voltadas para a educação ambiental. Assim, conclui-se que diante dos valores apresentados, e de todas as variáveis de um projeto desse porte poderá acontecer com o apoio e vontade das políticas públicas ou ONG's, sem visar lucros. O grande benefício está na questão ambiental e social.
\end{abstract}

Palavras-chave: Reciclagem. Destinação Final. Sustentabilidade. 


\title{
TECHNICAL AND ECONOMIC ANALYSIS FOR THE IMPLEMENTATION OF A SELECTIVE COLLECTION CENTER IN MONSENHOR PAULO - MG
}

\begin{abstract}
One of the major problems today is linked to urban solid waste, generated daily in quantities and varieties, causing various damages to the environment. One way to mitigate this problem is through waste management, a very important tool in this context is selective collection. In this context, the objective was to analyze the technical and economic feasibility of implementing a Selective Collection Center in the Municipality of Monsenhor Paulo, South of Minas Gerais. Surveys were carried out, such as the quantification of solid waste generation, cost analysis, necessary structures, point of installation and mode of operation, in addition to technical visits aimed at evaluating selective collection in two cities with different models, and subsequently defining a methodology for work that best fit the local reality of the municipality. In the cash flow estimate, the operating cost was below profit, that is, theoretically the project was maintained, but a value above $100 \%$ of the collection of recyclable materials was projected within the municipality, which would be something very far from happening, taking into account both local and country culture, that is, Brazilians in general are not in the habit of separating their household waste, requiring actions aimed at environmental education. Thus, it is concluded that given the values presented, and all the variables, that a project of this size, can happen with the support and willingness of public policies or NGOs, without aiming at profits. The big benefit is in the environmental and social issue.
\end{abstract}

Keywords: Recycling. Final Destination. Sustainability.

Recebido em: 07/10/2020. Aceito em: 27/01/2021. 
ANÁLISE TÉCNICA E ECONÔMICA

PARA IMPLANTAÇÃO DE UM

CENTRO DE COLETA SELETIVA EM

MONSENHOR PAULO - MG
Leonardo Martins da Silva Arantes

Thales Fernandes Leal

Rosângela Francisca de Paula Vitor Marques

Alisson Souza de Oliveira

\section{INTRODUÇÃO}

O desenvolvimento econômico, o crescimento populacional, a urbanização e a revolução tecnológica vêm sendo acompanhados por alterações no estilo de vida e nos modos de produção e consumo da população. Em decorrência direta desses processos, vem ocorrendo um aumento na produção de resíduos sólidos, tanto em quantidade como em diversidade. Além do acréscimo na quantidade, os resíduos produzidos atualmente passaram a abrigar em sua composição diversos elementos perigosos aos ecossistemas e à saúde humana.

De acordo com o IPEA (2012), a composição gravimétrica dos Resíduos Sólidos Urbanos (RSU) é de $51,4 \%$ de matéria orgânica, $31,9 \%$ de recicláveis e 16,7\% de rejeito. A ABRELPE (2016) tem em suas projeções de geração de resíduos, sendo que os números referentes à geração de RSU revelam um total anual de quase 78,3 milhões de toneladas no Brasil, o montante coletado em 2016 foi de 71,3 milhões de toneladas, uma cobertura de coleta de $91 \%$ para o país, consequentemente $9 \%$ tiveram destino impróprio.

Esses resíduos, acondicionados em aterros, descartados de maneira ambientalmente inadequada, podem comprometer a qualidade do solo, da água e do ar, por serem fontes de materiais poluentes (LANZA, 2009).

Segundo Gouveia e Prado (2010), com a decomposição de matéria orgânica tem como consequência a formação de um líquido de cor escura, o chorume, que devido ao potencial poluidor pode contaminar o solo e as águas superficiais ou subterrâneas. Pode ocorrer também a formação de gases tóxicos, asfixiantes e explosivos que se acumulam no subsolo ou são lançados na atmosfera, o que deve ser repensado dando prioridade para a destinação final ambientalmente adequada.

Assim, buscar meios para um melhor gerenciamento dos resíduos urbanos, visando à redução da quantidade de materiais a serem dispostos em aterros, é uma questão importantíssima. Nesse sentido, a coleta seletiva é uma ferramenta de grande valia nesse aspecto, pela preservação ambiental e o desenvolvimento sustentável, podendo prolongar a vida útil de um aterro sanitário em aproximadamente um terço, ou seja, aproximadamente $32 \%$.

A coleta seletiva é uma das atividades de um plano de gerenciamento integrado de resíduos sólidos definido como o conjunto articulado de ações normativas, operacionais, financeiras e de planejamento que uma administração municipal desenvolve, baseado em critérios sanitários, ambientais e econômicos para coletar, tratar e dispor o lixo da cidade (PINHEL; ZANIN; MÔNACO, 2011). Nesse sentido, diversos são os trabalhos envolvendo a coleta seletiva: Conke e Nascimento (2018); Anjos et al. (2019); Sanjad et al. (2019). 
ANÁLISE TÉCNICA E ECONÔMICA

PARA IMPLANTAÇÃO DE UM

CENTRO DE COLETA SELETIVA EM

MONSENHOR PAULO - MG
Leonardo Martins da Silva Arantes

Thales Fernandes Leal

Rosângela Francisca de Paula Vitor Marques

Alisson Souza de Oliveira

A Lei 12.305 de agosto de 2010 incentiva a coleta seletiva de resíduos sólidos conforme sua composição ou constituição. A logística reversa é uma importante ferramenta na destinação ambientalmente adequada de resíduos perigosos como: resíduos de agrotóxicos, pilhas, baterias, lâmpadas fluorescentes e eletrônicos (BRASIL, 2010). Um dos importantes princípios é a responsabilidade compartilhada, que trouxe a obrigatoriedade para o manejo ambientalmente adequado dos resíduos sólidos entre governo, empresas e a sociedade civil. O poder público municipal deve realizar planos de gerenciamento dos resíduos sólidos urbanos e também impulsionar o retorno dos produtos após seu uso, processo no qual foi denominado de logística reversa. A lei consagra a participação formal dos catadores organizados em cooperativas na cadeia da reciclagem e estabelece, em seu Artigo 35, a obrigatoriedade de a população destinar de forma ambientalmente adequada seus resíduos recicláveis caso o município já possua o serviço de coleta seletiva (ALVARENGA, 2015).

Para Alvarenga (2015), a participação social infere no sucesso de programas de coleta seletiva, e há diferentes respostas sociais em relação à participação. Os programas podem ser agrupados em três tipos: grupo ativo, de participação eventual e os que não participam. A utilização dos PEV demanda maior esforço ao cidadão, que além de separar seu próprio "lixo", precisa se deslocar até o mesmo. Tal atitude quando rotineira demonstra um maior nível de conscientização, já que a internalização desse hábito é imprescindível para o sucesso dos programas de coleta seletiva. No entanto, as duas modalidades de coleta (Porta-a-Porta e por PEVs) apresentam aspectos positivos e negativos. Além da questão social, melhoria e qualidade de vida da população no município, juntamente com o potencial de retorno econômico presente nos resíduos recicláveis, tanto em relação ao centro de coleta do município, como para a população, dentro do benefício de troca do "material reciclável" por vale compra, como forma de compensar a participação e colaboração com o processo de funcionamento do Centro de Coleta Seletiva Municipal.

Berticelli et al. (2020) fez um levantamento a respeito da coleta seletiva no Brasil nas três dimensões da sustentabilidade: ambiental, social e econômica e concluiu que a coleta seletiva no Brasil ainda envolve pequenas iniciativas nos municípios, não abrangendo a totalidade da população. E que os indicadores utilizados são úteis para possibilitar o diagnóstico avaliando o grau de sustentabilidade e monitoramento dos programas de coleta seletiva, nos quais auxiliam nas definições de objetivos e metas para melhoria contínua.

Os parâmetros e diretrizes adotados no projeto foram definidos de acordo com a DELIBERAÇÃO NORMATIVA COMPAM № 214 (MINAS GERAIS, 2017), e seguem as linhas de ações dispostas na Deliberação Normativa supracitada, que define educação ambiental, o que significa que todos os aspectos no ambiente de aplicação do programa devem ser levados em consideração: 
ANÁLISE TÉCNICA E ECONÔMICA

PARA IMPLANTAÇÃO DE UM

CENTRO DE COLETA SELETIVA EM

MONSENHOR PAULO - MG
Leonardo Martins da Silva Arantes

Thales Fernandes Leal

Rosângela Francisca de Paula Vitor Marques

Alisson Souza de Oliveira

“Um processo de ensino-aprendizagem permanente e de abordagem sistêmica, o qual reconhece o conjunto das Inter relações entre âmbitos naturais, culturais, históricos, sociais, econômicos e políticos, com intuito de permitir que os grupos sociais envolvidos com o empreendimento adquiram conhecimentos, habilidades e atitudes para o empoderamento e pleno exercício da cidadania".

Neste contexto, objetivou-se neste trabalho avaliar técnica e economicamente a viabilidade de implantação de um sistema de coleta seletiva para o município de Monsenhor Paulo - MG, desde a quantidade dos resíduos gerados, até as estruturas e custos de implantação e operação de um Centro de Coleta Seletiva Municipal, e, consequentemente, reduzir custos com o gerenciamento dos resíduos sólidos urbanos e os impactos ambientais gerados pelos resíduos sólidos urbanos dentro do município.

\section{MATERIAL E MÉTODOS}

\section{Caracterização do município de Monsenhor Paulo}

Segundo IBGE (2020), Monsenhor Paulo é um município da unidade federativa Minas Gerais, da mesorregião Sul/Sudoeste de Minas Gerais, o qual possui população estimada, em 2020, de 8727 habitantes e a densidade demográfica de $37,69 \mathrm{hab} / \mathrm{Km}^{-2}$. Seu território é composto $100 \%$ pelo bioma Mata Atlântica. O IDHM de Monsenhor Paulo é 0.721. Segundo a Câmara Municipal de Monsenhor Paulo (2021), a economia do município é mista, onde a pequena e média indústria convivem com a agricultura e a pecuária. O município conta com um parque industrial do ramo moveleiro e do ramo siderúrgico. O município está ligado - 15km - à rodovia federal Fernão Dias na altura do Trevo para Campanha.

\section{Caracterização quantitativa dos resíduos gerados - Pesagem}

Realizou-se um levantamento do volume de resíduos domiciliares gerados no município de Monsenhor Paulo. Os caminhões do tipo compactadores com capacidade de $12 \mathrm{~m}^{3}$ utilizados para coleta do lixo no município foram pesados diariamente no período de 05 de fevereiro de 2018 a 02 de março de 2018 e 05 de abril a 02 de maio de 2018 em uma balança própria para caminhões, instalada na empresa MGM Produtos Siderúrgicos LTDA.

A pesagem foi realizada pesando-se o caminhão cheio, obtendo o peso bruto e após este descarregar o resíduo no aterro controlado do município, o caminhão foi pesado vazio, sendo este peso a tara. A diferença entre o peso bruto e o peso do caminhão vazio obtendo o peso líquido diário de resíduos gerados, possibilitando avaliação e estimativas de geração de resíduos no município. 
ANÁLISE TÉCNICA E ECONÔMICA

PARA IMPLANTAÇÃO DE UM

CENTRO DE COLETA SELETIVA EM

MONSENHOR PAULO - MG
Leonardo Martins da Silva Arantes

Thales Fernandes Leal

Rosângela Francisca de Paula Vitor Marques

Alisson Souza de Oliveira

\section{Visitas técnicas}

Afim de verificar os modelos utilizados para o sistema de gerenciamento de resíduos sólidos urbanos foi realizada visita técnica em dois modelos de centros de reciclagem: o primeiro de Três Corações - MG (modelo - 1) e o segundo de Nova Resende - MG (modelo - 2), caracterizado por ter aproximadamente 80.032 habitantes e Nova Resende com 16832 habitantes respectivamente, segundo a projeção do IBGE (2020), onde funcionam sistemas de coleta seletiva, com metodologias diferenciadas e que apresentaram bons resultados avaliados durante as visitas técnicas.

\section{Escolha do modelo de coleta seletiva}

Após as visitas técnicas realizadas nos municípios, os modelos 1 e 2 foram levantadas informações sobre diversos aspectos dos processos de coleta seletiva, como: troca de informações, dificuldades encontradas, erros e acertos, metodologias empregadas em cada um dos dois municípios. Bem como levou-se em conta características do porte do município, hábitos da população e aporte financeiro. Em razão dessas características optou-se pela escolha pelo modelo de coleta seletiva por barganha (troca).

\section{Pesquisa de mercado para compra e venda dos materiais recicláveis}

Para a quantificação do valor de venda de cada produto reciclável foi realizada pesquisa de mercado por material, com levantamentos de tomada de preço em três empresas diferentes que compram materiais recicláveis na região de Monsenhor Paulo - MG. Em relação ao preço de compra, utilizou-se a tabela de preços praticados pelo modelo de Nova Resende como referência, pois notouse que em todos os preços, havia um lucro significativo.

Proposição e quantificação de custos e aquisição de material para o Centro de Coleta

\section{Seletiva e o Mercado Municipal}

O levantamento de valores foi realizado por itens, através do contato com fornecedores de serviços, equipamentos e mobiliários, entre outros, para chegar a um valor aproximado para os investimentos, para a implantação do centro de triagem e do Mercado Municipal. Cabe ressaltar que não foi incluído o custo do galpão de funcionamento, o qual, posteriormente ficará sob a responsabilidade da Prefeitura Municipal de Monsenhor Paulo-MG.

\section{RESULTADOS E DISCUSSÕES}

\section{Pesagem dos resíduos sólidos urbanos do município:}

Após a pesagem de 2 meses (fevereiro e abril), com intervalo de um mês sem pesar, foi levantado a geração de resíduos de resíduos sólidos em Monsenhor Paulo - MG, o que deu em média 36 viagens de caminhão ao aterro controlado do município, levando pouco mais de noventa e três toneladas de resíduos por mês no local (tabela 1). 
ANÁLISE TÉCNICA E ECONÔMICA

PARA IMPLANTAÇÃO DE UM

CENTRO DE COLETA SELETIVA EM

MONSENHOR PAULO - MG
Leonardo Martins da Silva Arantes

Thales Fernandes Leal

Rosângela Francisca de Paula Vitor Marques

Alisson Souza de Oliveira

Observou-se que no mês de fevereiro maiores quantidades de resíduos foram observadas na terceira e quarta semana, muito possivelmente podendo estar associado ao carnaval, com maiores quantidades de resíduos gerados. Em abril as maiores gerações foram na primeira e quarta semana, fato que pode estar relacionado aos pagamentos e vales, o qual pode associar a um maior consumo. Sendo fatores considerados por Bidone e Povinelli (1999) que contribuem para a geração de resíduos sólidos urbanos

Ressalta-se a quantidade gerada de resíduos sólidos urbanos no município de Monsenhor Paulo abaixo da média nacional conforme ABRELPE (2017) de 1,04 Kg.pessoa.dia-1 com 9,1 ton/mês em média, ressaltando-se que a geração per capita gira em torno de 0,350 Kg.pessoa.dia-1 ${ }^{-1}$ se aproximando do modelo de coleta seletiva visitado de Nova Resende.

Tabela 1 - Quantificação dos resíduos gerados no município de Monsenhor Paulo nos meses de fevereiro e abril de 2018.

\begin{tabular}{ccccccc}
\hline & \multicolumn{2}{c}{ Fevereiro } & \multicolumn{2}{c}{ Abril } & \multicolumn{2}{c}{ Média mensal } \\
\cline { 2 - 7 } & $\begin{array}{c}\text { No } \\
\text { Pesagens }\end{array}$ & Peso em (Kg) & No Pesagens & $\begin{array}{c}\text { Peso em } \\
(\mathrm{Kg})\end{array}$ & $\begin{array}{c}\mathrm{N}^{\circ} \text { de } \\
\text { pesagens }\end{array}$ & $\begin{array}{c}\text { Peso } \\
(\mathrm{Kg})\end{array}$ \\
\hline 1ㅇ semana & 9 & 22280 & 10 & 25610 & 35,5 & 91370 \\
2o semana & 7 & 15850 & 9 & 22640 & & \\
3o semana & 9 & 27640 & 9 & 21530 & & \\
4o semana & 8 & 23860 & 10 & 23230 & & \\
\hline Total mensal & 33 & 89630 & 38 & 93110 & & \\
\hline
\end{tabular}

Fonte: Elaborado pelos autores (2018).

Com base nos dados do IPEA (2012) e fazendo-se a extrapolação para o município de Monsenhor Paulo, na Tabela 2 são apresentados a composição gravimétrica com quantidades de resíduos sólidos urbanos nas seguintes tipologias: Matéria orgânica, reciclável e rejeito.

Tabela 2 - Porcentual de tipologias de resíduos com base nos dados do IPEA.

\begin{tabular}{cccc}
\hline Peso Total (Ton) & Material & Porcentagem IPEA (\%) & Peso final (Ton) \\
\hline \multirow{2}{*}{91,3} & Orgânico & 51,0 & 46,5 \\
& Reciclável & 32,0 & 29,2 \\
& Rejeito & 17,0 & 15,5 \\
\hline
\end{tabular}

Fonte: Elaborado pelos autores (2018).

Assim, teoricamente $32 \%$ desse volume seria material reciclável, com estimativa de aproximadamente 30 toneladas que poderia retornar a cadeia produtiva gerando emprego e renda e vale compras para as pessoas que assim separassem esse material. Além de aumentar a vida útil do 
ANÁLISE TÉCNICA E ECONÔMICA

PARA IMPLANTAÇÃO DE UM

CENTRO DE COLETA SELETIVA EM

MONSENHOR PAULO - MG
Leonardo Martins da Silva Arantes

Thales Fernandes Leal

Rosângela Francisca de Paula Vitor Marques

Alisson Souza de Oliveira

local de disposição final dos resíduos sólidos urbanos, o que possivelmente acarretaria em menores quantidades de áreas a serem impactadas pelo resíduo.

\section{Caracterização do processo de coleta seletiva dos municípios utilizados no estudo}

No município de Três Corações-MG, é adotado um sistema de coleta porta a porta, ou seja, a população separa os materiais entre úmido (orgânicos e rejeitos) e seco (reciclável), em diversos bairros da cidade, utilizando um veículo específico para a operação. A coleta é realizada em dias alternados à coleta convencional de resíduos sólidos urbanos. Posteriormente o material é levado ao local de funcionamento da associação, onde é segregado, processado e enfardado, para que ocorra a destinação final.

Em Nova Resende-MG foi adotado outro modelo de coleta seletiva. O sistema funciona de modo que o material seja separado nas residências, sendo opção em separar: somente recicláveis ou resíduos secos ou separados por tipologias. O material separado nas residências é levado até o "Galpão da Associação de Catadores", (Figura 1A) onde ocorre a barganha (troca) desse material por um ticket (Vale Compras), como forma de incentivo pela participação. O vale compras, pode ser utilizado em uma rede de opções que compõe o sistema, sendo um Mercado Municipal (Figura1B e 1 C), no qual possui todos os tipos de produtos alimentícios e é abastecido com verduras e hortaliças, produzidos em uma horta integrante do sistema.

Figura 1A - Centro Municipal de coleta seletiva do município de Nova Resende - MG.

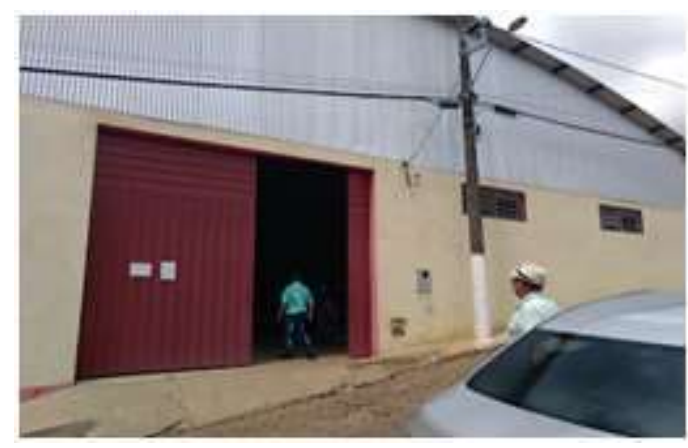

Fonte: Elaborado pelos autores (2018). 
Figura 1B - Mercado Municipal do município de Nova Resende - MG.

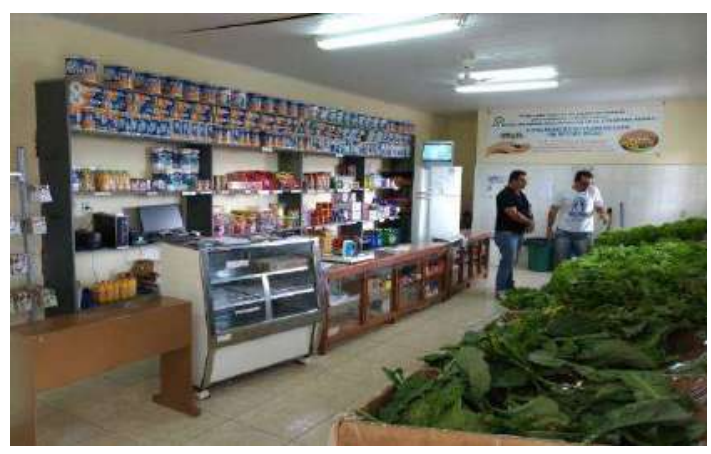

Fonte: Elaborado pelos autores (2018).

Figura 1C - Restaurante Municipal do município de Nova Resende - MG.

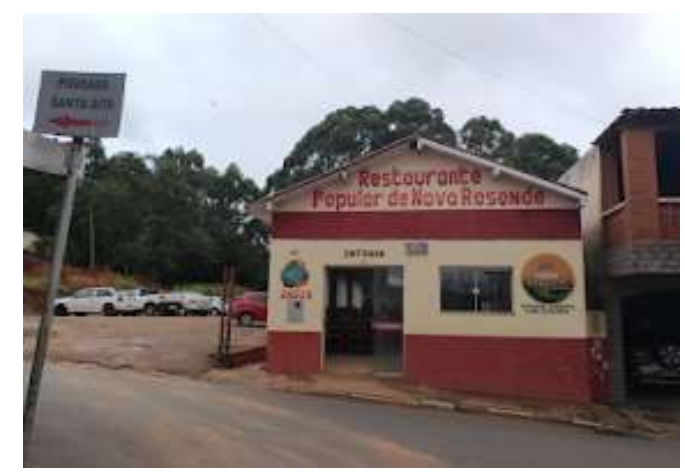

Fonte: Elaborado pelos autores (2018).

\section{Geração real de resíduos em Nova Resende - MG.}

Alguns fatores como culturais, hábitos de consumo, padrão de vida, número de habitantes e a renda familiar definem o poder de compra (BIDONE; POVINELLI, 1999). Assim, esses fatores devem ser levados em consideração para a escolha do melhor modelo para a implantação da coleta seletiva. Nesse sentido, optou-se em utilizar o modelo de Nova Resende devido à semelhança em termos do número de habitantes e hábitos de consumo, os quais influenciarão sobremaneira na quantidade de resíduos gerados. Assim, foi utilizado o percentual de geração de cada tipo de material reciclável, para estimar o percentual de cada um para Monsenhor Paulo. Na tabela 3, são apresentados os valores de geração consultados junto ao departamento de gerenciamento de Nova Resende-MG, valores reais.

Tabela 3 - Valores da geração de resíduos, percentual e preços de compra em Nova Resende-MG.

\begin{tabular}{ccccccc}
\hline Material & Quantidad & Percentua & Peso por & Preço & Gasto & Lucro \\
& e (Ton) & I (\%) & material & compra & estima & estimad \\
& & (Ton) & $(\mathrm{R} \$)$ & do (R\$) & o (R\$) \\
\hline
\end{tabular}




\begin{tabular}{ccccccc}
\hline Papelão & 8,35 & 39,7 & 11,59 & 0,12 & 1390,8 & 2318,00 \\
& & & & & 0 & \\
Plástico & 3,75 & 17,8 & 5,19 & 0,15 & 778,50 & 1816,50 \\
Metal & 6,10 & 29 & 8,46 & 0,15 & 1269 & 2961,00 \\
Vidro & 0,03 & 0,14 & 0,04 & 0,01 & 40,00 & 120,00 \\
Alumíni & 0,88 & 4,34 & 1,26 & 1,50 & 1890,0 & 3780,00 \\
o & & & & & 0 & \\
PEAD & 0,48 & 2,37 & 0,69 & 0,50 & 345,00 & 1104,00 \\
Cobre & 0,02 & 0,09 & 0,02 & 4,00 & 80,00 & 300,00 \\
Ráfia & 1,01 & 4,8 & 1,40 & 0,02 & 28,00 & 70,00 \\
Outros & 0,4 & 1,9 & 0,55 & - & 66,00 & - \\
\hline Total & 21,02 & 100 & 29,2 & & 5887,3 & 12469,5 \\
& & & & & & \\
\hline
\end{tabular}

Fonte: Elaborado pelos autores (2018).

Observou-se maior quantidade de papelão em relação a outros materiais $39,7 \%$, seguindo pela quantidade de metal e de plástico sendo de $29 \%$ e $17 \%$ respectivamente. A maior quantidade de papelão pode estar relacionada também aos comércios do município e grandes geradores, seguido por plásticos que se devem também por parcela da população e os hábitos de consumo.

Destaca-se na Tabela 3 que o preço adotado foi o preço intermediário, descartando o pior e o melhor preço oferecido pelas três empresas consultadas. Assim, o maior lucro estimado foi para o alumínio, seguido pelo metal e papelão respectivamente. Há de ressaltar que os lucros estimados variam em função do preço do tipo de material, assim o maior preço pago ainda é para o cobre, mas com quantidade de resíduos relativamente baixa.

\section{Estruturas e ferramentas necessárias}

Após as pesquisas de campo, referente a tudo que é necessário para operação do centro de coleta seletiva e do Mercado Municipal cotou-se os custos dos equipamentos necessários para o funcionamento do galpão, apresentado na tabela 4.

Tabela 4 - Custo de implantação dos equipamentos necessários ao funcionamento do galpão.

\begin{tabular}{cccc}
\hline Item & Ferramentas & Quantidade & Valor (R\$) \\
\hline 1 & Prensa enfardadeira & 1 & 25000,00 \\
2 & Paleteira & 1 & 2000,00 \\
3 & Girafa & 1 & 2500,00 \\
4 & Balança & 1 & 3000,00 \\
5 & Rolos de corda & 1 & 100,00 \\
6 & Mesa & 1 & 100,00 \\
7 & Calculadora & 2 & 20,00 \\
8 & Computador & 1 & 500,00 \\
9 & Facas & 5 & 50,00 \\
10 & Bags & 150 & 1000,00 \\
11 & Bebedouro & 1 & 250,00 \\
12 & Cadeira & 2 & 50,00
\end{tabular}




\begin{tabular}{cccc}
13 & Blocos de anotação & 5 & 300,00 \\
14 & Banner & 1 & 200,00 \\
15 & Balcão atendimento & 2 & 3000,00 \\
16 & Prateleiras & 8 & 4000,00 \\
\hline \multicolumn{4}{c}{ Total } \\
\hline
\end{tabular}

Fonte: Elaborado pelos autores (2018).

Para o funcionamento do sistema de Centro de Coleta Seletiva Municipal, é necessário um galpão que seja fechado e coberto, que atenda especificações ambientais e sanitárias. $O$ galpão deve ser destinado a receber os materiais pré-selecionados pela população do município, fazer a seleção secundária dos mesmos, e de acordo com cada material, processá-los e armazená-los para futura destinação final.

Os equipamentos e mobiliários dentro dele, para que possa operar, devem ser: balança, prensa enfardadeira, paleteira, girafa, rolos de cordas recicláveis, mesa, calculadora, computador, facas, bags, blocos de anotação, cadeiras, banner como tabela de preços, e para os funcionários do local, no mínimo, banheiro e bebedouro, caso os mesmos na hora da refeição, forem para casa, além é claro de acesso à água e à energia elétrica.

A proposição do Mercado Municipal, necessita de uma estrutura de um estabelecimento comercial, com água e energia elétrica e equipamentos e mobiliários como: balcão, balanças, prateleiras e bancadas. O qual deverá funcionar em recebimento e computação dos vales em troca de produtos alimentícios, atendimento, reposição de estoque e limpeza. E, ainda, o fornecimento de produtos alimentícios de qualidade em atendimento à população, pela colaboração no funcionamento do sistema de coleta seletiva do município.

Os produtos alimentícios a serem comercializados são os produtos que não são perecíveis, de fácil armazenamento, podendo ser mantido em temperatura ambiente, e, ainda os alimentos perecíveis que deverão ser refrigerados; utensílios domésticos básicos, produtos de limpeza e higiene pessoal.

Os preços tendem a serem praticados abaixo de outros pontos comerciais do município, considerando o principal objetivo do estabelecimento, que é o de incentivo e promoção à coleta seletiva e à ação social. Porém, esses preços seriam condicionados à troca por quantidades estipuladas de cada tipo de material reciclável. Assim, fazem-se necessários subsídios municipais, que podem ser através do ICMS Ecológico, porém cabe ressaltar que para a execução é imperativo a criação de legislações municipais.

O sistema pode funcionar todo por conta da prefeitura, ou seja, todos os funcionários necessários no processo serão de responsabilidade da prefeitura municipal de Monsenhor Paulo-MG, como pode ser também criado pela prefeitura uma cooperativa de catadores, ou ainda ONG's, porém, 
ANÁLISE TÉCNICA E ECONÔMICA

PARA IMPLANTAÇÃO DE UM

CENTRO DE COLETA SELETIVA EM

MONSENHOR PAULO - MG
Leonardo Martins da Silva Arantes

Thales Fernandes Leal

Rosângela Francisca de Paula Vitor Marques

Alisson Souza de Oliveira

nesses dois últimos casos é um processo um pouco mais lento e complicado, no qual o projeto passa a depender de duas frentes de trabalho. Portanto, optou-se somente por funcionários da prefeitura, sendo necessários dois operadores no Centro de Coleta Seletiva, um funcionário para o Mercado Municipal, sendo um, responsável também pelo gerenciamento de todo processo, fazendo a contabilização, tanto do Centro de Coleta como do mercado, avaliando e procedendo com a destinação dos materiais e compras de produtos para o mercado, sendo apresentado na Tabela 5, o custo fixo mensal para o funcionamento do galpão.

Tabela 5 - Custo fixo mensal para implantação do centro de triagem em Monsenhor Paulo.

\begin{tabular}{rccc}
\hline & Item & Quantidade & Valor (R\$) \\
\hline 1 & Funcionários & 3 & $9.570,00$ \\
2 & Água & - & 30,00 \\
3 & Luz & - & 800,00 \\
4 & Bags & 50 & 250,00 \\
5 & 2 & 40,00 \\
\hline & Blocos anotação & & $10.690,00$ \\
\hline
\end{tabular}

Fonte: Elaborado pelos autores (2018).

Outro valor importante a ser levado em consideração, é em relação a economia com o caminhão de coleta de resíduos sólidos urbanos.

Estimou-se de maneira superficial, com base em informações do motorista do veículo coletor, o deslocamento de cerca de $25 \mathrm{~km}$ a cada viagem, sendo realizadas 35 viagens por mês com o veículo coletor. Se 32 \% de material reciclável for retirado de sua carga, pode-se reduzir no mínimo metade do percentual em relação às viagens.

A tabela 6 apresenta a redução de custos em relação a combustíveis. Cada viagem são $25 \mathrm{~km}$, considerando a média do veículo em $2 \mathrm{~km}$ por litro, sendo gastos 13 litros por viagem. O litro do óleo diesel em Monsenhor Paulo está em $\mathrm{R} \$ 3,78$ com estimativa de gasto por viagem de $\mathrm{R} \$ 49,04$ e, ainda desconsiderando o desgaste do veículo e tempo do motorista e os dois coletores.

Tabela 6 - Redução de custos em relação a combustíveis no período avaliado.

\begin{tabular}{cccc}
\hline Custo por viagem R\$ & $\begin{array}{c}\text { Custo mensal de } 35 \\
\text { viagens }\end{array}$ & Redução em percentual (\%) & Valor (R\$) \\
\hline 49,04 & 1719,90 & 16 & 317,52 \\
\hline
\end{tabular}

Fonte: Elaborado pelos autores (2018). 
ANÁLISE TÉCNICA E ECONÔMICA

PARA IMPLANTAÇÃO DE UM

CENTRO DE COLETA SELETIVA EM

MONSENHOR PAULO - MG
Leonardo Martins da Silva Arantes

Thales Fernandes Leal

Rosângela Francisca de Paula Vitor Marques Alisson Souza de Oliveira

\section{Fluxo de caixa}

O Fluxo de caixa estimado para o funcionamento do processo de coleta seletiva em Monsenhor Paulo, foi feito de forma geral, pois ainda existem fatores que podem influenciar, são muitas variáveis e condicionantes que podem interferir diretamente nesse levantamento, porém, acredita-se ser uma base muito útil na hora de avaliar em relação à implantação do projeto (Tabela 7).

Tabela 7 - Fluxo de caixa.

\begin{tabular}{|c|c|c|c|}
\hline \multicolumn{2}{|c|}{ Investimento } & \multicolumn{2}{|c|}{$\mathrm{R} \$ 42070,00$} \\
\hline \multicolumn{2}{|c|}{ Custo Mensal(R\$) } & \multicolumn{2}{|c|}{ Lucro mensal(R\$) } \\
\hline Operação & Compra & Venda & Economia \\
\hline 5905,60 & 5887,30 & 12469,50 & 317,52 \\
\hline \multicolumn{2}{|c|}{ Total } & \multicolumn{2}{|c|}{ Total } \\
\hline \multicolumn{2}{|c|}{11792,90} & \multicolumn{2}{|c|}{12786,50} \\
\hline \multicolumn{2}{|c|}{ Lucro -liquido } & \multicolumn{2}{|c|}{993,60} \\
\hline
\end{tabular}

Fonte: Elaborado pelos autores (2018).

Ressalta-se que o lucro líquido é de apenas R $\$ 993,60$. Entretanto, conforme mencionado, a partir das estipulações de quantidade de cada material reciclado. Assim, apesar de preços abaixo do valor de mercado, o lucro do Mercado Municipal é ainda estimado em média de aproximadamente $20 \%$ sobre o preço pago nos produtos adquiridos para o mercado, a partir de subsídios municipais. Assim, a porcentagem abaixo da média de outros comércios se dá pela proposta de atrativo ao programa de coleta seletiva no município de Monsenhor Paulo - MG, além de reduzir custos ambientais e com a saúde pública, quando a operação é ambientalmente adequada. Em estudo realizado por Rodrigues e Santana (2012), avaliando a viabilidade econômica da implantação da coleta seletiva em comparação com a coleta convencional em Palmas-TO concluiu também que a variação econômica do bem-estar do cidadão não pode ser compensada com a implantação da coleta seletiva. Porém, os mesmos autores destacaram a importância da implantação da coleta seletiva, uma vez que os inúmeros benefícios que a coleta seletiva traz para as gerações atuais e futuras extrapolam a avaliação econômica dos indivíduos sobre seu bem-estar presente.

Cabe ressaltar também que deve ser realizado campanhas educacionais e informativos para que o projeto possa ser validado, haja vista que a participação da sociedade é imprescindível para o sucesso da coleta seletiva. Segundo Bringhenti e Günther (2011), a efetividade de programas e iniciativas de coleta seletiva é imperativa sobre o envolvimento dos cidadãos, considerados, no extremo da cadeia de produção e consumo, os geradores dos resíduos sólidos. E, para que o programa de coleta seletiva seja de sucesso, deve-se haver informações e divulgações dos programas/iniciativas implantados, sendo que a comunidade deve estar sensibilizada e motivada com incorporação no 
cotidiano. Assim, acredita-se que com o projeto e incentivo a troca por alimentos com menor preço associado às divulgações possa vir a ser um "case" de sucesso, com vistas a assegurar sua operacionalização, viabilidade e continuidade para garantir a sustentabilidade do programa.

\section{Caracterização do galpão}

O galpão a ser instalado possui área de 219 metros quadrados. O mesmo será implantado na rua Santos Baldim, número 12, centro de Monsenhor Paulo, conforme planta baixa apresentada na Figura 2.

Figura 2 - Fluxograma de funcionamento para o município de Monsenhor Paulo.

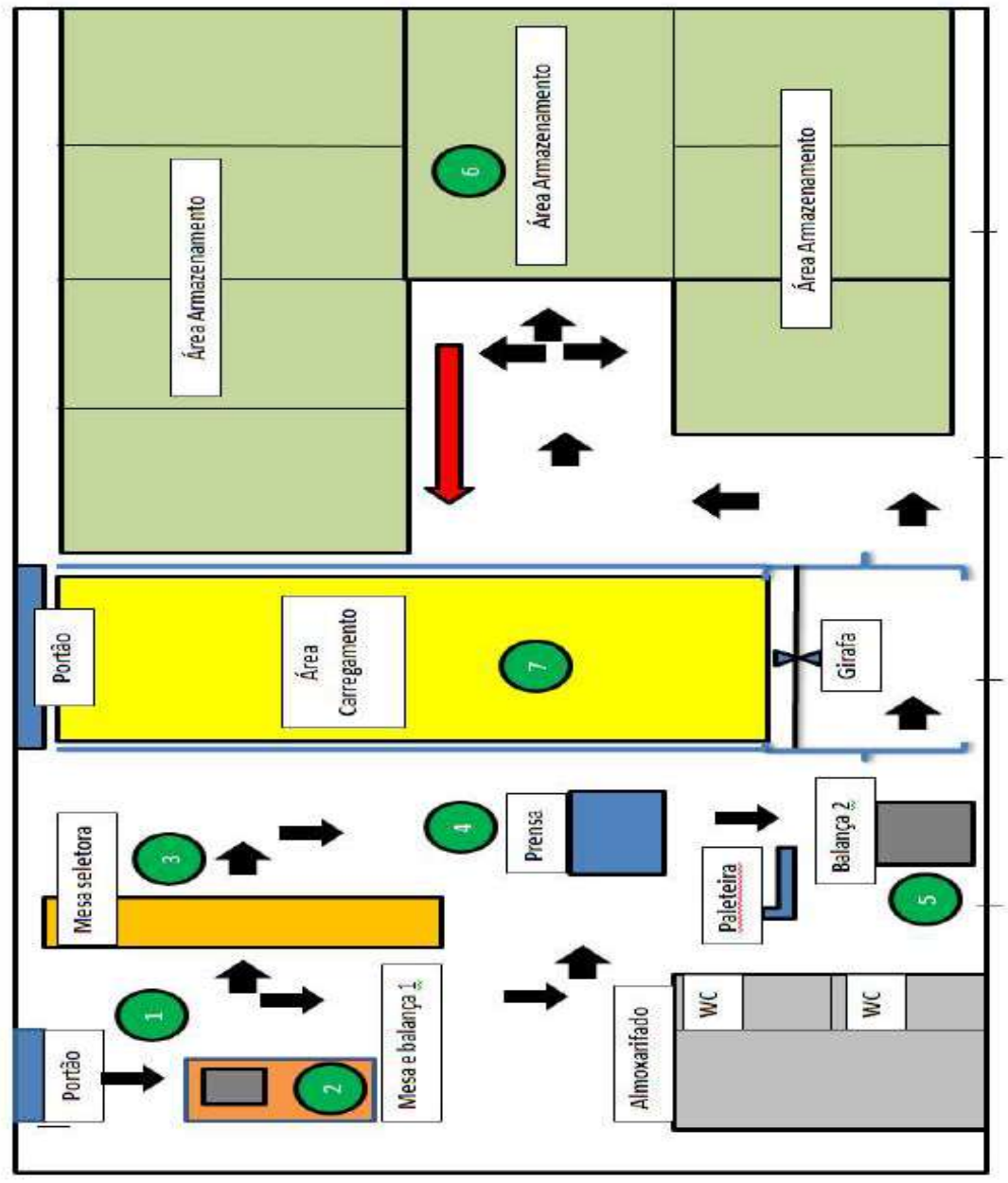

Fonte: Elaborado pelos autores (2018).

O local foi escolhido por já ser uma área disponível no município para a implantação de estruturas que tragam benefício à população paulense, além de ser um ponto favorável, por estar localizado no centro, área próxima toda plana, de fácil acesso aos moradores, próxima a outras 
ANÁLISE TÉCNICA E ECONÔMICA

PARA IMPLANTAÇÃO DE UM

CENTRO DE COLETA SELETIVA EM

MONSENHOR PAULO - MG
Leonardo Martins da Silva Arantes

Thales Fernandes Leal

Rosângela Francisca de Paula Vitor Marques

Alisson Souza de Oliveira

benfeitorias municipais em local adequado de acordo com a lei de parcelamento do solo e o zoneamento.

O layout foi feito através do levantamento de espaço disponível do terreno a ser utilizado, assim como do estudo de necessidades de materiais e ferramentas necessárias para o funcionamento do galpão. Depois foram realizadas as medidas de cada item necessário no seu lugar, de acordo com a logística de funcionamento a ser implantada, pensando em cada etapa de funcionamento dentro do Centro de Coleta Seletiva, pensando no fluxo dos materiais desde o recebimento, pesagem, separação, prensagem, enfardamento, armazenamento e destino final.

As figuras 3 e 4 apresentam a área em que o galpão deverá ser instalado.

Figura 3 - Área do centro de Coleta Seletiva Municipal.

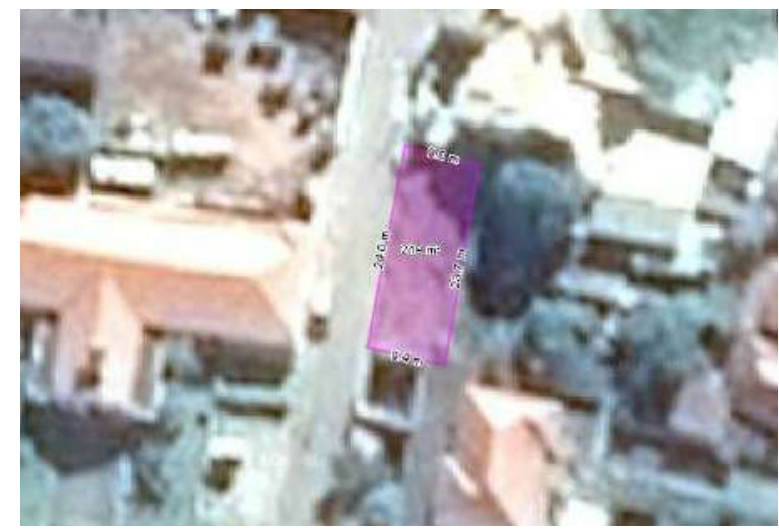

Fonte: Prefeitura de Monsenhor Paulo (2018).

Figura 4 - Ponto de instalação do centro da Coleta Seletiva Municipal.



Fonte: Prefeitura de Monsenhor Paulo (2018).

O fluxograma de funcionamento do Centro de Coleta Seletiva (Figura 5) proposto será da seguinte maneira, o material é separado pelo cidadão em sua residência, depois levado ao Centro de Coleta Seletiva. Assim, o material é recebido, pesado, segregado, prensado, armazenado, depois é 
ANÁLISE TÉCNICA E ECONÔMICA

PARA IMPLANTAÇÃO DE UM

CENTRO DE COLETA SELETIVA EM

MONSENHOR PAULO - MG
Leonardo Martins da Silva Arantes

Thales Fernandes Leal

Rosângela Francisca de Paula Vitor Marques

Alisson Souza de Oliveira

carregado no veículo, pesado novamente e parte para o destino final. O cidadão que recebeu o ticket alimento, vai ao mercado, troca o ticket que recebeu, pelo alimento ou utensílio desejado.

Figura 5 - Fluxograma do centro de triagem.

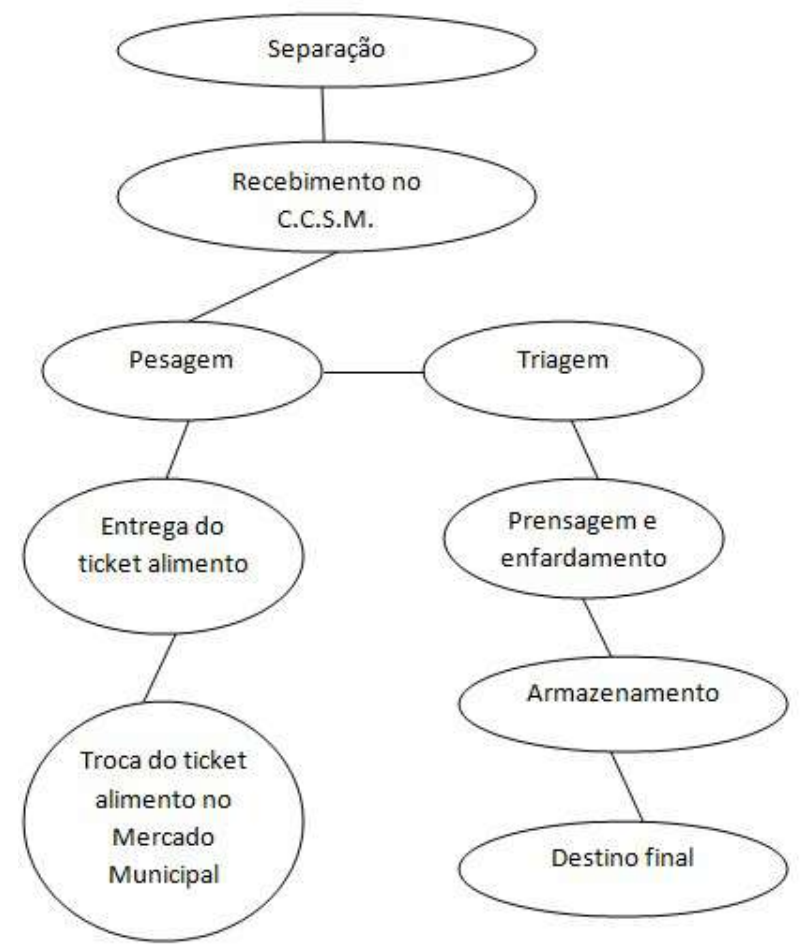

\section{C.C.S. M - Centro de Coleta Seletiva Municipal}

Fonte: Elaborado pelos autores (2018).

\section{CONSIDERAÇÕES FINAIS}

Quando se fala em projetos que possam trazer benefícios ambientais e sociais, deve-se considerar os fatores positivos, como a redução de descarte e aproveitamento de resíduos que seriam descartados como rejeitos, transformando-os em materiais recicláveis, geração de emprego e renda, ou seja, é um projeto que visa à sustentabilidade ambiental.

Porém, como na maioria dos projetos ambientais, existe um custo para implantação e manutenção do mesmo. Na estimativa do fluxo de caixa, o custo operacional está abaixo do lucro, ou seja, teoricamente o projeto se manteria, porém foi projetado um valor em cima de $100 \%$ da coleta de materiais recicláveis dentro do município, o que seria algo muito distante de acontecer em curto prazo, levando em consideração a cultura tanto local como do País, sendo portanto, a falta de hábito de separar o seu resíduo domiciliar, o que possivelmente perpassa por hábitos culturais ou a falta de percepção quanto à educação ambiental. 
ANÁLISE TÉCNICA E ECONÔMICA

PARA IMPLANTAÇÃO DE UM

CENTRO DE COLETA SELETIVA EM

MONSENHOR PAULO - MG
Leonardo Martins da Silva Arantes

Thales Fernandes Leal

Rosângela Francisca de Paula Vitor Marques

Alisson Souza de Oliveira

Diante dos valores apresentados, e de todas as variáveis que existem nesta linha de trabalho, observou-se que um projeto deste porte, poderá somente acontecer com o apoio e vontade das políticas públicas, investimentos ou por meio de organizações não governamentais - ONG 's sem visar lucros financeiros. O grande benefício está na questão ambiental, social e de saúde pública.

Algo a ser avaliado, futuramente, em relação à implantação do projeto no município, onde se acredita que daria um peso maior ao mesmo, seria a estimativa de gasto a destinar ou construir um aterro sanitário, visto que na atualidade faz-se o descarte/disposição final em aterro controlado, o que já não é mais permitido por Lei 12305/2010 (BRASIL, 2010).

Sendo assim, conclui-se que ambientalmente o projeto é extremamente viável, pois deixaria de ser descartado no solo do aterro controlado cerca de 32 toneladas mês de resíduos sólidos urbanos, com a ressalva de que a manutenção do aterro, necessitaria de verbas advindas do poder público para o seu pleno funcionamento, pois somente a arrecadação do Centro de Coleta Seletiva e do Mercado Municipal não seriam suficientes.

Em relação à questão social, o benefício à população é avaliado de forma positiva, principalmente às famílias de menor renda, que encontrariam uma alternativa na busca por alimentos e utensílios, e ainda, pode-se sanar problemas de saúde pública, quando esses resíduos são dispostos de maneira ambientalmente adequada.

\section{REFERÊNCIAS}

ABRELPE. Panorama dos resíduos sólidos no Brasil 2015. São Paulo: ABRELPE, 2016.

ABRELPE. Panorama dos resíduos sólidos no Brasil 2017. São Paulo: ABRELPE, 2017.

ANJOS, J. S. et al. Mobilização e implantação da coleta seletiva no município de Guanhães. Revista Gestão \& Sustentabilidade Ambiental, [S. I.], v. 8, n. 1, p. 600-628, 2019.

ALVARENGA, J. C. F. Gerenciamento de resíduos sólidos urbanos: uma análise da distribuição espacial dos pontos de entrega voluntária de material reciclável em Viçosa/MG. Revista Políticas Públicas \& Cidades, [S. I.], v. 2, n. 1, p. 45-66, 2015.

BERTICELLI, R. et al. Contribuição da coleta seletiva para o desenvolvimento sustentável municipal. Revista em Agronegócios e Meio Ambiente, Maringá, PR, v. 13 , n. 2, p. 781-796, 2020.

BIDONE, F. R. A.; POVINELLI, J. Conceito básico de resíduos sólidos. São Carlos: EESC: USP, 1999.

BRINGHENTI, Jacqueline R .; GÜNTHER, Wanda M. Risso. Participação social em programas de coleta seletiva de resíduos sólidos urbanos. Engenharia Sanitaria e Ambiental, Rio de Janeiro, v. 16, n. 4, p. 421-430, 2011. Disponível em http://www.scielo.br/scielo.php?script=sci_arttext\&pid=S141341522011000400014\&Ing=en\&nrm=iso. Acesso em: 26 jan. 2021. 
BRASIL. Lei no 12.305, de 2 de agosto de 2010. Institui a Política Nacional de Resíduos Sólidos; altera a Lei no 9.605, de 12 de fevereiro de 1998; e dá outras providências. Brasília, DF: Presidência da República, 2010.

CÂMARA MUNICIPAL DE MONSENHOR PAULO. História de Monsenhor Paulo. MONSENHOR PAULO CÂMARA MUNICIPAL, $\quad[S . \quad$ l.], $2021 . \quad$ Disponível em: http://camaramonsenhorpaulo.mg.gov.br/historia/. Acesso em: 26 jan. 2021.

MINAS GERAIS (Estado). Conselho Estadual de Política Ambiental. Deliberação Normativa COPAM no 214, de 26 de abril de 2017. Estabelece as diretrizes para a elaboração e a execução dos Programas de Educação Ambiental no âmbito dos processos de licenciamento ambiental no Estado de Minas Gerais. Diário do Executivo de Minas Gerais, Belo Horizonte, p. 10, 29 abr. 2017.

CONKE, L. S.; NASCIMENTO, E. P. A coleta seletiva nas pesquisas brasileiras: uma avaliação metodológica. Revista Brasileira de Gestão Urbana, [S. I.], v. 10, n. 1, p. 199-212, 2018.

GOUVEIA, N.; PRADO, R. R. Riscos à saúde em áreas próximas a aterros de resíduos sólidos urbanos. Revista Saúde Pública, [S. I.], v. 44, n. 5, p. 859-866, 2010.

IBGE. Brasil / Minas Gerais / Nova Resende. IBGE, [S. I.], 2020. Disponível em: https://cidades.ibge.gov.br/brasil/mg/nova-resende/panorama. Acesso em: 26 jan. 2021.

IPEA. Diagnóstico dos resíduos sólidos urbanos: relatório de pesquisa. Brasília, DF: IPEA, 2012. Disponível em: https://www.ipea.gov.br/portal/images/stories/PDFs/relatoriopesquisa/121009_relatorio_residuos_ solidos_urbanos.pdf. Acesso em: 26 jan. 2021.

LANZA, V. C. V. Caderno técnico de reabilitação de áreas degradadas por resíduos sólidos urbanos. Belo Horizonte: Fundação Estadual de Meio Ambiente, 2009.

PINHEL, J. R.; ZANIN, M.; MÔNACO, G. Catador de resíduos recicláveis: um perfil profissional em construção. In: ZANIN, M.; GUTIERREZ, R. F. Cooperativas de catadores: reflexões sobre práticas. São Carlos: Claraluz, 2011. p. 169-210.

PREFEITURA DE MONSENHOR PAULO. Prefeitura de Monsenhor Paulo. [Monsenhor Paulo]: Google Earth, 2018. 1 imagem de satélite, color, 3D. Lat. 21ㄴ5'23"S, 4532'18"W. Disponível em: https://earth.google.com/web/search/centro+de+coleta+seletiva,+Monsenhor+Paulo,+MG/@-

$21.75613432,-$

45.53942403,898.78886509a,135.57885082d,35y,13.10406202h,2.53321917t,359.99999914r/data= CigiJgokCWSCFOxdvDXAETfUUubrwTXAGUu9DrswwkbAISBRDR9|xkbA. Acesso em: 18 nov. 2018.

RODRIGUES, Waldecy; SANTANA, Willian Cardoso. Análise econômica de sistemas de gestão de resíduos sólidos urbanos: o caso da coleta de lixo seletiva em Palmas, TO. Revista Brasileira de Gestão Urbana, Curitiba, v. 4, n. 2, p. 299-312, 2012. Disponível em: http://www.scielo.br/scielo.php?script=sci_arttext\&pid=S2175$33692012000200011 \&$ Ing=en\&nrm=iso. Acesso em: 26 jan. 2021.

SANJAD, H. C.; ARAÚJO JUNIOR, A. J. S.; COSTA, C. E. A. S. Reciclagem como alternativa para reduzir despesas gerenciais no setor de resíduos. Revista Observatorio de la Economía Latinoamericana, [S. l.], p. 1-15, 2019. Disponível em: https://www.eumed.net/rev/oel/2019/12/reciclagem-reduzirresiduos.html. Acesso em: 26 jan. 2021. 


\title{
POLÍTICA DE PROIBIÇÃO DA DIPIRONA: UMA REFLEXÃO
}

\author{
Flávia de Paula Gonçalves Guimarães \\ Graduanda em Farmácia pela Universidade Federal de Juiz de Fora (UFJF), \\ Juiz de Fora, MG, Brasil. \\ flavinhaguimaraes74@gmail.com \\ Ernane Cláudio Souza-Júnior \\ Doutor em Química de Produtos Medicinais e Naturais, \\ University of lowa, USA. \\ ernane_souza@pba.edu \\ Carlos Alberto Mourão Júnior \\ Pós-Doutorado no Instituto de Matemática Pura e Aplicada (IMPA), \\ Pós-Graduado em Filosofia pela UFJF. \\ camouraojr@gmail.com \\ Jorge Willian Leandro Nascimento \\ Doutor em Fármacos e Medicamentos pela Universidade de São Paulo (USP), \\ São Paulo, SP, Brasil \\ jorge.willian@ufjf.edu.br
}

\begin{abstract}
RESUMO
A dipirona é um dos analgésicos/antipiréticos mais utilizados no Brasil. Entretanto, devido às suspeitas de causar agranulocitose, esse medicamento foi retirado do mercado de mais de 30 países, incluindo: Estados Unidos, Japão, Austrália, e grande parte da União Europeia. Nosso objetivo foi questionar a proibição do medicamento. Dessa forma, foi realizada uma revisão comentada da literatura acerca das possíveis reações adversas e toxicidade associadas ao uso da dipirona bem como a polêmica questão relacionada à sua proibição. Apesar de a dipirona estar historicamente associada à ocorrência de agranulocitose, diversos estudos mostraram que quando comparada com outros analgésicos/antipiréticos disponíveis no mercado, esse fármaco apresenta melhor relação risco-benefício, além de possuir toxicidade em níveis aceitáveis. Em contrapartida, sua ampla disponibilidade, boa margem de segurança e baixo custo constituem-se importantes justificativas para seu uso e comercialização como medicamento isento de prescrição. Este ensaio discute ainda aspectos éticos, sociológicos e políticos que perpassam a proibição da dipirona.
\end{abstract}

Palavras-chave: Dipirona. Metamizol. Agranulocitose. Toxicidade. Farmacovigilância. 


\title{
USE OF MEDICINAL PLANTS IN THE CITIES OF CRUZÍLIA, SÃO GONÇALO DO SAPUCAÍ AND VARGINHA MG
}

\begin{abstract}
Dipyrone is one of the most widely used analgesics / antipyretics in Brazil. However, due to the suspicion of causing agranulocytosis, this drug has been withdrawn in more than 30 countries, including: United States, Japan, Australia, and much of the European Union. The goal of this essay was bringing up some issues related to dipyrone's forbiddance. Thus, a commented literature review was carried out about the possible adverse reactions and toxicity associated with the use of dipyrone as well as the controversial issue related to its prohibition. Although dipyrone has historically been associated with the occurrence of agranulocytosis, several studies have shown that when compared to other analgesics / antipyretics available, this drug has a better risk-benefit ratio, in addition to having toxicity at acceptable levels. On the other hand, its widespread, good margin of safety and low cost are important justifications for its use and commercialization as a non-prescription medicine. This essay also discusses ethical, sociological and political aspects that go beyond the prohibition of dipyrone.
\end{abstract}

Keywords: Dipyrone. Metamizole. Agranulocytosis. Toxicity. Pharmacovigilance. 


\section{PROBLEMA}

A dipirona está no mercado mundial há mais de 90 anos, sendo comercializada em mais de 100 países, entre eles a Alemanha, Espanha, Rússia, Índia, Israel, Argentina e México (Arellano e Sacristan, 1990; Maluf, Hamerschlak et al., 2009). No Brasil, encontra-se entre os medicamentos isentos de prescrição mais utilizados pela população, sendo comprovadamente eficaz no que diz respeito a suas ações analgésicas e antipiréticas.

A dipirona (ácido 1-fenil-2,3-dimetil-5-pirazolona-4-metilaminometanossulfônico; Novalgina ${ }^{\circledR}$; Metamizol), é um dos analgésicos/antipiréticos mais utilizados no Brasil, sendo indicada para tratamento de cefaléias, neuralgias, dores reumáticas, pós-operatórias e de outras origens, além do tratamento da febre (ARELLANO e SACRISTAN, 1990).

O ponto controverso em sua utilização seria o possível efeito depressor sobre a medula óssea, o que poderia levar a uma anemia aplásica ou, principalmente, à agranulocitose. Esta reação adversa seria o motivo para que os órgãos de saúde de dezenas de países, incluindo os Estados Unidos, Japão e boa parte da Europa retirassem este fármaco do mercado e proibissem sua comercialização. Entretanto, em países como Espanha, Polônia, Rússia, Índia e, praticamente, em toda a América Latina sua venda é liberada, sendo inclusive comercializada no Brasil nas diversas apresentações farmacêuticas como medicamento isento de prescrição (MIP) (HALFELD, 1990).

Entretanto, poucos estudos clínicos controlados foram realizados de forma a, efetivamente, justificar a proibição da dipirona pelos órgãos regulatórios destes países e, os que existem, mostram-se inconclusivos. As diferenças genéticas entre as populações, variações metodológicas entre os estudos, diferentes formas de condução da farmacovigilância em cada país ou o uso concomitante de outros fármacos podem ter contribuído para a inconsistência das informações a respeito das discrasias sanguíneas promovidas pela dipirona, tornando ainda mais polêmica sua proibição (MALUF, HAMERSCHLAK et al., 2009).

Desta forma, devido à obscuridade de seu mecanismo de ação e demais características farmacológicas e terapêuticas e às controvérsias internacionais quanto ao risco da utilização da dipirona, estudos relacionados ao tema podem auxiliar na definição do custo-benefício do uso terapêutico deste medicamento. 


\section{REAÇÕES ADVERSAS}

A taxa de internação hospitalar devido a reações adversas ocasionadas pela dipirona varia entre $2,5 \%$ a $38 \%$, sendo que a prevalência de internação corresponde ao uso em crianças, idosos ou em pessoas com antecedentes de alcoolismo ou doenças pépticas (HUIC, MUCOLIC et al., 1994).

Diversos estudos mostraram que a dipirona, quando comparada com outros analgésicos/antipiréticos comercializados no mercado, apresenta uma boa relação riscobenefício, além de possuir uma toxicidade em níveis aceitáveis, o que permite a esse medicamento ser comercializado no Brasil na forma isenta de prescrição. Os efeitos adversos, compreendem-se por reações anafiláticas, alterações hematológicas, dermatológicas, no trato gastrointestinal, no sistema nervoso central, no sistema cardiovascular e no sistema renal, segundo consta a própria bula do medicamento. Esta a qual pesa o fato de que todas as bulas de medicamento contém uma miríade de potenciais efeitos adversos, até para que os laboratórios e as indústrias farmacêuticas se preservem judicialmente (CAETANO, 2005).

\section{A DIPIRONA NO MUNDO}

A dipirona foi sintetizada pela primeira vez na Alemanha em 1920 pela Indústria Farmacêutica Hoechst AG (BROGDEN, 1986), tendo sido introduzida no Brasil em 1922 sob o nome de Novalgina ${ }^{(R)}$. Sua comercialização no âmbito mundial foi crescente até a década de 1970, quando estudos que relataram casos de agranulocitose, possivelmente associados ao uso deste fármaco, foram utilizados como fundamento para a sua proibição em diversos países do Hemisfério Norte (HAMERSCHLAK, MALUF et al., 2005).

Um desses estudos, realizado em 1964, apontou a incidência de apenas um caso de agranulocitose para cada 127 indivíduos expostos à aminopirina, cuja molécula apresenta estrutura semelhante à da dipirona (veja a Figura 1). Tendo como base essa semelhança química, os autores do trabalho não fizeram distinção entre as duas moléculas e assumiram que os dados obtidos para a aminopirina seriam também aplicáveis à dipirona (Huguley Junior e Atlanta, 1964). Considerando os resultados divulgados neste estudo, os EUA promulgaram a retirada da dipirona do mercado em 1977 (HALFELD, 1990).

Figura 1: Representação das estruturas químicas da aminopirina e da dipirona. 
<smiles>Cc1c(N(C)C)c(=O)n(-c2ccccc2)n1C</smiles>

Aminopirina<smiles></smiles>

Dipirona

Fonte: Desenhada pelos autores.

Entretanto, apenas em 1980 começou a ser empreendido o primeiro grande estudo populacional, controlado, para se avaliar a prevalência de agranulocitose associada à molécula de dipirona propriamente dita (LAKS, BOLSI et al., 1999). Esse importante trabalho ficou conhecido como Estudo Boston e foi conduzido em Israel e em 7 países Europeus (Alemanha, Itália, Hungria, Espanha, Israel, Bulgária e Suécia) entre 1980 e 1984, tendo envolvido mais de 40 pesquisadores, 300 hospitais e 22,2 milhões de pessoas. Os resultados desse estudo apontaram uma incidência de agranulocitose de 1,1 casos por milhão de pessoas que estiveram expostas ao uso da dipirona durante o período de 7 dias antes do início da doença. Ainda em Israel, entre 1960 e 1972, foram avaliados 390.000 pacientes hospitalizados e verificou-se que a incidência de agranulocitose possivelmente relacionada à dipirona foi de $1: 130.000$, ou seja, $0,0007 \%$, com probabilidade de morte inferior a $0,0002 \%$. Outros estudos associando dipirona e agranulocitose também foram realizados em diversos outros países. $\mathrm{Na}$ Índia, um estudo retrospectivo envolvendo 431.896 pacientes hospitalizados entre 1969 e 1978 revelou 3 casos de agranulocitose possivelmente associados ao uso de dipirona, o que corresponde a uma taxa de 0,007\% (HALFELD, 1990).

Na Suécia, a dipirona foi retirada do mercado em 1999 após um período curto de licenciamento. Um estudo internacional patrocinado pela indústria farmacêutica Hoechst, em 1986, relatou um baixo risco de agranulocitose para o uso da dipirona, de aproximadamente um único caso por milhão de usuários. Entretanto, alguns estudos contradisseram estes dados. Entre 1969 e 1974 (ano em que o fármaco foi retirado do mercado sueco) 50 pacientes com graves efeitos adversos na contagem de leucócitos foram registrados na Suécia. Entre 1973 e 1975, foram avaliados, em Estocolmo, 45 pacientes diagnosticados com agranulocitose medicamentosa, dos quais um estava possivelmente relacionado ao uso de dipirona 
POLÍTICA DE PROIBIÇÃO

DA DIPIRONA: UMA REFLEXÃO
Flávia de Paula Gonçalves Guimarães Ernane Cláudio Souza-Júnior

Carlos Alberto Mourão Júnior

Jorge Willian Leandro Nascimento

(ARNEBORN e PALMBLAD, 1979). De 1995 (primeiro ano em que foi re-licenciado) a 1999, 14 casos de agranulocitose foram documentados, calculando-se uma frequência de 1 para cada 1439 pacientes que utilizaram este medicamento (HEDENMALM e SPIGSET, 2002).

Na Polônia, país com um consumo de cerca de 75 milhões de comprimidos de dipirona por ano, foi empreendido um estudo no qual observou-se a prevalência de 0,16 casos por milhão de usuários deste fármaco. Esses valores são semelhantes àqueles observados em outros estudos internacionais, mas muito menores do que aqueles encontrados na Suécia (SOLLERO, 1976; MAJ e CENTKOWSK, 2004; BASAK, DROZD-SOKOLOWSKA et al., 2010).

No Brasil, foi realizado um estudo retrospectivo que abrangeu o período de 1954 a 1974, tendo sido avaliados 531.261 pacientes, dos quais 15 tinham sido diagnosticados com agranulocitose. Dentre esses, 8 casos estavam relacionados ao uso prévio de derivados pirazolônicos e apenas 1 associado diretamente ao uso da dipirona (Sollero, 1976).

Em 2001 foi realizado o "Painel sobre eficácia e segurança da dipirona" promovido pela Agência Nacional de Vigilância Sanitária do Brasil em que estiveram presentes autoridades e pesquisadores de reconhecimento internacional para discutir a respeito da segurança e eficácia da dipirona e sobre uma possível mudança em seu status regulatório. Tendo como base trabalhos presentes na literatura e evidências epidemiológicas existentes até o momento, houve consenso entre as autoridades e pesquisadores presentes de que a retirada da dipirona do mercado brasileiro ou mesmo uma alteração do seu status regulatório para "medicamento com venda sob prescrição médica" não atenderia aos interesses da população naquele momento, uma vez que a dipirona apresentava menor toxicidade do que outros fármacos da mesma classe e excelente relação custo-benefício (Agência Nacional De Vigilância Sanitária)

Neste Painel foi concluído ainda que seria recomendado aguardar a finalização do estudo envolvendo grandes amostras populacionais de países latinos como: Brasil, Argentina e México.

Um famoso estudo (HAMERSCHLAK, MALUF et al., 2008), publicado em 2008, ficou conhecido como Latin Study e consistiu em estudo de caso-controle, prospectivo, realizado entre janeiro de 2002 a dezembro de 2005, envolvendo 7 centros de diferentes regiões do Brasil (Campinas, Curitiba, Goiânia, Juiz de Fora, Manaus, Ribeirão Preto e São Paulo), 2 centros na Argentina (ambos em Buenos Aires) e um centro no México (Monterrey). O estudo 
POLÍTICA DE PROIBIÇÃO

DA DIPIRONA: UMA REFLEXÃO
Flávia de Paula Gonçalves Guimarães Ernane Cláudio Souza-Júnior

Carlos Alberto Mourão Júnior Jorge Willian Leandro Nascimento

teve como amostra populacional 548 milhões de pessoas, havendo registrado apenas 52 casos de agranulocitose (0,38 casos por milhão de habitantes/ano).

Apenas no Brasil, a incidência foi de 0,35 casos por milhão de habitantes-ano; na Argentina, de 2,09 casos por milhão de habitantes-ano; e na região investigada no México nenhum caso de agranulocitose foi identificado. Além disso, o estudo reportou que a agranulocitose é significativamente maior entre mulheres (75\%), sendo que crianças (abaixo de 10 anos) e idosos (acima de 60 anos) encontram-se significativamente mais susceptíveis a apresentar essa doença. O estudo concluiu que, embora a média de fatalidade para agranulocitose seja alta (11,5\%), sua incidência é relativamente baixa, não constituindo-se num problema eminente de saúde pública nas regiões investigadas (HAMERSCHLAK, MALUF et al., 2008).

\section{DISCUSSÃO}

A possibilidade da dipirona induzir discrasias sanguíneas, sobretudo a agranulocitose, tem sido objeto de discussão ao longo de muitos anos, exigindo a necessidade de se encontrar um parecer definitivo, fundamentando-se em evidências científicas comprovadas, sobre sua potencial toxicidade e segurança, já que este tema é de grande interesse da população. Entretanto, muitos dos estudos presentes na literatura a respeito deste tema tão polêmico apresentam resultados controversos e metodologias enviesadas, não podendo ser considerados como conclusivos.

Um desses estudos, por exemplo (Huguley Junior e Atlanta, 1964), publicado na década de 60, apresentou graves erros metodológicos e gerou muita polêmica, pois aplicava à dipirona os resultados de estudos realizados com a aminopirina. Mesmo sem realizar qualquer estudo com a dipirona propriamente dita, os autores concluíram que este fármaco em questão teria os mesmos efeitos que a aminopirina como potencial causador de agranulocitose (Huguley Junior e Atlanta, 1964). No entanto, apesar das semelhanças estruturais, esses medicamentos são quimicamente distintos devendo-se, portanto, ser realizados estudos específicos para avaliar os efeitos toxicológicos de cada um separadamente (Halfeld, 1990). Adicionalmente, o número amostral e as análises estatísticas empregadas neste estudo são consideradas inadequadas para os padrões exigidos atualmente. 
POLÍTICA DE PROIBIÇÃO

DA DIPIRONA: UMA REFLEXÃO
Flávia de Paula Gonçalves Guimarães Ernane Cláudio Souza-Júnior

Carlos Alberto Mourão Júnior

Jorge Willian Leandro Nascimento

Entretanto, naquele momento, este estudo foi um dos principais responsáveis pela retirada da dipirona do mercado dos Estados Unidos, o que fez com que outros países fossem influenciados, uma vez que a agência regulatória americana, o Food and Drug Administration (FDA), é um órgão respeitado mundialmente. Por outro lado, na década de 1980, com o objetivo de recuperar o mercado internacional da dipirona, a indústria farmacêutica Hoescht empreendeu o estudo Boston, envolvendo grandes amostras populacionais. Este trabalho apresentou um delineamento metodológico muito mais aprimorado do que os anteriores a fim de esclarecer as especulações que existiam até o momento sem embasamento científico adequado. Dessa forma, o laboratório investiu massivamente para a realização deste estudo e concluiu que a incidência de agranulocitose na população era baixa e não necessariamente coincidia com um maior consumo da dipirona. No entanto, este laboratório era o principal interessado em comprovar que um dos seus principais produtos, a dipirona, não estava envolvido de maneira significativa como causador de agranulocitose, havendo um evidente conflito de interesse. Adicionalmente, apesar da grande amostra populacional, de cerca de 22,2 milhões de pessoas, esse estudo é alvo de críticas por incluir poluentes e fatores ambientais como denominadores comuns para o cálculo da proporção de risco de agranulocitose ao invés de discriminar os fatores induzidos apenas por fármacos em uma categoria à parte, levando a uma redução no risco total estimado (HALFELD, 1990; OLIVEIRA, 2001; HAMERSCHLAK, MALUF et al., 2005)

Vários outros estudos realizados posteriormente em diversas regiões do mundo - entre eles o Latin Study - também apontaram uma baixa incidência de agranulocitose potencialmente causada pela dipirona. Embora os autores desses estudos reportassem significância estatística próxima de zero para este fator, a dipirona era curiosamente apontada como o fármaco mais comumente associado às causas dessa discrasia sanguínea (SOLLERO, 1976; HAMERSCHLAK, MALUF et al., 2008). A incidência exata de agranulocitose, no entanto, é difícil de ser quantificada, já que normalmente apenas os casos graves o suficiente para requerer atenção médica são reportados. É importante ressaltar ainda que os critérios de classificação de leucopenia/agranulocitose eram bastante imprecisos à época em que muitos dos estudos referidos foram realizados. Adicionalmente, a ineficiência dos sistemas de farmacovigilância e o uso concomitante de outros medicamentos certamente contribuiram para uma maior divergência dos riscos estimados. Dessa forma, quando comparados os 
resultados obtidos em tais estudos, pode-se observar uma variação significativa da incidência de agranulocitose entre as diversas regiões avaliadas (HUGULEY JUNIOR E ATLANTA, 1964; HUIC, MUCOLIC et al., 1994; HEDENMALM e SPIGSET, 2002).

Uma hipótese para a discrepância da incidência de agranulocitose entre essas regiões baseia-se nos polimorfismos genéticos existentes entre as populações. As variações étnicas, como diferenças nas características enzimáticas, implicariam em diferentes velocidade de acetilação hepática e estariam envolvidas numa disparidade de metabolização do fármaco, culminando numa maior ou menor taxa de toxicidade. Dessa forma, indivíduos acetiladores lentos teriam maior predisposição a apresentar efeitos toxicológicos do fármaco, ao passo que acetiladores rápidos apresentariam menor decorrência dos seus efeitos secundários, uma vez que estes últimos expressam capacidade de eliminação do fármaco consideravelmente superior aos primeiros (BENSEÑOR, 2001; HAMERSCHLAK, MALUF et al., 2005).

Outra hipótese para as divergências leva em consideração uma análise mais crítica sobre a metodologia empregada nos estudos e os conflitos de interesse existentes na época em que os mesmos foram realizados. Dois interessantes estudos (CHTLEY, 1993; BENSEÑOR, 2001) relataram uma grande disputa mercadológica entre o paracetamol, de patente americana, e a dipirona, de patente alemã, porquanto ambos os medicamentos estavam envolvidos numa disputa direta pelo mercado mundial de analgésicos e antipiréticos naquele momento.

Além disso, quando comparados países onde o consumo de dipirona é permitido e países onde o seu uso é proibido, não foi observada nenhuma diferença significativa das taxas de mortalidade relacionadas à agranulocitose (OLIVEIRA, 2001). Em outro estudo, quando a dipirona foi comparada com outros fármacos analgésicos/antipiréticos, como a aspirina, paracetamol ou diclofenaco, concluiu-se que o risco estimado de mortalidade causada por agranulocitose, anemia aplástica, anafilaxia e complicações no trato gastrointestinal superior foram de: 1,85 casos por milhão para a aspirina; 5,92 por milhão para o diclofenaco; 0,20 por milhão para o paracetamol e 0,25 por milhão para a dipirona. Dessa forma, segundo este estudo, a avaliação global do risco de ocorrência de efeitos adversos e de letalidade foi menor com a dipirona, quando comparada aos três outros fármacos (BENSEÑOR, 2001; MALUF, HAMERSCHLAK et al., 2009). 
POLÍTICA DE PROIBIÇÃO

DA DIPIRONA: UMA REFLEXÃO
Flávia de Paula Gonçalves Guimarães Ernane Cláudio Souza-Júnior

Carlos Alberto Mourão Júnior Jorge Willian Leandro Nascimento

Outro fator confundidor para o risco do uso da dipirona seria os principais sintomas característicos de um estado agranulocítico: dor de garganta, febre, calafrios e cefaléias. Tais sintomas são comuns em muitas outras doenças e, para o tratamento dos mesmos, são normalmente indicados medicamentos analgésicos/antipiréticos como a dipirona. Por isso, é possível que haja casos nos quais a agranulocitose não tenha sido causada diretamente pelo consumo de dipirona, e sim a dipirona tenha sido usada para tratar os sintomas iniciais de agranulocitose (Huguley Junior e Atlanta, 1964; Laks, Bolsi et al., 1999; HEDENMALM e SPIGSET, 2002).

De forma geral, em números absolutos, a incidência global de discrasias sanguíneas, como agranulocitose e anemia aplástica, encontram-se em níveis extremamente baixos na população e podem ser causadas não apenas pela dipirona, mas por muitos outros medicamentos, assim como por agentes químicos e pesticidas e, dos pacientes acometidos com esses quadros patológicos, cerca de $90 \%$ recuperam-se completamente com medidas terapêuticas apropriadas (OLIVEIRA, 2001; HAMERSCHLAK, MALUF et al., 2008; MALUF, HAMERSCHLAK et al., 2009).

Não obstante, devido ao seu consolidado uso clínico por quase um século, existem fortes evidências de que a dipirona apresenta uma excelente relação risco-benefício, além de possuir toxicidade em níveis aceitáveis, o que permite a ampla comercialização desse medicamento no Brasil, inclusive como medicamento isento de prescrição (Agência Nacional De Vigilância Sanitária; BENSEÑOR, 2001; CAETANO, 2005). Seu uso foi ainda estabelecido pelo Ministério da Saúde como um medicamento alternativo para o tratamento dos sintomas da dengue, apesar da notável escassez de estudos que avaliem sua interferência sobre a agregação plaquetária, o que aumentaria o risco do desenvolvimento de hemorragias nestes pacientes (QUIJANO, CENTENO et al., 2005).

Embora a eficácia da dipirona como analgésico e antipirético seja inquestionável, ainda existe a necessidade de mais estudos epidemiológicos prospectivos com diferentes aplicações clínicas para que se possa ter um posicionamento definitivo sobre a controversa e polêmica questão de sua segurança. Além disso, torna-se imperativa a necessidade de orientar a população e, em especial aos profissionais de saúde, quanto à prescrição e ao uso racional deste medicamento, realizando uma farmacovigilância eficiente, a fim de promover o devido acompanhamento dos pacientes, fornecendo-Ihes informações com linguagem adequada e 
POLÍTICA DE PROIBIÇÃO

DA DIPIRONA: UMA REFLEXÃO
Flávia de Paula Gonçalves Guimarães Ernane Cláudio Souza-Júnior

Carlos Alberto Mourão Júnior Jorge Willian Leandro Nascimento

reportando sempre que necessário os riscos e efeitos adversos relacionados ao uso deste fármaco.

\section{CONSIDERAÇÕES FINAIS}

Embora a dipirona esteja historicamente associada à ocorrência de agranulocitose, existe ainda grande controvérsia sobre as estimativas precisas desta reação na população. Essa incerteza e especificidades de cenários nacionais de exposição podem levar a ponderações sobre risco-benefício diversas e por conseguinte a decisões regulatórias diferentes entre países. Dessa forma, embora a reação seja reconhecida como rara, existe forte necessidade de serem realizados mais estudos que considerem os vários fatores envolvidos no perfil toxicológico da dipirona, inclusive abrangendo áreas recentes do conhecimento como a farmacogenética.

Há consenso de que a dipirona constitui-se, atualmente, num importante fármaco do arsenal terapêutico, o qual vem demonstrando eficácia tanto por seus efeitos antipiréticos como no tratamento de dores agudas, leves e moderadas. Além disso, quando comparada a outros fármacos analgésicos/antipiréticos, os riscos associados à dipirona são similares, ou até mesmo menores que seus pares. Consequentemente, seu baixo custo, adequada disponibilidade e boa margem de segurança continuam sendo importantes justificativas para sua utilização clínica e uma mudança da regulamentação atual que determinasse a retirada da dipirona do mercado poderia favorecer o aumento do consumo de outros fármacos de toxicidade ainda maior, agravando os riscos da ocorrência de efeitos adversos.

Finalizamos esse ensaio, deixando algumas reflexões para que o leitor busque suas próprias conclusões: (i) A quem poderia interessar a proibição de um medicamento supostamente eficaz e de baixo custo? (ii) Por que medicamentos eficazes, já usados há longa data, quando têm despencados seus custos por perderem as suas patentes, muitas vezes são retirados do mercado de maneira açodada, abrupta e injustificada? (iii) Até que ponto é ético, em uma sociedade cada vez mais desigual como a nossa, incentivar, ou até mesmo permitir, o investimento em medicamentos de alto custo, em detrimento de simplesmente manter outros que, muitas vezes, são tão ou mais eficazes e de custo baixo? (iv) Com que interesse a indústria e a própria mídia desestimulam o uso de medicamentos seguros e antigos (porém 
POLÍTICA DE PROIBIÇÃO

DA DIPIRONA: UMA REFLEXÃO
Flávia de Paula Gonçalves Guimarães Ernane Cláudio Souza-Júnior

Carlos Alberto Mourão Júnior

Jorge Willian Leandro Nascimento

de baixo custo), exacerbando a ocorrência dos efeitos colaterais descritos em suas bulas, o que na verdade, todos os medicamentos apresentam? (v) Quando a decisão da proibição de um medicamento ocorre em apenas alguns países, ela é uma decisão galgada unicamente em critérios técnicos e científicos? Ou pode haver a interferência de outros fatores numa decisão como essa, tendo em vista que, se essa substância fosse realmente nociva, ela não teria ficado tanto tempo no mercado e não permaneceria liberada em tantos outros países.

Por fim, a análise dessas questões transdisciplinares, que perpassam a área biomédica e assumem matizes sociológicos, econômicos e antropológicos, nos leva a acreditar que há muitas outras variáveis em jogo, quando órgãos públicos decidem por liberar ou proibir medicamentos.

\section{REFERÊNCIAS}

AGÊNCIA NACIONAL DE VIGILÂNCIA SANITÁRIA. Painel internacional de avaliação da segurança da dipirona [relatório]. Brasília, 2001. Disponível em: http://www.pharmanet.com.br/pdf/relatoriodipirona2.pdf. Acessado em 21/09/2020.

ARELLANO, F.; SACRISTAN, J. A. Metamizole: reassessment of its therapeutic role. Eur J Clin Pharmacol v. 38, p. 617-619, 1990.

ARNEBORN, P.; PALMBLAD, J. Drug-induced neutropenia in the Stockholm region 1973-1975: frequency and causes. Acta Med Scand n. 204, p. 83-86, 1979.

BASAK, G. W.; DROZD-SOKOLOWSKA, J.; WIKTOR-JEDRZEJCZAK, W. Update on the Incidence of Metamizole Sodium-Induced Blood Dyscrasias in Poland. J Intern Med Research v. 38, p. 1374-1380, 2010.

BENSEÑOR, M. I. To use or not to use dipyrone. Or maybe, Central Station versus ER? That is the question. São Paulo Med J v. 119, n. 6, p. 2001, 2001.

BROGDEN, R. N. Pyrazolone derivatives. Drugs, v. 32, n. 4, p. 60-70, 1986.

CAETANO, N. Guia de Remédios. 7ạ Edição. ed. São Paulo: Escala, 2005.

CHTLEY, A. Dypirone: a drug no one needs. Buelefeld: BUKO Pharma-Campaign, 1993.

HALFELD, G. Uma análise crítica sobre benefícios e riscos da dipirona. Bol Acad Bras Med v. 150, p. 23-45, 1990. 
HAMERSCHLAK, N.; MALUF, E.; BIASI CAVALCANTI, A.; AVEZUM JÚNIOR, A.; ELUF-NETO, J.; PASSETO FALCÃO, R. Incidence and risk factors for agranulocytosis in Latin American countries - the Latin Study: A multicenter study. Eur J Clin Pharmacol v. 64 n. 9, p. 921-929, 2008.

HAMERSCHLAK, N.; MALUF, E.; PASQUINI, R.; ELUF-NETO, J.; MOREIRA, F. R.; CAVALCANTI, A. B. Incidence of aplastic anemia and agranulocytosis in Latin America: the LATIN study. São Paulo Medical Journal v. 123, p. 101-104, 2005.

HEDENMALM, K.; SPIGSET, O. Agranulocytosis and other blood dyscrasias associated with metamizol. Eur J Clin Pharmacol v. 58, p. 265-274, 2002.

HUGULEY JUNIOR, C. M.; ATLANTA, M. D. Agranulocytosis induced by dipyrone, a hazardous antipyretic and analgesic. Jama v. 189, p. 162-165, 1964.

HUIC, M.; MUCOLIC, V.; VRHOVAC, B.; FRANCETIC, I.; BAKRAN, I.; GILJANOVICS, S. Adverse drug reactions resulting in hospital admission. Int J Clin Pharmacol Ther v. 32, n. 12, p. 675682, 1994.

LAKS, D.; BOLSI, D. C.; LONGHI, F. Dipirona e agranulocitose. Rev Med PUCRS v. 9, p. 105-108, 1999.

MAJ, S.; CENTKOWSK, P. A prospective study of the incidence of agranulocytosis and aplastic anemia associated with the oral use of metamizole sodium in Poland. . Med Sci Monit v. 10, p. 93-95, 2004.

MALUF, E.; HAMERSCHLAK, N.; CAVALCANTI, A. B.; JÚNIOR, A. A.; ELUF-NETO, J.; FALCÃO, R. $P$. Incidence and risk factors of aplastic anemia in Latin American countries: the LATIN casecontrol study. Haematologica v. 94, n. 9, p. 1220-1226, 2009.

OLIVEIRA, G. G. Painel Internacional de avaliação da segurança da Dipirona [International Panel for the Evaluation of the Safety of Dipyrone]. Brasília, 2001. (Diário Oficial da União de 16/08/2001, Seção 1, página 201).

QUIJANO, F. A. D.; CENTENO, L. A. V.; VEJA, R. A. M. Efecto de la administración temprana de dipirona sobre la gravedad del dengue en una cohorte prospectiva. Enferm Infecc Microbiol Clin v. 23, n. 10 p. 593-597, 2005.

SOLLERO, L. Incidence of agranulocytosis and the use of dipyrone in Brazil. Results of an inquiry carried out by F. A. P. B., reviewing the incidence of this blood dyscrasia and its medico-social relevance in Brazil. Rev Pesquisas Med Biol v. 9, p. 79-86, 1976. 


\title{
POSSÍVEIS EVIDÊNCIAS DA VITAMINA B12 NA DOR NEUROPÁTICA Seria um fator de proteção em Doenças Neurológicas?
}

\author{
Adalgiza Mafra Moreno \\ Doutorado em Ciências Cardiovasculares pela Universidade Federal Fluminense, Brasil \\ Coordenadora de Pesquisa da Universidade Iguaçu (UNIG), Brasil \\ adalgizamoreno1@gmail.com \\ Marco Orsini \\ Departamento de Neurologia, Universidade Iguaçu (UNIG), Brasil. \\ bentoorsini2013@gmail.com \\ Jacqueline Stephanie Fernandes do Nascimento \\ Graduanda de Medicina na Universidade Iguaçu (UNIG), Brasil. \\ jac.fn@hotmail.com \\ Nicolle dos Santos Moraes Nunes \\ Graduanda de Medicina na Universidade Iguaçu (UNIG), Brasil. \\ nicollemnunes18@gmail.com
}

\begin{abstract}
RESUMO
Introdução: A prevalência de pacientes acometidos por dor neuropática na população em geral pode chegar a 10\%. Quando comparado com demais síndromes de dor crônica, os pacientes com dor neuropática descrevem pior estado de saúde mental e física, tornando-se desafiador seu controle. Dado o visível quantitativo de doenças associadas à dor neuropática e as respostas restritas aos manejos atuais, revela-se a busca por novas terapêuticas a serem utilizadas como monoterapia ou em combinação com os tratamentos vigentes. Uma dessas terapêuticas baseia-se na suplementação com vitamina B12, ainda que não seja evidenciado sinais sugestivos de deficiência. Metodologia: Trata-se de estudo exploratório descritivo que emprega o método de revisão integrativa, categoria que consiste em explorar o conhecimento já definido, incluindo pesquisas com diferentes técnicas. Realizou-se em abril de 2020 o levantamento de artigos indexados nas bases de dados eletrônicas PubMed, MedLine, LILACS e BIREM. Resultados e Discussão: Há vários anos, a vitamina B12 tem sido empregada sob forma de monoterapia ou combinadas a demais fármacos para o tratamento de dor em diversas condições clínicas, como dor inflamatória, neuropática, doenças neurodegenerativas, radiculopatia, e etc. demonstrando evidências positivas. Conclusão: Dada as evidências, a vitamina B12 apresenta-se como um candidato potencial para o tratamento da neuropatia periférica com boa segurança e baixa incidência de efeitos colaterais, destacando-se pelos efeitos analgésicos em diferentes síndromes dolorosas e neuropáticas, como adjuvantes ou em monoterapia.
\end{abstract}

Palavras-chave: Vitamina B12. Dor. Metilcobalamina. Neuropatia Periférica. 


\title{
POSSIBLE EVIDENCE OF VITAMIN B12 IN NEUROPATHIC PAIN Would it be a protective factor in Neurological Diseases?
}

\begin{abstract}
Introduction: The prevalence of patients with neuropathic pain in the general population can reach $10 \%$. When compared with other chronic pain syndromes, patients with neuropathic pain describe a worse state of mental and physical health, making their control challenging. Given the quantitative visible of diseases associated with neuropathic pain and the responses restricted to current management, the search for new therapies to be used as monotherapy or in combination with current treatments is revealed. One of these therapies is based on vitamin B12 supplementation, although no signs suggestive of deficiency are evident. Methodology: This is a descriptive exploratory study that uses the method of integrative review, a category that consists of exploring the knowledge already defined, including research with different techniques. In April 2020, a survey of articles indexed in the electronic databases PubMed, MedLine, LILACS and BIREM was carried out. Results and Discussion: For several years, vitamin B12 has been used in the form of monotherapy or combined with other drugs for the treatment of pain in various clinical conditions, such as inflammatory, neuropathic pain, neurodegenerative diseases, radiculopathy, etc. demonstrating positive evidence. Conclusion: Given the evidence, vitamin B12 presents itself as a potential candidate for the treatment of peripheral neuropathy with good safety and low incidence of side effects, standing out for the analgesic effects in different painful and neuropathic syndromes, as adjuvants or as monotherapy .
\end{abstract}

Keywords: B12 vitamin. Pain. Methylcobalamin. Peripheral neuropathy. 


\section{INTRODUÇÃO}

A Associação Internacional para Estudo da Dor (IASP) descreve a dor neuropática como sendo uma condição ocasionada por uma injúria ou doença do sistema nervoso somatossensorial. Tal caracterização se aplica a um vasto espectro heterogêneo de síndromes de dor que se manifestam com uma alta gama de sinais e sintomas, além de diversos mecanismos fisiopatológicos subjacentes ${ }^{1,2}$.

A dor neuropática possui origem central ou periférica. Patologias periféricas como consumo crônico de álcool, diabetes mellitus, lesões nervosas traumáticas, toxicidade de drogas e câncer, assim como condições centrais, como o acidente vascular encefálico, lesões medulares e esclerose múltipla fazem parte da etiologia da dor neuropática ${ }^{2,3}$. Vale ressaltar que nem todas as síndromes de dor possuem apenas uma origem somatossensorial fisiopatológica, por exemplo, a radiculopatia cervical caracteriza-se como uma síndrome de dor mista, na qual uma lesão nervosa causa uma síndrome de dor neuropática comum ${ }^{4}$.

A experiência sensitiva ocasionada pela dor neuropática é ampla. Muitas sensações são relatadas pelos pacientes, como dor espontânea, contínua, evocada e paroxística. Dentro do espectro da dor evocada temos a alodínia, que consiste na percepção dolorosa precipitada por estímulos não nocivos, além da hiperalgesia, que consiste em uma resposta exagerada a um estímulo nocivo. Os pacientes também relatam sensações como parestesia, que incluem percepções de pontadas, queimação, formigamento e choque elétrico. Tais sensações levam a importantes morbidades e efeitos deletérios na qualidade de vida ${ }^{5,6}$.

A prevalência de pacientes acometidos por dor neuropática na população em geral pode chegar a $10 \%^{7}$. Quando comparado com demais síndromes de dor crônica, os pacientes com dor neuropática descrevem pior estado de saúde mental e física, tornando-se desafiador seu controle. Utiliza-se de monoterapia farmacológica e tratamentos combinados para alivio da dor. Entretanto, tais esquemas terapêuticos estão relacionados a efeitos colaterais potencialmente graves, que podem não ser suportados pelos pacientes ${ }^{6}$.

Dado o visível quantitativo de doenças associadas à dor neuropática e as respostas restritas aos manejos atuais, revela-se a busca por novas terapêuticas a serem utilizadas como monoterapia ou em combinação com os tratamentos vigentes ${ }^{8}$. 
Uma dessas terapêuticas baseia-se na suplementação com vitamina B12, ainda que não seja evidenciado sinais sugestivos de deficiência. A B12, também nomeada como cobalamina, é uma vitamina com propriedades importantes para diversas funções biológicas. É uma substância neurotrófica com predileção para tecidos neuronais, sendo também reconhecida pela sua ação no que diz respeito a manutenção e regeneração dos nervos periféricos ${ }^{8}$.

Dentro de suas muitas funções, a B12 promove o processo de mielinização, levando à restauração funcional e regeneração de nervos através da regulação positiva da transcrição do gene. Além disso, a B12 inibe descargas ectópicas espontâneas dos neurônios sensoriais primários periféricos em estados de dor neuropática, o qual poderia explicar porque auxilia na atenuação de sintomas dolorosos ${ }^{9}$.

Com isso, o objetivo do presente estudo visa avaliar as principais evidências disponíveis na literatura vigente que destacam a vitamina B12 como alternativa à monoterapia ou terapia combinada para o tratamento da dor neuropática.

\section{METODOLOGIA}

Trata-se de estudo exploratório descritivo que emprega o método de revisão integrativa, categoria que consiste em explorar o conhecimento já definido, incluindo pesquisas com diferentes técnicas. Realizou-se em abril de 2021 o levantamento de artigos indexados nas bases de dados eletrônicas PubMed, MedLine, LILACS e BIREME.

Os termos de busca utilizados, segundo os Descritores em Ciências da Saúde (DeCS), foram, respectivamente em português, inglês e espanhol: "Vitamina B 12", "Vitamin B 12", "Vitamina B 12", "Traumatismos dos Nervos Periféricos", "Peripheral Nerve Injuries", "Traumatismos de los Nervios Periféricos". Para se incluir o maior número de artigos possível que abordassem o foco temático, a busca foi realizada selecionando os termos relevantes. Em todas as associações foi empregado o conectivo "and". Dessa maneira, utilizou-se as seguintes chaves de busca: "Vitamina B 12" and "Traumatismo dos Nervos Periféricos".

Priorizou-se por aplicar como filtro de pesquisa "textos completos", pois os autores entendem que é de suma importância o reconhecimento das obras disponíveis gratuitamente 
e, sobretudo, por considerarem que esses materiais são essenciais para promoverem acesso igualitário à informação.

Como critério de inclusão evidenciou-se a disponibilidade do artigo original completo indexado em português, inglês ou espanhol. Não contemplou os critérios de inclusão, aqueles que não tinham relação direta com o tema e outros tipos de produção, como dissertações, editoriais de revistas, teses, apresentação de pôsteres, anais de congresso.

Após levantamento preliminar, 24 artigos foram encontrados. Selecionados os estudos únicos, títulos e resumos foram analisados, selecionando aqueles que condiziam com o tema de interesse. Quando apenas a leitura dos títulos e resumo não foram suficientes para compreender o estudo, optou-se pela leitura integral do artigo.

Posteriormente a seleção cautelosa, foi iniciado a leitura na íntegra dos 24 artigos da amostra e organizado os resultados. Utilizou-se método de análise de conteúdo. Neste enfoque qualitativo, os materiais foram examinados e sistematizados, reconhecendo temas comuns, conformidades ou discrepâncias e tendências gerais.

\section{RESULTADOS E DISCUSSÃO}

A vitamina B12, também denominada de metilcobalamina, compõe uma família de compostos intitulados de maneira geral de cobalaminas. Configura-se como uma vitamina hidrossolúvel, sintetizada tão somente por microrganismos, encontrada em quase todos os tecidos animais e estocada primordialmente no fígado na forma de adenosilcobalamina ${ }^{10}$. Alimentos de origem animal, como ovos, leite e carne são fontes naturais de vitamina B12 na dieta humana. Além disso, existem diversas evidências dos efeitos antihiperalgésicos das vitaminas do complexo $B$, em especial a vitamina B12, em diferentes formas de dor neuropática, motivo pelo qual justifica o objetivo do presente trabalho ${ }^{11}$.

As vitaminas do complexo B são essenciais para a síntese de ácido nucleico e proteínas, bem como para a síntese da fosfatidilcolina. A fosfatidilcolina configura-se como um fosfolipídio da membrana celular, que se transforma em colina e posteriormente é empregada na síntese de acetilcolina, um importante neurotransmissor ${ }^{12}$.

Os prováveis mecanismos analgésicos e anti-neurálgicos das vitaminas B, principalmente a vitamina B12, apresentados em estudos experimentais incluem: 
estabilização da excitabilidade elétrica dos nervos impedindo descargas ectópicas; interação com os mediadores responsáveis pela dor, com posterior aumento da disponibilidade e eficácia da noradrenalina e da 5-hidroxitriptamina na via descendente inibitória da dor; reestruturação de fibras dos nervos deteriorados com recuperação das funções neuromusculares na hiperalgesia periférica e alodínia; ganhos significativos no transporte axonal, maximizando a velocidade de condução nervosa ${ }^{13}$.

Há vários anos, a vitamina B12 tem sido empregada sob a forma de monoterapia ou combinadas a demais fármacos para o tratamento de dor em diversas condições clínicas, como dor inflamatória e neuropática, demonstrando evidências positivas ${ }^{14}$.

A neuralgia pós-herpética e suas várias formas possui base na literatura vigente e diversos estudos apoiam a inclusão da B12 no tratamento convencional. Um estudo realizado por Xu et al. analisou o uso de $1000 \mu \mathrm{g}$ de metilcobalamina, via subcutânea pela manhã, num período de seis vezes por semana, por quatro semanas. O grupo controle recebeu metilcobalamina $500 \mu \mathrm{g}$, por via oral, três vezes ao dia ${ }^{9}$.

Os resultados revelaram que a intensidade da dor foi atenuada no grupo de intervenção, após sete dias, e assim permaneceu decaindo até a finalização do estudo, em 28 dias. Fora observado também, atenuação expressiva da dor no grupo que recebeu B12 oral, no entanto, significativamente menor quando comparado as infiltrações subcutâneas. Ainda no grupo B12 subcutâneo, fora observado redução em outras modalidades de dor, como alodínia e dor paroxística. Secundariamente, esses pacientes tiveram melhora em sua qualidade de vida e impacto positivo em suas atividades cotidianas. Não foram relatados efeitos colaterais advindos de quaisquer grupos ${ }^{9}$.

Em uma coorte analisada por 28 dias, com 80 participantes portadores de neuralgia pós-herpética, divididos de maneira homogênea em quatro grupos fora administrado as seguintes soluções: um grupo recebeu 1000 mg de cobalamina por via subcutânea, outro recebeu 100 mg de tiamina por via subcutânea, outro recebeu infiltrações de lidocaína e o último recebeu uma associação de 100 mg de tiamina e B12 1000 g por via subcutânea. Ao final do estudo, observou-se expressiva redução da dor apenas nos grupos na qual a B12 estava inserida. Em concordância com os demais estudos, não foram relatados efeitos colaterais em quaisquer grupos ${ }^{15}$. 
Um estudo realizado em 98 pacientes portadores de neuralgia herpética oftálmica aguda, avaliou a infiltração local em contraste com a via intramuscular de metilcobalamina e lidocaína. Foram divididos em dois grupos. O grupo intervenção recebeu $1000 \mu \mathrm{g}$ de vitamina B12 associados a 20 mg de lidocaína, via subcutânea, uma vez ao dia. Por outro lado, o grupo controle recebeu 1000 ug de B12 mais 20 mg de lidocaína, por via intramuscular, uma vez ao dia. Ambos os grupos sofreram intervenções seis vezes por semana por um período de duas semanas $^{16}$.

Verificou-se que, apesar do grupo controle vivenciar melhorias significativas na severidade da dor, tal efeito permanecia por pouco tempo, atenuando paulatinamente após 14 dias. Contudo, fora observado que o grupo intervenção apresentou importante atenuação da intensidade da dor, sustentada por até um ano após a intervenção. O referido estudo, revela a superioridade da administração local de tais compostos em comparação com a via intramuscular para neuralgia herpética oftálmica aguda. Além disso, observou-se melhoras na qualidade de vida em ambos os grupos. Nenhum efeito colateral foi referido em todos os $\operatorname{grupos}^{16}$.

Ainda, segundo $\mathrm{Xu}$ et al., um estudo fora realizado em 204 pacientes. No referido estudo, foi avaliado o tratamento da manifestação troncular de neuralgia pós-herpética e não de neuralgia herpética oftálmica aguda. Ambos os grupos foram divididos e mediados de maneira similar. Observou-se que a intensidade da dor no grupo de intervenção fora superior ao grupo controle. Houve melhora na qualidade de vida de ambos os grupos, o que corrobora com os achados realizados no estudo anteriormente mencionado. Ademais, nenhum efeito adverso fora observado.

Levando em consideração esses resultados e os demais registros encontrados na literatura, existem evidências que apoiam a B12 como uma nova terapia na atenuação da dor, seja como terapia combinada ou monoterapia. Tal fato é sólido, e independe do local de manifestação da neuralgia pós-herpética ${ }^{17}$.

Em sua maioria, as bases de pesquisa descrevem a vitamina B12 como monoterapia ou terapia combinada para o tratamento da dor de pacientes com polineuropatia periférica de qualquer causa. Destacando as neuropatias diabéticas, neuropatias induzidas por quimioterapia e neuropatia a álcool ${ }^{16}$. 
Um estudo aberto randomizado, realizado por Mimenza Alvarado e Navarro, analisaram o gerenciamento da dor em uma população de pacientes portadores de neuropatia diabética de baixa e moderada intensidade. No referido estudo, as terapias confrontadas foram um regime de aumento de dosagem de Gabapentina, Tiamina e Cianocobalamina versus Pregabalina isolada administrada por via oral. Ao longo de 12 semanas de monitorização, ambos os grupos demonstraram importante atenuação da dor. Houve melhora significativa na qualidade do sono dos pacientes, com cada grupo referindo aumento no número de horas de sono ${ }^{18}$.

A monoterapia com vitamina B12 também foi avaliada em um estudo realizado por Talaei et al. Dois grupos foram estudados. O primeiro recebeu a dose de $2.000 \mu \mathrm{g}$ de vitamina B12, por via intra muscular, duas vezes por semana. Em contrapartida, $10 \mathrm{mg}$ de nortriptilina, por via oral, fora administrada no segundo grupo. Ao final, foi possível concluir que embora ambos os grupos tenham apresentado melhoras expressivas no que diz respeito a dor, o grupo que utilizou B12 apresentou atenuação significativamente maior em relação ao grupo nortriptilina ${ }^{19}$.

Evidências foram encontradas relatando a melhora dos sintomas dolorosos relacionados a neuropatia diabética urêmica com a inclusão de vitamina B12. No referido estudo de coorte prospectivo foram administrados $500 \mu \mathrm{g}$ de metilcobalamina por via intravenosa, três vezes por semana, por um período de seis meses em pacientes submetidos a hemodiálise regular com polineuropatia decorrente de uremia e diabetes. Observou-se melhoras significativas nos escores da dor neuropática ${ }^{20}$.

Ainda, fora avaliada a eficácia terapêutica da inclusão da vitamina B12 em 30 pacientes com lesões de raízes nervosas causadas por compressão, após excisão de hernia de disco. Todos os pacientes foram submetidos a eletroneuromiografia e avaliações no 10 ㅇ e 60 ㅇ dia após a cirurgia. Os autores do estudo observaram melhora clínica e eletrofisiológica estatisticamente importante com o uso terapêutico da vitamina B12. Ademais, concluíram que tal inclusão se aplica a radiculopatias de diferentes causas com expressivos ganhos na atenuação da dor ${ }^{24}$. 


\section{B12 como fator de proteção ou atenuação de doenças neurológicas?}

Uma coorte realizada com pacientes portadores de doenças neurodegenerativas visou observar se níveis baixos de B12 estariam associadas ao desenvolvimento de comprometimento cognitivo e progressão de tais doenças. O estudo fora realizado por meio de uma análise transversal dos níveis de vitamina B12 apurado no momento do diagnóstico em pacientes com Doença de Parkinson, Doença de Alzheimer, Atrofia Múltipla de Sistemas, Demência Frontotemporal, Demência com Corpos de Lewy, Paralisia Supranuclear Progressiva ou Comprometimento Cognitivo Leve. Apenas pacientes com mais de 3 anos de diagnóstico foram incluídos. Observou-se que os níveis de B12 eram significativamente mais baixos em pacientes com Doença de Parkinson, Doença de Alzheimer e Comprometimento Cognitivo Leve, embora uma certa redução dos níveis de B12 tenha sido observada nas demais condições $^{21}$.

Além das condições aqui já mencionadas, há registros na literatura que apoiam os promissores efeitos neuroprotetores da vitamina B12 em pacientes portadores de Esclerose Lateral Amiotrófica. Tais estudos atentam que a administração de metilcobalamina é responsável pela regeneração nervosa, podendo aumentar os potenciais de ação muscular desses pacientes, além disso, acredita-se que seus efeitos sobrepõem a ação analgésica, pressupõe que tal composto estaria atuando não só na melhora dos sintomas, mas no retardo da progressão da disfunção motora ${ }^{22}$.

Esses resultados apoiam e reafirmam a necessidade de suplementação de B12 nas doenças em questão. Como no estudo de um paciente apresentando história de 2 meses de distúrbios progressivos da marcha e mudanças comportamentais, com comprometimento da sensibilidade vibratória e sinais de lesão piramidal. Ao exame, fora evidenciado níveis baixos de vitamina B12 e a ressonância magnética revelou sinal hiperintenso nos tratos corticoespinais, um padrão similar ao observado na doença do neurônio motor. Foi implementado a terapia de reposição de B12, sendo então observado a melhora motora e cognitiva. Os autores concluíram que a encefalopatia relacionada aos níveis baixos de B12 era responsável por mimetizar aspectos de neuroimagem da doença do neurônio motor ${ }^{23}$. 


\section{CONCLUSÃO}

A vitamina B12 apresenta-se como um candidato potencial para o tratamento da neuropatia periférica com boa segurança e baixa incidência de efeitos colaterais, destacandose pelos efeitos analgésicos em diferentes síndromes dolorosas e neuropáticas, como adjuvantes ou em monoterapia. Embora mais pesquisas sejam necessárias, as evidências vigentes apontam a vitamina B12 como uma alternativa segura e de baixo custo, configurando-se como uma excelente opção para tratamentos álgicos.

\section{REFERÊNCIAS}

The IASP Subcommittee on Taxonomy Pain terms a list with definitions and notes on usage. Recommended by the IASP subcommittee on taxonomy. 1979, 6:249.

Bouhassira D. Neuropathic pain: Definition, assessment and epidemiology. Rev. Neurol. 2018 175:16-25. doi: 10.1016/j.neurol.2018.09.016.

Brozou V., Vadalouca A., Zis P. Pain in platin-induced neuropathies: A systematic review and meta-analysis. Pain Ther. 2018 7:105-119.

Murphy D.R., Hurwitz E.L., Gerrard J.K., Clary R. Pain patterns and descriptions in patients with radicular pain: Does the pain necessarily follow a specific dermatome? Chiropr. Osteopat. 2009 17:9. doi: 10.1186/1746-1340-17-9.

Girach A., Julian T.H., Varrassi G., Paladini A., Vadalouka A., Zis P. Quality of life in painful peripheral neuropathies: A systematic review. Pain Res. Manag. 2019 23:1-9. doi: 10.1155/2019/2091960.

Freynhagen R., Bennett M.I. Diagnosis and management of neuropathic pain. BMJ. 2009 339:b3002. doi: 10.1136/bmj.b3002.

van Hecke O., Austin S.K., Khan R.A., Smith B.H., Torrance N. Neuropathic pain in the general population: A systematic review of epidemiological studies. Pain. 2014 155:654662. doi: 10.1016/j.pain.2013.11.013.

Huang Z.-F., Lin B.-Q., Torsha T.T., Dilshad S., Yang D.-S., Xiao J. Effect of mannitol plus vitamins $B$ in the management of patients with piriformis syndrome. J. Back Musculoskelet. Rehabil. 2019 32:329-337. doi: 10.3233/BMR-170983.

Xu G., Lv Z.-W., Feng Y., Tang W.-Z., Xu G.X. A single-center randomized controlled trial of local methylcobalamin injection for subacute herpetic neuralgia. Pain Med. 2013 14:884894. doi: 10.1111/pme.12081

Henry, J. B. Diagnósticos clínicos e tratamento por métodos laboratoriais. 2. ed. São Paulo: Manole Ltda, 1999. Cap. 26, p. 621-5. 
Fairbanks, v. F.; klee, g. G. Aspectos bioquímicos da hematologia. In: burtis, C. A.; ashwood, E. R. Tietz: fundamentos de química clínica. 4. ed. Rio de Janeiro: Guanabarra Koogan S. A., 1998. Cap. 36, p. 699-703.

Granados-Soto V, Sánchez-Ramírez G, la Torre MR, Caram-Salas NL, Medina-Santillán R, Reyes-García G. Effect of diclofenac on the antiallodynic activity of vitamin B12 in a neuropathic pain model in the rat. Proc West Pharmacol Soc. 2004;47:92-4.

Zhang M, Han W, Hu S, Xu H. Methylcobalamin: a potential vitamin of pain killer. Neural Plast. 2013;2013;424651

Pérez-Flores E, Medina-Santillán R, Reyes-García G, Mateos-García E. Combination of diclofenac plus $B$ vitamins in acute pain after tonsillectomy: a pilot study. Proc West Pharmacol Soc. 2003;46:88-90.

Xu G., Lv Z.W., Xu G., Tang W.Z. Thiamine, cobalamin, locally injected alone or combination for herpetic itching: A single-center randomized Controlled Trial. Clin. J. Pain. 2014 30:269278. doi: 10.1097/AJP.0b013e3182a0e085.

Xǔ G., Xu S., Cheng C., Xú G., Tang W.-Z., Xu J. Local administration of methylcobalamin and lidocaine for acute ophthalmic herpetic neuralgia: A single-center randomized controlled trial. Pain Pract. 2016 16:869-881. doi: 10.1111/papr.12328.

Xǔ G., Xu S., Tang W.-Z., Xú G., Cheng C., Xu J. Local Injection of Methylcobalamin Combined with Lidocaine for Acute Herpetic Neuralgia. Pain Med. 2015 17:572-581. doi: 10.1093/pm/pnv005.

Mimenza Alvarado A., Aguilar Navarro S. Clinical trial assessing the efficacy of gabapentin plus $b$ complex (b1/b12) versus pregabalin for treating painful diabetic neuropathy. J. Diabetes Res. 2016 :4078695. doi: 10.1155/2016/4078695.

Talaei A., Siavash M., Majidi H., Chehrei A. Vitamin B 12 may be more effective than nortriptyline in improving painful diabetic neuropathy. Int. J. Food Sci. Nutr. 2009 60(Suppl. 5):71-76. doi: 10.1080/09637480802406153.

Kuwabara S., Nakazawa R., Azuma N., Suzuki M., Miyajima K., Fukutake T., Hattori T. Intravenous methylcobalamin treatment for uremic and diabetic neuropathy in chronic hemodialysis patients. Intern. Med. 1999 38:472-475. doi: 10.2169/internalmedicine.38.472.

Luthra NS, Marcus AH, Hills NK, Christine CW. Vitamin B12 measurements across neurodegenerative disorders. J Clin Mov Disord. 2020; 7: 3. doi: 10.1186/s40734-02000085-8

Ikeda K, Iwasaki Y, Kaji R. Neuroprotective effect of ultra-high dose methylcobalamin in wobbler mouse model of amyotrophic lateral sclerosis. J Neurol Sci. 2015, 15;354(1-2):704. doi: 10.1016/j.jns.2015.04.052. 
Pinto WBVR, de Souza PVS, Rogério RM, Pedroso JL, Barsottini OGP. Vitamin B12 deficiency mimicking neuroimaging features of motor neuron disease. Arq. Neuro-Psiquiatr. 2014, 72 (1).

E Alfonsi , GF Berzero , C Zandrini , G Felicetti. The role of drug therapy in the treatment of nerve root lesions caused by compression. Clinical and electrophysiological study of 30 patients operated on for the removal of herniated disks. Minerva Med. 1984, 14;75(2829):1727-32. 


\title{
EDUCAÇÃO AMBIENTAL: DIAGNÓSTICO DOS PROJETOS DESENVOLVIDOS NAS ESCOLAS MUNICIPAIS DE CURITIBA, PR
}



\begin{abstract}
RESUMO
A educação ambiental no ensino formal pode contribuir na mudança de valores e postura em relação a natureza, mudanças sociais e aspectos relacionados a vida dos estudantes como um todo. Projetos de educação ambiental estimulam a interdisciplinaridade e auxilia na sensibilização nos temas ambientais. O objetivo desta pesquisa foi avaliar os projetos de educação ambiental nas escolas municipais de Curitiba, PR. Foram entrevistadas 35 escolas, divididas em escolas municipais com educação integral, com as séries iniciais e finais. Foram aplicados questionários com questões de múltipla escolha sobre os projetos de educação ambiental. Constatou-se que os projetos estão associados ao projeto político pedagógico e as disciplinas do currículo, sendo que a formulação é de iniciativa dos professores e o desenvolvimento conta com os diversos atores da escola. O principal tema abordado foi a água. Conclui-se que os projetos estão alinhados com os conteúdos escolares, além da interação com diversos atores, especialmente os estudantes, que melhoram sensivelmente o interesse nas atividades.
\end{abstract}

Palavras-chave: Meio ambiente. Políticas públicas. Água. 


\title{
ENVIRONMENTAL EDUCATION: DIAGNOSIS OF PROJECTS DEVELOPED IN MUNICIPAL SCHOOLS IN CURITIBA, PR
}

\begin{abstract}
Environmental education in formal education can contribute to changing values and attitude towards nature, social changes and aspects related to the lives of students as a whole. Environmental education projects encourage interdisciplinarity and help raise awareness of environmental issues. The objective of this research was to evaluate environmental education projects in municipal schools in Curitiba, PR. 35 schools were interviewed, divided into municipal schools with integral education, with the initial and final grades. Questionnaires with multiple choice questions about environmental education projects were applied. It was found that the projects are associated with the political pedagogical project and the subjects of the curriculum, with the formulation being the initiative of the teachers and the development relying on the various actors of the school. The main topic addressed was water. It is concluded that the projects are aligned with the school contents, in addition to the interaction with several actors, especially the students, that significantly improve the interest in the activities.
\end{abstract}

Keywords: Environment. Public policies. Water.

Recebido em: 23/09/2021. Aceito em: 13/07/2021. 


\section{INTRODUÇÃO}

A educação ambiental surgiu com as preocupações no aumento populacional e a escassez de recursos naturais em meados da década de 1960, e que aos poucos foi se constatando que muitos dos problemas eram devido ao consumo excessivo de uma parcela pequena da população, dada a concentração de riquezas que acarretava no acúmulo e desperdício de vários produtos (REIGOTA, 2017). Posteriormente foi fortalecida com um viés de proteção e conservação ambiental, mas segundo o mesmo autor, a educação ambiental também está atrelada a aspectos políticos, econômicos, sociais e culturais entre os seres humanos e a natureza, afim de ter uma participação livre (na busca de soluções e alternativas para o bem comum), consciente e democrática.

As primeiras políticas públicas para a promoção da educação ambiental (EA) no Brasil iniciaram a partir de 1995, com enfoque no ensino fundamental (LAMOSA, LOUREIRO; 2011). No final dessa década surgiu a Política Nacional de Educação Ambiental (PNEA) na forma de lei, para orientar as ações a nível nacional.

Na PNEA, a educação ambiental é abordada como uma prática educativa integrada, contínua e permanente, não devendo se constituir disciplina específica no currículo de ensino, exceto nos cursos de pós-graduação, extensão e nas áreas voltadas ao aspecto metodológico da educação ambiental (BRASIL, 2012). Assim, no que concerne o ensino formal no currículo escolar da educação básica (ensino infantil, fundamental e médio), educação superior, educação especial, educação profissional e educação de jovens e adultos, tanto para o ensino público quanto para o privado a educação deve ser desenvolvida como prática contínua, permanente, inter e transdisciplinar (BRASIL, 1999; REIS; SEMÊDO; GOMES, 2016).

Nesse contexto, a escola é um ambiente adequado para repassar diversos conhecimentos, que envolvem valores e postura em relação a natureza, mudanças sociais e aspectos relacionados a vida como um todo (SOUZA; BONOTTO, 2019). De forma interdisciplinar e sistêmica, a escola no ensino formal tem um papel fundamental na formação de cidadãos sensibilizados como meio que estão inseridos e capazes de desenvolver atividades que promovam a sensibilização ambiental (SANTOS et al., 2018).

No ensino fundamental foi averiguado a aplicação da educação ambiental nas escolas através do censo escolar realizado em 2001 e 2003, pelo Instituto Nacional de Estudos e Pesquisas Educacionais Anísio Teixeira (INEP). O censo verificou se as escolas aplicavam 
educação ambiental nas modalidades de projetos, inserção no projeto político pedagógico ou disciplina especial e constatou-se um aumento nas atividades de educação ambiental, principalmente na modalidade projetos (LAMOSA; LOUREIRO, 2011).

Os projetos de educação ambiental possuem alternativas de trabalhar a interdisciplinaridade nas escolas, estimulando a criatividade e o raciocínio dos estudantes a partir de atividades teórico-prático de forma participativa e dinâmica (NARCIZO, 2009).

Considerando a importância da educação ambiental nas práticas de ensino formal, o objetivo desse trabalho foi avaliar como os projetos de educação ambiental são desenvolvidos nas escolas de ensino fundamental da rede pública do município de Curitiba, Paraná.

\section{MATERIAL E MÉTODOS}

A pesquisa foi realizada em Curitiba, capital do estado do Paraná que contempla cerca de 9.029 escolas de educação básica, dos quais, 783 escolas estão localizadas em Curitiba, deste total 484 escolas contemplam o ensino fundamental, mas são apenas 185 escolas disponíveis na rede pública de ensino (SARTORI, 2015; INSTITUTO NACIONAL DE ESTUDOS E PESQUISAS EDUCACIONAIS ANÍSIO TEIXEIRA - INEP, 2017).

As escolas municipais de Curitiba abrangem os anos escolares de 10 a 5 을 e de 10 a 9 응 do Ensino Fundamental, os quais algumas escolas disponibilizam o ensino em tempo integral (contraturno), em que é oferecido um adicional de quatro horas diárias de atividades educativas diferenciada (CURITIBA, 2006).

Para averiguar se havia diferenças na aplicação do tema EA entre nos anos iniciais (1은 ao 5ㅇ) e finais (6음 ao 9) e entre os conteúdos do período regular e no contraturno, as escolas foram divididas em 3 estratos: "Escolas Municipais com as séries iniciais denominado de ciclo 1 (EMCiclo1)", "Escolas Municipais com as séries finais denominado de ciclo 2 (EMCiclo2)" e "Escolas Municipais com educação integral (EMIntegral)". Essa divisão foi feita com base na lista de escolas disponíveis nas Unidades Educacionais (CURITIBA, 2017), a qual considerou como "EMIntegral", as escolas com centro de educação infantil (CEI).

Para efetuar a coleta de dados, a seleção do número de escolas foi calculada através do método de amostragem para uma população finita e desvio padrão desconhecido, considerando como população total o número de escolas municipais em Curitiba (LUCHESA; CHAVES NETO, 2011). 
Foi utilizado uma proporção amostral de sucesso e de fracasso de $50 \%$, tendo em vista que é o percentual recomendado quando a população não é homogênea. A variável aleatória normal padrão utilizada foi de $80 \%$ e o erro amostral foi de $10 \%$ resultando em um $\mathrm{n}$ de no mínimo 34 escolas, como uma das escolas amostradas tinha sede em dois locais diferentes, foi coletado informações das duas escolas resultando em um n de 35 escolas amostradas, distribuídas em 15 escolas para o "EMCiclo1", por abranger um maior número de escolas, 10 escolas para o "EMCiclo2" e 10 escolas para o "EMIntegral".

A seleção das escolas foi realizada randomicamente com base na divisão regional de Curitiba, a partir de um sorteio aleatório seguindo o número de escolas amostradas para cada estrato, distribuídas nas dez regionais do município (FIGURA 1). Caso alguma das escolas selecionadas tivesse algum impedimento para realizar a entrevista, houve substituição por outra escola da mesma regional.

Figura 1: Localização das escolas amostradas



Fonte: Elaborado pelas autoras, 2021. 
A coleta de dados foi iniciada após a aprovação do projeto pela Secretaria Municipal da Educação da Prefeitura Municipal de Curitiba que concedeu uma autorização para a visitação nas escolas.

A coleta dos dados foi referente às atividades de EA formal nas escolas amostradas e foi realizada a partir de entrevistas in loco nas escolas que se dispuseram a auxiliar na pesquisa após contato telefônico, o qual era recomendado que o entrevistado fosse o representante que mais entendia sobre as atividades de EA desenvolvidas na escola, tais como: diretor, vicediretor, articulador pedagógico ou professor. A coleta teve duração de quarenta minutos até uma hora, por meio de um questionário impresso adaptado de Mendonça e Trajber (2007) como uma abordagem quantitativa, composto por perguntas sobre o perfil do entrevistado e referente aos projetos de EA desenvolvidos na escola (FIGURA 2), que foram aplicados no período de agosto de 2016 a abril de 2017.

Figura 2: Questionário aplicado nas escolas

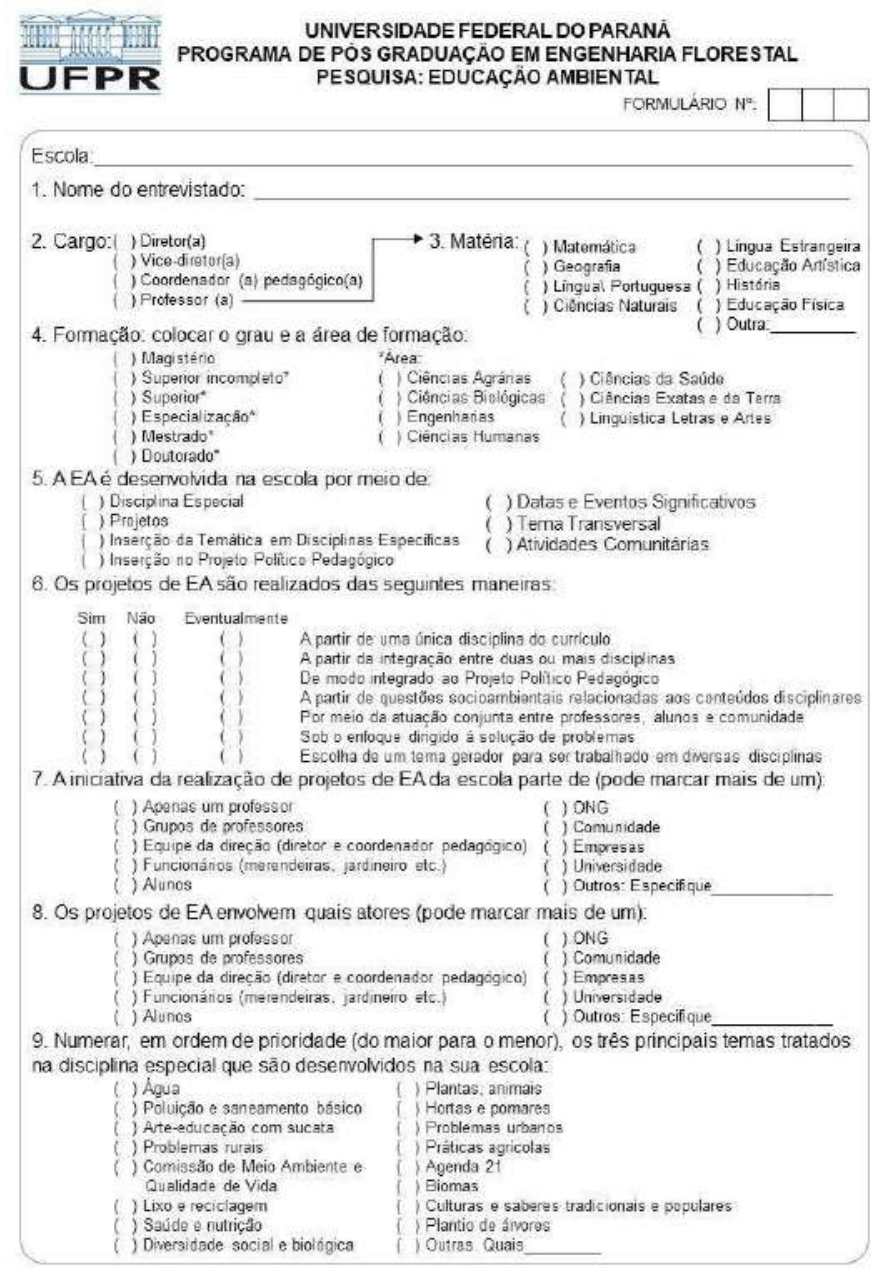

Fonte: Elaborado pelas autoras, 2021 
Após a coleta, os dados foram compilados em planilhas do Excel e foi analisado a descrição das frequências das respostas de cada questão, para a amostra total e por estrato, o qual foi verificado se havia diferença estatística entre os estratos e se as escolas com contraturno tinha alguma vantagem para desenvolver projetos que os demais, para tal foi utilizado a "estatística não paramétrica ou livres de distribuição", ou seja, quando os dados não apresentam uma distribuição normal (SIEGEL; CASTELLAN JR, 2006).

O teste estatístico escolhido para a análise foi o qui-quadrado a 5\% de significância, que compara se dois grupos independentes que diferem em relação a alguma característica, utilizando o software R versão R i386 3.3.1 (SIEGEL; CASTELLAN JR, 2006; R CORE TEAM, 2016).

A análise estatística foi realizada para as perguntas do questionário que mostravam ter uma possível mudança de comportamento entre as escolas, devido à inserção de mais atividades de EA.

\section{RESULTADOS E DISCUSSÃO}

O perfil dos entrevistados das 35 escolas foi na maioria articuladores (as) pedagógicos (as) com $42,9 \%$, seguido de professores com $25,7 \%$ do total.

Os articuladores pedagógicos surgiram em Curitiba com a função de promover diálogo entre os turnos diurno e noturno e aos poucos foram adquirindo diversas funções, tais como: atuação no processo pedagógico da escola, atender os estudantes, auxiliar o professor, realizar conselho de classe, atender o público em geral, entre outros (BRANDT, 2017). Devido as diversas funções demandadas nesse cargo, as escolas consideram esses profissionais mais preparados para responder as questões referentes a educação ambiental.

Os cargos articulador pedagógico, articulador do integral, diretor (a) e vice-diretor (a), não lecionam nenhuma disciplina, participam dos processos de gestão da escola, assim, na distribuição de disciplinas lecionadas, a maior parte dos entrevistados não ministravam disciplina no momento $(71,4 \%)$ seguido da disciplina de ciências naturais $(14,3 \%)$.

Em relação à formação dos entrevistados, $82,9 \%$ são da área de humanas e a maior parte $(77,1 \%)$ tem o nível de especialização, que em geral não está associado a temas que envolvem a EA, assim embora a Política Nacional de Educação Ambiental prevê a capacitação de recursos humanos para preparar profissionais na área de meio ambiente para atender a 
demanda de cada segmento (BRASIL, 1999), não é especificado qual a formação ideal, já que o tema é tratado como transversal aos diversos nichos de conhecimento, portanto uma qualificação específica no assunto não contribui necessariamente para melhor aplicação dos temas relacionados as questões ambientais.

Das 35 escolas entrevistadas, 23 tinham projetos com enfoque em educação ambiental, das quais, quando questionados como os projetos de educação ambiental eram aplicados da escola (TABELA 1), a maior parte integrava o tema ao projeto político pedagógico da escola $(73,9 \%)$ e a partir de questões socioambientais relacionadas aos conteúdos disciplinares $(73,9 \%)$, principalmente para as escolas com turno integral que ocorreu em todas as escolas consultadas. Também é possível perceber que há uma integração entre duas ou mais disciplinas do currículo para a realização dos projetos com um total amostrado de $60,9 \%$, mas ao analisar por tipo de ensino, a EMCiclo2 apresentou baixa interação entre as disciplinas com $28,6 \%$.

Tabela 1: Formas que os projetos de educação ambiental são realizados

\begin{tabular}{|c|c|c|c|c|c|c|c|c|c|c|c|c|}
\hline \multirow{2}{*}{ Opções } & \multicolumn{3}{|c|}{ EMCiclo1 (\%) } & \multicolumn{3}{|c|}{ EMCiclo2 (\%) } & \multicolumn{3}{|c|}{ EMIntegral (\%) } & \multicolumn{3}{|c|}{ Total (\%) } \\
\hline & $\mathbf{E}$ & Não & Sim & $\mathbf{E}$ & Não & Sim & $\mathbf{E}$ & Não & Sim & $\mathbf{E}$ & Não & Sim \\
\hline \multicolumn{13}{|l|}{ A partir de questões } \\
\hline $\begin{array}{l}\text { socioambientais relacionadas } \\
\text { aos conteúdos disciplinares }\end{array}$ & 14,3 & 14,3 & 71,4 & 28,6 & 28,6 & 42,9 & 0,0 & 0,0 & 100,0 & 13,0 & 13,0 & 73,9 \\
\hline $\begin{array}{l}\text { De modo integrado ao Projeto } \\
\text { Político Pedagógico }\end{array}$ & 0,0 & 14,3 & 85,7 & 14,3 & 14,3 & 71,4 & 22,2 & 11,1 & 66,7 & 13,0 & 13,0 & 73,9 \\
\hline $\begin{array}{l}\text { A partir da integração entre } \\
\text { duas ou mais disciplinas }\end{array}$ & 28,6 & 14,3 & 57,1 & 28,6 & 42,9 & 28,6 & 0,0 & 11,1 & 88,9 & 17,4 & 21,7 & 60,9 \\
\hline $\begin{array}{l}\text { Sob o enfoque dirigido à } \\
\text { solução de problemas }\end{array}$ & 28,6 & 28,6 & 42,9 & 14,3 & 28,6 & 57,1 & 33,3 & 0,0 & 66,7 & 26,1 & 17,4 & 56,5 \\
\hline Escolha de um tema gerador & & & & & & & & & & & & \\
\hline $\begin{array}{l}\text { para ser trabalhado em } \\
\text { diversas disciplinas }\end{array}$ & 28,6 & 42,9 & 28,6 & 57,1 & 14,3 & 28,6 & 22,2 & 0,0 & 77,8 & 34,8 & 17,4 & 47,8 \\
\hline $\begin{array}{l}\text { Por meio da atuação conjunta } \\
\text { entre professores, estudantes } \\
\text { e comunidade }\end{array}$ & 28,6 & 28,6 & 42,9 & 42,9 & 28,6 & 28,6 & 33,3 & 11,1 & 55,6 & 34,8 & 21,7 & 43,5 \\
\hline $\begin{array}{l}\text { A partir de uma única disciplina } \\
\text { do currículo }\end{array}$ & 0,0 & 85,7 & 14,3 & 14,3 & 57,1 & 28,6 & 0,0 & 88,9 & 11,1 & 8,7 & 78,3 & 13,0 \\
\hline
\end{tabular}

Ao avaliar estatisticamente a aplicação de projetos nos diferentes tipos de ensino, não houve diferença estatística na forma que os tipos de ensino realizam as atividades de educação ambiental nas escolas, mas embora estatisticamente não tenha aparecido 
diferenças vale ressaltar que nem todas as escolas entrevistadas do EMCiclo1 e EMCiclo2 desenvolveram projetos em seu currículo, já as escolas as escolas que tinham atividades no contraturno (EMIntegral), todas as entrevistadas aplicavam projetos de educação ambiental.

Em comparação com a análise feita no Brasil por Mendonça e Trajber (2007), as escolas também realizam projetos principalmente a partir de questões socioambientais relacionadas aos conteúdos disciplinares (77\%) e estão associados ao projeto político pedagógico (76\%), ao avaliarem a região sul, a pesquisa não contemplou o estado do Paraná, mas comparando com os estados selecionados, Santa Catarina e Rio Grande do Sul, as escolas também realizam projetos integrados ao projeto político pedagógico (60\%) e a partir de questões socioambientais relacionadas aos conteúdos disciplinares (59\%). Por outro lado, esses estados também evidenciaram um aspecto negativo de que muitos projetos partem de uma única disciplina do currículo (59\%), diferentemente da presente pesquisa com uma frequência de $13 \%$ para o município de Curitiba, Paraná. Esses resultados mostram que tanto em âmbito nacional, quanto na região sul, a educação ambiental nas escolas está integrada ao projeto político pedagógico e aos conteúdos disciplinares.

Cruz (2011) afirma a necessidade de incluir ações de educação ambiental desde o início do desenvolvimento da criança, para que possam entender o ambiente onde estão inseridas, observarem o seu funcionamento, sua importância e sua preservação, no qual as escolas podem iniciar esse trabalho associando ao mundo real dos estudantes, ao incluir por exemplo, hábitos, atitudes, comportamentos, sensibilidade, solidariedade, respeito mútuo e a ética na agenda ambiental da escola incluída no projeto político pedagógico.

Analisando a iniciativa para a realização desses projetos, $87,0 \%$ relatam que em geral parte de um grupo de professores, mas também conta com a participação da equipe de direção $(69,6 \%)$, principalmente nas escolas compostas no grupo EMIntegral (100\%) e com menor efetividade no EMCiclo1 com 42,9\%. Também foi possível observar uma baixa relação com a comunidade, empresas ou universidades, as quais auxiliaram apenas uma escola, já as ONGs não incentivaram nenhum projeto das escolas consultadas em Curitiba (TABELA 2). 
Tabela 2: Iniciativa da realização de projetos de educação ambiental

\begin{tabular}{|c|c|c|c|c|c|c|c|c|}
\hline \multirow{2}{*}{ Opções } & \multicolumn{2}{|c|}{ EMCiclo1 } & \multicolumn{2}{|c|}{ EMCiclo2 } & \multicolumn{2}{|c|}{ EMIntegral } & \multicolumn{2}{|c|}{ Total } \\
\hline & $\mathbf{N}$ & $\%$ & $\mathbf{N}$ & $\%$ & $\mathbf{N}$ & $\%$ & $\mathbf{N}$ & $\%$ \\
\hline Grupos de professores & 6 & 85,7 & 6 & 85,7 & 8 & 88,9 & 20 & 87,0 \\
\hline Equipe da direção (diretor e coordenador pedagógico) & 3 & 42,9 & 4 & 57,1 & 9 & 100,0 & 16 & 69,6 \\
\hline Estuantes & 2 & 28,6 & 3 & 42,9 & 6 & 66,7 & 11 & 47,8 \\
\hline Outro & 1 & 14,3 & 3 & 42,9 & 1 & 11,1 & 5 & 21,7 \\
\hline Funcionários (merendeiras, jardineiro etc.) & 1 & 14,3 & 1 & 14,3 & 2 & 22,2 & 4 & 17,4 \\
\hline Apenas um professor & 1 & 14,3 & 0 & 0,0 & 1 & 11,1 & 2 & 8,7 \\
\hline Comunidade & 0 & 0,0 & 1 & 14,3 & 0 & 0,0 & 1 & 4,3 \\
\hline Empresas & 0 & 0,0 & 1 & 14,3 & 0 & 0,0 & 1 & 4,3 \\
\hline Universidade & 1 & 14,3 & 0 & 0,0 & 0 & 0,0 & 1 & 4,3 \\
\hline ONG & 0 & 0,0 & 0 & 0,0 & 0 & 0,0 & 0 & 0,0 \\
\hline
\end{tabular}

LEGENDA: EMCiclo1 = Escolas Municipais com as séries iniciais; EMCiclo2 = Escolas Municipais com as séries finais; EMIntegral = Escolas Municipais com educação integral; N = número de escolas.

Fonte: Elaborado pelas autoras, 2021.

A iniciativa de projetos por agentes fora da comunidade escolar pode ser mais difícil, pois cada escola tem uma realidade e envolvimentos com os temas ambientais de forma diferenciada, sendo os próprios agentes da escola que conhecem as suas eventuais necessidades, mas há casos de campanhas genéricas, como a mobilização contra o Aedes aegypti (FIGURA 3), que são realizados primeiramente por iniciativas externas e que podem ter continuidade em outros projetos ou relacionar com as disciplinas que forem abordar o tema água e insetos.

Figura 3: Palestra sobre a dengue pelo programa de saúde na escola - Curitiba

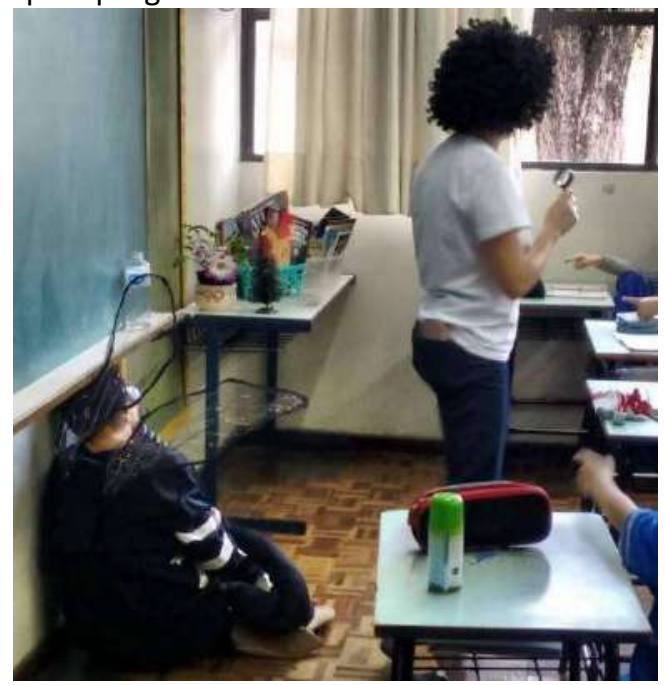

Fonte: Elaborado pelas autoras, 2021. 
Embora o presente trabalho não tenha contemplado iniciativas por parte de ONGs, há trabalhos que identificaram essa parceria na realização de projetos não formais e contam com participação ativa das ONGs por um período, em seguida a responsabilidade da continuidade ficava a cargo da escola (PALMIERI; CAVALARI, 2012). Segundo os mesmos autores, é mais interessante que um agente externo dialogue com a comunidade escolar a respeito de um projeto do que apresentar uma proposta pronta, pois possibilita alinhamento do projeto com as demandas e a necessidade da escola.

Dentre os atores envolvidos para a realização dos projetos nas escolas, 95,7\% são compostos por estudantes e grupos de professores, enquanto $82,6 \%$ das escolas afirmaram que a equipe de direção também auxilia nessa ação, assim como os funcionários (52,2\%), caso seja necessário. Notou-se também uma baixa ação da comunidade em ajudar nas atividades das escolas em todos os tipos de ensino (TABELA 3). As escolas afirmaram que a comunidade do entorno não se preocupa com os projetos desenvolvidos na escola, mas não foi objeto dessa pesquisa avaliar se o entorno teve oportunidade para participar dessas ações e como foi a abordagem por parte da escola.

Tabela 3: Atores envolvidos nos projetos

\begin{tabular}{|c|c|c|c|c|c|c|c|c|}
\hline \multirow{2}{*}{ Opções } & \multicolumn{2}{|c|}{ EMCiclo1 } & \multicolumn{2}{|c|}{ EMCiclo2 } & \multicolumn{2}{|c|}{ EMIntegral } & \multicolumn{2}{|c|}{ Total } \\
\hline & $\mathbf{N}$ & $\%$ & $\mathbf{N}$ & $\%$ & $\mathbf{N}$ & $\%$ & $\mathbf{N}$ & $\%$ \\
\hline Estudantes & 7 & 100,0 & 6 & 85,7 & 9 & 100,0 & 22 & 95,7 \\
\hline Grupos de professores & 7 & 100,0 & 7 & 100,0 & 8 & 88,9 & 22 & 95,7 \\
\hline Equipe da direção (diretor e coordenador pedagógico) & 6 & 85,7 & 6 & 85,7 & 7 & 77,8 & 19 & 82,6 \\
\hline Funcionários (merendeiras, jardineiro etc.) & 2 & 28,6 & 4 & 57,1 & 6 & 66,7 & 12 & 52,2 \\
\hline Comunidade & 2 & 28,6 & 1 & 14,3 & 2 & 22,2 & 5 & 21,7 \\
\hline ONG & 1 & 14,3 & 1 & 14,3 & 0 & 0,0 & 2 & 8,7 \\
\hline Outro & 0 & 0,0 & 1 & 14,3 & 1 & 11,1 & 2 & 8,7 \\
\hline Apenas um professor & 0 & 0,0 & 0 & 0,0 & 1 & 11,1 & 1 & 4,3 \\
\hline Empresas & 0 & 0,0 & 1 & 14,3 & 0 & 0,0 & 1 & 4,3 \\
\hline Universidade & 1 & 14,3 & 0 & 0,0 & 0 & 0,0 & 1 & 4,3 \\
\hline
\end{tabular}

Para Palmieri e Cavalari (2013), ao incorporar os estudantes nos projetos de educação ambiental no ensino formal é possível trabalhar com a realidade local, inserir novos conhecimentos e promover mudança de valores, atitudes e comportamentos. Há pesquisas 
que reforçam a participação dos estudantes no processo educativo para haver um maior interesse nos projetos realizados na escola. O envolvimento de diversas partes, tais como os professores, na integração das diversas disciplinas nos projetos, pais dos estudantes, toda comunidade escolar e do entorno, melhoram o modelo tradicional de ensino e abrem portas para novas concepções e práticas de educação ambiental (PALMIERI; CAVALARI, 2012).

Para Narcizo (2009), não basta fazer projetos impostos por um grupo isolado ou por um professor, com atividades que não proporcione mudança na mentalidade dos estudantes, o trabalho tem que ser de forma integrada, com mais agentes da comunidade escolar e com alternativas que promovam uma contínua reflexão, possivelmente conseguirá implantar um projeto de educação ambiental fidedigno.

Em relação aos principais temas abordados nos projetos, foi pedido que as escolas listassem os três principais e o primeiro tema a ser tratado foi "água" com 34,8\%, o segundo foi "lixo e reciclagem" com $26,1 \%$ e o terceiro foi "saúde e nutrição" com $26,1 \%$. Um dos exemplos desse último tema foi o projeto prato limpo (FIGURA 4), realizado por uma escola que avalia o desperdício de comida de cada turma e aquela que tiver menor desperdício fazia um piquenique no parque.

Figura 4: Projeto prato limpo - Curitiba

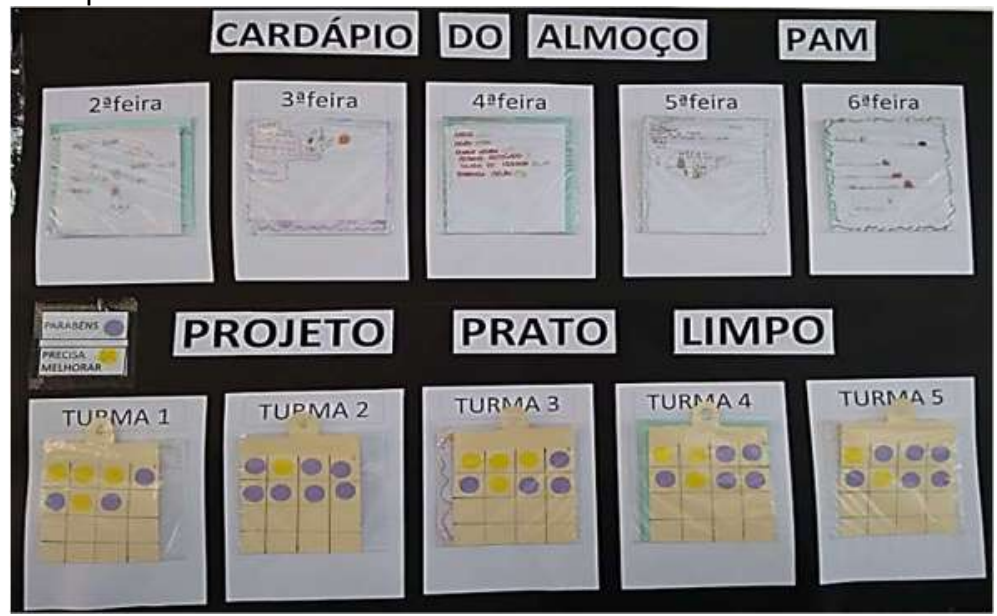

Fonte: Elaborado pelas autoras, 2021

Na avaliação feita a nível nacional, o tema principal avaliado nos projetos também foi a água $(98,1 \%)$ seguido de lixo e reciclagem com $62,8 \%$. Assim, para o estado de Santa Catarina e Rio Grande do Sul, esses temas também foram os principais, seguido de saúde e nutrição (MENDONÇA; TRAJBER, 2007).

A água como principal tema nos projetos de educação ambiental, tanto para o presente estudo como em outros estados, pode estar atrelado ao fato de ser um assunto 
constantemente em discussão pelos cidadãos em diversos segmentos sociais, mídias, legislações e está pautada em livros didáticos e em propostas pedagógicas, cabendo a escola contribuir para um pensamento global a respeito da crise hídrica e práticas voltadas a novos hábitos e atitudes no uso racional da água (FREITAS, MARIN; 2015).

Um exemplo de novos hábitos foi descrito por Higuchi, Zattoni e Bueno (2012), em que uma escola passou a reutilizar a água de bebedouros que antes eram desperdiçadas e começaram a armazenar em caixas d'água para posterior uso em descargas de vasos sanitários e lavagem do pátio da escola, projeto que só foi possível com a participação de todos os atores da comunidade escolar.

Narcizo (2009) também acredita que a participação dos atores, principalmente os estudantes, é muito importante, pois por exemplo, em um projeto de resíduos sólidos, não basta que os estudantes separem os resíduos nas lixeiras corretas e sim ações que proporcione uma mudança de comportamento em reduzir o consumo, reutilizar e reciclar os resíduos, para essas atitudes se estendem em todo o ambiente escolar e em outros locais fora da escola.

Outro projeto que foi frequente nas escolas consultadas foi o projeto de "horta e pomares" (FIGURA 5), que embora não esteja entre os três temas principais abordados nas escolas, está associado a outros assuntos, tais como a água, saúde e nutrição.

Figura 5: Atividade de horta nas escolas - Curitiba
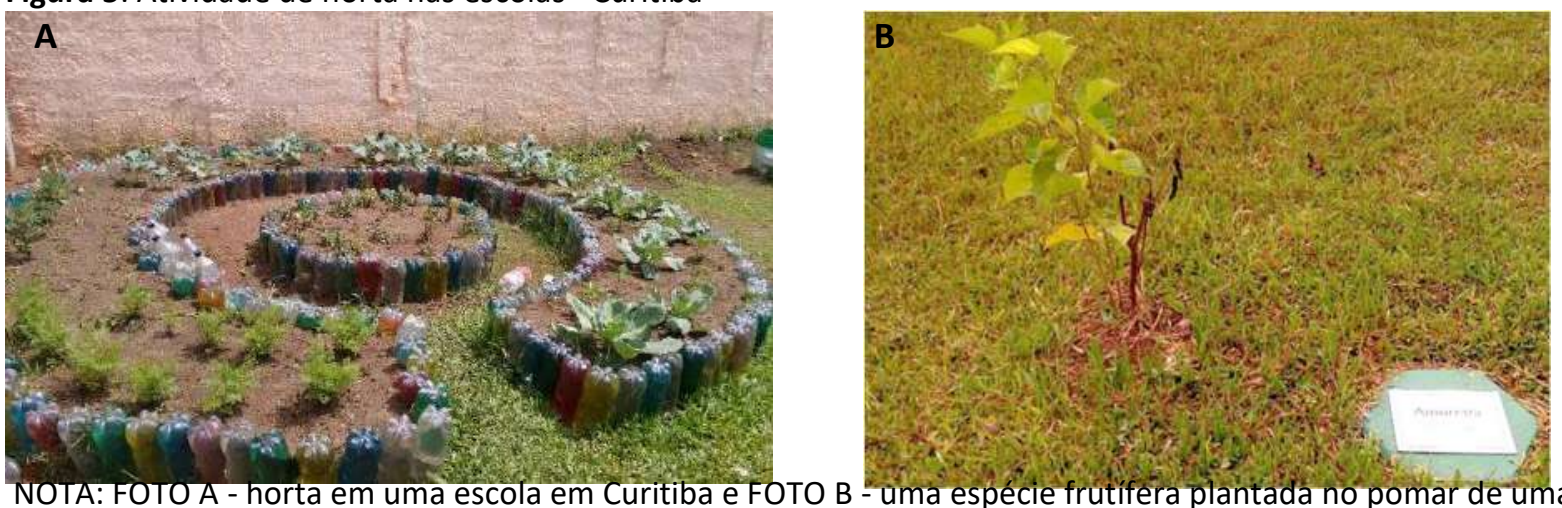
escola em Curitiba

Fonte: Elaborado pelas autoras, 2021.

Para Cribb (2010) projetos como horta, faz com que os estudantes auxiliem os professores na rega das hortaliças, incentiva o uso de produtos recicláveis utilizando garrafas pet como recipiente para mudas ou até mesmo para delimitar o canteiro e estimulam as crianças a consumirem o alimento que elas ajudaram a produzir. Essas atividades também 
auxiliam no contato dos estudantes com as plantas, aprendendo desde o preparo da terra até o seu plantio, além de acompanhar os estágios de desenvolvimento dos vegetais (MOURO; AUGUSTO, 2019).

Projetos que envolvam mais de um tema específico, possibilita que os estudantes pensem em soluções mais sustentáveis no seu dia a dia. Para Rezende e Bampi (2019), a escola é um espaço privilegiado para desenvolver novas condutas, concepções e valores ambientais, possibilitando aos estudantes uma postura sustentável.

\section{CONSIDERAÇÕES FINAIS}

Das 35 escolas municipais avaliadas em Curitiba, 23 apresentam atividades de educação ambiental que envolve projetos no ensino formal, dos quais não houve diferença estatística na forma que esses projetos são aplicados entre os tipos de ensino, embora apenas as com ensino integral tinham projetos em todas as escolas avaliadas, que provavelmente está atrelado as atividades do contraturno.

Dentre as formas que os projetos são desenvolvidos, a maior parte integrava o tema ao projeto político pedagógico da escola e a partir de questões socioambientais relacionadas aos conteúdos disciplinares, o que demostra que as atividades estão alinhadas a política escolar e estão de acordo com a política nacional de educação ambiental, com o compromisso de repassar os temas de forma transversal e interdisciplinar.

As atividades realizadas nas escolas são engajadas geralmente por um grupo de professores, seguido também pela participação de diversos agentes da comunidade escolar, ressaltando a importância da inclusão dos alunos no desenvolvimento dos projetos, para melhorar o interesse em relação aos temas aplicados, dos quais os mais abordados foram a água, o lixo e reciclagem e a saúde e nutrição.

\section{REFERÊNCIAS}

BRANDT, L. S. O papel do articulador pedagógico frente às tecnologias de informação e comunicação na EJA da rede municipal de Curitiba. Curitiba. Anais... Curitiba: XIII Congresso de educação, 2017. 
BRASIL. Lei n.o 9.795, de 27 de abril de 1999. Diário Oficial da União. Dispõe sobre a educação ambiental, institui a Política Nacional de Educação AmbientalDisponível em: <http://www.mma.gov.br/port/conama/legiabre.cfm?codlegi=321>. Acesso em: 04 ago. 2019.

BRASIL. Parecer CNE/CP n. 14/2012, 6 de junho de 2012a. Diretrizes Curriculares Nacionais para a Educação Ambiental. Diário Oficial da União. Disponível em: <http://portal.mec.gov.br/index.php?option=com_content\&id=17631\&ltemid=866>. Acesso em: 04 ago. 2019.

CRIBB, S. Contribuições da educação ambiental e horta escolar na promoção de melhorias ao ensino, à saúde e ao ambiente. Revista Eletrônica do Mestrado Profissional em Ensino, Saúde e Ambiente, Rio Grande, v. 3, n. 1, p. 42 - 60, 2010.

CURITIBA. Diretrizes Curriculares para a Educação Municipal de Curitiba: Educação Especial e Inclusiva, Educação Integral, Educação de Jovens e Adultos. Curitiba: Secretaria Municipal Educação, 2006.

CURITIBA. Unidades Educacionais. 2017. Disponível em: <http://www.educacao.curitiba.pr.gov.br/>. Acesso em: 10 de abr. 2017.

CRUZ, S. Educação ambiental e o projeto político-pedagógico: em busca da sustentabilidade ambiental. Periódico Eletrônico Fórum Ambiental da Alta Paulista, v. 7, n. 6, p. 921 - 933, 2011.

FREITAS, N. T. A.; MARIN, F. A. D. G. Educação ambiental e água: concepções e práticas educativas em escolas municipais. Nuances: estudos sobre Educação, Presidente Prudente, v. 26, número especial 1, p. 234 - 253, 2015.

INSTITUTO NACIONAL DE ESTUDOS E PESQUISAS EDUCACIONAIS ANÍSIO TEIXEIRA - INEP. Sistema de Consulta a Matrícula do Censo Escolar. 2017. Disponível em: < http://portal.inep.gov.br/resultados-e-resumos>. Acesso em: 10 jun. 2017.

LAMOSA, A. C.; LOUREIRO, C. F. B. A educação ambiental e as políticas educacionais: um estudo nas escolas públicas de Teresópolis (RJ). Educação e Pesquisa, São Paulo, v. 37, n.2, p. 279 - 292, 2011.

LUCHESA, C. J.; CHAVES NETO, A. Cálculo do tamanho da amostra nas pesquisas em administração. Curitiba: Edição do autor, 2011.

MENDONÇA, P. R.; TRAJBER, R. O que fazem as escolas que dizem que fazem educação ambiental. ed. 6. Brasília: Secretaria de Educação Continuada, Alfabetização e Diversidade, 2007. 262 p.

MOURO, B. C.; AUGUSTO, T. G. S. Educação ambiental e a horta escolar: um diagnóstico de projetos desenvolvidos e das possibilidades de ação. Educação Ambiental em Ação, revista 
eletrônica, $\quad$ n. $2019 . \quad$ Disponível

http://www.revistaea.org/artigo.php?idartigo=3494>. Acesso em: 10 jan. 2019.

NARCIZO, K. R. S. Uma análise sobre a importância de trabalhar educação ambiental nas escolas. Revista Eletrônica do Mestrado em Educação Ambiental, Rio Grande, v. 22, p. 86 94, 2009.

HIGUCHI, M. I. G.; ZATTONI, M.; BUENO, F. P. Educação Ambiental em contextos não escolares: definindo, problematizando e exemplificando. Pesquisa em Educação Ambiental, Rio Claro, v. 7, n. 2, p. 119-132, 2012.

PALMIERI, M. L. B.; CAVALARI, R. M. F. Objetivos de projetos de educação ambiental desenvolvidos em escolas brasileiras: um estudo de dissertações e teses (1988-2008). Revista Comunicações, Piracicaba, v. 20, p. 99 - 118, 2013.

PALMIERI, M. L. B.; CAVALARI, R. M. F. Limites e possibilidades dos projetos de educação ambiental desenvolvidos em escolas brasileiras: análise de dissertações e teses. Revista Eletrônica do Mestrado em Educação Ambiental, Rio Grande, v. 29, p. 1-17, 2012.

R CORE TEAM. 2016. R: A language and environment for statistical computing. R Foundation for Statistical Computing, Vienna, Austria. Disponível em: <https://www.R-project.org/>. Acesso em: 04 jun. 2017.

REIGOTA, M. O que é educação ambiental. São Paulo: Editora Brasiliense, 2017. 88p.

REIS, L. C. L.; SEMÊDO, L. T. D. A. S.; GOMES, R. C. Conscientização ambiental: da educação formal a não formal. Revista Fluminense de Extensão Universitária, Vassouras, v. 2, n. 1, p. 47 - 60, 2016.

REZENDE, F. S. S. L.; BAMPI, A. C. Práticas pedagógicas em educação ambiental na educação básica: dificuldades e potencialidades da inserção da temática nas escolas. Educação Ambiental em Ação, revista eletrônica, n. 67, 2019. Disponível em: < http://www.revistaea.org/artigo.php?idartigo=3597>. Acesso em: 10 jan. 2019.

SANTOS, T. M. M.; OLIVEIRA, J. L. S.; OLIVEIRA, H M.; SILVA, E. Recursos hídricos: problemas ambientais e a importância da educação e percepção ambiental. Educação Ambiental em Ação, revista eletrônica, n. 65, 2018. Disponível em: < http://www.revistaea.org/artigo.php?idartigo=3416>. Acesso em: 10 jan. 2019.

SARTORI, J. T. D. Estatísticas da educação particular do Paraná: educação básica e superior. 1.ed. Curitiba: Sinepe/PR, 2015. 104 p.

SIEGEL, S.; CASTELLAN JR, N. J. Estatística não-paramétrica para ciências do comportamento. Porto Alegre: Artmed Editora SA., ed. 2006.

SOUZA, D. A.; BONOTTO, D. M. B. Valores Éticos e Estéticos Relativos à Temática Ambiental e a Literatura Infantil. Pesquisa em Educação Ambiental, São Paulo, v. 14, n. 1, p. 132 


\title{
NARRATIVAS DIGITAIS DE PROFESSORES: UMA REVISÃO SISTEMÁTICA EM TESES E DISSERTAÇÕES BRASILEIRAS
}

\author{
Marcus Alexandre de Pádua Cavalcanti Bastos \\ Doutor em Educação em Ciências e Saúde pela Universidade Federal do Rio de Janeiro - UFRJ \\ Rio de Janeiro, RJ, Brasil \\ marcus_nathan120@hotmail.com
}

Eliane Cristina Tenório Cavalcanti

Doutoranda em Educação em Ciências e Saúde pela Universidade Federal do Rio de Janeiro - UFRJ

- Rio de Janeiro, RJ, Brasil

eliane.cavalcanti@hotmail.com.br

Marcelo de Jesus Pereira

Mestrando em Educação em Ciências -Universidade do Grande Rio, UNIGRANRIO

Rio de Janeiro, RJ, Brasil marcelo.pereira@transluxtransportes.com.br

Shirley Araújo Cabral
Mestre em Desenvolvimento Local - Centro Universitário Augusto Motta - UNISUAM
Rio de Janeiro, RJ, Brasil
shirleyacabral@gmail.com.br
Bacharelando em Farmácia Universidade Estácio de Sá - UNESA
Rio de Janeiro, RJ, Brasil
nathan-psytrance@hotmail.com

RESUMO

Este trabalho teve como objetivo realizar uma revisão sistemática de teses e dissertações que tratam de narrativas digitais de professores atuantes em escolas de Educação Básica e Educação Superior no país. Para tanto, buscou-se analisar dissertações e teses existentes no Portal de Periódicos da Capes do período de 2016 a 2018 sobre essa temática. Trata-se de uma a pesquisa exploratória e descritiva sendo que os seus dados e sua análise foram explorados de forma quantitativa e qualitativa. O material da investigação foi composto por 07 trabalhos que atenderam aos critérios de inclusão e exclusão previamente definidos. A análise permitiu observar que o tema foi pouco explorado no cenário brasileiro até 2017 . Os resultados apontam que a partir de 2018 houve uma mudança significativa no que se refere ao aumento de pesquisas sobre as narrativas digitais de professores. Entre as áreas mais exploradas, o destaque é para a Educação, em seguida, a seguir estão os trabalhos na área de Ensino de Ciências e Cognição e Linguagem.

Palavras-chave: Narrativa digital. Professores. Portal da Capes 


\title{
DIGITAL NARRATIVES OF TEACHERS: A SYSTEMATIC REVIEW IN BRAZILIAN THESES AND DISSERTATIONS
}

\begin{abstract}
This work aimed to carry out a systematic review of theses and dissertations that deal with digital narratives of teachers working in schools of Basic Education and Higher Education in the country. To this end, we sought to analyze dissertations and theses existing on the Capes Journal Portal from the period 2016 to 2018 on this theme. It is an exploratory and descriptive research and its data and analysis were explored in a quantitative and qualitative way. The investigation material was composed of 07 works that met the inclusion and exclusion criteria previously defined. The analysis allowed to observe that the theme was little explored in the Brazilian scenario until 2017. The results show that, from 2018 on, there was a significant change regarding the increase in research on teachers' digital narratives. Among the most explored areas, the highlight is Education, followed by work in the area of Science and Cognition and Language Teaching.
\end{abstract}

Keywords: Digital narrative. Teachers. Capes Journals Portal 
NARRATIVAS DIGITAIS DE PROFESSORES: UMA REVISÃO SISTEMÁTICA EM TESES E DISSERTAÇÕES BRASILEIRAS
Marcus Alexandre de Pádua Cavalcanti Bastos Eliane Cristina Tenório Cavalcanti Marcelo de Jesus Pereira Shirley Araújo Cabral

Nathan da Costa Cavalcanti Bastos

\title{
1 INTRODUÇÃO
}

As narrativas fazem parte da história da humanidade, elas trazem consigo a possibilidade de contar e recontar a história, não permitindo que esta história caia no esquecimento. Narrar constitui-se, assim, como um instrumento que permite o acesso a certo tipo de conhecimento, um processo fundamental de desenvolvimento cognitivo e de percepção do real que possibilita a compreensão da representação que o sujeito faz da realidade na qual está inserido (BARTHES, 2013).

De acordo com Bruner (2007) a narrativa é um modo de pensamento, pois ela se apresenta como princípio organizador da experiência humana no mundo social, do seu conhecimento sobre ele e das trocas que ele mantém. $\mathrm{O}$ autor considera que a narrativa é uma importante ferramenta para a construção do significado em nossa cultura.

Recentemente, a pesquisa em educação vem adotando as narrativas de professores como um instrumento de investigação da prática docente. A narrativa é uma das formas mais comuns do professor expressar um tipo de saber (VAZ, MENDES, MAUÉS, 2001).

As pesquisas sobre narrativas buscam produzir conhecimentos que não estão ao alcance dos métodos tradicionais de investigação científica, como os significados que as pessoas dão às suas vivências, às situações e às ações de suas vidas, inseridas no grupo e na coletividade (POLKINGHORNE, 2007).

Bruner (2002, p. 46) define a narrativa como

\begin{abstract}
Uma sequência singular de eventos, estados mentais, ocorrências envolvendo seres humanos como personagens ou atores situados em determinado contexto, no tempo dos acontecimentos, permitindo avançar ou retroceder no tempo, de acordo com as intenções em processos de construção de conhecimentos e negociação de significados, que englobam as relações entre mente e cultura.
\end{abstract}

De acordo com Almeida e Valente (2012, p. 59), "as narrativas, que eram tradicionalmente orais ou escritas, podem ser agora produzidas com uma combinação de mídias, o que pode contribuir para que esta atividade seja muito mais rica e sofisticada". Em consonância com Almeida e Valente (2012), Rodrigues e Gonçalves (2014, p. 216) destacam que essas narrativas "podem ser produzidas por meio das tecnologias digitais de informação 
NARRATIVAS DIGITAIS DE PROFESSORES: UMA REVISÃO SISTEMÁTICA EM TESES E DISSERTAÇÕES BRASILEIRAS
Marcus Alexandre de Pádua Cavalcanti Bastos Eliane Cristina Tenório Cavalcanti Marcelo de Jesus Pereira Shirley Araújo Cabral

Nathan da Costa Cavalcanti Bastos

e comunicação (TDICs) e numa textualidade eletrônica que é multimidiática, o sujeito pode lançar mão de uma diversidade ainda maior de recursos para se expressar".

As narrativas têm ganhado novos significados e usos com o advento das tecnologias digitais de informação e comunicação (PALÁCIO; STRUCHINER, 2017). A habilidade da narração em tempos das TDICs vem sendo incorporada na educação (BELL, 2014). Elas são produzidas com uma combinação de mídias (ALMEIDA; VALENTE, 2012), cuja construção constitui-se "num processo de produção textual que assume o caráter contemporâneo dos recursos audiovisuais e tecnológicos capazes de modernizar 'o contar histórias', tornando-se uma ferramenta pedagógica eficiente e motivadora" (CARVALHO, 2008, p. 87), Assim, os professores passaram a ter novos suportes e possibilidades de formato digital (LISBÔA E COUTINHO, 2012):

O presente estudo tem como objetivo Identificar e analisar pesquisas realizadas em teses e dissertações que tratam de narrativas digitais de professores na Educação Básica e Superior de todo o país. Partimos do pressuposto de que o uso das narrativas digitais pelos professores potencializa a aprendizagem e influência no processo educativo.

\section{AS NARRATIVAS DIGITAIS}

As narrativas digitais emergem como mais uma possibilidade de investigação, pois esse tema agrega vários elementos além daqueles associados à oralidade e à escrita em sua forma tradicional. Almeida e Valente (2012, p. 59), apontam que "as narrativas, que eram tradicionalmente orais ou escritas, podem ser agora produzidas com uma combinação de mídias, o que pode contribuir para que esta atividade seja muito mais rica e sofisticada".

Associada aos recursos digitais, a narrativa digital vem sendo utilizada e estudada sob diversas nomenclaturas e com diferentes abordagens: digital storytelling (ROBY, 2010; CLARKE; ADAM, 2012; ROBIN; MCNEIL, 2012), narrativa multimídia (MAGALHÃES, 2010; ARAÚJO, 2010), digital stories (XIN, 2014) e digital narratives (LOVELL; BAKER, 2009).

Delas fazem parte imagens, animações, sons, links e uma série de outros recursos que compõem esse tipo de narrativa. Miller (2014) aponta que elas

Possuem caracteres possíveis apenas em meios digitais: principalmente os que podem ser controlados por computadores; Interativos: o usuário pode controlar ou 
NARRATIVAS DIGITAIS DE PROFESSORES: UMA REVISÃO SISTEMÁTICA EM TESES E DISSERTAÇÕES BRASILEIRAS
Marcus Alexandre de Pádua Cavalcanti Bastos Eliane Cristina Tenório Cavalcanti Marcelo de Jesus Pereira Shirley Araújo Cabral

Nathan da Costa Cavalcanti Bastos

impactar aspectos da história; Não lineares: os fatos narrados não ocorrem em uma ordem fixa; Profundamente imersivos: atrativos da história e do meio que conduzem e mantém o usuário dentro do enredo; Participativos: possibilidade de o usuário participar da história; Navegáveis: os usuários fazem seu próprio caminho através da história ou através do ambiente virtual (MILLER, 2014, p. 14).

Almeida e Valente (2012, p. 63) afirmam que elas "podem ser utilizadas tanto para investigar o conhecimento que as pessoas expressam quanto para auxiliar processos de construção de conhecimento". Na área da educação, elas auxiliam nos processos de produção de conhecimento (ALMEIDA E VALENTE 2012, 2014).

De acordo com Rodrigues (2017) as investigações no cenário brasileiro sobre esse tema ainda são bastante incipientes e escassas. Almeida e Valente $(2012,2014)$ ressaltam a importância das narrativas digitais na educação, uma vez que elas "podem ser produzidas com uma combinação de mídias, o que pode contribuir para que esta atividade seja muito rica e sofisticada" (ALMEIDA E VALENTE, 2012, p. 59). Os autores destacam ainda que o trabalho com as narrativas digitais é uma forma de explorar o potencial das tecnologias digitais de informação e comunicação (TDIC) em distintas áreas do conhecimento (ALMEIDA E VALENTE, 2012, p. 58). Eles ainda acrescentam que "na narrativa digital, produzida por meio das TDIC, o sujeito pode lançar mão de uma diversidade ainda maior de recursos para se expressar" (ALMEIDA E VALENTE, 2014, p. 216).

\section{PROCEDIMENTOS METODOLÓGICOS}

O método utilizado foi a Revisão Sistemática da Literatura que segundo Freire (2013, p.33) "absorve os resultados dos estudos de outros pesquisadores, tratando seus resultados como estudos secundários. Esse método foi escolhido para que se possa fazer uma síntese do conhecimento já adquirido sobre o tema e assim possibilitar caminhos para identificar possíveis avanços ao se comparar e estatisticamente relacionar os resultados de diferentes pesquisas que levem a novos resultados (VELLUZZI, 1998)

A pesquisa foi elaborada a partir da necessidade de identificar estudos sobre a utilização de Narrativas Digitais de professores atuantes em escolas de Educação Básica e Educação Superior de todo o país. A coleta dos artigos foi realizada no Banco de Teses e Dissertações da CAPES. A busca nessa base se justifica pelo fato de que ela atende às 
NARRATIVAS DIGITAIS DE PROFESSORES: UMA REVISÃO SISTEMÁTICA EM TESES E DISSERTAÇÕES BRASILEIRAS
Marcus Alexandre de Pádua Cavalcanti Bastos Eliane Cristina Tenório Cavalcanti Marcelo de Jesus Pereira Shirley Araújo Cabral

Nathan da Costa Cavalcanti Bastos

demandas dos setores acadêmico, produtivo e governamental, possibilitando a promoção do aumento da produção científica nacional e da inserção científica brasileira no exterior.

Para a realização desta revisão, foram utilizados os seguintes procedimentos: elaboração da questão de pesquisa, levantamento do material bibliográfico analisado que constituiu em teses e dissertações, cujos dados coletados foram: título, autor, ano, instituição, tipo de trabalho e programa. Estabelecemos os critérios para inclusão e exclusão de estudos, definição das informações a serem extraídas dos estudos selecionados, avaliação dos estudos incluídos na revisão, interpretação dos resultados e síntese do conhecimento.

Definiram-se como critérios de inclusão os trabalhos que abordem narrativas digitais de professores atuantes em escolas de toda a Educação Básica e em Instituições de Ensino Superior (IES). Como critério de exclusão os trabalhos que não envolvam narrativas digitais de professores. O lapso temporal abarcado foi de 2016 a 2018.

A questão que orientou esse trabalho foi a seguinte: Como as narrativas digitais vêm sendo utilizadas por professores do ensino básico e superior no país?

Condizente com essa indagação ficaram definidos para as buscas os descritores "narrativas digitais", realizou-se a busca 1, a partir da qual advieram 85 trabalhos. Logo após esta, a fim de especificar e afunilar, ainda mais, a pesquisa, lançou-se mão da equação "narrativa digital" and "professor" (BUSCA 2), por meio da qual derivaram 72 obras.

Todavia, como o quantitativo de trabalho resultante da busca 2 foi grande (72 trabalhos), optou-se por continuar a busca, desta vez, tentando com as mesmas palavraschave, mas em ordem inversa, isto é, "professor" AND "narrativa digital", resultando 7 estudos.

Após a aplicação dos critérios e o refinamento da busca a partir da leitura dos artigos pré-selecionados, a amostra restringiu-se a 07 artigos. O Quadro 1 mostra os resultados quantitativos dessa busca em pesquisa realizada na data de 20 de dezembro de 2019. 
NARRATIVAS DIGITAIS DE PROFESSORES: UMA REVISÃO SISTEMÁTICA EM TESES E DISSERTAÇÕES BRASILEIRAS
Marcus Alexandre de Pádua Cavalcanti Bastos Eliane Cristina Tenório Cavalcanti Marcelo de Jesus Pereira Shirley Araújo Cabral

Nathan da Costa Cavalcanti Bastos

Quadro 1. Quantidade de trabalhos encontrados no Banco de Teses e Dissertações da CAPES, com a utilização dos descritores "narrativa digital" AND "professor".

\begin{tabular}{|l|l|}
\hline Descritores utilizados na pesquisa & Número de trabalhos \\
\hline Narrativas digitais & 85 \\
\hline Narrativa digital AND Professor & 72 \\
\hline Professor AND Narrativa digital & 07 \\
\hline
\end{tabular}

Fonte: Elaborada pela autora.

Mediante esse resultado panorâmico, optou-se por utilizar os materiais bibliográficos encontrados na busca das palavras-chave associadas "Professor' AND 'Narrativa digital', por serem os descritores que mais se relacionam com o objetivo desta pesquisa".

\section{RESULTADOS E DISCUSSÃO}

Após a aplicação dos critérios e o refinamento da busca a partir da leitura dos artigos pré-selecionados, como descrito na metodologia, foi possível alcançar como resultado 07 trabalhos distribuídos na seguinte ordem: autor(es), título, instituição, tipo de trabalho, ano e programa. O Quadro 02 mostra os resultados quantitativos dessa busca em pesquisa realizada na data de 20 de dezembro de 2019.

Alguns trabalhos não traziam de forma explícita o assunto das narrativas digitais ou algum tema relacionado nos títulos e resumos, o qual se configurou como um problema na pesquisa, sendo, preciso então fazer uma leitura das palavras-chaves, linhas de pesquisa, introdução e até o texto na íntegra para ser possível uma categorização e na tentativa de encontrar a motivação dos pesquisadores para o desenvolvimento dos estudos realizados.

Quadro 2. Trabalhos selecionados para análise na pesquisa

\begin{tabular}{|c|c|l|c|c|c|c|}
\hline No & Autor & \multicolumn{1}{|c|}{ Título } & Instituição & $\begin{array}{c}\text { Tipo de } \\
\text { trabalho }\end{array}$ & Ano & Programa \\
\hline 1 & $\begin{array}{l}\text { SANTOS, } \\
\text { Vanessa } \\
\text { Aparecida }\end{array}$ & $\begin{array}{l}\text { Tenho um tablet, e } \\
\text { agora? narrativas de } \\
\text { professores de ciências } \\
\text { sobre a inserção da } \\
\text { tecnologia digital na } \\
\text { prática docente (T01) }\end{array}$ & $\begin{array}{c}\text { Universidade } \\
\text { Federal de Itajubá }\end{array}$ & Dissertação & 2016 & $\begin{array}{c}\text { Ensino de } \\
\text { Ciências }\end{array}$ \\
\hline 2 & $\begin{array}{l}\text { CASTELANO, } \\
\text { Karine Lobo }\end{array}$ & $\begin{array}{l}\text { Escrita e autoria escolar: } \\
\text { criação e produção de } \\
\text { narrativas digitais na }\end{array}$ & $\begin{array}{c}\text { Universidade } \\
\text { Estadual do Norte }\end{array}$ & Tese & 2017 & $\begin{array}{c}\text { Cognição e } \\
\text { Linguagem }\end{array}$ \\
\hline
\end{tabular}




\begin{tabular}{|c|c|c|c|c|c|c|}
\hline & & $\begin{array}{l}\text { formação de professores } \\
\text { (T02) }\end{array}$ & $\begin{array}{l}\text { Fluminense Darcy } \\
\text { Ribeiro }\end{array}$ & & & \\
\hline 3 & $\begin{array}{l}\text { CANANI, Carlos } \\
\text { Eduardo }\end{array}$ & $\begin{array}{l}\text { Narrativas Digitais de } \\
\text { Professores: } \\
\text { Perspectivas } \\
\text { Educomunicativas Para } \\
\text { As Práticas Pedagógicas } \\
\text { (T03) }\end{array}$ & $\begin{array}{l}\text { Universidade do } \\
\text { Planalto } \\
\text { Catarinense }\end{array}$ & Dissertação & 2018 & Educação \\
\hline 4 & $\begin{array}{l}\text { CONCEIÇÃO, } \\
\text { Daiane Leal da }\end{array}$ & $\begin{array}{l}\text { Ensino da Matemática: } \\
\text { Potencialidades de Uso } \\
\text { em Concepções e } \\
\text { Práticas Docentes (T04) }\end{array}$ & $\begin{array}{c}\text { Universidade } \\
\text { Federal de Pelotas }\end{array}$ & Dissertação & 2018 & Educação \\
\hline 5 & $\begin{array}{c}\text { TOQUETÃO, } \\
\text { Sandra Cavaletti }\end{array}$ & $\begin{array}{l}\text { Narrativas digitais } \\
\text { multimodais na } \\
\text { formação de professores } \\
\text { da educação infantil } \\
\text { (T05) }\end{array}$ & $\begin{array}{c}\text { Pontifícia } \\
\text { Universidade } \\
\text { Católica de São } \\
\text { Paulo }\end{array}$ & Dissertação & 2018 & Educação \\
\hline 6 & $\begin{array}{l}\text { ARGUELHO, } \\
\text { Miriam Brum }\end{array}$ & $\begin{array}{l}\text { Aprendi fazendo! } \\
\text { Enquanto } \\
\text { aprendia, ensinava: } \\
\text { formação de professores } \\
\text { mediada pelo scratch } \\
\text { (T06) }\end{array}$ & $\begin{array}{l}\text { Universidade } \\
\text { Católica Dom } \\
\text { Bosco }\end{array}$ & Tese & 2018 & Educação \\
\hline 7 & $\begin{array}{l}\text { MADDALENA, } \\
\text { Tania Lucía }\end{array}$ & $\begin{array}{l}\text { Digital Storytelling: } \\
\text { uma experiência de } \\
\text { pesquisa-formação na } \\
\text { cibercultura (T07) }\end{array}$ & $\begin{array}{l}\text { Universidade do } \\
\text { Estado do Rio de } \\
\text { Janeiro }\end{array}$ & Tese & 2018 & Educação \\
\hline
\end{tabular}

Fonte: Elaborado pela autora.

$\mathrm{Na}$ tentativa de responder a questão levantada nesta pesquisa que dizia respeito a como as narrativas digitais vêm sendo utilizadas por professores do ensino básico e superior no país, a busca encontrou 5 (cinco) trabalhos no campo da educação, 1 (um) trabalho na área de Ensino de Ciências e 1 (um) trabalho no campo da Cognição e Linguagem. Essa realidade revela que as pesquisas que tratam das narrativas digitais de professores estão intrinsecamente ligadas à área educacional.

Todos os 07 (sete) trabalhos selecionados possuem a característica de serem empíricos, sendo que 4 (quatro) destes são dissertações e 3 (três) são teses conforme pode ser observado na Tabela 1. 
NARRATIVAS DIGITAIS DE PROFESSORES: UMA REVISÃO SISTEMÁTICA EM TESES E DISSERTAÇÕES BRASILEIRAS
Marcus Alexandre de Pádua Cavalcanti Bastos Eliane Cristina Tenório Cavalcanti Marcelo de Jesus Pereira Shirley Araújo Cabral Nathan da Costa Cavalcanti Bastos

Tabela 1. Distribuição por ano e tipo de material publicado

\begin{tabular}{|l|l|l|l|}
\hline Ano de publicação & \multicolumn{1}{|c|}{ Teses } & Dissertações & Total \\
\hline 2016 & 00 & 01 & 01 \\
\hline 2017 & 01 & 00 & 01 \\
\hline 2018 & 05 & 03 & 02 \\
\hline
\end{tabular}

Fonte: Elaborado pela autora.

Além dos trabalhos trazerem à baila o Professor e Narrativa digital, as produções permeiam diferentes motes como: Ensino de Ciências; Cognição e Linguagem e Educação. É necessário ressaltar que para essa análise seguiremos a ordem dada no Quadro 02 do presente trabalho.

O trabalho T01 teve por objetivo investigar os efeitos do processo de construção de narrativas digitais na percepção de professores de ciências sobre o uso dos tablets na prática docente. O estudo foi de caráter qualitativo cujo percurso metodológico se desenvolveu a partir da confeç̧ão de narrativas digitais que permitiram ao professor rememorar suas experiências relacionadas à tecnologia, em especial ao uso pedagógico do tablet.

Já o estudo 02 apresenta os resultados de uma intervenção realizada com a técnica da narrativa digital (ND), cujo objetivo geral foi investigar se o estímulo de licenciandos a uma relação autoral com a escrita, por meio da produção de NDs, pode influenciar no desempenho da escrita deles e de seus alunos. Para tanto. A metodologia utilizada foi a pesquisa intervenção a fim de compreender a a criação das narrativas digitais. Os resultados dessa experiência demonstraram que a construção de narrativas digitais facilita a relação que os licenciandos e têm com a escrita, uma vez que os sujeitos, ao reconhecerem sua autoria nos diversos usos e combinações expressivas de linguagens, apresentam crescente coesão, coerência e criatividade.

O trabalho T03 buscou analisar as perspectivas educomunicativas que emergem na produção de narrativas digitais por professores do sistema municipal da educação de Lages SC, em relação à utilização das Tecnologias Digitais da Informação e Comunicação (TDIC). Nesse sentido, foram tematizadas as mídias digitais a partir de conceitos que traduzem a 
NARRATIVAS DIGITAIS DE PROFESSORES: UMA REVISÃO SISTEMÁTICA EM TESES E DISSERTAÇÕES BRASILEIRAS
Marcus Alexandre de Pádua Cavalcanti Bastos Eliane Cristina Tenório Cavalcanti Marcelo de Jesus Pereira Shirley Araújo Cabral

Nathan da Costa Cavalcanti Bastos

ressignificação dos comportamentos dos sujeitos nas diferentes esferas da vida cotidiana, com implicações importantes para a educação. A pesquisa desenvolvida foi de caráter qualitativo, com uma abordagem fenomenológica-hermenêutica. Os resultados desta investigação sugerem que as TDIC vêm sendo utilizadas na vida social e nas escolas desses professores e parte deles desenvolve atividades que se aproximam de uma perspectiva educomunicativa.

Seguindo a seqüência foi analisado o estudo T04 que teve como objetivo principal investigar as concepções dos docentes sobre as potencialidades do uso de Aplicativos Educacionais no ensino da Matemática, em um contexto educacional em que o uso dessas tecnologias digitais móveis vem sendo proibido ou restrito ao uso pedagógico. Os sujeitos da pesquisa foram 31 professores de Matemática em atuação na educação básica, da rede pública de ensino de diferentes regiões do Brasil.

O estudo T05 investigou como são produzidas as narrativas digitais multimodais em uma escola de educação infantil, bem como compreender o potencial dessas narrativas como recurso na formação de professores, numa perspectiva crítico-colaborativa. A pesquisa baseou-se na abordagem teórico-metodológica. O contexto da pesquisa foi uma escola pública municipal de São Paulo. Os participantes são uma gestora e dez professores que compõem um grupo de formação da escola em questão. Os dados foram produzidos a partir dos três instrumentos de coleta: questionário semiestruturado sobre registro e documentação pedagógica; os excertos da gravação de áudio das sessões reflexivas e a produção, pelos professores, das narrativas digitais multimodais com recorte das cenas de temas específicos. A análise dos dados foi realizada pelo processo de descrever, informar, confrontar e reconstruir práticas pedagógicas e pela análise multimodal com base nas categorias enunciativas, descritivas e linguísticas. Os resultados indicaram uma desconstrução do senso comum, pelos professores, sobre as produções audiovisuais que permeiam a educação infantil. O processo reflexivo proposto nesta pesquisa sugeriu o desenvolvimento dos participantes por meio de um novo plano de formação em Cadeia Criativa para produzir novos significados às narrativas compartilhadas

O estudo T06 buscou conhecer as concepções dos professores sobre as tecnologias e suas relações com a prática docente. Buscou-se compreender que elementos emergem nesse contexto de formação no sentido de (re)significar o uso das tecnologias - mais 
NARRATIVAS DIGITAIS DE PROFESSORES: UMA REVISÃO SISTEMÁTICA EM TESES E DISSERTAÇÕES BRASILEIRAS
Marcus Alexandre de Pádua Cavalcanti Bastos Eliane Cristina Tenório Cavalcanti Marcelo de Jesus Pereira Shirley Araújo Cabral

Nathan da Costa Cavalcanti Bastos

especificamente do scratch e analisar as implicações da formação com e para as tecnologias, na prática desses professores. O campo empírico da investigação foi um espaço virtual, constituído por um grupo fechado na rede social Facebook. A pesquisa foi de caráter qualitativa, do tipo formação e pretendeu contribuir para a formação continuada de professores para a utilização de tecnologias com base no desenvolvimento profissional e humano dos docentes, por meio da ação reflexiva, na criação e resolução de problemas relacionados às tecnologias no contexto escolar.

Finalizando a seqüência, foi analisado o estudo T07 que abordou a Digital Storytelling (narração digital de histórias) como ato de currículo na formação de professores, tendo como principal objetivo compreender como o conto de histórias por meio digitais pode potencializar as narrativas de si dos professores em formação. A abordagem teórico-metodológica da pesquisa inspirou-se na perspectiva epistemológica da multirreferencialidade $\mathrm{O}$ campo de pesquisa foi realizado na turma da disciplina Tecnologia e Educação do curso de Pedagogia na Universidade do Estado do Rio de Janeiro - UERJ.

\section{CONSIDERAÇÕES FINAIS}

Este trabalho teve como objetivo realizar uma revisão sistemática de teses e dissertações que tratam de narrativas digitais de professores atuantes em escolas de Educação Básica e Educação Superior no país. A análise permitiu observar que o tema foi pouco explorado no cenário brasileiro até 2017. Os resultados apontam que a partir de 2018 houve uma mudança significativa no que se refere ao aumento de pesquisas sobre as narrativas digitais de professores. Entre as áreas mais exploradas, o destaque está para a Educação, em seguida vêm os trabalhos na área de Ensino de Ciências e Cognição e Linguagem.

Os resultados apresentados neste artigo não esgotam todas as possibilidades de análise acerca do tema, tendo em vista que poderiam haver inúmeras outras questões, perfis, bases e suportes que enriqueceriam ainda mais as discussões, todavia, foi possível conhecer algumas tendências de pesquisas. Como toda revisão sistemática, pode-se considerar que o presente estudo vem servir para nortear o desenvolvimento de futuros projetos, indicando novos rumos para futuras investigações. 
NARRATIVAS DIGITAIS DE PROFESSORES: UMA REVISÃO SISTEMÁTICA EM TESES E DISSERTAÇÕES BRASILEIRAS
Marcus Alexandre de Pádua Cavalcanti Bastos Eliane Cristina Tenório Cavalcanti Marcelo de Jesus Pereira Shirley Araújo Cabral Nathan da Costa Cavalcanti Bastos

\section{REFERÊNCIAS}

ALMEIDA, M. E. B.; VALENTE, J. A. Integração currículo e tecnologias e a produção de narrativas digitais. Currículo sem Fronteiras, v. 12, n. 3, p. 57-82, 2012.

ARAÚJO, Cristina Freitas Gonçalves de. TV digital e convergência de mídias: estudo exploratório sobre narrativas interativas. 2010. 129 f. Dissertação (Mestrado em Televisão Digital: Informação e Conhecimento) - Universidade Estadual Paulista Júlio de Mesquita Filho, Bauru, SP, 2010. Disponível em: https://www.faac.unesp.br/Home/PosGraduacao/MestradoeDoutorado/Televisao- Digital/cristiana-freitas-goncalves-dearaujo.pdf. Acesso em: 2 dez. 2019.

BARTHES, Roland. Introdução à análise estrutural da narrativa. In: BARTHES, Roland et al. Análise estrutural da narrativa. 8. ed. Petrópolis: Vozes, 2013. p. 19-62.

BELL, K.R. Online 3.0-The rise of the gamer educator the potential role of gamification in online education. 2014. 166. (Order No. 3635727) - University of Pennsylvania, Ann Arbor, 2014.

BRUNER, J. Atos de significação. 2a ed.Trad. Sandra Costa. Porto Alegre: Artmed, 2002.

The narrative construction of reality. Critical Inquiry, v.17, p.1-21, 2007.

CLARKE, Robert; ADAM, Andrea. Digital storytelling in Australia: academic perspectives and reflections. Arts and Humanities in Higher Education, v. 11, n. 1-2, p. 157-176, 2012. Disponível em: eric.ed.gov/?id=EJ955497. Acesso em: 12 dez. 2019.

CUNHA, M.I. CONTA-ME AGORA! as narrativas como alternativas pedagógicas na pesquisa e no ensino. Revista da Faculdade de Educação, v. 23 n. 1-2, São Paulo Jan./Dec. 1997.

FENTY, Nicole S.; ANDERSON, Elizabeth. Creating digital narratives: guideline for early childhood educators. Childhood Education, v. 92, n. 1, p. 58-63, 2016. Disponível em: http://eric. ed.gov/?id=EJ1086121. Acesso em: 3 dez. 2019.

FREIRE, Patrícia de Sá. Aumente a qualidade e quantidade de suas publicações científicas: manual para elaboração de projetos e artigos científicos. Curitiba: Crv, 2013.

FREIRE, Paulo. Pedagogia do oprimido. 11. ed. Rio de Janeiro: Paz e Terra, 1987.

GALVÃO, C. Narrativas em Educação. Ciência \& Educação, v. 11, n. 2, p. 327-345, 2005.

LOVELL, Sue; BAKER, Sarah. Digital narratives of youth transition: engaging university students through blended learning. Youth Studies Australia, Austrália, v. 28, n. 4, p. 52-59, 2009. Disponível em: http://eric.ed.gov/?id=EJ867260. Acesso em: 2 dez. 2019. 
NARRATIVAS DIGITAIS DE PROFESSORES: UMA REVISÃO SISTEMÁTICA EM TESES E DISSERTAÇÕES BRASILEIRAS
Marcus Alexandre de Pádua Cavalcanti Bastos Eliane Cristina Tenório Cavalcanti Marcelo de Jesus Pereira Shirley Araújo Cabral

Nathan da Costa Cavalcanti Bastos

MILLER, Caroline Handler. Digital storytelling: A Creator"s Guide to Interactive Entertainment. 3. ed. Burlington, EUA: Focal Press, 2014.

RODRIGUES, A.; ALMEIDA, M. E. B. Narrativas digitais na educação e na formação de professores: uma revisão sistemática de literatura. Cadernos de Educação, v.1, n. 56, p. 107-130, 2017.

RODRIGUES, Alessandra; GONÇALVES, Lina Maria. Narrativas digitais na formação de professores: da memória, do registro e do discurso emergem posturas e experiências. Revista Contexto e Educação, ljuí, v. 29, n. 94, p. 212-237, 2014. Disponível em: https://www.revistas.unijui.edu.

br/index.php/contextoeducacao/article/view/3979/4673. Acesso em: 19 dez. 2019.

POLKINGHORNE de Validity issues in narrative research. Qual Inq. 2007;

ROBIN, Bernard R.; MCNEIL, Sara G. What Educators Should Know about Teaching Digital Storytelling. Digital Education Review, Texas, v. 22, p. 37-51, dez. 2012. Disponível em: eric. ed.gov/?id=EJ996781. Acesso em: 12 dez. 2019.

ROBY, Teshia Young. Opus in the classroom: Striking CoRDS with content-related digital storytelling. Contemporary Issues in Technology and Teacher Education, v. 10, n. 1, p. 133144, 2010. Disponível em: http://eric.ed.gov/?id=EJ904607. Acesso em: 15 dez. 2019.

RODRIGUES, Alessandra. Narrativas digitais, autoria e currículo na formação de professores mediada pelas tecnologias: uma narrativa-tese. 2017. $274 \mathrm{f}$. Tese (Doutorado em Educação: Currículo) - Pontifícia Universidade católica de São Paulo, São Paulo, 2017. Disponível em: <https://tede2.pucsp.br/handle/handle/20196>. Acesso em: 07 dez. 2019.

SANTOS, Vanessa Aparecida Schumann; RODRIGUES Alessandra, REZENDE JUNIOR, Mikael Frank. A construção de narrativas digitais por professores de ciências: análise de uma experiência de formação mediada pelas tecnologias. Revista Brasileira de Ensino de Ciências e Matemática , v. 2, p. 99-118, 2019.

SANTOS, Vanessa Aparecida. "Tenho um Tablet, e agora?": Narrativas de professores de Ciências sobre a inserção da Tecnologia Digital na prática docente. 2016. 97 f. Dissertação (Mestrado Profissional em Ensino de Ciências) - Universidade Federal de Itajubá, Itajubá, 2016.

CARVALHO, G. S. As Histórias Digitais: Narrativas no Século XXI. O Software Movie Maker como Recurso Procedimental para a Construção de Narrações. Dissertação (Mestrado em Educação), Universidade de São Paulo. São Paulo, 2008. Disponível em: http://www.teses.usp.br/teses/disponiveis/48/48134/tde-27082010-104511/publico/ Gracinda_Souza_de_Carvalho.pdf. ACESSO em: 28 out. de 2019. 
NARRATIVAS DIGITAIS DE PROFESSORES: UMA REVISÃO SISTEMÁTICA EM TESES E DISSERTAÇÕES BRASILEIRAS
Marcus Alexandre de Pádua Cavalcanti Bastos Eliane Cristina Tenório Cavalcanti Marcelo de Jesus Pereira Shirley Araújo Cabral Nathan da Costa Cavalcanti Bastos

VAZ, Arnaldo, MENDES, Regina, MAUÉS, Ely. Episódios e narrativas de professores: experiências e perspectivas docentes discutidas a partir de pesquisa sobre conhecimento pedagógico de conteúdo. In: REUNIÃO ANUAL DA ANPED, 24, 2001, Caxambu. Anais... Rio de Janeiro, 2001. p. 1-12.

XIN, Joy F. Digital stories in writing instruction for middle school students with autism. CSCanada: Studies In Literature and Languages, Quebec, v. 9, n. 1, p. 1-10, 2014. Disponível em: http:// www.cscanada.net/index.php/sll/article/view/5180/6211. Acesso em: 9 dez. 2019 


\title{
RELAÇÃO COVID-19 X EVASÃO NO ENSINO SUPERIOR LATO SENSU NA MODALIDADE EAD
}

\author{
Dayane Priscila Bicalho de Souza \\ UFVJM \\ dayanepriscila90@hotmail.com
}

\begin{abstract}
RESUMO
O COVID-19 vem afetando vários ramos no mundo todo. Afim de analisar a educação a distância no Brasil, buscou-se identificar a relação entre casos confirmados de COVID-19 e evasão de alunos dentre as cidades e regiões brasileiras. A coleta de dados sobre evasão foi realizada em uma Instituição de Ensino Superior a qual oferta cursos na modalidade EaD em âmbito nacional e os dados sobre Covid-19 foram extraídos do site Coronavírus Brasil. A pesquisa trouxe dados interessantes sobre a relação COVID-19 x Evasão relacionados aos números de desempregos no Brasil podendo destacar a situação financeira dos alunos um dos principais motivos que o leva a evadir. Destaca-se que futuras pesquisas poderão ser realizadas com base no fundamento deste trabalho.
\end{abstract}

Palavras-chave: Pandemia. Evasão de alunos. Desemprego 


\title{
RATIO COVID-19 X DROPOUT IN HIGHER EDUCATION LATO SENSU IN THE EAD MODALITY
}

\begin{abstract}
COVID-19 has been affecting several branches worldwide. In order to analyze distance education in Brazil, we sought to identify the relationship between confirmed cases of COVID19 and dropout rates among Brazilian cities and regions. Evasion data collection was carried out at a Higher Education Institution which offers distance education courses nationwide and data on Covid-19 were extracted from the Coronavirus Brazil website. The research brought interesting data on the relationship between COVID-19 $\times$ Evasion related to the number of unemployed in Brazil, highlighting the students' financial situation, one of the main reasons that leads them to evade. It is noteworthy that future research may be carried out based on the basis of this work.
\end{abstract}

Keywords: Pandemic. Dropout of students. Unemployment 


\section{INTRODUÇÃO}

Pesquisas relacionadas ao COVID-19 vêm sendo realizadas em todo mundo e a cada dia. De acordo com o site Coronavírus Brasil ${ }^{1}$ o COVID-19 é uma doença causada pelo Coronavírus que apresenta uma relação de infecções assintomáticas a quadros graves. Além da saúde, essa doença vem impactando também a economia mundial e brasileira, conforme dados levantados nos últimos meses decorrente ao surgimento da COVID-19.De acordo com a temática, verificou-se publicações brasileiras relacionadas aos impactos causados pela pandemia, sendo os assuntos mais citados: economia e educação.

Dias e Pinto (2020) citam que o confinamento fez com que várias atividades sofressem com a paralisação devido ao COVID-19, inclusive escolas públicas e privadas do ensino básico ao ensino superior. Os autores também ressaltam que secretários e gestores devem pensar na saúde mental dos professores, pois a exaustão mental destes pode interferir no progresso de ensino podendo interferir na evasão.

Entende-se que a evasão é uma variável constante, presente e praticamente inevitável, contudo, uma análise aprofundada no cenário atual será discutida para confirmar os principais fatores que estão levando os alunos a evadirem dos cursos com maior frequência em relação a pandemia.

No entanto, o presente trabalho apresenta uma análise da relação entre evasão de alunos do ensino superior lato sensu e o número de casos de COVID-19 em cidades brasileiras. A coleta de dados de alunos evadidos no período da pandemia foi realizada através de banco de dados de uma Instituição de Ensino Superior (IES), a qual oferta esses cursos na modalidade de Ensino a Distância (EaD). A Instituição e a modalidade EaD foram escolhidas por conter alunos espalhados por toda a região brasileira. Os dados sobre a COVID-19 foram extraídos da base de dados disponibilizada e atualizada diariamente pelo Coronavírus Brasil.

Através da análise desse conjunto de dados, buscou-se identificar a relação entre Covid-19 e evasão no ensino superior de cursos da modalidade EaD (lato sensu) de uma instituição de ensino privada, uma vez que, por serem mais acessíveis e alcançarem um

\footnotetext{
${ }^{1}$ https://covid.saude.gov.br
} 
número maior de pessoas ao contrário de cursos presenciais, esses alunos já estão adaptados a estudar em casa com o apoio de recursos tecnológicos.

\section{REFERENCIAL TEÓRICO}

A necessidade pelo distanciamento social proporcionou um novo desafio para o mundo. Seja no âmbito profissional ou educacional, a continuidade dos processos tem sido afetada diretamente. Consequentemente, na educação não fora diferente. O ensino remoto ganhou espaço em tempos de pandemia, requerendo a adaptabilidade e uso de metodologias e práticas pedagógicas diferentes das salas de aula tradicionais. Todavia, não se pode assegurar que o processo de absorção e conhecimento seja o mesmo (BEZERRA et al., 2020).

No ensino a distância, as dificuldades encontradas durante a pandemia se diferem em boa parte do ensino presencial. Apesar da necessidade de adaptação, vantagens podem ser observadas com a evolução das Tecnologias Digitais da Informação e Comunicação (TDIC's) no EaD. O ensino remoto pode se adaptar a uma forma de ensino similar fazendo uso de ferramentas já utilizadas previamente pelo mesmo, afinal, seu crescimento propiciou o desenvolvimento de novos sistemas e ferramentas a serem utilizadas ao longo dos últimos anos (ABED, 2018).

Foi realizada uma busca por trabalhos relacionados ao tema, utilizando as palavraschave: evasão, EaD, impactos na educação, Ensino Superior e Covid-19. Destaca-se a seguir os principais trabalhos encontrados referentes à busca proposta.

Gomes e Bryto (2018) realizaram uma pesquisa com abordagem qualitativa e quantitativa, onde utilizaram entrevistas com alunos de cursos presenciais com o objetivo de adquirir informações que apontasse os principais fatores para a evasão de alunos de cursos. Os autores destacaram fatores econômicos como principais motivos a não permanência em cursos presenciais.

Maciel et al. (2019) desvelaram publicações como teses, dissertações e artigos, cujos objetivos discorram sobre permanência e evasão na educação superior divulgadas. Os analisados trazem em seus conteúdos assuntos concentrados em evasão em um conjunto de cursos, evasão na EaD e evasão em um curso de uma instituição específica a evasão. Os autores por fim descreveram que os fatores adaptação, rendimento e vivências acadêmicas no ensino superior foram fatores para o abandono do curso. 
Matta et al. (2017) realizaram uma revisão de artigos publicados entre 2005 e 2015, referentes à adaptação universitária relacionada às vivências acadêmicas, afim de investigar o nível de adaptação, rendimento acadêmico e permanência de graduandos de engenharia de uma universidade federal do estado do Paraná. Conclui-se que os relacionamentos interpessoais e o apoio acadêmico podem favorecer o rendimento e adiar a evasão.

O objetivo da pesquisa de Silva e Santos (2017) foi verificar o efeito da concessão de bolsas do PROUNI e FIES na contenção da evasão através de pesquisa quantitativa com dados disponíveis pelo BRASIL (2015d) e INEP (2015). Foi utilizada a técnica de análise de painéis com o software GRETL. A evasão foi obtida ao nível dos Estados e Distrito. Foram coletados dados da evasão de 2005 a 2013 concluindo-se que gestores públicos podem direcionar políticas públicas que tenham eficácia na contenção da evasão haja vista seus efeitos adversos em relação à ociosidade de recursos e perda de receita.

Júnior et al. (2016) realizaram uma pesquisa com o objetivo de identificar os fatores da evasão no curso de Administração Pública a Distância da Universidade Federal de Santa Catarina (UFSC), nas turmas denominadas PNAP 1 e PNAP 2. O trabalho analisou as causas de evasão nesse curso, através de turmas com ingresso em 2009 e 2011, intituladas respectivamente PNAP1 e PNAP2. A amostra foi definida pelo número de respostas retornadas do questionário enviado. No PNAP1 retornaram 37 respostas e no PNAP2 retornaram 12. Além da questão pessoal, os fatores didático-pedagógicos e institucionais estiveram mais presentes como causas da evasão. Concluiu-se também que nas duas turmas, constataram-se dificuldades dos graduandos em se adaptar à modalidade a distância.

Gonçalves et al. (2020) estudaram sobre a evasão nos cursos de graduação presencial do campus Agrícola, utilizando-se quatro variáveis: sexo, idade ao ingressar no curso, renda per capta e cor/raça no IFES em Alegre. Este estudo apontou como perfil do aluno evadido ter mais de 30 anos de idade, ser da cor branca com renda per capta inferior a 0,5 Saláriosmínimos, independente do sexo.

Guerra et al. (2019) objetivaram analisar os fatores que contribuem para a evasão no Curso Superior de Tecnologia em Gestão Pública do Instituto Federal. A pesquisa de cunho exploratório-descritiva, cujos dados foram coletados a partir de fontes primárias (questionário) e secundárias em um universo de 263 alunos que se evadiram ou cancelaram o Curso Superior de Tecnologia em Gestão Pública, destacou, como principais fatores 
causadores da evasão, a dificuldade em conciliar trabalho e estudo, e a dificuldade em conciliar o Curso Superior de Tecnologia em Gestão Pública com outro curso de graduação.

Junior e Real (2020) realizaram uma pesquisa qualitativa através dos bancos de dados do Instituto Brasileiro de Informação em Ciência e Tecnologia (IBICT) e da Coordenadoria de Aperfeiçoamento de Pessoal de Nível Superior (Capes). Com o intuito de analisar o cenário da produção de dissertações e de teses sobre a evasão na educação superior no período de 2000 a 2018, buscaram identificar se e como o fator institucional é apontado como um dos responsáveis por esse fenômeno nas Instituições de Educação Superior (IES) no Brasil. Concluise que o fator institucional relacionado à evasão tem sido pouco explorado nas pesquisas acadêmicas.

Couto e Santana (2017) realizaram uma pesquisa para diagnosticar as causas de dois problemas enfrentados em universidades brasileiras, a evasão e a retenção. A metodologia dos autores aplica algoritmos de classificação em uma grande base de dados totalizando 175.779 ramos utilizando método Random Forest. Os resultados apontaram que o método Rede Bayesiana atingiu precisão geral de aproximadamente $86 \backslash \%$ sendo considerada uma solução satisfatória para descoberta de conhecimento acerca do desempenho acadêmico dos alunos da graduação, prevendo a evasão.

Oliveira et al. (2019) buscaram identificar as principais causas que levam a desistência e nortear o desenvolvimento de ações que impactem na redução desse fenômeno nas IES do país. A metodologia utilizada foi pesquisa qualitativa, através da análise bibliográfica de artigos científicos, que versam sobre o assunto. Observou-se que, aproximadamente $65 \backslash \%$ dos motivos que levam a evasão estão relacionadas a fatores externos e questões pessoais, enquanto $45 \backslash \%$ referem-se ao ambiente acadêmico.

Fatores econômicos e culturais também podem contribuir com a evasão escolar mediante a dificuldades financeiras ou de adaptação. Além disso, a saúde mental também é estudada com o objetivo de compreender as consequências causadas pela doença. De acordo com Kontoangelos et al. (2020) a pandemia do novo Coronavírus pode causar uma preocupação excessiva e exacerbada pela ansiedade existente. O uso da psiquiatria pode ser benéfico para o acompanhamento não somente de pessoas infectadas, como também de suas famílias ou pessoas próximas.

Sobre impactos da pandemia na educação foi possível identificar 03 trabalhos contendo essa informação em seus conteúdos, de acordo com os autores abaixo: 
Oliveira et al. (2019) buscaram evidenciar como as políticas públicas educacionais, direcionadas ao enfrentamento da pandemia de COVID-19, não levam em consideração a realidade desigual de acesso às TDICs e aos bens sociais, econômicos e culturais de professores e estudantes dos sistemas de educação brasileiros. Um questionário virtual, foi aplicado a estudantes e profissionais da educação do Brasil, os dados foram coletados no período de abril a agosto de 2020. Utilizando o software R-Studio os dados coletados foram codificados e categorizado. Os autores, de acordo com a pesquisa, avaliaram que as políticas públicas educacionais direcionadas ao enfrentamento da pandemia da nova corona vírus, até o momento, não levaram em consideração a realidade da situação da educação brasileira.

Granja et al. (2020) realizaram uma análise sobre os impactos causados pela Covid19 na educação do Brasil, a fim de comparar as diferentes consequências na Rede Pública e Privada de ensino. Utilizou-se para este fim, técnicas de estatística descritiva para descrever e sumarizar os dados obtidos através do Formulário que foi enviado para docentes e discentes, para afirmar ou negar algumas hipóteses levantadas sobre esses fatores. Os resultados apontaram que a falta de aparelho tecnológico e a falta de acesso à internet são dois grandes desafios para os alunos durante a pandemia.

Felippe (2020) buscaram reflexões através de pesquisa de caráter quantitativo sobre a realidade dos alunos nesse período e sobre as consequências das escolhas políticas que podem ser feitas pelos cursos e pelas instituições de ensino superior a partir da aplicação de um questionário sobre as condições de permanência desses alunos em tempos de pandemia. Foi possível identificar que alunos estão em situação de maior dificuldade para arcar com seus gastos regulares. A instituição tentou resolver essa situação por meio de bolsas institucionais emergenciais.

Segundo Senhoras (2020), dentre várias consequências e impactos negativos previstos com a pandemia do COVID-19 sobre a educação, destacam-se o comprometimento do processo de ensino-aprendizagem e o aumento da evasão escolar, pois ambos demandam ações contínuas e estratégicas em um curto espaço de tempo, além dos problemas para a normalização dos ciclos escolares a médio prazo.

\subsection{Pandemia e o novo Coronavírus}


No final de 2019, foi descoberto na cidade de Wuhan, na China, um novo vírus com letalidade considerada baixa, variando entre $0,3 \%$ e $3 \%$, mas com elevada capacidade de transmissão. O vírus, denominado como SARS-CoV-2, causador da COVID-19, se espalhava rapidamente, sendo que, em apenas 30 dias já havia disseminado de uma cidade para o país inteiro, em crescimento exponencial (DIAZ-CASTRILLON; TORO-MONTOYA, 2020; WU; MCGOOGAN, 2020)

No Brasil, o primeiro caso da doença foi notificado em 25 de fevereiro de $2020^{2}$ e o número de contagiados pelo vírus tem crescido, desde então, gradativamente, como pode ser observado na Figura1:

Figura 1 - Casos acumulados de COVID-19 por data de notificação



Fonte: Coronavírus Brasil (https://www.gov.br/saude/)

Segundo Santos et al. (2020), a pandemia afetou no contexto mundial, não somente a saúde também aspectos econômicos, sociais e políticos. Na educação 52.898 .349 alunos foram afetados, sendo $52 \backslash \%$ no ensino médio e $20 \backslash \%$ no ensino superior.

\subsection{A Evasão No Ead}

De acordo com o censo EAD.BR ABED (2018), a faixa etária predominante dos estudantes de EaD vai dos 21 aos 30 anos. Para os cursos de pós-graduação, a faixa predominante passa a ser de 31 a 40 anos. A variedade de cursos oferecidos em EaD no Brasil continua expressiva, o que garante uma grande abrangência dessa modalidade de ensino.

\footnotetext{
${ }^{2}$ https://www.gov.br/saude/
} 
No que tange às taxas de evasão, embora continuem sendo uma preocupação para o mercado de $\mathrm{EaD}$, em comparação com os anos anteriores, esses números têm reduzido. Acredita-se que o estudo e o conhecimento das causas da evasão tenham contribuído significativamente com o controle desse fenômeno. Se em 2017, aproximadamente $50 \%$ das instituições com fins lucrativos e públicas federais desconheciam o motivo das evasões, em 2018 , como revela o gráfico da Figura 2, o nível de conhecimento aumentou para $88,2 \%$ das instituições que oferecem cursos regulamentados totalmente a distância e conhecem os motivos de evasão.

Figura 2 - Instituições que afirmam conhecer os motivos de evasão por modalidade

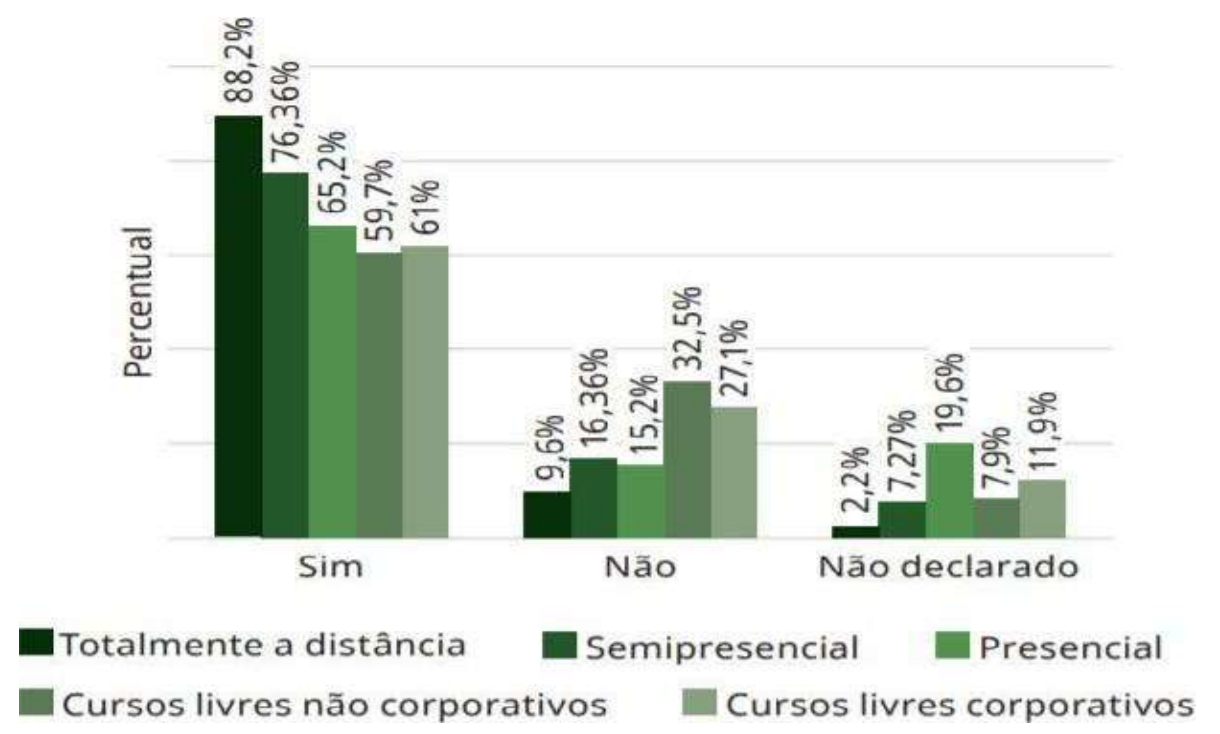

Fonte: Censo (ABED, 2018)

Para Velho (2005), as taxas de evasão estão muito mais associadas à cultura institucional dos programas de pós-graduação, tais como a falta de uma comunidade como referência, seja intelectual ou social, levando o estudante a trabalhar de forma isolada. Ademais, à falta de conhecimento e discussão sobre as normas e expectativas do programa. A autora cita ainda a falta de informação prévia sobre o conteúdo do programa e de orientação sobre o mercado de trabalho futuro.

De acordo com Ferreira et al. (2020), características do aluno e seu relacionamento com a Instituição de Ensino podem interferir em sua permanência ou não no curso escolhido. Os autores realizaram uma pesquisa bibliográfica com o intuito de abranger fatores preditores sobre evasão, destacando que nenhum fator é isolado, porém os que mais se destacam são fatores emocionais e relações com a instituição e equipe pedagógica. 
Contudo, grandes partes referem-se basicamente ao relacionamento entre instituição e aluno. Pouco se considera os fatores externos como grandes influentes na evasão de alunos de programas de pós-graduação.

\section{Materiais e Métodos}

A metodologia aplicada é de cunho quanti-qualitativa buscando compreender a relação do número de evasão de alunos de cursos lato sensu da modalidade EaD e o número de casos de COVID-19 em âmbito nacional.

A coleta de dados de alunos evadidos de cursos de pós-graduação lato sensu na modalidade EaD foi realizada através do banco de dados de uma IES que oferta cursos para alunos de todo o Brasil. A mesma foi escolhida por ter um grande número de alunos matriculados em cursos de pós-graduação, totalizando aproximadamente 300 mil estudantes pela modalidade EaD. Os dados sobre a COVID-19 são fornecidos por sites organizacionais do governo, que fornecem dados como número de casos, mortes, entre outros. Esses dados foram relacionados para identificar a possível relação entre o maior e o menor número de casos de COVID-19 e alunos que evadiram dos cursos no período de 01 de janeiro de 2020 a 17 de novembro de 2020 .

Através do banco de dados da IES foi possível coletar dados de 17.305 alunos que realizaram o cancelamento do curso no período de 01/01/2020 a 17/11/2020. As informações levantadas desses alunos foram: cidade, estado, data de nascimento e sexo (masculino ou feminino). De acordo com o IBGE, o Brasil possui 5.570 municípios. Através do banco de dados Institucional constata-se a existência de alunos em 2685 cidades distintas, sendo 14.075 do sexo feminino e 3.325 do sexo masculino totalizando 17.400 alunos evadidos nesse período.

Sendo valores que ainda crescem constantemente, o número utilizado sobre casos confirmados de COVID-19 nos estados brasileiros foi o total de 6.901 .990 registrados na base nacional na data: 14 de dezembro de 2020.informados pelo do $\mathrm{G} 1^{3}$.

\footnotetext{
${ }^{3}$ https://g1.globo.com
} 


\section{Resultados e Discussão}

Realizou-se inicialmente, análise dos dados coletados em uma instituição de ensino superior provada. A primeira análise foi referente ao número elevado de evasões no ano de 2020 (com pandemia) referente ao ano anterior (2019). A Figura 3 apresenta o somatório das evasões registradas nos dois anos para o mesmo período (janeiro - novembro).

Figura 3 - Aumento de evasões em 2020

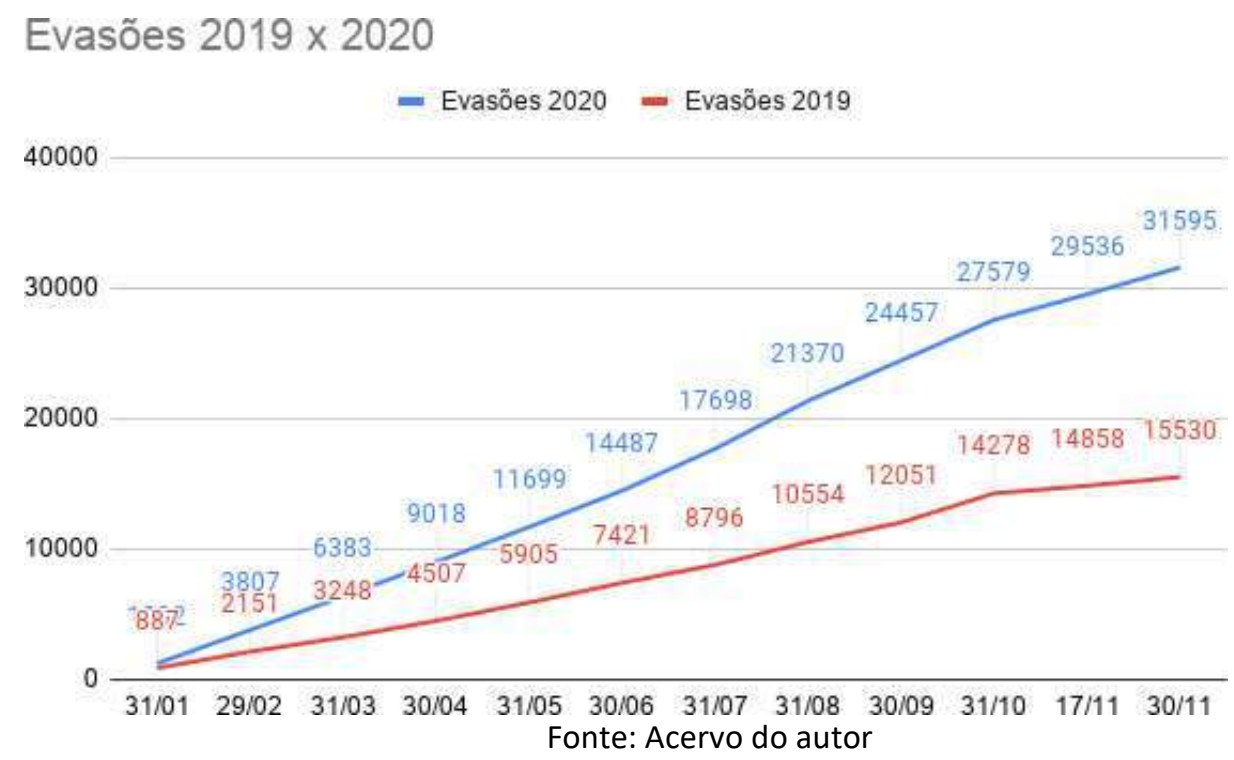

Nota-se que, em ambos os casos, o número de evasões cresceu regularmente ao longo do ano. Além disso, a quantidade de evasões em 2020 esteve sempre próxima do dobro registrado no ano anterior. Paralelamente, o número de casos de COVID registrados ao longo do ano, no mesmo período, é apresentado na figura 4.

Figura 4 - Número de casos de COVID

\section{Casos confirmados de COVID}

8000000




A Figura 5 traz um gráfico com as opções assinaladas por um número de 170 alunos que cancelaram suas matrículas dos cursos de EaD, de uma instituição de ensino privada, num período registrado de novembro de 2018 até novembro de 2019, ou seja, antes da pandemia, mostrando que a situação financeira do aluno também foi um fator que influenciou para a desistência do curso.

Figura 5 - Justificativa por evasão segundo alunos

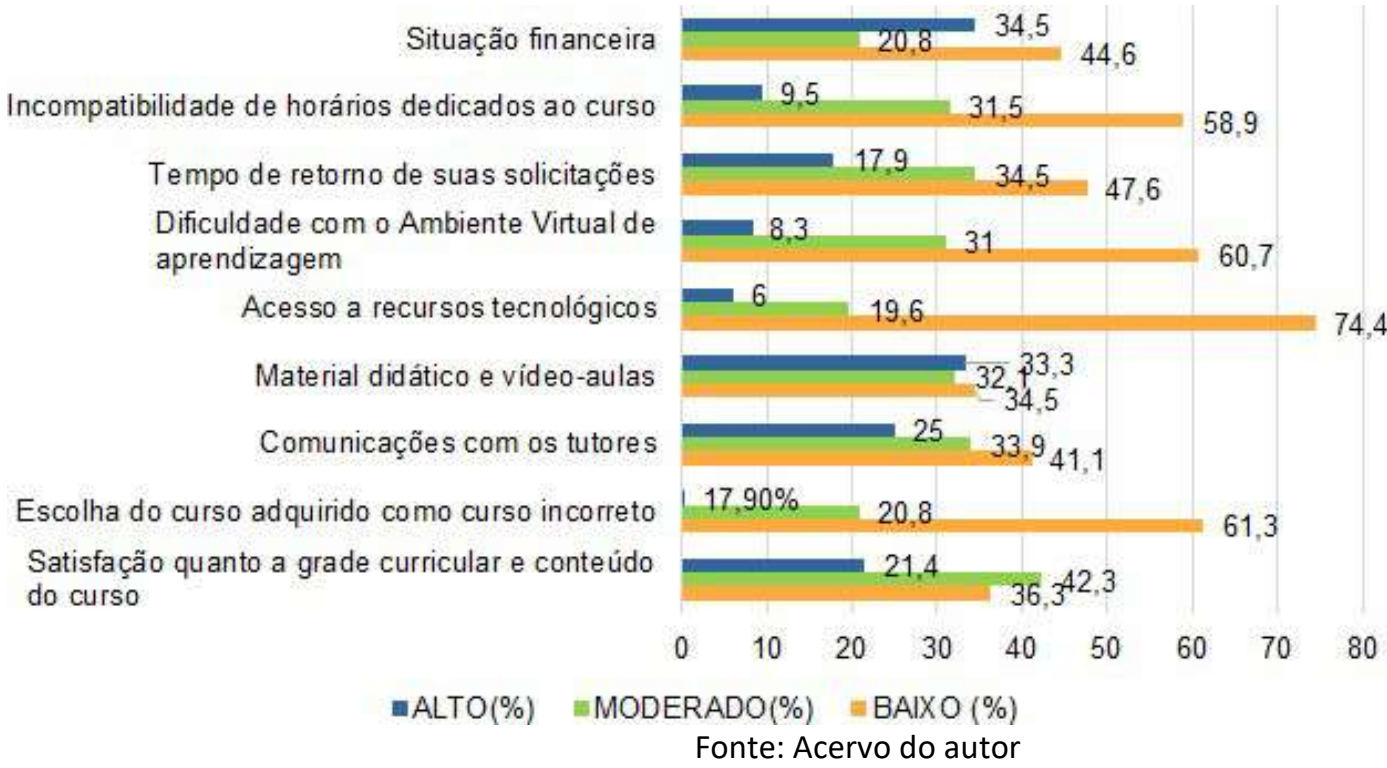

A partir do gráfico exposto na Figura 6 é possível identificar que os maiores índices de desemprego referente ao período de maio a setembro de 2020 foram registrados nos estados da Bahia, Maranhão, Amazonas, Amapá, Alagoas e Rio de Janeiro. Os maiores índices de evasão concentram-se nos estados de São Paulo, Minas Gerais, Rio de Janeiro, Bahia, Ceará e Distrito Federal, de acordo com o período avaliado de janeiro de 2020 a meados de novembro de 2020. Já os estados com maiores números de casos de COVID-19 acumulados até 14 de dezembro de 2020 foram registrados em São Paulo, Minas Gerais, Bahia, Santa Catarina, Rio de Janeiro e Acre. 


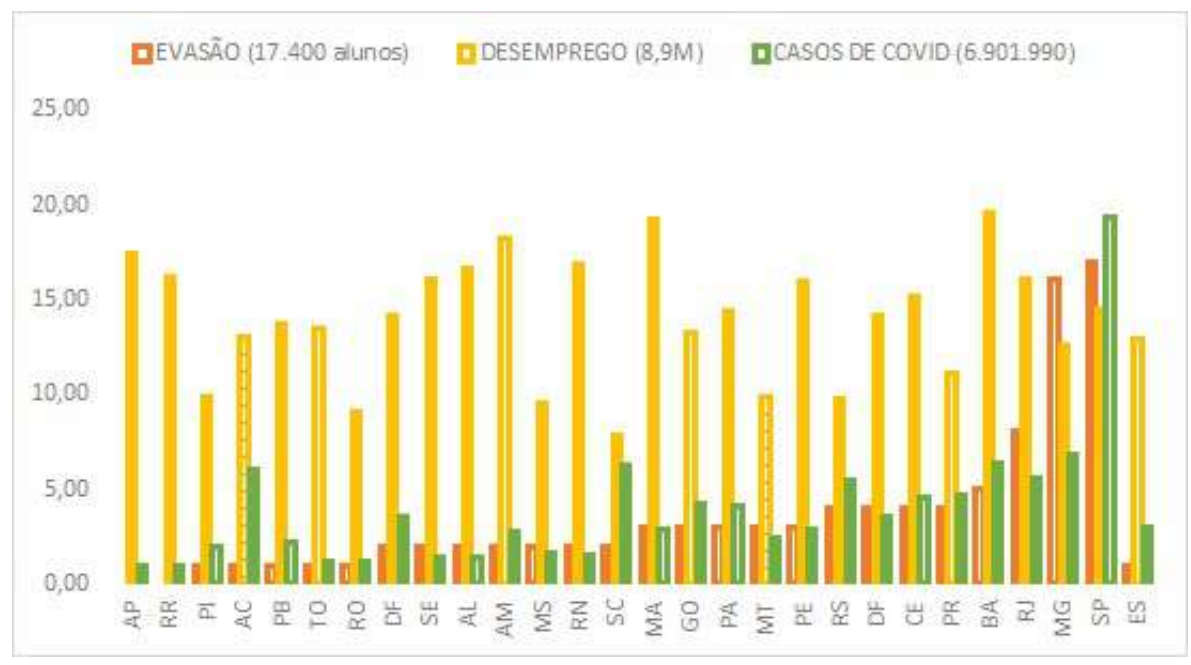

Fonte: Acervo do autor

A partir deste gráfico, os fatores evasão com 17.400 alunos, desemprego com 8,9 milhões e 6.901.990 casos de COVID-19 apresentados possuem valor percentual por estados, apresentando substancialmente taxas mais elevadas nas mesmas regiões, o que pode significar uma correlação entre estados com maior índice de evasão, maior taxa de desemprego e maior número de caso de COVID-19. Segundo Neves et al. (2020)p.4,"aumento do desemprego traduz-se na queda da renda do consumidor", essa afirmação se associa ao abandono escolar privado, uma vez que não terão como manter as mensalidades.

\section{Conclusão}

Através do número de trabalhos relacionados e assuntos abordados em seus conteúdos, foi possível identificar que ainda há poucos trabalhos abordando sobre fatores econômicos como impacto na evasão. Dentre os trabalhos relacionados, foi possível identificar conclusões sobre a evasão na educação presencial e EaD, destacando dificuldades como, o acesso à Internet, Tecnologias de Informação e Comunicação e fatores institucionais como grandes responsáveis para a evasão antes e durante a pandemia. Salienta-se que alunos tiveram que se adaptar totalmente ao ensino remoto, logo, tiveram dificuldades em conciliar trabalho, família e estudo. Crê-se que esses fatores persistem como motivos para evasão, mas entende-se com esse estudo, que há outros fatores que estão envolvidos para esse desfecho no período de pandemia. 
De acordo com os dados institucionais abordados, foi capaz identificar uma possível relação entre taxa de desempregos, números de casos de COVID-19 e evasão em estados semelhantes do Brasil. Porém, esse estudo foi realizado com levantamento de dados de nível nacional relacionado a uma porcentagem de alunos evadidos de apenas uma instituição de Ensino. Afim de confirmar essa afirmação, sugere-se que futuras pesquisas sejam realizadas, investigando dados institucionais e aplicação de questionários a alunos evadidos de outras instituições que ofertem cursos na modalidade EaD, com o intuito de atingir uma maior parte dos estados brasileiros.

\section{REFERÊNCIAS}

ABED. Relatório analítico da aprendizagem a distância no Brasil. [S.I.]: Editora Intersaberes, 2018. v. 1. 215 p.

AMBIEL, Rodolfo Augusto Matteo et al. Motivos de evasão na pós-graduação no Brasil: um instrumento de medida. Interação em Psicologia, v. 24, n. 1, 2020.

ÁVILA, Alinny Luiza Ricco. CAUSAS DA EVASÃO DISCENTE NO CURSO DE ESPECIALIZAÇÃO À DISTÂNCIA EM ENSINO DE SOCIOLOGIA/IFCH/UFRGS. Revista Contraponto, v. 5, n. 1, 2018.

BRANCO, Lilian Soares Alves; CONTE, Elaine. EVASÃO NA EDUCAÇÃO A DISTÂNCIA: PRINCÍPIOS E PERSPECTIVAS SOBRE A QUESTÃO. SEFIC 2017, 2017.

BEZERRA, Kelianny Pinheiro et al. Ensino remoto em universidades públicas estaduais: o futuro que se faz presente. Research, Society and Development, v. 9, n. 9, p. e359997226e359997226, 2020.

COUTO, D.; SANTANA, A. Mineração de Dados Educacionais Aplicada à Identificação de Variáveis Associadas à Evasão e Retenção. In: Araújo A.; Rebouças A.; Souza F.; Aguiar Y. II Congresso sobre Tecnologia na Educação. 2017. p. 333-344.

DA SILVA, Adriano Maniçoba; SANTOS, Beatriz Carolini Silva. Eficácia de políticas de acesso ao ensino superior privado na contenção da evasão. Avaliação: Revista da Avaliação da Educação Superior, v. 22, n. 3, p. 741-757, 2017. 
DE OLIVEIRA, Bruna; GUIMARÃES, Lucas José; SANTANA, Thainá Nunes Pires. O CAMINHO PARA A REDUÇÃO DA EVASÃO DE ESTUDANTES NAS INSTITUIÇÕES DE ENSINO SUPERIOR. Humanidades \& Inovação, v. 6, n. 18, p. 155-164, 2019.

DE SOUSA GOMES, Bruna Valéria; BRYTO, Klêner Kleni Costa. A evasão no ensino superior presencial: O curso de Administração da Estácio do Pará, sob o olhar das forças macroambientais de Porter. Revista de Administração e Contabilidade-RAC, v. 5, n. 9, p. 128145, 2018.

DIAS, E; PINTO, F. C. F. A educação e a covid-19. Ensaio: Avaliação e Políticas Públicas em Educação, SciELO Brasil, v. 28, n. 108, p. 545-554, 2020.

DÍAZ-CASTRILLÓN, Francisco Javier; TORO-MONTOYA, Ana Isabel. SARS-CoV-2/COVID-19: el virus, la enfermedad y la pandemia. Medicina y Laboratorio, v. 24, n. 3, p. 183-205, 2020.

FELIPPE, Jonis Manhães Sales. Permanência na educação em tempos de Pandemia: reflexões a partir da licenciatura em Letras do IFF. Revista Tempos E Espaços Em Educação, v. 13, n. 32, p. 69, 2020.

FERNANDES, Eduardo Francisco et al. PANORAMA DO FENÔMENO DA EVASÃO DISCENTE NA PÓS-GRADUAÇÃO: UMA ANÁLISE A PARTIR DO GEOCAPES. 2017.

FERREIRA, Ludmila de Oliveira Amaral et al. Preditores de permanência e evasão em cursos superiores a distância: revisão de literatura. Devir Educação, p. 225-246, 2020.

GONÇALVES, Oldair Luiz; TUDE, João Martins; JUNIOR, Jair Sampaio Soares. Evasão e permanência em cursos superiores de uma Instituição Agrícola-o caso do Campus Alegre do IFES. Revista Cocar, v. 14, n. 28, p. 322-340, 2020.

GUERRA, Lenin Cavalcanti Brito; FERRAZ, Rita Maria Correia; MEDEIROS, Jássio Pereira. Evasão na educação superior de um instituto federal do nordeste brasileiro (Evasion in higher education of a federal institute of the brazilian northeast). Revista Eletrônica de Educação, v. 13, n. 2, p. 533-553, 2019.

JUNIOR, José da Silva Santos; REAL, Giselle Cristina Martins. Fator institucional para a evasão na educação superior. Revista Internacional de Educação Superior, v. 6, p. e020037-e020037, 2020. 
MACIEL, Carina Elisabeth; CUNHA JÚNIOR, Mauro; LIMA, Tatiane da Silva. A produção científica sobre permanência e evasão na educação superior no Brasil. Educação e Pesquisa, v. 45, 2019.

MATTA, Cristiane Maria Barra da; LEBRÃO, Susana Marraccini Giampietri; HELENO, Maria Geralda Viana. Adaptação, rendimento, evasão e vivências acadêmicas no ensino superior: revisão da literatura. Psicologia Escolar e Educacional, v. 21, n. 3, p. 583-591, 2017.

OLIVEIRA, Pedro Rodrigues de; OESTERREICH, Silvia Aparecida; ALMEIDA, Vera Luci de. Evasão na pós-graduação a distância: evidências de um estudo no interior do Brasil. Educação e Pesquisa, v. 44, 2018.

PIMENTEL, Fernando Silvio Cavalcante; DE FRANÇA LIMA, Mônica Rejane. Evasão na EAD: o caso do curso de pós-graduação em EDHDI/UFAL. Debates em Educação, v. 10, n. 21, p. 185199, 2018.

SILVA, Vinícius Delfino; PASSOS, Marize Lyra Silva; NOBRE, Isaura Alcina Martins. EVASÃO NA EDUCAÇÃO A DISTÂNCIA: AS CAUSAS DO ABANDONO EM UM CURSO DE PÓS-GRADUAÇÃO LATO SENSU. Revista Ifes Ciência, v. 5, n. 2, p. 114-124, 2019.

SOUSA, Andréia da Silva Quintanilha; MACIEL, Carina Elisabeth. Expansão da educação superior: permanência e evasão em cursos da Universidade Aberta do Brasil. Educação em Revista, v. 32, n. 4, p. 175-204, 2016.

VELLOZO, Sarah Rachel Gonczarowska et al. Evasão na educação a distância: uma revisão sistemática. Revista EDaPECI, v. 19, n. 3, p. 85-94, 2019. 
ESTUDO DE CASO À LUZ DA PSICOLOGIA SÓCIO-HISTÓRICA SOBRE O FILME “EXTRAORDINÁRIO": ANÁLISE DA AUTOESTIMA DO PERSONAGEM AUGGIE PULLMAN

\author{
Gilson Gomes Coelho \\ Faculdade Católica Dom Orione, Araguaína, TO, Brasil \\ gilsonpsico@gmail.com \\ Ana Luiza Machado Fulaneti \\ Faculdade Católica Dom Orione, Araguaína, TO, Brasil \\ analuizafulaneti@catolicaorione.edu.br \\ Maycon Douglas Silva Ribeiro \\ Faculdade Católica Dom Orione, Araguaína, TO, Brasil \\ maycondouglasribeiro@catolicaorione.edu.br
}

\begin{abstract}
RESUMO
Este artigo tem o objetivo de analisar o processo de construção da autoestima do protagonista Auggie Pullman do filme "O extraordinário", através de uma pesquisa qualitativa, do tipo estudo de caso e baseada na teoria da Psicologia Sócio-Histórica. Com estas metodologias verificou-se que o processo de instituição da autoestima do garoto se realiza a partir da predominância de comportamentos positivos, oriundos sobretudo da família: contribuindo para um desenvolvimento satisfatório dos processos de internalização de acordo com o repertorio histórico cultural do seu próprio meio. Neste enfoque, concluímos que os marcadores sociais que influenciam na autoestima de Auggie é primeiro a sua família e de maneira assistente o contexto escolar apenas sinalizado no trabalho sem maior foco. Porém, observamos que mesmo na ocorrência de comportamentos positivos, somam também os negativos, que impactam no processo de construção da autoestima de Auggie, o que se verifica ao mesmo tempo que a família e entre outros marcadores sociais podem contribuir assertivamente, por outro lado, também podem colaborar negativamente.
\end{abstract}

Palavras-chaves: Autoestima. Família. Psicologia sócio-histórica. 


\title{
CASE STUDY IN THE LIGHT OF SOCIO-HISTORICAL PSYCHOLOGY ABOUT THE FILM "WONDER": ANALYSIS OF OF THE SELFESTEEM OF AUGGIE PULLMAN CHARACTER
}

\begin{abstract}
This article aims to analyze the process of building the selfesteem of the protagonist Auggie Pullman from the film "Wonder", through a qualitative research, of the case study type and based on the theory of Socio-Historical Psychology. With these methodologies it was found that the process of institution of the boy's selfesteem takes place from the predominance of positive behaviors, mainly from the family: contributing to a satisfactory development of the internalization processes according to the cultural historical repertoire of his own environment. In this approach, we conclude that the social markers that influence Auggie's selfesteem are first his family and, in an assistant way, the school context only signaled at work without greater focus. However, we observed that even in the occurrence of positive behaviors, there are also negative ones, which impact on the process of building Auggie selfesteem, which is verified at the same time that the family and among other social markers can assertively contribute, on the other hand, they can also collaborate negatively.
\end{abstract}

Keywords: Selfesteem. Family. Psychology Socio-Historical. 


\section{INTRODUÇÃO}

O presente artigo se trata de um estudo de caso à luz da Psicologia Sócio-Histórica, tendo por objetivo analisar o personagem Auggie Pullman do filme Extraordinário, somado ao objetivo de analisar, a nossa finalidade é mostrar aspectos do processo de construção da autoestima do personagem frente ao contexto que o lança em experiências negativas e positivas que repercutem na construção da autoestima de Auggie. Em vista disso, a proposta teórica da Psicologia Sócio-Histórica mostra que a autoestima se dá na interação com o meio onde o indivíduo vive e se relaciona com outros sujeitos, onde por meio desta interação poderá sofrer experiências satisfatórias ou insatisfatórias que contribuem para comportamentos e consciência de si mais adequados ou inadequados (LUCCI, 2006).

O filme de produção estrangeira, com título principal da língua inglesa: Wonder, (traduzido ao português: Extraordinário), é baseado no romance da norte-americana R. J. Palácio, cujo o filme leva o mesmo nome, lançado em 2017 pela Paris Filmes, o longametragem tem a direção de Stephen Chbosky e conta com o elenco: Julia Roberts, Jacob Tremblay e Owen Wilson. Com classificação não recomendada à menores de 10 anos, o filme narra a história do menino Auggie Pullman (interpretado pelo ator mirim Jacob Tremblay).

Auggie Pullman é um garoto que nasceu com uma deformação facial, o que o fez passar por 27 cirurgias plásticas. Aos 10 anos de idade, Auggie precisará pela primeira vez frequentar uma escola regular assiduamente, como qualquer criança de sua idade. Na rua e muito mais na escola precisará lidar com os olhares alheios sobre a sua estética facial muito sempre causando estranheza, sendo constantemente observado por todos à sua volta.

Sua inserção no ambiente escolar, como para qualquer criança, representa um marco em sua vida. Trata-se do primeiro contato com o mundo externo à sua casa e à sua família. Esse momento faz parte de um processo crucial para o desenvolvimento de habilidades sociais, pois exige dele iniciativa para conhecer novas pessoas, compreender a autoridade de pessoas desconhecidas sobre ele, e uma infinidade de novas experiências. O que para o garoto é ainda mais intenso, uma vez que, com sua condição facial muitas pessoas poderão sentir receio, evitando uma aproximação. Para Vygotsky (1991), em sua obra A Formação 
Social da Mente propõe que o homem na sua especificidade de ser humano desenvolve processos superiores, como o pensamento e o planejamento por exemplo, os quais se expandem a partir da socialização com o meio se tornando por meio disso cada vez mais refinado e aprimorado. "As funções cognitivas e comunicativas da linguagem tornam-se, então, a base de uma forma nova e superior de atividade nas crianças" (VYGOTSKY, 1991, p.23), isto é, esse processo de expansão se dá desde o início da vida, e a linguagem torna-se uma facilitadora disso.

Conforme Neves e Damiani (2006), e Freitas (2000), as relações sociais fazem parte da estruturação do sujeito a partir do viés da Psicologia Sócio Histórica, segundo eles, Vygotsky entende que essas relações se dão por um caráter semiológico, na qual os chamados instrumentos e signos farão esse papel mediador do sujeito para com o meio. Segundo Joenk (2007) os instrumentos mediam o homem com o objeto de seu trabalho, possibilitando sua ação sobre a natureza e modificando-a, sendo um elemento externo a ele. Já os signos funcionam como instrumentos psicológicos, sobre os quais Vygotsky (1999 apud JOENK, 2007, p.5) diz que " a invenção e o uso de signos como meios auxiliares para solucionar um dado problema psicológico (lembrar, comparar coisas, relatar, escolher, etc.) é análoga à invenção e uso de instrumentos, só que agora no campo psicológico". Isto é, voltado para o próprio sujeito. O signos e instrumentos agem contribuindo na organização psíquica dos conteúdos recém obtidos a partir do que já existe socialmente, historicamente e culturalmente, sendo internalizados, constituindo sua própria consciência a respeito deles. Dessa forma, assim como os signos e instrumentos, o sujeito é um ser social, histórico e cultural.

Mediante esta estruturação mediadora do sujeito, de acordo com a proposta de Vygotsky para os indivíduos com deficiências múltiplas (1993, p.30), ele dirá que "uma criança cujo desenvolvimento é impedido por um defeito não é simplesmente uma criança menos desenvolvida do que seus pares, mas uma criança que se desenvolveu de maneira diferente". Ou seja, para Vygotsky (1993), o defeito ou deficiência, no caso de Auggie, sua deformação facial não o impediria de desenvolver-se como qualquer outra criança de sua idade em condições facilitadoras do desenvolvimento, porém, ao caso do personagem ou de qualquer condição que se assemelhe à esta, os impactos podem vir a ser predominantemente mais negativos dado a ações sociais não acolhedoras como o preconceito e a discriminação. Neste 
caso, desenvolver-se de maneira diferente como aponta Vygotsky (1993), pode implicar em maiores estratégias que não são comuns entre seus pares que não apresentam algum defeito, mas sendo efetivamente possível desenvolver-se. Estas maiores estratégias como colocamos, podemos verificar nas diferentes sociedades por meio da disposição cultural que elaborou, e ainda hoje cria formas inclusivas para as diferentes deficiências humanas (por exemplo, as pessoas com deficiência visual, cegas, foram desenvolvidos livros escritos em Braille), onde funcionam igualmente como mediadores da aquisição de conhecimento para os inscritos nesta condição humana.

Dessa maneira, ao retratarmos o filme alguns elementos como: a autoestima, e o contexto familiar serão destacados para a análise na concepção da Psicologia Sócio Histórica para investigação da construção da autoestima no personagem. Ao apontarmos a autoestima como um fator influente na análise do nosso caso, é preciso considerar que ela se constitui por meio dos padrões estéticos instituídos historicamente, no qual ao nível psicológico constitui uma consciência de si alinhada as expectativas e normas sociais enquanto parâmetro regulador do bonito ou feio (ROCHA, 2003; LANE, 2014).

A teoria Sócio-Histórica ou Psicologia Sócio Histórica, tem como fundador Lev Semionovitch Vygotsky, um importante psicólogo e intelectual do século XX que construiu uma das teorias do desenvolvimento humano de referência até hoje, sendo o seu diferencial entre os outros teóricos do desenvolvimento humano, o conceito onde, para que o indivíduo se desenvolva ocorrerá fundamentalmente uma interação social possibilitada através de mediadores, tendo a linguagem como principal, sendo também, as condições de vida um indicador potencializador deste desenvolvimento humano (LUCCI, 2006).

Consolidada na antiga união soviética (hoje a atual Rússia), a teoria sócio-histórica surgia então em oposição as psicologias da época, onde Vygotsky por sua vez exerce um papel crítico entre as várias formas da atuação da ciência psicológica, estabelecendo novas maneiras do fazer psicológico atrelado às diversas faces da realidade humana, com bases epistemológicas singulares no olhar ao sujeito, na indispensável perspectiva da interação social, cultural, histórica, e individual ao qual se inscrevem os indivíduos por mediação da linguagem (LUCCI, 2006). 
A psicologia sócio histórica se esforça na formulação de explicações sobre a construção do psiquismo sem separá-lo das condições concretas que sustentam sua formação epistêmica, identificando no materialismo histórico e dialético da filosofia de Karl Marx, o aporte de sua proposta. Sendo assim, as contribuições da epistemologia marxiana estão concretizadas na psicologia sócio histórica desde seu plano teórico, metodológico, investigativo, e à sua práxis (MARTINS, 2008), oferecendo um arcabouço teórico comprometido com a complexidade da realidade humana e os desdobramentos históricos, culturais e sociais no transcorrer das épocas e dos fenômenos concretos à disposição.

\section{METODOLOGIA}

Para nossa análise utilizamos duas bases metodológicas, a primeira se trata do tipo de pesquisa estudo de caso, e a segunda é a teoria: Psicologia Sócio Histórica, já apresentada anteriormente. $\mathrm{O}$ estudo de caso está inscrito no caráter qualitativo da pesquisa, é "um tipo de pesquisa cujo objeto é uma unidade que se analisa profundamente. Visa ao exame detalhado de um ambiente, de um simples sujeito ou de uma situação em particular" (GODOY, 1995, p. 25). Esta metodologia permite uma investigação cuidadosa com alcance de características holísticas e subjetivas dos eventos da vida real, desde processos coletivos e maturacionais, dado algum desenvolvimento da vida humana (YIN, 2001). O estudo de caso tem sido um método comum da pesquisa em psicologia, sociologia, e demais áreas das ciências humanas. A adoção destas metodologias permitirá analisar e discutir sobre quais as características implicam no processo de construção da autoestima do personagem

\section{ANÁLISE E DISCUSSÃO: ASPECTOS E CONSTRUÇÃO DA AUTOESTIMA DO PERSONAGEM AUGGIE PULLMAN}

É exatamente a atividade criadora que faz do homem um ser que se volta para o futuro, erigindo-o e modificando o seu presente. (VYGOTSKY, 2018, p. 16)

Na modernidade, cada vez mais somos lançados à uma cultura da boa aparência, onde a beleza é a medida para a aceitação ou rejeição, não ter alguma beleza, então, corresponde 
a ser rejeitado (ROCHA, 2003). É a autoestima também um fator fundamental no desenvolvimento humano, ter uma boa estética abre muitas vantagens nas relações sociais. Ainda que tenhamos criado parâmetros estéticos que medem o bonito ou feio, há um valor social crítico que coloca a essência interna das pessoas como sendo realmente o que importa, porém, na realidade, ainda que exista esse reconhecimento sobre a essência interna dos sujeitos acontece que o que se sobressai socialmente são os critérios estéticos que são por vezes limitantes das relações entre os sujeitos.

A autoestima ou autoimagem como preferem alguns autores, é concebida na interação do indivíduo com os aspectos da vida social, é dada como a atitude valorativa que o sujeito tem sobre sua própria imagem (ROCHA, 2003). A autoestima se define de modo geral sobre a maneira como cada sujeito individualmente se vê e pensa sobre si, podendo citar todos os aspectos do seu próprio "eu" ou de si mesmo enquanto pessoa; suas características físicas, sua personalidade, sua capacidade, etc.

Segundo Franco e Davis (2011, p. 99):

\begin{abstract}
Autoestima é, então, vista enquanto uma valoração que o sujeito faz acerca do que acredita ser, uma apreensão construída nas relações que ele mantém com o mundo físico e social. Dessa forma, a autoestima não é natural, dada ou inata ao homem: ela é algo tênue, que surge das diferentes formas pelas quais se significam as situações vividas ao longo da vida. Pode ser, assim, predominantemente positiva ou negativa, ainda que as significações sejam sempre contraditórias e nem sempre claras. De qualquer maneira, a tendência positiva ou negativa, se recorrente, tende a se estabilizar. Por outro lado, como a vida sempre oferece novas circunstâncias ao sujeito, tais significações podem vir a ser modificadas, sofrendo, mesmo, alterações de vulto, que imprimem uma nova marca na consciência de si.
\end{abstract}

Ou seja, essa nova marca é dada junto a novas possibilidades ao indivíduo, onde, em um longo processo de construção da sua personalidade inscrita no mundo material e na relação com os outros; se revelará as novas autoavaliações acerca de como se vê, o que se faz ou deixa de fazer, podendo ser esta nova marca uma alteração de vulto que corresponde à um olhar mais complacente de si; sobre a própria estética e o próprio corpo. No entanto, há uma diversidade estética que marca, então, a consciência de si enquanto da qualidade do que é diferente, e não anormal, ou estranho, apenas diferente (FRANCO E DAVIS, 2011). 
Tais possibilidades de modificação dos significados sobre a própria consciência de si estão inseridas no contexto social e pessoal. Assim, a sociedade impacta diretamente na transformação e na aquisição de uma autoavaliação positiva, como também a família enquanto contexto pessoal (ROCHA, 2003; FRANCO E DAVIS, 2011).

Neste sentido, a inserção do garoto ao ambiente escolar e familiar conta com muitas emoções, situações, alterações e significados. Na escola, logo que faz sua matrícula, o diretor Busanfa imagina que Auggie teria dificuldades em se inserir socialmente, por demonstrar aparentemente receio a nova experiência com o ambiente escolar e as novas pessoas que fariam parte do seu cotidiano a partir dali. Sendo assim, na intenção de aproximá-lo dos outros, o diretor pede para que três crianças que já estudam no colégio (Jullian Albans, Charlotte Cody e Jack Will), apresentem a escola ao novo e distinto colega de turma. Porém, a presunção do garoto Jullian que faz algumas chacotas e questiona a inteligência de Auggie ao fato de não frequentar uma escola na idade regular, e a orgulhosa garota Charlotte que fala deliberadamente sobre si mesma, acabam não sendo estratégias tão receptivas. Mas Jack Will, mesmo tendo ido contra sua vontade e movido pela "piedade" e o "medo" de parecer ingrato por sua bolsa de estudo oferecido pelo programa escolar, demonstra alguma abertura para Auggie, o que mais tarde se torna em uma amizade, havendo apenas alguns desentendimentos que contribuem negativamente à autoestima de Auggie.

A partir disso, nos primeiros meses de aula, Auggie e Jack constroem uma relação de companheirismo. Até que chega à data mais esperada do ano, o halloween, onde para Auggie: "ninguém se importa com as aparências, já que parecer estranho é a intenção das fantasias nesta data". Mas no contexto da tal festa, Auggie escuta o próprio Jack falando palavras ofensivas sobre ele junto ao Jullian (em tom de segredo) como se Auggie representasse um monstro por causa do seu rosto diferente. Nesse momento, a data comemorativa perde o encanto para Auggie e consequentemente seu encanto pelo amigo também. Depois da festa, ao chegar em casa, Auggie fala do ocorrido e tem o apoio de sua irmã, Via, que mesmo passando por momentos ruins, convence o irmão a irem juntos às ruas pedirem por doces ou travessuras como uma tentativa de não deixar o garoto "para baixo". 
O tempo passa e Jack percebe o distanciamento do colega. Quando descobre o motivo, tenta se reaproximar por meio de uma atividade escolar (em dupla) com Auggie, ao invés de Jullian (que já foi um amigo muito próximo de Jack). Mas, Jullian, não gostou de ser deixado de lado pelo seu velho parceiro e tem atitudes preconceituosas em relação a Auggie, como até chama-lo de "aberração". Este e entre outros comportamentos de Jullian leva Jack a se envolver em uma briga com o próprio Jullian, que se revela autor de diversas atitudes intolerantes à Auggie. A briga, bem como as atitudes intolerantes do garoto Jullian são descobertas pelo professor Brownie e direcionadas ao diretor Busanfa, que suspende as aulas de Jullian e o proíbe de ir ao acampamento de outono junto a sua turma, como forma de advertência. Depois desta reviravolta, como forma de reaproximação, Jack procura Auggie por meio de um jogo virtual já comum entre eles. Ali fazem as pazes e a amizade segue.

O penúltimo acontecimento expressivo do filme, se trata de uma colônia de férias (promovida pelo colégio aos alunos), onde Auggie e Jack se envolvem em uma briga com garotos um pouco mais velhos, porém, naquele momento recebem a ajuda dos ex amigos de Jullian, e acabam vencendo a briga braçal. Isto faz com que os ex amigos de Jullian que também eram intolerantes passam a partir disso a conhecê-lo melhor, e percebem o quanto Auggie é "mais legal do que parecia", diz um dos garotos mais velhos.

Diante de muitos acontecimentos negativos e positivos ao mesmo tempo, um fim significativo é preparado para todos os estudantes. Uma festa de formatura (pela aprovação) e encerramento do ano letivo, reúne Auggie e sua família que prestam toda a admiração que sentem por ele. Pelo seu excelente rendimento escolar, por sua motivação, força e coragem (diz o diretor escolar na cerimônia da formatura), Auggie é premiado e aplaudido por todos. Ali, Auggie faz uma reflexão sobre se abrir para conhecer as pessoas, e o quanto estava feliz de ter conseguido passar pelas barreiras de cada um, e "convencido" a todos de conhecê-lo de verdade.

Como já retratado, no seu primeiro dia de aula, Auggie demonstra certo receio ao perceber que todos lançam olhares arredios na sua direção, ainda assim não mostra desistir do pleito de estudar em um ambiente antes jamais planejado. É, então, contemplado por um diretor e um professor cujo seus princípios pedagógicos zelam pela inclusão e não admitem a 
intolerância, mesmo que apesar disso tais princípios não impedem experiências negativas no contexto escolar em que o garoto se insere, mas facilita atravessar esta nova vivência.

Além disso, sua singular rede de apoio pessoal, a sua família, contribui em primeira mão ao passo que estabelece um vínculo afetivo e facilitador, dirimindo as dificuldades experienciadas. Em especial, a mãe de Auggie desempenha um apoio integral (tendo que desde o nascimento do garoto deixar de lado alguns objetivos de vida pessoais). Sua mãe lhe diz uma lição que ressoa em todas as suas vivências escolares, na qual diz que quando Auggie estivesse em um lugar que não quisesse estar ou não se sentisse bem, bastaria imaginar o lugar e as pessoas com quem gostaria de estar. Se lembrando disso o seu desconforto deveria passar, logo é mais fácil enfrentar o ou os momentos difíceis que viriam.

O seio familiar, ainda que não necessariamente tradicional nuclear (pai, mãe, filhos), pode apresentar apenas uma das figuras sendo uma família monoparental: pai e filhos, mãe e filhos, ou ainda, família extensa representando o cuidado pelos avós, tias, tios, primos ou qualquer relação de parentesco (SILVA, 2016). Ao longo do tempo houveram diversas transformações sobre o conceito de família, hoje a legislação especialmente no Brasil reconhece os vários formatos de família seguindo as transformações na estrutura social, partindo dessas mudanças, atualmente se reconhece as famílias homoparentais; sendo as famílias formadas por pessoas do mesmo sexo, mesmo que não possuam filhos (SILVA, 2016; SILVA E CHAVEIRO, 2009). Sendo assim, a família brasileira hoje é plural.

No caso da família do personagem, é caracterizada pela família nuclear, formada pela mãe, o pai, e uma irmã, exercendo um papel singular e fundamental na humanização, na personalidade e construção da autoestima de Auggie. O que faz existir este modelo de família, bem como outros, é o constante desenvolvimento sociocultural humano que efetiva suas mais diversas formas de "padrões" a serem seguidos ou não na organização do tecido social das distintas sociedades (VYGOTSKY, 1991; DESSN E POLONIA, 2007; SILVA, 2016), assim postula Vygotsky (1991) dizendo que, a relação do indivíduo com os objetos e o mundo não é direta, mas mediada por uma organização simbólica em que a linguagem tem um papel fundamental, é então a família o primeiro sistema que ocupa o papel de possibilitar uma transferência de 
saber entre os indivíduos, neste intercâmbio o sujeito consegue abstrair e generalizar o pensamento frente ao seu desenvolvimento

Neste sentido, a família é um forte núcleo pelo qual o sujeito tem as primeiras impressões da vida social (SILVA, 2016), ao qual no contexto do desenvolvimento humano histórico, é reconhecida como a primeira instituição social em conjunto com outras, na finalidade de garantir o progresso e o bem-estar dos membros e do grupo, contendo a proteção e o bem-estar à criança (DESSEN E POLONIA, 2007). “Ela é a matriz da aprendizagem humana, com significados e práticas culturais próprias que geram modelos de relação interpessoal e de construção individual e coletiva" (DESSEN E POLONIA, 2007, p. 22), é, portanto, as diversas formas de família estabelecidas até hoje que garantem a continuação da espécie humana e o progresso da descendência, e é como já colocado, potencialmente um símbolo mediador na aquisição de estratégias de sobrevivência entre os feitos sociais, culturais e econômicos das sociedades.

As situações nas experiências familiares possibilitam a formação de repertórios comportamentais, que propiciam à criança ações significativas para a resolução de dificuldades individuais ou coletivas na relação com os outros, assim, a estrutura familiar também é um ambiente que corresponde a transformação social, se dado a condições assertivas, influenciará em atitudes comportamentais positivas, presentes e futuras (SARTI, 2004; DESSEN E POLONIA, 2007; SILVA, 2016).

Molon (2002), ao escrever sobre a relação da Psicologia com a formação continuada de educadores, afirma que toda produção de conhecimento deve estar vinculada ao reconhecimento do seu valor social. O cuidado na perspectiva da inclusão e do combate a intolerância faz parte do repertório pedagógico do professor Browne alinhado com o diretor Busanfa, como já analisamos anteriormente aqui. llustrado em uma cena onde as crianças vão tirar uma foto em turma, e Auggie tenta se afastar, porém, o professor Browne o traz de volta para o retrato. A fotografia simbólica no contexto revela uma estratégia de inclusão, trazendo um dos temas centrais dos estudos de Vygotsky, a mediação semiótica.

Pino (1991) indica que por mediação semiótica entende-se toda intervenção de um terceiro "elemento", que tenha um significado e viabilize a interação entre os integrantes de 
uma relação. A partir da mediação, ocorre um outro processo chamado internalização, no qual o sujeito se apropria do que lhe é externo, já construído no plano sociocultural. Trazendo para o plano individual, ele passa a constituir sua consciência, possibilitando o pensamento, e em seguida devolve para o plano externo por meio de ações, mas dessa vez, com suas próprias impressões já adquiridas de processos anteriores, e mediando o processo de internalização de outros sujeitos. Neste sentido, Vygotsky $(2018$, p.15) dirá que, "nosso cérebro mostra-se um órgão que conserva nossa experiência anterior e facilita a sua reprodução".

Desde o acampamento até a cerimônia final, o filme traz o processo contínuo de aquisição da capacidade de compreensão em que Auggie se encontra, com a mediação da família e da escola. Desse modo, "a atividade que antes precisava ser mediada (regulação interpsicológica ou atividade interpessoal) passa a constituir-se um processo voluntário e independente." (REGO, 1995, p. 61). Sendo assim, o papel orientador da família do garoto, junto a postura inclusiva da escola (como sinalizamos neste artigo) foram importantes no desempenho da sua autoestima, que apesar das adversidades durante o seu processo consegue estabelecer mais consciência de si satisfatórios. Dessa maneira, sua autoestima se constitui proveitosa: a) a partir do caráter social construído e b) da forma funcional em que se dá seus processos de internalização face a potencialidade dos seus mediadores.

\section{CONSIDERAÇÕES FINAIS}

Este artigo teve a finalidade de apresentar aspectos da construção da autoestima do personagem Auggie Pullman que apresenta uma deformação facial. Sua condição estética, o modo como se relaciona a partir disso consigo mesmo e com os outros, sobretudo a sua base familiar, são as categorias selecionadas para verificar os desdobramentos que indicam um processo de construção adequado da autoestima, e ainda, assim, ao mesmo tempo analisar quais as ações negativas interferem neste processo.

Apoiado nas contribuições da perspectiva teórica da Psicologia Sócio Histórica de Vygotsky, e adotando o estudo de caso como metodologia que permite uma análise cuidadosa dos fenômenos da vida cotidiana, tornou-se possível com estas bases investigar que os fatores que implicam na construção da autoestima do personagem acontecem primordialmente no contexto da família e em alguns momentos no contexto escolar. Prezamos como enfoque 
analisar a família como instrumento mediador deste processo. Neste sentido, a teoria sóciohistórica nos apontou que para o indivíduo se desenvolver no mundo é necessário que um outro indivíduo possa mediar este processo de aquisição dos signos e símbolos que estão inseridos na sua própria cultura, e sobretudo, fundamentalmente, a linguagem é uma das condições pela qual se torna possível criar o mundo e os objetos, e que permite a internalização dos atributos de sua própria cultura.

Sendo assim, como conferimos enfoque, é importante lembrar que necessariamente a família quando em condições adequadas de sobrevivência e disposta funcionalmente diante das necessidades, sucessos e fracassos do indivíduo, culminará nas circunstâncias pela qual o sujeito obterá consciência e comportamento adequado diante das adversidades da própria vida. No caso de Auggie, a sua deformação facial, sua diferença singular é desde muito cedo acolhida por sua família de maneira cuidadosa e empática. De modo geral independente desta diferença, a conjuntura adequada da família: moralmente, economicamente, emocionalmente, ajudará o sujeito na aquisição de estratégias possíveis que possam dirimir as afetações negativas que podem decorrer da interação com os outros.

Tais marcadores apontam para a concretude da proposta da Psicologia Sócio-histórica que possui uma cosmovisão interacionista, cujo o ser humano no mundo está em seu processo contínuo de desenvolvimento e construção, onde a linguagem é um dos intermediários na aquisição de comportamento e consciência adequados. Considera-se que este processo sempre sofre alterações e podem implicar em uma nova consciência de si quando há mediação adequada.

As contribuições da abordagem sócio-histórica se mostram inesgotáveis na análise de contextos como este, isso porque a realidade concreta nesta perspectiva não se pode ser analisada separada do ponto crucial: histórico-social, onde a atividade do pensamento, sentimento, afetos, linguagem e imaginação estão inseparáveis do ponto crucial e contidas no esquema do indivíduo. O filme não é uma ficção da qual as comparações não se aplicam à realidade cotidiana, ao contrário, oferece elementos importantes que se fundem em nossa realidade inscrita em preconceitos e discriminações às diferenças. Essa perspectiva teórica oferece um segundo contexto pelo qual não nos aprofundamos, a escola. Sem dúvidas 
também influencia na construção da autoestima e se revela um campo potencial a ser pesquisado.

Finalmente, observamos que esta possiblidade de alteração na atividade de uma pessoa pela interferência da outra é fundamental na teoria de Vygotsky no qual se alinha a abordagem Psicologia Sócio Histórica, é o motivo pelo qual a analise deste material selecionado indica uma relação de efetividade das questões apresentadas em observação teórica, mas isto não esgota a variabilidade de inquéritos contidos no plano histórico cultural humano, tendo em vista que nesta perspectiva teórica o indivíduo está em constante transformação, e portanto, requer uma sofisticação no trato de suas questões psicológicas e socioculturais.

\section{REFERÊNCIAS}

DESSEN, M. A; POLONIA, A.C. A família e a escola como contextos de desenvolvimento humano. Paidéia, v.17, n.36, p. 21-32, 2007.

FREITAS, M. T. As apropriações do pensamento de Vygotsky no Brasil: um tema em debate. Psicologia da educação. São Paulo, n. 10/11, p. 9-28, 2000.

GODOY, A. A. Pesquisa qualitativa: Tipos fundamentais. Revista de Administração de Empresas. São Paulo, v. 35, n.3, p. 20-29, jan, 1995.

JOENK, I.K. Uma Introdução ao pensamento de Vygotsky. Revista Linhas, v. 3, n. 1, p.1-12, 2007.

LUCCI, M. A. A proposta de Vygotsky: a psicologia sócio-histórica. Revista Profesorado. v. 10, n. 2, p. 1-11, 2006.

ANE, S.T.M. Como nos tornamos sociais. In: . O que é psicologia social. São Paulo: Brasiliense, 2014. p. 37-84, 87 p.

MOLON, S. I. Entrelaçando a psicologia e a educação: uma reflexão sobre a formação continuada de educadores à luz da psicologia sócio-histórica. Revista Contrapontos. n. 5. p. 237-250, 2002.

NEVES R. A.; DAMIANI M. F. Vygotsky e as teorias da aprendizagem. UniRevista, v. 1, n. 2, p. 1-10, abril, 2006

PINO, A. S. O conceito de mediação semiótica em Vygotsky e seu papel na explicação do psiquismo humano. Cadernos Cedes, Campinas, n. 24, p. 32-43, mar. 1991. 
REGO, T. C. A cultura torna-se parte da natureza humana. In: Vygotsky: Uma perspectiva histórico-cultural da educação. Petrópolis, RJ: Vozes, 1995. p. 37-84. 138 p.

ROCHA, N. M. A autoestima $x$ autoconceito. In: ROCHA, N.M. A autoestima como um dos fatores determinantes do aprendizado da criança. Brasília: Centro Universitário de Brasília, p. 24-24. 2003.

SARTI, C. A. A família como ordem simbólica. Psicologia USP, v.15, n.3, p. 11-28, 2004.

SILVA, M. C; CHAVEIRO, E. F. Demografia e família: as transformações da família no século XXI. B. Goiano Geografia, v.29, n.2, p. 171-183, jul-dez, 2009.

SUELLEN, M. S. Reconfiguração do conceito de família no século XXI: Os desafios das famílias homoparentais. Orientador: Maurício Capela. 2016. 124 f. Trabalho de conclusão de curso (Graduação em Comunicação Social - Jornalismo) - Universidade de Santo Amaro, São Paulo, 2016.

VYGOTSKY, L.S. A Formação Social da Mente. 4ed. São Paulo: Livraria Martins Fontes, 1991. 90 p. Disponível em: https://edisciplinas.usp.br/pluginfile.php/3317710/mod_resource/con tent/2/A\%20formacao\%20social\%20da\%20mente.pdf Acesso em: 07 jan. 2021.

VIGOTSKI, L. S. Criação e imaginação. In: Imaginação e Criação na Infância. 1ed. São Paulo: Expressão popular, 2018. p.13-19.

VIGOTSKY, L. S. Introducion: The fundamentals of problems defectology. In: The collected works of L. S. Vygotsky: the fundamentals of defectology (abnormal psychology and learning disabilities). v.2. New York: Plenum, 1993. p. 30-30. Disponível em: https://www.springer.com/gp/book/9780306424427 Acesso em: 18 nov. 2020.

YIN, R.K. Estudo de caso: planejamentos e métodos. 2. ed. Porto Alegre: Bookman, 2001. 


\title{
O ENSINO REMOTO EMERGENCIAL E AS LIÇÕES DO NOVO CORONAVÍRUS PARA A SEARA DA EDUCAÇÃO
}

\author{
Hildon Oliveira Santiago Carade \\ Instituto Federal Baiano, BA, Brasil \\ hildoncarade@yahoo.com.br
}

\begin{abstract}
RESUMO
Este ensaio apresenta algumas reflexões sobre a adoção do ensino remoto emergencial, uma vez que as escolas foram obrigadas a fechar as portas, como uma medida de retardamento da disseminação do novo coronavírus. A partir da análise de notícias de jornais, refletiremos sobre se a instrução virtual significaria uma sentença de morte às escolas, ao menos no tocante ao seu modelo de aulas presenciais. As narrativas colhidas nos levarão a um debate pedagógico sobre o lugar da escola e dos estudantes no processo de ensino-aprendizagem, o que nos proporcionará uma mirada mais crítica sobre a decantada obsolescência dos aparatos escolares.
\end{abstract}

Palavras-chave: Escola; Educação; Coronavírus; Ensino remoto emergencial. 


\title{
EMERGENCY REMOTE EDUCATION AND LESSONS FROM THE NEW CORONAVIRUS FOR THE FIELD OF EDUCATION
}

\begin{abstract}
This essay presents some thoughts on the adoption of emergency remote education, since schools were forced to close their doors, as a measure to delay the spread of the new coronavirus. From the analysis of news from newspapers, we will reflect on whether virtual instruction would mean a death sentence for schools, at least with regard to their face-to-face classes model. The collected narratives will lead us to a pedagogical debate about the place of the school and the students in the teaching-learning process, which will provide us with a more critical look at the decanted obsolescence of the school apparatus.
\end{abstract}

Keywords: School; Education; Coronavirus; Emergency remote education. 


\section{INTRODUÇÃO}

A pandemia do novo coronavírus forçou os poderes estatais a adotarem medidas de distanciamento social, com o intuito de conter a disseminação comunitária do vírus. Assim como aconteceu com as demais esferas societárias, a educação escolar assistiu a uma mudança abrupta da sua rotina. Obrigadas a fecharem as suas portas, as escolas públicas e privadas tiveram que se adaptar, como que da noite para o dia, a esse contexto emergencial, em uma tentativa de contenção dos prejuízos com os processos de ensino-aprendizagem. Em levantamento realizado pela Organização das Nações Unidas, entre os meses de maio e junho de 2020, há a estimativa de cerca de 1,6 bilhões de estudantes, residentes em mais de 190 países do globo, afetados pelas diretrizes de controle sanitário. Na ótica da entidade supranacional, o fechamento dos colégios e demais espaços de instrução pode encerrar toda uma geração a uma perda educacional sem precedentes na história (ONU, 2020).

À medida em que governos e instituições privadas foram adotando soluções de ensino remoto, as disparidades educacionais preexistentes à pandemia se tornaram mais clarividentes. A instrução virtual evidenciou a diferença entre os estudantes que possuem uma conexão confiável de internet e outros que não a possuem; entre aqueles que detém um laptop ou tablet para acompanhamento das atividades e os que precisam compartilhar esses equipamentos com os demais membros da família; entre os pais detentores de tempo e instrução para assistir seus filhos em suas tarefas escolares e aqueles menos capazes de cumprir esse papel; entre as crianças que, com o fechamento das escolas, ficaram privadas de serviços de caráter assistencial e de proteção social (notadamente, a nutrição e a fuga da violência doméstica) e outras não dependentes dessa provisão (ONU, 2020). Enfim, a pandemia do COVID-19 reavivou as discussões em torno do lugar e das responsabilidades da escola na estrutura dos Estados nacionais.

Este estado de emergência sanitária irrompe em um momento em que a escola vivencia uma crise de legitimidade. De acordo com Teodoro (2003), neste terceiro milênio os aparatos escolares parecem, por um lado, não mais cumprir o seu papel de integração social e de capacitação para as emergentes necessidades da "economia do conhecimento"; e, por outro, estariam sendo incapazes de garantir a emancipação, porquanto não produzam a mobilidade social tão acalentada por diversos estratos sociais, para quem a escolarização, 
especialmente em seus níveis superiores, representaria um meio de ascensão social, ou de manutenção do estilo de vida já alcançado.

Tendo em vista esta tão decantada crise da escola, o objetivo do presente ensaio é ensejar uma reflexão sobre a seguinte questão: em que medida a adoção do ensino remoto emergencial, com a utilização das plataformas digitais enquanto meios facilitadores de aprendizagem, significaria uma sentença de morte ao ensino presencial, uma vez que a permanência dos sujeitos na instituição escolar esteja agora aquém das promessas da modernidade de desenvolvimento, de mobilidade social e de igualdade? Em outras palavras, a pandemia do COVID-19 implicaria necessariamente o reconhecimento, de uma vez por todas, da obsolescência dos aparatos escolares, cujas tecnologias remontam à época das revoluções burguesas do século XVIII? Veremos mais adiante que esse debate nos levará a uma reflexão pedagógica, na qual autores como Dewey e Freire serão mobilizados, sobre o lugar dos estudantes e da escola nos processos de ensino-aprendizagem.

Para responder a estes questionamentos, recorremos à leitura de artigos e matérias publicadas na imprensa escrita. Durante o período entre março e setembro de $2020^{1}$, viemos acompanhando a cobertura dos principais jornais do Brasil e do mundo sobre o SARS-CoV-2 e suas implicações para a área da educação ${ }^{2}$. O levantamento elaborado não considerou diretrizes quantitativas, ou seja, não se preocupou em descrever numericamente e codificar unidades temáticas, o que implicaria o agrupamento das notícias a partir do grau de relevância e repetição dos conteúdos por elas veiculados.

Antes, assumimos aqui o horizonte de uma análise antropológica da notícia (MOTTA, 2002). Esta assume como abordagem metodológica a narratologia, que vem a ser a teoria dos textos narrativos, isto é, uma conceituação que se interessa pelo conjunto sistemático e encadeamento de narrativas. Tal análise "coloca o seu foco de atenção sobre os sentidos produzidos pela sintaxe narrativa. Enfoca a história, muito mais do que um discurso. Privilegia

\footnotetext{
${ }^{1}$ Em setembro de 2020, começava a ser mais sustentável o movimento de reabertura das escolas, uma vez que a pandemia perdia certo fôlego, mas esse processo não durou muito tempo, haja a vista o recrudescimento nos índices de novos contágios desde então, o que obrigou a um novo fechamento dos serviços não essenciais em todo o mundo.

${ }^{2}$ Foram consultados os jornais The New York Times, The Washington Post, The Guardian, O Globo e o portal UOL que congrega notícias do Estadão, da Folha de São Paulo, da Agência Brasil e da TV e rádio Bandeirantes.
} 
o enredo, ainda quem sem prescindir do discurso" (MOTTA, 2002, p. 21). Cabe enfatizar aqui que este método não se preocupará, em primeira instância, com o discurso jornalístico relativo ao ensino remoto, isto é, o pensamento de editores e jornalistas sobre a referida questão; antes, nosso foco será a realidade da instrução virtual apresentada pelos interlocutores ouvidos pelos veículos da imprensa escrita.

A partir desse ponto de vista, a pandemia do coronavírus se apresentará como um enredo, que se desenrola temporalmente, apresentando uma história com ações, personagens, conflitos e tensões, como se fosse uma narrativa ficcional qualquer. Digamos que o COVID-19 será o pivô da tessitura da intriga. Vale a pena aqui citar literalmente Todorov (1971, p. 124):

\begin{abstract}
A intriga mínima consiste na passagem de um equilíbrio a outro. Uma narrativa ideal começa por uma situação estável que uma força qualquer vem perturbar. Daí resulta um estado de desequilíbrio; por ação de uma força dirigida em sentido inverso, o equilíbrio é restabelecido; o segundo equilíbrio é semelhante ao primeiro, mas os dois nunca são idênticos.
\end{abstract}

Nestes termos, o ensino remoto emergencial ${ }^{3}$ passa a ser o ingrediente manejado para a construção de um novo equilíbrio. Nesse processo, as narrativas de pais, alunos, professores e demais sujeitos da educação, ao serem produzidas pela intriga suscitada pelo vírus - que teve no fechamento das escolas seu principal desenlace -, terminam por nos apontar uma determinada maneira de conhecer a realidade. Assim, as notícias aqui referenciadas, o são em virtude da apresentação de pontos de vista, descrições e experiências dos sujeitos que estão vivenciando essa imersão na instrução virtual. À luz do referencial antropológico, o material jornalístico é tomado como discurso nativo, ou seja, material primário de pesquisa, um meio para se coletar, etnograficamente, episódios concernentes a um dado estado de coisas.

De maneira a entendermos melhor toda trama deslindada pelo ensino remoto emergencial, antes da análise propriamente dita dos dados empíricos, cabe uma pequena digressão genealógica acerca da escola, a partir das considerações de Sibilia (2012) e Ariès

\footnotetext{
${ }^{3}$ Os especialistas em educação fazem questão de pontuar as diferenças entre o ensino remoto emergencial e a educação à distância. A primeira nomenclatura enfatiza o distanciamento geográfico, uma vez que professores e alunos estão impedidos de frequentar as instituições escolares, impedimento este de caráter temporário, bem como seu caráter de excepcionalidade, na medida em que o planejamento do ano letivo de 2020 teve de ser readaptado como que do dia para a noite. A segunda, por seu turno, demarca a existência de uma modalidade específica de ensino, cujo conteúdo programático e metodologias foram pensados para serem realizados de maneira não presencial.
} 
(1981). Concebidos como tecnologias de época, os aparatos escolares surgirão, na ótica desses autores, como que contrapostos às novas tecnologias digitais. Este, pois, é o tema da próxima seção deste ensaio.

\section{A escola: uma tecnologia de época}

Em sua História social da infância e da família, Ariès (1981) edifica a tese segundo a qual, durante todo o período medieval, não havia uma consciência sobre a existência da infância, concebida como uma fase específica da vida humana, com características singulares. Antes da idade moderna, a premissa que imperava era a de que não havia crianças, mas sim adultos em miniatura. Em termos gerais, até fins do medievo, eram hegemônicas as maneiras informais de socialização nos âmbitos familiar e comunitário. Isto significava que as crianças eram socializadas em meio aos adultos.

Contudo, com as mudanças no campo e o crescimento das cidades, que alteraram a estrutura das famílias, surgem concepções modernas sobre a criança. Ariès (1981) aponta dois sentimentos acerca da infância: o primeiro, oriundo da esfera doméstica, é a paparicação; o segundo, a exasperação, propalado entre os círculos de educadores e moralistas do século $\mathrm{XVII}$, que condenavam o excesso de mimo destinado às crianças, voltando-se a elas com interesses morais e civilizatórios. O historiador postula que toda a educação foi erguida a partir dos pilares do segundo sentimento até os primórdios do século XX. Nas palavras do autor: "os pais não se contentavam mais em pôr filhos no mundo, em estabelecer apenas alguns deles, desinteressando-se dos outros. A moral da época lhes impunha proporcionar a todos os filhos, e não apenas ao mais velho - e, no fim do século XVII, até mesmo às meninas -, uma preparação para a vida" (ARIÈS, 1981, p. 277).

Foi assim que surgiram as escolas modernas como os locais mais apropriados para essa preparação dos sujeitos à vida. Os aparatos escolares demarcaram uma separação radical entre o mundo da criança e o mundo do adulto. Eles se transformaram em "um meio de isolar cada vez mais as crianças durante um período de formação tanto moral como intelectual, de adestrá-las graças a uma disciplina mais autoritária, e, desse modo, separá-las da sociedade dos adultos" (ARIÈS, 1981, p. 165). 
Por estar tão vinculada ao contexto de triunfo dos ideais iluministas e de laicidade do Estado, plenamente assumidos no horizonte aberto pela independência das colônias americanas e pelo revolucionarismo francês, é que Sibilia (2012) nos chama atenção para a necessidade de reconhecermos o quanto a escola é uma tecnologia datada de uma época em que a sociedade pensou a si mesma como sendo igualitária, fraterna e democrática. Era preciso, então, assumir a responsabilidade de educar todos os cidadãos, ensinando-os a ler, escrever e a fazer operações matemáticas. Para este intento, enfim, foram criados os estabelecimentos escolares.

Ora, também data dos oitocentos a preocupação estatal para com a destinação dos sujeitos imaturos oriundos dos setores mais desprivilegiados da sociedade. Explode nessa época a criação de escolas de aprendizes artífices, de educandários, de reformatórios e de seminários para a internação dos meninos e meninas pobres das grandes cidades, numa clara medida de higienização social, com o fito de "desinfetar" as ruas das capitais do nosso país (RIZZINI e RIZZINI, 2004).

Na perspectiva de Sibilia (2012), a vocação uniformizadora, homogeneizante e normalizadora da escola - construída a partir da separação dos estudantes em grupos de idade - entra em dissonância com as competências exigidas atualmente. Na época de gestação do capitalismo, a separação rígida entre as esferas pública e privada orquestrou a construção de um sujeito solipsista, cuja subjetividade seria vislumbrada como uma espécie de lugar recôndito ao qual poucos poderiam ascender. Em outras palavras, o individualismo moderno era sinônimo de vida interiorizada, de um ator social que ensejava um diálogo consigo mesmo na sua busca por uma identidade mais autêntica. O livro, o papel, o lápis e o ambiente privado do lar foram instrumentos importantes para a lapidação desse tipo de indivíduo. Sibilia (2012) chega mesmo a afirmar que o hábito da leitura em silêncio se consolidou no exato momento em que o capital se mostrou triunfante. Consequentemente, a escola, com sua lógica de confinamento, estava em consonância com os ideais destes tempos.

Todavia, pondera Sibilia (2012), o isolamento e a vida interior são relíquias de um passado que se mostra cada vez mais distante. Aquele espaço íntimo e denso romanticamente intitulado de "a beleza interior" - virou peça de museu. Foi-se o tempo em que precisávamos de paredes, de preferência num quarto próprio, um teto todo nosso para construirmos o nosso verdadeiro "eu", longe dos olhares alheios. Num mundo dominado pelas 
novas tecnologias portáteis e pelas redes digitais, não há mais espaço para as subjetividades interiorizadas. A velha intimidade tem se deixado dialogar com diversas intrusões daquilo que acontece na esfera do "online". A autora se pergunta: onde está o silêncio e a solidão já que estamos confabulando com inúmeras presenças? Não precisamos mais da introspecção para nos constituirmos como sujeitos?

Segundo Sibilia (2012), tudo se passa como se não houvesse mais a necessidade de se confinar em um quarto próprio para se constituir enquanto sujeito. É preciso, pois, se tornar visível para ser alguém; estar conectado é agora um imperativo. Visibilidade e conectividade são as palavras do momento atual. Na ótica da autora, o capitalismo contemporâneo implora por corpos mais voltados para fora, não mais intro-dirigidos, mas alter-dirigidos. Por este motivo, os muros da escola caíram no ostracismo. Prescindimos agora do confinamento para nos tornarmos corpos dóceis e úteis. Nos liberamos das paredes, mas nos escravizamos de outras formas, muito mais imperceptíveis, no amplo e onipresente domínio das redes digitais, sentencia a pesquisadora.

Este, pois, marca o terreno da crise atual dos aparatos escolares. Cada vez mais imersos no mundo das novas tecnologias digitais, os estudantes parecem não suportar mais os limites físicos impostos pela estrutura de confinamento erguida pelas escolas. Por conta da pandemia do novo coronavírus, as organizações acadêmicas tiveram que adotar o ensino remoto emergencial, uma vez que os estabelecimentos de ensino foram obrigados a fechar suas portas, como uma medida de contenção da expansão viral. Ao adotarem esse subterfúgio, a chamada instrução virtual poderia desferir o último golpe contra as escolas, estas tecnologias antigas forjadas pela sociedade moderna?

Para estabelecermos certos termos de compreensão do debate ensejado por essa pergunta, na próxima seção trataremos das narrativas colhidas nos jornais sobre as experiências de ensino remoto nas mais diversas regiões do mundo.

\section{0 ensino remoto emergencial na voz dos sujeitos ouvidos pela imprensa escrita}

As narrativas construídas pelos interlocutores dos veículos jornalísticos nos oferecem detalhes da pandemia do novo coronavírus como um evento a marcar rupturas em nosso cotidiano, alterando dinâmicas da nossa reprodução social e das vivências em coletividade. 
Não seria diferente na arena da educação, uma vez que as escolas, por concentrarem grandes aglomerações humanas, foram fechadas pelos poderes públicos. E assim, uma nova trama passa a ser desenhada no horizonte dos sujeitos imersos nos processos educativos, a saber, aquela construída em torno da adoção da instrução virtual. Quais seriam as mudanças no cotidiano escolar a partir desta modalidade de ensino? As matérias dos jornais, na medida em que estimulam nos leitores (leitor-implícito) certos imaginários (MOTTA, 2002), podem nos oferecer algumas respostas.

No início, parecia que tudo seriam flores... A estudante Laís de Hollanda de Oliveira, 12 anos, em matéria publicada pelo O Estado de São Paulo, expressou o seguinte sentimento em torno das mudanças da sua rotina escolar, em virtude da pandemia do novo coronavírus: "No começo fiquei muito feliz, porque era meu sonho estudar em casa, mas é horrível ficar diante da tela de um computador ouvindo a aula. Está muito difícil ficar na quarentena sem poder sair, abraçar os amigos, estudar na escola" (FELIX, 2020).

No começo, Tobias Jones, correspondente do jornal britânico The Guardian, ficara bastante surpreso com a notícia de fechamento das escolas na região da Emília-Romanha, norte da Itália. Era a última semana de fevereiro de 2020, e em todo território italiano apenas 3 mortes e 152 casos de infecção pelo COVID-19 haviam sido reportados. A primeira semana em que ele e sua esposa se viram longe dos compromissos escolares relacionados a seus três filhos - Benny (15 anos), Emma (13 anos) e Leo (9 anos) - pareceu um feriado prolongado. A família, inclusive, resolvera transigir em algumas regras anteriormente firmadas. Os pais se permitiram beber álcool em dias de semana; as crianças tiveram liberado o acesso à programação da televisão.

Mas vieram as águas de março e com elas a calmaria foi cedendo lugar à tempestade. Enquanto a família se divertia subindo montanhas e plantando árvores em torno da cidade de Parma, a situação piorava rapidamente na Itália. Em 12 de março de 2020, o país computava mais de mil mortes; e quatro dias depois, essa cifra havia praticamente dobrado (JONES, 2020). Exatamente nessa semana o lockdown tornou-se realidade em todo território italiano. De acordo com o correspondente, neste ponto os professores resolveram enviar uma enxurrada de atividades a seus pupilos. Após quinze dias de plena liberdade, os estudantes estavam agora sobrecarregados (JONES, 2020). 
Também foi com certo entusiasmo que Emma Brockes encarou a oportunidade de passar mais tempo com seus dois filhos logo quando foi decretado o fechamento de todos os serviços não essenciais na cidade de Nova York. Mas não demorou muito para que ela, já uma admiradora confessa dos professores de seus rebentos, percebesse o quão trabalhoso é o ofício da educação. “Como, diabos, em um único ano de jardim da infância, eles [educadores] conseguem mantê-las [as crianças] sentadas em silêncio, lendo, escrevendo e contando - e isso em uma classe com outras 20 crianças?" - pergunta-se ela (BROCKES, 2020).

Tomada como um enredo, a pandemia do coronavírus proporcionou, de início, uma sensação de êxtase para aqueles que se viram desobrigados a arcar com os hodiernos custos do ensino presencial, notadamente, o deslocamento para a escola; e, no caso dos estudantes, a permanência diária em um ambiente com tendências ao enclausuramento. A necessidade de continuação da programação do ano letivo possibilitou, como que num piscar de olhos e sem a devida reflexão, o encontro entre tecnologias, em princípio, tidas como contrastantes: a escola e as redes digitais. À medida em que as instituições de ensino foram adotando ferramentas de videoconferência tais como o Zoom e o Google Meet, capazes de agregar centenas de pessoas em uma mesma chamada de vídeo, em substituição às aulas presenciais, tanto professores quanto alunos, bem como especialistas de diversas áreas do conhecimento, vêm alertando para os problemas e mesmo os perigos suscitados pelo ensino remoto.

Comecemos pelo aspecto da tecnologia tomada em si mesma. Murphy (2020), jornalista do The New York Times, sintetiza algumas das cautelas que devemos manter, para além daquelas concernentes aos aspectos de segurança e privacidade. De acordo com ela, psicólogos, cientistas da computação e neurologistas afirmam que distorções e delays [atrasos] inerentes à comunicação em vídeo podem nos deixar com um senso de isolamento, ansiedade e desconexão. O problema, pontua a articulista, é que as formas como as imagens de vídeo são codificadas e decodificadas digitalmente, alteradas e ajustadas, corrigidas e sintetizadas, introduzem todos os tipos de artefatos: bloqueio, congelamento, desfoque, irregularidade e áudio fora de sincronia. Essas interrupções, algumas não captadas pela nossa esfera de consciência, confundem a percepção e misturam sutilmente os sentidos. Nossos cérebros se esforçam para preencher as lacunas e dar sentido à desordem, o que nos deixa vagamente perturbados, inquietos e cansados, sem saber bem o porquê (MURPHY, 2020). 
Sheryl Brahnam, professora do Departamento de Tecnologia da Informação e Cibersegurança da Universidade do Estado de Missouri, nos traz uma comparação que pode bem explicar os sentimentos de fadiga, estresse e alienação suscitados pela comunicação virtual (MURPHY, 2020). Segundo ela, os encontros presenciais estão para as videoconferências assim como os alimentos in natura estão para as comidas processadas. As últimas, repletas de sabores artificiais e conservantes, quando consumidas em excesso, provocam enjoo. O mesmo acontece com as chamadas de vídeo.

Nos deteremos mais pormenorizadamente nesse aspecto de artificialidade trazido a lume pelo uso das tecnologias de comunicação virtual na educação, pois ele pode ser elucidativo de como aquilo que supostamente éramos familiarizados - a nossa presença no ambiente online - pode produzir novos assombros e inquietações, quando deslocado de seu contexto usual. O ensino remoto, enquanto cópia de seu símile presencial, parece ter produzido um distinto senso de pudor em subjetividades já devidamente acostumadas à exposição. Vejamos mais de perto.

Ao elaborar um relato sobre sua experiência de ensino remoto, Karen Strassler, professora de antropologia do Queens College, aponta para o compartilhamento inesperado de intimidades que ferramentas como o Zoom podem proporcionar. Em suas palavras:

\footnotetext{
...enquanto discutimos nossas leituras, observo os pôsteres, fotos e tapeçarias que decoram as paredes dos meus alunos. Observo seus parceiros e animais de estimação se movendo como sombras ao fundo. Vejo áreas de trabalho improvisadas em espaços apertados e desajeitados. Eu ouço ruídos de fundo perturbadores quando um aluno ativa o microfone para falar...(STRASSLER, 2020).
}

De acordo com ela, ao mesmo tempo em que são cativantes, esses momentos têm o poder de quebrar certo contrato implícito da sala de aula, por intermédio do qual os estudantes conservam alguma medida de controle sobre quais aspectos de suas vidas particulares devem ser partilhados na escola.

Após transformar sua sala de estar em uma sala de aula, tal não foi a surpresa de Chauntae Brown, uma professora do segundo grau de um colégio novaiorquino, quando seus alunos acessaram o ambiente da reunião virtual para o primeiro encontro à distância. Segundo ela, a sessão parecia uma festa de pijama, porquanto muitas crianças ainda estavam vestindo roupas de dormir, com os seus pais inclusos na cena. À medida em que novos encontros se sucediam, os estudantes foram, paulatinamente, surgindo com trajes mais formais (CHEN, 2020). E aqui aparece a questão da etiqueta comportamental nas plataformas de 
comunicação online. Ouvido pelo jornal O Globo, Carlos Affonso Souza, professor de Direito Civil da UERJ, pontua a seguinte questão: "o que um aluno pode exibir se sua câmera estiver aberta para os outros participantes?" (FISCHBERG, 2020).

Para além das carências materiais de acesso e equipamento, Débora Foguel, professora de Bioquímica Médica da UFRJ, em artigo publicado pelo jornal $O$ Globo, arrola como um dos problemas para um efetivo processo de ensino e aprendizagem virtual, a falta de um cômodo isolado que permita os estudos.

\begin{abstract}
Esse problema não pode ser menosprezado, pois transformar a casa em um espaço multifuncional, onde trabalho e intimidade familiar se misturam, também traz desconforto a todos. Alguma territorialidade nas nossas vidas é muito importante, até para que cada um se sinta confortável de falar e se comunicar com seus alunos ou com seus professores guardando alguma intimidade (FOGUEL, 2020).
\end{abstract}

Ao que parece, engajados no ensino remoto, por vezes, detalhes tão pequenos de nossas vidas pessoais transbordam nas telas dos computadores e telefones inteligentes, contra nossas vontades. Uma vez que já estávamos acostumados a publicar nossas intimidades em redes sociais digitais, particularmente, o Instagram e o Facebook, criando subjetividades visíveis, justamente as mais adequadas aos tempos atuais, as fronteiras borradas entre as esferas pública e privada não deveriam nos incomodar, no entanto, nas chamadas de vídeo, imagens de camas, fotos, objetos de decoração e animais de estimação têm provocado um novo e indesejável senso de proximidade. A leitura dos relatos sobre as experiências de instrução virtual, tomados como produtores de novas tramas e intrigas, nos levanta questões sobre se o isolamento e a vida interior são, de fato, relíquias do passado.

Continuando com o rol dos fatos inesperados desenrolados pela pandemia do novo coronavírus, em seus reflexos no terreno da educação, precisamos ainda nos referir ao engajamento dos atores quando da utilização das plataformas digitais de aprendizagem. Jeffrey Golde, professor da Columbia Business School, já havia lecionado com o auxílio do Zoom. Todavia, durante o estado de emergência sanitária, sua postura diante da ferramenta sofreu algumas alterações. "Tenho notado, não apenas nos estudantes, mas também em mim, uma tendência ao esmorecimento. Fica difícil se concentrar na rede e é complicado pensar de uma maneira robusta" (MURPHY, 2020). Vivenciando a mesma situação de aprendizagem online, mesmo com sua universidade garantindo um laptop para o acompanhamento das atividades virtuais, a estudante Loretta Charles-Cregan desabafou ao jornal The Guardian: "Eu não consigo me motivar" (HALL e BATTY, 2020). 
Por seu turno, a atuação dos professores nessas experiências de ensino remoto tem sido afetada pela falta de expertise no uso das plataformas digitais. Nas matérias consultadas, há várias reclamações sobre as dificuldades com as gravações de vídeos e produção de conteúdos; o manuseio dos aplicativos; e a comunicação com os estudantes. Para aqueles que foram obrigados a se transformarem em youtubers repentinamente, a sensação é de sobrecarga de trabalho. "A impressão que eu tinha até a pandemia era de trabalhar oito horas por dia, agora tenho a impressão que trabalho as 24 horas", desabafou Lia Rodrigues Lessa, professora bilíngue de educação infantil em uma escola privada de Mossoró, Rio Grande do Norte (AGÊNCIA BRASIL, 2020).

Os professores de educação infantil ouvidos pelo jornal The New York Times também relataram estar sobrecarregados com o ensino virtual. Segundo eles, as crianças demandam mais atenção que os adultos, pois eles precisam de um auxílio maior para logar nos aplicativos, ler as instruções, clicar nos locais corretos e responder as atividades nos espaços apropriados (CHEN, 2020; GONCHAR e DOYNE, 2020). Em Napóles, sul da Itália, Sara Scotellaro, professora de cerca de 120 pupilos, explicou ao The Guardian o que vem acontecendo com a relação professor-aluno na ausência das aulas presenciais e como isso tem afetado sua rotina de trabalho: "Eles [os estudantes] não têm mais horário e você tem que estar sempre disponível. Eles precisam ser imediatamente tranquilizados - que o trabalho deles foi recebido, que está tudo bem, que você está feliz com eles" (JONES, 2020).

Para além das questões que nos direcionariam para uma discussão sobre a precarização do trabalho docente em tempos de pandemia, queremos enfatizar aqui um outro aspecto mais relacionado ao domínio do uso das tecnologias digitais e suas consequências para as relações professor-aluno. Na escola tradicional, forjada pelas revoluções burguesas, onde a educação é direito de todos e dever do Estado, os ideais de igualdade guiaram as práticas pedagógicas no sentido da homogeneização dos sujeitos aos quais incidiam as suas ações. "Transformar os súditos em cidadãos", conforme Saviani (2017: 654), implicava no reconhecimento dos professores como os agentes capazes de acender a chama da razão e do conhecimento no espírito dos infantes. Estes, por sua vez, eram tomados como tábulas rasas onde se sedimentariam, progressivamente, todos os saberes obtidos pela humanidade. Assim sendo, a aprendizagem seria um processo eminentemente unidirecional, deixando patente a posição do professor como polo ativo, e o estudante como polo passivo, porquanto se 
esperasse dele apenas a recepção daquilo que lhe foi transmitido. De acordo com Gôngora (1985), implícita nesta visão está a ideia de o trajeto cultural em direção aos conteúdos ministrados pelos educadores ser o mesmo para todos os educandos, desde que os últimos se esforcem. Logo, "os menos capazes devem lutar para superar as dificuldades e conquistar um lugar junto aos mais capazes. Caso não consigam, devem procurar um ensino mais profissionalizante" (GÔNGORA, 1985, p. 23).

De acordo com Freire (1998), concebida desta forma a educação se torna um ato de depositar, em que os professores são os depositários e os alunos, os depositantes.

\begin{abstract}
Em lugar de comunicar-se, o educador faz "comunicados" e depósitos que os educandos, meras incidências, recebem pacientemente, memorizam e repetem. Eis aí a concepção "bancária" da educação, em que a única margem de ação que se oferece aos educandos é a de receberem os depósitos, guardá-los e arquivá-los. Margem para serem colecionadores ou fixadores das coisas que arquivam. (...) $\mathrm{Na}$ visão "bancária" da educação, o "saber" é uma doação dos que se julgam sábios aos que julgam nada saber (FREIRE, 1997, p. 62).
\end{abstract}

Pois bem, analisando os relatos colhidos em notícias de jornais, o ensino remoto emergencial tem oportunizado a atualização da concepção bancária da educação, bem como novas vias de crítica. Em várias experiências de instrução virtual realizadas ao redor do mundo, as lições consistem em ritos de memorização, em que os professores recitam os conteúdos presentes nos livros didáticos, trazendo para as telas dos computadores e dos aparelhos móveis as narrações que seriam feitas nas aulas presenciais. Ouvida pelo The Washington Post, Nadia Naviwala, especialista na educação paquistanesa, revela os problemas dessa opção: "é quase como se pensássemos que as crianças são dispositivos USB e estamos apenas baixando essas informações nelas e isso as tornará educadas" (GEORGE, 2020).

De outra ponta, na medida em que os professores estão literalmente "pilotando o avião enquanto o constroem", para nos utilizar da expressão cunhada por Richard A. Carranza, dirigente de uma escola americana entrevistado pelo The New York Times (GONCHAR e DOYNE, 2020), nada impede que os passageiros, ocasionalmente, saibam mais sobre as instruções de voo do que os próprios comandantes da aeronave. Solange Steiner, professora do primeiro ano do ensino fundamental, com alunos entre seis e sete anos de idade, percebeu que seus pupilos sabiam manipular melhor do que ela as plataformas digitais. "Eles sabem trocar fundo de tela; eles sabem ligar e desligar a câmera. Na minha primeira aula, eu fiz um powerpoint e, quando eu projetei, um aluno meu foi lá e riscou toda a tela", disse ela sobre a intimidade das crianças com a tecnologia (BAND, 2020). 
Os apuros que os professores vêm vivenciando com o uso das tecnologias digitais exemplificado aqui pelo relato de Solange - possibilitam uma inversão na tradicional hierarquia do saber: agora os estudantes já não surgem mais como os sujeitos passivos, carentes de conhecimento, pois muitas vezes dominam melhor que seus mestres as plataformas de mediação dos saberes. É como se a pandemia do novo coronavírus, em seus impactos na educação, trouxesse a lume todas as afirmações de Paulo Freire sobre a intercambialidade entre os papéis de professor e aluno. Na perspectiva de uma pedagogia libertária advogada por este autor, "o educador já não é mais o que apenas educa, mas o que enquanto educa, é educado, em diálogo com o educando que ao ser educado, também educa. Ambos, assim, se tornam sujeitos do processo em que crescem juntos e em que os argumentos de autoridade já não valem" (FREIRE, 1998, p. 68, grifos do autor).

Mais do que nunca o ensino remoto emergencial, ao que parece, nos leva a reconsiderar os estudantes como produtores de conhecimento no mesmo patamar de seus professores. Toda uma tradição de pensamento que vai de Dewey e desemboca em Freire (MURARO, 2013) - que admite a educação como uma prática democrática, isto é, uma atividade compartilhada na qual o educador é um educando e o educando, sem o saber, um educador - faz agora todo o sentido, especialmente quando as narrativas sobre as experiências de instrução virtual nos direcionam para o reconhecimento da necessidade de se recolocar, uma vez mais, os estudantes no centro dos processos de ensino-aprendizagem, cujo protagonismo não raro tem sido eclipsado pela burocracia escolar e pela tradicional visão do professor como agente de toda a autoridade. Conforme o relato da professora italiana Betta Salvini, entrevistada pelo The Guardian, nas plataformas digitais os docentes estão tendo que aprender novas formas de atrair a atenção de seus alunos: "eu não conseguia mais fazer a clássica aula frontal de transmissão de conhecimento [a "educação bancária", diria Freire]. Agora eu os envolvo o tempo todo, viro a lição de cabeça para baixo para que eles sejam os protagonistas, para que eu ouça suas vozes", disse ela (JONES, 2020).

A partir desses relatos, tudo se passa como se os encontros virtuais, ou seja, os ingredientes que foram manejados para forjar um novo equilíbrio na trama educacional, que sofrera uma reviravolta em virtude da pandemia do COVID-19, produzissem novos distúrbios e inquietações. De repente, as telas dos computadores, dos tablets e dos smartphones, plataformas com as quais já éramos bastante familiarizados, passaram a produzir em nós uma 
sensação de estranhamento, exaustão e mesmo intimidação, exatamente no momento em que elas se transformaram em mediadoras dos processos de ensino-aprendizagem. Será que essas ferramentas digitais são exímias em dispersar e inimigas de atividades que exigem a concentração? Ou elas reafirmam a necessidade de se retomar o velho debate sobre a arte e a ciência da educação, a antiquíssima pedagogia?

É com algumas reflexões sobre as questões acima elencadas que vamos finalizar esse ensaio.

\section{Considerações finais}

A coleta das narrativas apresentadas nas notícias de jornais e o acompanhamento da trama por elas deslindada, no que se refere ao ensino remoto emergencial, nos coloca diante de problemas da prática educacional de nossa época, notadamente aqueles relacionados ao lugar da escola enquanto espaço de socialização dos sujeitos e detentora do monopólio de produção de conhecimentos formais. A pandemia do novo coronavírus, ao forçar as instituições escolares e seus profissionais a encontrarem uma maneira de se garantir a continuação das atividades letivas, nos oferece um momento oportuno para se questionar, uma vez mais, os processos educativos centrados na figura do professor e dos conteúdos obrigatórios que ele deve ministrar indiscriminadamente a todos, desconsiderando as especificidades sociais e psicológicas dos sujeitos. Em outras palavras, se por um lado, a crise sanitária provocada pelo vírus obrigou o reconhecimento do aparato escolar como imprescindível para a promoção dos direitos sociais para além da educação, por outro, a instrução virtual nos direciona a repensar as escolas no tocante às suas funções de homogeneização e disciplinamento do corpo social.

No início do século $X X$, em suas críticas às pedagogias tradicionalistas, que consideram o professor como o agente principal da transmissão do conhecimento, Dewey já chamava a atenção para o fato de as crianças não serem uma espécie de lousa em branca que seria preenchida por lições morais e civilizatórias ministradas pelos professores. Quando a criança chega à classe, ela já traz em sua mochila as tarefas do lar e do entorno em que vive, cabendo ao educador o trabalho de remodelar essa bagagem, com o objetivo de garantir o crescimento ativo dos sujeitos (WESTBROOK, 2010). De acordo com Westbrook (2010), o filósofo 
americano defendeu essa ideia contra os defensores de uma educação tradicional, centrada no currículo, bem como em oposição aos partidários de uma pedagogia centrada na criança.

A pedagogia de Dewey requer que os educadores realizem uma tarefa extremamente difícil, que é a de reincorporar os temas de estudo na experiência. Os temas curriculares, como todos os conhecimentos humanos, são produtos do esforço do homem para resolver os problemas que sua experiência lhe coloca. Mas, antes de se constituir esse conjunto formal de conhecimentos, eles foram abstraídos das problemáticas em que foram originalmente desenvolvidos (WESTBROOK, 2010, p. 18).

Retomamos as ideias de Dewey porque elas nos parecem pertinentes para entender os conflitos suscitados pela pandemia do novo coronavírus na seara da educação. A pedagogia que o vírus vem nos ensinando pode nos ofertar lições sobre os limites e dificuldades do ensino remoto emergencial, tal como ele foi adotado a partir de março de 2020. Em primeiro lugar, a mirada pragmatista adotada pelo filósofo americano concebe a escola como um agente da transformação social e não um mero sustentáculo da organização da vida social dominante. Embora a sua matéria-prima seja os saberes e experiências derivados do cotidiano dos sujeitos, isso não significa que o conjunto formal de conhecimentos por ela forjados não implique um repensar desses mesmos saberes e experiências. Ora, os relatos aqui colhidos nos dão uma impressão de inadequação dos sujeitos em torno das ferramentas manejadas para o ensino remoto. Essa inadequação, e mesmo aflição que muitos têm manifestado a partir do uso das plataformas virtuais para os processos de ensino-aprendizagem, embora insólita, uma vez que somos indivíduos plenamente acostumados com as vivências proporcionadas pelas tecnologias digitais, se justifica porque a maneira repentina com a qual a instrução virtual teve de ser levada a cabo impossibilitou uma maior reflexão sobre como os conteúdos poderiam ser ministrados para aqueles que agora não podem acessá-los de maneira presencial.

Desse modo, tem havido por parte dos profissionais da educação a tentativa de se garantir a veiculação do conteúdo programático da escola, o que implica a adoção da pedagogia tradicional ao ambiente digital. A questão aqui não é simplesmente levantar questões sobre a impropriedade de se transpor o modelo da aula expositiva para as plataformas virtuais, mas de chamar a atenção para o fato de o chamado ensino remoto emergencial ter, a partir das narrativas aqui apresentadas, incorrido na desconsideração dos saberes digitais daqueles que já estavam bastante acostumados com as vivências peculiares a uma sociedade da cibernética, quais sejam, as crianças e os adolescentes, a assim denominada 
geração millennials. E assim, mais uma vez colocados à margem dos processos de ensinoaprendizagem, esses sujeitos vivenciam agora na tela de seus computadores e celulares inteligentes a aflição e a apatia que eles já sentiam nas aulas presenciais. Mesmo no momento em que a escola e as novas tecnologias de comunicação se encontraram, a fusão de horizontes entre o mundo dos estudantes e o mundo dos professores proposta pela pedagogia de Dewey dificilmente tem acontecido.

Conforme argumenta Couto (2014), as redes sociais digitais se transformaram em espaços proeminentes para a proliferação das narrativas de si, cujo objetivo maior é dar visibilidade ao eu. O autor defende a ideia de que nessas plataformas os sujeitos, sempre conectados, falam de si, produzem e divulgam textos, imagens fotográficas, memes, vídeos, comentam e pavoneiam comportamentos sociais, profissionais e acadêmicos. No plano mais abrangente, essas condutas terminam por borrar as fronteiras entre o público e o privado, o anônimo e a celebridade; na arena mais específica da educação, os limites entre o ensino e a aprendizagem se tornam mais difusos. $\mathrm{O}$ autor pontua que os integrantes da geração internet são primordialmente colaboradores em todas as dinâmicas da vida; são ativos, almejam participar, compartilhar e trabalhar em conjunto. Para ele, os pais e os educadores deveriam estar mais atentos a estas características. Pois bem, ao que parece, nas experiências de ensino remoto aqui elencadas, ao serem utilizados aplicativos como o Zoom e o Google Meet, houve um não aproveitamento dessa capacidade que as crianças e os adolescentes têm de produzir conteúdos. É como se essas novas plataformas tivessem sido manejadas para dar conta de velhas práticas, notadamente aquelas centradas no currículo escolar e no modelo de ensino hierarquizado, unidirecional e padronizado. Não à toa a professora Betta Salvini, ouvida pelo The Guardian, percebeu a necessidade de trazer os estudantes para o centro de seus diálogos em classe.

Quando a interioridade dos estudantes apareceu nas aulas virtuais, foi quase sempre de uma maneira não deliberada, não desejada, ou seja, uma narrativa de si acidental. Foram, pois, as imagens vazadas de suas intimidades: objetos de decoração de seus lares; seus animais de estimação; seus parentes mais próximos; suas roupas domésticas. Embora as novas tecnologias digitais tenham proporcionado uma invasão do privado na esfera pública, colorindo-o, pavoneando-o, nos transformando em consumidores alegres da vida alheia, isso não quer dizer que não estamos mais nos preocupando com aquilo que deve ou não ser 
exibido. Em outras palavras, há sim uma seleção do material que compõe a privacidade que é compartilhada na arena pública da internet. Confinados em nossas casas, misturando as dinâmicas do lar com as do trabalho, parece que ainda estamos aprendendo a editar melhor quais partes das nossas subjetividades podem ser exibidas ou não nos aplicativos de videoconferência.

E aqui chegamos à pitada de ficcionalidade que a própria narratividade das notícias sugere, embora não tenha sido o nosso foco a análise do texto jornalístico em si. Longe de ser um artifício, uma mentira deliberada, a presença da ficção nos relatos da imprensa escrita nos encaminha para a interpretação dos temas recorrentes, das construções imagéticas, das lições morais predominantes (MOTTA, 2002). A lição moral preponderante, a imagem arquetípica construída pelas matérias aqui arroladas, impõe no leitor a convicção de as aulas presenciais serem melhores que as aulas virtuais. Melhor dizendo, sugerem, pela ótica do não dito, a inexistência de problemas didáticos e metodológicos com o formato da aula expositiva, como se as escolas não estivessem vivenciando um período de crise de legitimidade e autoridade.

E por falar nas escolas, algumas palavras ainda precisam ser ditas sobre esta tecnologia moderna. Sabemos que desde os seus primórdios os aparatos escolares manejam os estudantes através de sua redistribuição em espaços fechados, homogeneizando-os na lógica dos grupos de idade. Ainda que o seu modus operandi tenha sido utilizado para formatar corpos dóceis, ele também foi responsável por criar um senso de comunidade e pertencimento difícil de ser mimetizado em outros campos. E por causa da sua habilidade em criar uma atmosfera de igualdade, um faz-de-conta sem o qual as sociedades democráticas não conseguem sobreviver, a escola ainda tem muita vida pela frente, a despeito da concorrência dos meios de comunicação de massas e das novas tecnologias digitais. Se uma lição pode ser aprendida das notícias aqui tratadas, é que existe sim uma crise das pedagogias tradicionais e do poder disciplinar da escola, mas não da escola em si mesma. Pelo menos, é isso que a pandemia do novo coronavírus tem nos demonstrado.

\section{REFERÊNCIAS}

AGÊNCIA BRASIL. Professores passam a contar com apoio emocional na pandemia, UOL, 11 ago. 2020. Disponível em: https://noticias.uol.com.br/ultimas-noticias/agenciabrasil/2020/08/11/professores-passam-a-contar-com-apoio-emocional-na-pandemia.htm. Acesso em: 02 out. 2020. 
ARIÉS, Philipe. História social da criança e da família. Rio de Janeiro: Zahar, 1981.

BAND. Especial: o impacto da pandemia e do ensino remoto na educação do país, UOL, 13 jul. 2020. Disponível em: https://noticias.band.uol.com.br/noticias/100000994836/especial-oimpacto-da-pandemia-e-do-ensino-remoto-na-educacao-do-pais.html. Acesso em: 27 set. 2020.

BROCKES, Emma. After just half a day of home-schooling, I am officially in awe of all teachers, The Guardian, 20 março 2020.2 Disponível em: https://www.theguardian.com/commentisfree/2020/mar/20/home-schooling-teacherschild-coronavirus. Acesso em: 03 out. 2020.

CHEN, David W. Teachers' herculean task: moving 1.1 million children to online school, The New York Times, 29 março 2020. Disponível em: https://www.nytimes.com/2020/03/29/nyregion/coronavirus-new-york-schools-remotelearning.html. Acesso em: 1 out. 2020.

COUTO, Edvaldo de Souza. Pedagogias das conexões: compartilhar conhecimentos e construir subjetividades nas redes sociais digitais. In: PORTO, Cristiane; SANTOS, Edmea (Orgas.). Facebook e educação: publicar, curtir, compartilhar. Campina Grande: EDUEPB, 2014. p. 4765.

FELIX, Paula. A difícil rotina longe da turma da escola durante a pandemia, O Estado de São Paulo, São Paulo, 30 ago. 2020. Disponível em: https://educacao.estadao.com.br/noticias/geral,a-dificil-rotina-longe-da-turma-da-escoladurante-a-pandemia,70003418556.amp. Acesso em: 12 set. 2020.

FISCHBERG, Josy. Escolas devem zelar pela segurança de suas salas de aula virtuais, $O$ Globo, Rio de Janeiro, 20 abr. 2020. Disponível em: https://oglobo.globo.com/sociedade/educacao/escolas-devem-zelar-pela-seguranca-desuas-salas-de-aula-virtuais-24383184. Acesso em: 20 set. 2020.

FOGUEL, Débora. Ensino remoto de emergência durante a pandemia: nossas inúmeras carências e o som das entranhas das nossas crianças e jovens, $O$ Globo, Rio de Janeiro, 25 maio 2020. Disponível em: https://blogs.oglobo.globo.com/ciencia-matematica/post/ensinoremoto-de-emergencia-durante-pandemia-nossas-inumeras-carencias-e-o-som-dasentranhas-das-nossas-criancas-e-jovens.html. Acesso em: 27 set. 2020.

FREIRE, Paulo. Educação "bancária" e educação libertadora. In: PATTO, Maria Helena de Souza (Orga.). Introdução a Psicologia escolar. 3 ed. São Paulo: Casa do Psicólogo, 1997. p. 61-80.

. Pedagogia do oprimido. 25 ed. Rio de Janeiro: Paz e Terra, 1998.

GEORGE, Susannah. In the world's fifth most-populous country, distance learning is a single television channel, The Washington Post, Washington, 19 maio 2020. Disponível em: https://www.washingtonpost.com/world/asia_pacific/pakistan-coronavirus-education- 
teleschool/2020/05/18/9ee159a8-8eee-11ea-9322-a29e75effc93_story.html. Acesso em: 17 ago 2020 .

GÔNGORA, Francisco Carlos. Tendências Pedagógicas na Pratica Escolar. São Paulo: Edições Loyola, 1985.

GONCHAR, Michael; DOYNE, Shannon. Has your school switched to remote learning? How is it going so far?, The New York Times, 30 março 2020. Disponível em: https://www.nytimes.com/2020/03/30/learning/has-your-school-switched-to-remotelearning-how-is-it-going-so-far.html. Acesso em: 14 set. 2020.

HALL, Rachel; BATTY, David. 'I can't get motivated': the students struggling with online learning, The Guardian, 4 maio 2020. Disponível em: https://www.theguardian.com/education/2020/may/04/i-cant-get-motivated-the-studentsstruggling-with-online-learning. Acesso em: 20 ago. 2020.

JONES, Tobias. Italian lessons: what we've learned from two months of home schooling, The Guardian, 24 abr. 2020.2 Disponivel em: https://www.theguardian.com/education/2020/apr/24/italy-home-schooling-coronaviruslockdown-what-weve-learned. Acesso em: 23 jul. 2020.

OTTA, Luiz Gonzaga. Para uma antropologia da notícia, Revista Brasileira de Ciências da Comunicação, São Paulo, v. 25, n. 2, p. 11-41, ul./dez. 2002.

MURARO, Darcísio Natal. Relações entre a filosofia e a educação de John Dewey e de Paulo Freire, Educação \& Realidade, Porto Alegre, v. 38, n. 3, p. 813-829, jul./set. 2013.

MURPHY, Kate. Why Zoom is terrible, The New York Times, 4 maio 2020. Disponível em: https://www.nytimes.com/2020/04/29/sunday-review/zoom-video-

conference.html ?action=click\&module=RelatedLinks\&pgtype=Article. Acesso em: 25 ago. 2020.

ONU. Policy brief: education during COVID-19 and beyond. Nova York: ONU, 2020.

RIZZINI, Irene; RIZZINI, Irma. A institucionalização de crianças no Brasil: percurso histórico e desafios do presente. Rio de Janeiro: Ed. PUC-Rio; São Paulo: Loyola, 2004.

SAVIANI, Dermeval. Democracia, educação e emancipação humana: desafios do atual momento brasileiro, Psicologia Escolar e Educacional, São Paulo, v. 21, n. 3, p. 653-662, set./dez. 2017.

SIBILIA, Paula. Redes ou paredes: a escola em tempos de dispersão. Rio de Janeiro: Contraponto, 2012. 
STRASSLER, Karen. What we lose when we go from the classroom to Zoom, The New York Times, 10 maio 2020. Disponível em: https://www.nytimes.com/2020/05/04/sundayreview/zoom-college-classroom.html. Acesso em: 4 jun. 2020.

TEODORO, António. Globalização e educação: políticas educacionais e novos modos de governação. Porto: Edições Afrontamento, 2003.

TODOROV, Tzvetan. Poética da prosa. Lisboa: Edições 70, 1971.

WESTBROOK, Robert. John Dewey. In: WESTBROOK, Robert et al. (Orgs.). John Dewey: textos selecionados. Recife: Fundação Joaquim Nabuco, 2010. p. 11-32. 